Aus der Medizinischen Klinik

der Veterinärmedizinischen Fakultät der Universität Leipzig

\title{
Stoffwechselmonitoring in kleinen und mittelgroßen Milchrindbetrieben im Emsland
}

\author{
Inaugural-Dissertation \\ zur Erlangung des Grades eines \\ Doctor medicinae veterinariae (Dr. med. vet.) \\ durch die Veterinärmedizinische Fakultät \\ der Universität Leipzig
}

eingereicht von

Johanna Bothmann

aus Pirna

Leipzig, 2015 
Mit Genehmigung der Veterinärmedizinischen Fakultät der Universität Leipzig

Dekan: $\quad$ Prof. Dr. Manfred Coenen

Betreuer: $\quad$ apl. Prof. Dr. Manfred Fürll

Gutachter: $\quad$ apl. Prof. Dr. Manfred Fürll,

Medizinische Tierklinik

Veterinärmedizinische Fakultät der Universität Leipzig

Prof. Dr. Rolf Mansfeld

Klinik für Wiederkäuer mit Ambulanz und Bestandsbetreuung

Tierärztliche Fakultät der Ludwig-Maximilians-Universität München

Tag der Verteidigung: 14. April 2015 
Meinen Eltern

mit großer Dankbarkeit gewidmet 



\section{Inhaltsverzeichnis}

$1 \quad$ Einleitung

2 Literaturübersicht 3

2.1 Indikationen, Anforderungen und Modelle von Stoffwechseluntersuchungen 3

$2.2 \quad$ Auswahl und Anzahl der Tiere 6

$2.3 \quad$ Probenmaterial und Parameter 8

$2.4 \quad$ Frühdiagnostik von Krankheiten anhand verschiedener Parameter 13

$\begin{array}{lll}2.5 & \text { Referenzbereiche und Auswertung } & 14\end{array}$

$3 \quad$ Tiere, Material und Methoden 19

$4 \quad$ Ergebnisse 23

$\begin{array}{lll}4.1 & \text { Betriebsanamnese } & 23\end{array}$

$\begin{array}{lll}4.1 .1 & \text { Fütterung } & 24\end{array}$

4.1.2 Gründe für Abgänge im Betrieb und Einsendungen der Proben 26

4.2 Ergebnisse der Proben als Gesamtheit 30

4.2.1 Allgemeine Auswertung der Einsendungen, Proben- und Parameteranzahl 30

$\begin{array}{lll}\text { 4.2.2 Blutproben } & 33\end{array}$

4.2.2.1 Parameter des Energie-Fett-Leber-Stoffwechsels (Glucose, FFS, BHB, AST, GGT, GLDH, Gallensäuren, Bilirubin, Cholesterol) 34

4.2.2.2 Parameter des Eiweißstoffwechsels (TP, Albumin, Kreatinin, Harnstoff) 40

4.2.2.3 Parameter des Mineralstoffwechsels (Na, K, Cl, Ca, $\mathrm{P}_{\mathrm{i}}, \mathrm{Fe}, \mathrm{Mg}, \mathrm{AP}$ ) und des Muskelstoffwechsels (CK) 41

4.2.2.4 Spurenelemente $(\mathrm{Cu}, \mathrm{Se}, \mathrm{Zn}, \mathrm{Mn})$, B-Carotin, Coeruloplasmin und die Trolox äquivalente Antioxidative Kapazität (TEAC) 46

$\begin{array}{lll}\text { 4.2.3 Harnproben } & 50\end{array}$

4.3 Ergebnisse der Proben im Jahresvergleich 52

4.3.1 Parameter des Energie-Fett-Leber-Stoffwechsels (FFS, BHB, Bilirubin, Cholesterol) 52 
4.3.3 Parameter des Mineralstoffwechsels $\left(\mathrm{Ca}, \mathrm{P}_{\mathrm{i}}\right)$ und des Muskelstoffwechsels $(\mathrm{CK}) \quad 60$

4.3.4 Spurenelemente ( $\mathrm{Cu}, \mathrm{Se})$, ß-Carotin und die Trolox äquivalente Antioxidative Kapazität (TEAC)

$\begin{array}{lll}4.4 & \text { Ergebnisse ausgewählter Betriebe } & 69\end{array}$

$\begin{array}{lll}\text { 4.4.1 Betriebliche Veränderungen } & 69\end{array}$

4.4.2 Veränderungen der Parameter 71

$\begin{array}{lll}\text { 4.4.3 Mehrfach untersuchte Kühe } & 72\end{array}$

$\begin{array}{lll}5 & \text { Diskussion } & 76\end{array}$

$\begin{array}{lll}5.1 & \text { Ergebnisse der Betriebsanamnese } & 76\end{array}$

5.2 Entwicklung der Einsendungen und Probenanzahlen sowie Auswahl der Parameter 78

$\begin{array}{lll}5.3 & \text { Ergebnisse der Blutprobenanalyse } & 79\end{array}$

5.3.1 Parameter des Energie-Fett-Leber-Stoffwechsels $\quad 79$

$\begin{array}{lll}\text { 5.3.2 Parameter des Eiweißstoffwechsels } & 84\end{array}$

5.3.3 Parameter des Mineralstoffwechsels und des Muskelstoffwechsels $\quad 85$

5.3.4 Spurenelemente, B-Carotin, Coeruloplasmin und TEAC $\quad 89$

5.3.5 Zusammenfassung Jahresvergleich 92

5.4 Ergebnisse ausgewählter Betriebe und Kühe 93

$\begin{array}{lll}5.5 & \text { Schlussfolgerungen } & 94\end{array}$

$\begin{array}{lll}6 & \text { Zusammenfassung } & 97\end{array}$

$\begin{array}{lll}7 & \text { Summary } & 99\end{array}$

8 Literaturverzeichnis 101

9 Anhang 116

$\begin{array}{ll}\text { Danksagung } & 130\end{array}$ 


\section{Abkürzungen}

a.p. ante partum

ACL Antioxidant Capacity of

Lipid-soluble antioxidants

ACW Antioxidant Capacity of

Water-soluble antioxidants

Alb Albumin

anorg. anorganisch

AP Alkalische Phosphatase

AST Aspartat-Amino-Transferase

B Blut

BE Basenüberschuss

Betr. Betriebe

BHB ß-Hydroxybutyrat

Bili Bilirubin

BSQ Basen-Säuren-Quotient

Ca Calzium

Chol Cholesterol

CK Creatinkinase

Cl Chlorid

Co Cobalt

Cpl Coeruloplasmin

$\mathrm{Cu} \quad$ Cupfer

d Tage

DDR Deutsche Demokratische Republik

DGKC Deutsche Gesellschaft für Klinische Chemie

EL Emsland

et al. und Mitarbeiter

$\mathrm{Fe} \quad$ Eisen

FEQ Fett/ Eiweiß-Quotient

FFS Freie Fettsäuren

frakt. fraktioniert

GGT $\gamma$-Glutamyl-Transferase

GLDH Glutamat-Dehydrogenase

Glob Globulin
Glu Glucose

GPX Gluthationperoxidase

GS Gallensäuren

H Harn

Ha Haare

Hast Harnstoff

$\mathrm{Hb} \quad$ Hämoglobin

Hkt Hämatokrit

IBR Infektiöse Bovine Rhinotracheitis

IGF Insulin-like growth factor

J Jod

K Kalium

KK Ketonkörper

Konf Konfidenzintervall

Krea Kreatinin

KST Kolmogorov-Smirnov-Test

KV Konzentrationsverteilung

LKV Landeskontrollverband

LMV Labmagenverlagerung

LS Laktationsstadium

Max Maximum

Mg Magnesium

Min Minimum

MLF Milchleistungsfutter

Mn Mangan

Mo Monate

MW, $\bar{x}$ Mittelwert

n Anzahl

$\mathrm{n}_{\text {ges }} \quad$ Gesamtanzahl

$\mathrm{Na} \quad$ Natrium

NEFA Nonesterified fatty acids

NH4+ Ammonium

nn nicht normal verteilt

no normal verteilt 
NSBA Netto-Säure-Basen-Ausscheidung

P Parameter

p Signifikanzwert

p. p. post partum

$\mathrm{P}_{\mathrm{i}} \quad$ anorganisches Phosphat

Pro Proben

Q1 1. (unteres) Quartil

Q3 3. (oberes) Quartil

RBP Retinol binding protein

Ref. Referenzbereich

rel. relativ

SD Standardabweichung

Se Selen

sign. US signifikante Unterschiede

SOD Superoxiddismutase

B-Car B-Carotin

TEAC Trolox Equivalente of Antioxidative

Capacity

TGL Technischen Normen, Gütevorschriften und Lieferbedingungen

TNF Tumornekrosefaktor

TP Totales Protein, Gesamteiweiß

Wo Wochen

Zn Zink 


\section{$1 \quad$ Einleitung}

In Deutschland beträgt die durchschnittliche Nutzungsdauer von Deutschen Holstein Kühen gerade mal 36 Monate. In dieser Zeit erreichen die wenigsten Kühe eine ausreichend hohe Leistung, um die Aufzuchtskosten zu decken. Außerdem zeigen Kühe ihre höchsten Milchleistungen erst während der dritten und vierten Laktation und somit können Jungkühe ihr Leistungspotenzial bis zum durchschnittlichen Abgangsalter gar nicht zeigen. Abgangsursachen sind hauptsächlich verschiedene Erkrankungen, wobei die höchste Abgangsrate in den ersten 30 Tagen nach der Kalbung vorzufinden ist (RÖMER 2010, ACKERMANN et al. 2013b).

Die meisten wirtschaftlichen Einbußen bei Milchviehbetrieben kommen neben dem frühzeitigen Abgang der Tiere durch Milchleistungsverluste, fehlende Inhaltsstoffe in der Milch, Behandlungskosten sowie herabgesetzte Fruchtbarkeit der Kühe und deren Folgen zustande (VAN SAUN 2010).

Um die Nutzungsdauer der Kühe zu verlängern und Kosten zu verringern, ist es wichtig frühzeitig mögliche Erkrankungen bzw. Imbalancen zu erkennen, um diesen dann gezielt entgegenwirken zu können. Deshalb wird in zahlreichen in- und ausländischen Veröffentlichungen zur regelmäßigen Stoffwechselkontrolle in Milchviehbetrieben geraten.

In Deutschland bestehen auch heute noch große Unterschiede in den landwirtschaftlichen Betriebsstrukturen zwischen den alten und neuen Bundesländern. Während in Ostdeutschland nach wie vor größere Milchviehbetriebe mit durchschnittlichen Tierzahlen je Betrieb von über 130 (STATISTISCHES BUNDESAMT 2014) dominieren, sind es in den alten Bundesländern eher Einzelund Familienunternehmen (WIENER et al. 2004) mit durchschnittlichen Tierzahlen unter 90 (STATISTISCHES BUNDESAMT 2014). In der Zeit der DDR entwickelten sich in Form der Landwirtschaftlichen Produktionsgenossenschaften Betriebe mit bis zu mehreren tausend Milchkühen. Für diese industriemäßige Milchproduktion wurden mehrere Systeme für Stoffwechseluntersuchungen entwickelt (ROSSOW et al. 1973, GÜRTLER 1976, SEIDEL und EHRENTRAUT 1976). Nach der Wiedervereinigung und dem damit verbundenen Strukturwandel konnten diese Systeme in Folge neuer Erkenntnisse weiter entwickelt und ergänzt werden (u. a. SCHOLZ 1990, BENDER et al. 2003, GELFERT und STAUFENBIEL 2007, FÜRLL 2013a).

Eine tierärztliche Gemeinschaftspraxis im Emsland (EL) praktiziert seit mehreren Jahren die systematische Stoffwechselkontrolle in Zusammenarbeit mit der Medizinischen Klinik der Veterinärmedizinischen Fakultät Leipzig. Die gesammelten Erfahrungen sollen in dieser retrospektiven Analyse anhand der eingesendeten Proben ausgewertet werden. Dabei differenzieren sich folgende Fragestellungen heraus. 


\section{Einleitung}

- Erhebung anamnestischer Angaben mithilfe eines Fragebogens zu Betriebsstrukturen, Haltungs- und Fütterungsmanagement, Milch- und Fruchtbarkeitsleistungen, Abgangsursachen sowie Gründe für die Probeneinsendung.

- Analyse der ermittelten Probenergebnisse hinsichtlich Abweichungen von Referenzbereichen, Verhalten im Laktationsverlauf, zwischen den einzelnen Einsendungsjahren mit Entwicklungstendenzen, abgeleiteten Maßnahmen sowie Erfolgsbewertung.

○ Bewertung des Stoffwechselmonitorings für die regionalen Betriebsstrukturen in Form von kleinen bzw. mittelgroßen Betrieben. Prüfung der Frage, ob auch in landwirtschaftlichen Kleinunternehmen Stoffwechseluntersuchungen sinnvoll sind. Hierfür sollen die Betriebe mit mehrfacher Einsendung überprüft werden, ob es eine Veränderung der Stoffwechselsituation im Einsendungsverlauf gegeben hat und wie sich dabei einzelne Parameter verhalten haben 


\section{$2 \quad$ Literaturübersicht}

\subsection{Indikationen, Anforderungen und Modelle von Stoffwechselunter- suchungen}

Stoffwechselkrankheiten sind Krankheiten, welche durch nicht bedarfsgerechte Fütterung und Managementfehler hervorgerufen werden (GÜRTLER 1976).

Neben der nicht adäquaten Fütterung stellt zusätzlich noch eine hohe Leistung mögliche Ursachen für gehäuftes Auftreten solcher Krankheiten dar. Der Begriff Stoffwechselstörungen umfasst die Krankheitsbilder, welche durch Mineralstoffstörungen, Spurenelement-Unterversorgung, Vitaminmangelsituationen, Leberparenchymschäden und Intoxikationen hervorgerufen werden können (SEIDEL und EHRENTRAUT 1976).

Aufgrund von steigendender Milchleistung treten, vor allem im geburtssnahen Zeitraum, bei Hochleistungsrindern vermehrt Stoffwechselstörungen auf. Auf diese folgen dann in erhöhtem Maße Organstörungen bzw. Produktionskrankheiten. Dies bedeutet für die Betriebe erhebliche wirtschaftliche Verluste (BAUMGÄRTNER 1979).

Um diese Verluste zu verringern, beschreiben PAYNE et al. (1970) bereits Anfang der 70er Jahre die Durchführung eines sogenannten „Metabolic Profil Test“. Dabei soll der Stoffwechselstatus einer Herde bestimmt werden, um beurteilen zu können, ob die Milchkühe einer Herde leistungsgerecht versorgt werden. Dies soll sowohl prophylaktisch als auch bei verstärktem Auftreten von Problemen erfolgen. Die Autoren beschreiben diese Herangehensweise als „modern preventive medicin“, da sie als Hilfe für vorbeugende Maßnahmen genutzt werden soll. Dass Stoffwechseluntersuchungen ein wichtiges Werkzeug darstellen, um frühzeitig Abweichungen festzustellen, am besten noch bevor es zum Auftreten von klinischen Symptomen kommt, beschreiben neben Payne weitere Autoren, u. a. SOMMER (1970), LOTTHAMMER et al. (1971), ROSSOW et al. (1973), GÜRTLER (1976), SEIDEL und EHRENTRAUT (1976), KIDA (2002b), OETZEL (2004), GELFERT und STAUFENBIEL (2007), FÜRLL (2013a). Dem entgegengesetzt stellten MANSFELD et al. (1995) regelmäßige Stoffwechseluntersuchungen aus wirtschaftlichen Gründen und aufgrund ungenügender Informationen in Bezug auf Früherkennung von Stoffwechselerkrankungen in Frage.

In der Demokratischen Republik Deutschland (DDR) ist die TGL 34313, letzte Fassung von 1988, zur „Stoffwechselüberwachung in der Rinderproduktion“ entwickelt worden. Diese technischen Normen, Gütevorschriften und Lieferbedingungen (TGL) waren in der DDR rechtsverbindliche Vorschriften (MÜCKE 2010). Damals erfolgte die Milchproduktion in Ost-Deutschland hauptsachlich in Milchviehanlagen mit einer hohen Tieranzahl und wurde als industriemäßige Produktion (ROSSOW et al. 1973, 1975, GÜRTLER 1976, SEIDEL und EHRENTRAUT 1976) bezeichnet. Die TGL 34313 
diente als Standard bei der Stoffwechselüberwachung bis zur Wiedervereinigung Deutschlands. Diese Vorschrift beschreibt neben den Ursachen für Stoffwechselstörungen die genaue Durchführung der Untersuchungen. Dabei wird definiert, wann, wie oft und bei welchen besonderen Bedingungen Untersuchungen durchzuführen sind und welche Angaben zu den Betrieben erfolgen sollen. Außerdem wird die Auswahl des Tiermaterials, die Stichprobengröße und der Untersuchungszeitpunkt für spezielle Tiergruppen, sowie der Entnahmeort, die Aufbereitung, die Aufbewahrung und der Transport der Proben genau vorgegeben. Des Weiteren wird definierten Untersuchungszeiträumen bzw. speziellen Problemkreisen das jeweilige Untersuchungsspektrum zugeordnet. Abschließend werden die Richtwerte der Parameter, unterteilt nach bestimmten Altersgruppen und die Anleitung zur Auswertung der Ergebnisse beschrieben (Anhang Abbildung 9.1).

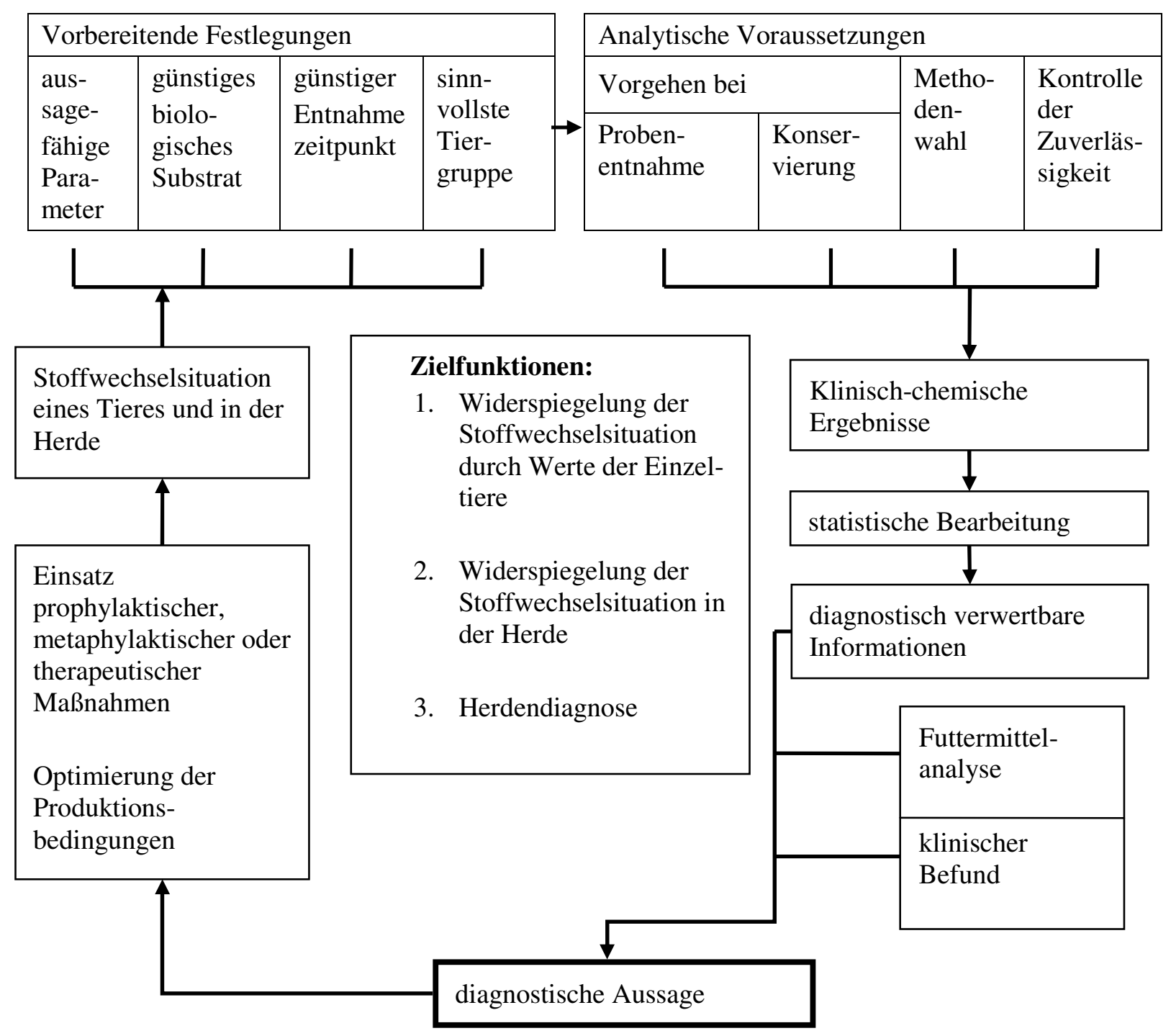

Abbildung 2.1 System der Stoffwechselüberwachung für Kühe nach Gürtler (1976), modifiziert (FÜRLL 2013a) 
Weitere Ziele für Stoffwechseluntersuchungen sind die Steigerung der Milchleistung, Verbesserung der Fruchtbarkeit und Senkung von Kälberverlusten in den ersten Wochen p. p. (ROSSOW et al 1975).

GÜRTLER (1976) entwickelte ein Modell zur Herangehensweise und Durchführung von Stoffwechseluntersuchungen. Diese von FÜRLL (2013a) modifizierte Übersicht ist in Abbildung 2.1 zu sehen. Dabei werden die Voraussetzungen sowie die beeinflussenden Faktoren beschrieben, welche für eine erfolgreiche Stoffwechselüberwachung von Bedeutung sind.

Folgende Anforderung werden von SOMMER (1970) an die Untersuchung auf des Gesundheitsstatus der Tiere gestellt.

- $\quad$ kostengünstig

- niedriger Zeitaufwand

- einfache standardisierte Untersuchungsmethode

- hoher spezifischer Aussagewert

- reproduzierbar

- Möglichkeit der Automatisierung

- Möglichkeit der Auswertung mit Computern

ROSSOW et al. (1973) stellen weitere Bedingungen an Stoffwechseluntersuchungen, welche im Folgenden aufgeführt sind.

- $\quad$ sollten in den technologischen Prozess einzuordnen sein

- unter Praxisbedingungen einfach und risikolos sein

- schneller Transport zum Untersuchungslabor

- $\quad$ schnelle Aufbereitung der Proben, Auswertung und Übersendung der Ergebnisse

- Probenentnahme möglichst immer im gleichen zeitlichen Abstand zur Fütterung

Stoffwechseluntersuchungen können sowohl Einzeltierbezogen, das heißt, dass jedes Tier einer Herde untersucht wird (SOMMER 1970, BAUMGÄRTNER 1979), als auch auf Herdenbasis (PAYNE et al. 1970, ROSSOW et al. 1973, 1975, SEIDEL und EHRENTRAUT 1976, WILLER et al. 1976, GÜRTLER 1976, LOTTHAMMER 1981, KIDA 2002a, b, GELFERT und STAUFENBIEL 2007, BORCHARDT und STAUFENBIEL 2012) mithilfe einer Auswahl von Tieren als Prüfgruppe erfolgen.

Um den Stoffwechselstatus auf Herdenbasis zu bestimmen, werden mittlerweile auch Poolproben erfolgreich genutzt. Da eine hohe Korrelation zwischen den Mittelwerten von einzeln untersuchten Proben und den Ergebnissen von Poolproben besteht, macht es klinisch gesehen keinen Unterschied welches Verfahren genutzt wird (BORCHARDT und STAUFENBIEL 2012). Durch die Verwendung von Poolproben kommt es zur Verringerung der Laborarbeit. Außerdem werden die Kosten stark herabgesetzt, wodurch die Möglichkeit besteht, günstiger ein größeres Parameterspektrum abzudecken 
(GELFERT und STAUFENBIEL 2007). Bei einer Gruppengröße von zehn Tieren kommt es zu einer Einsparung der Laborkosten von 90\% (BORCHARDT und STAUFENBIEL 2012).

\subsection{Auswahl und Anzahl der Tiere}

\section{Kriterien und Zeitpunkt zur Auswahl der Tiere}

Zur Untersuchung auf den allgemeinen Stoffwechselstatus und subklinisch vorkommende Erkrankungen sollen Kühe ausgewählt werden, die klinisch gesund sind (PAYNE et al. 1973, GELFERT und STAUFENBIEL 2007, BORCHARDT und STAUFENBIEL 2012, FÜRLL 2013a). Des Weiteren soll die Auswahl der Tiere zufällig erfolgen (ROWLANDS und POCOCK 1971, GELFERT und STAUFENBIEL 2007).

In der Mehrzahl der Modelle, werden die Herden in verschiedene Gruppen eingeteilt. Dabei kann zwischen der leistungsabhängigen und der laktationsabhängigen Einteilung unterschieden werden. PAYNE et al. (1970) sowie ROWLANDS und POCOCK (1971) bilden in Ihren Untersuchungen drei Gruppen. Dabei werden der ersten Gruppe die trockenstehenden Kühe zugeordnet. Die zweite Gruppe besteht aus Tieren mit der durchschnittlichen Herdenleistung und die dritte Gruppe aus Tieren mit den jeweils höchsten Tagesleistungen der Herde. LEE et al. (1978) bilden ebenfalls drei Gruppen, wovon eine auch aus Trockenstehern besteht. Der Unterschied ist, dass einer weiteren Gruppe Kühe mit hoher Leistung und der letzten Gruppe Kühe mit niedriger Leistung zugeordnet werden.

ROSSOW et al. (1973, 1975) nehmen sowohl die Leistung als auch das Laktationsstadium als Kriterium für die Gruppenbildung. In der ersten Untersuchung wird die erste Gruppe aus trockenstehenden Kühen, welche in der vorherigen Laktation eine hohe Leistung verzeichneten, gebildet und die zweite Gruppe mit Kühen, die zwei bis vier Wochen p. p. sind und eine hohe Einsatzleistung hatten. In der zweiten Untersuchung besteht die erste Gruppe aus Kühen, welche sich in der ersten Woche p. p. befinden. Die Kühe der zweiten Gruppe sind ebenfalls zwei bis vier Wochen p. p. und anstelle der Einsatzleistung wird in diesem Fall die aktuelle hohe Leistung als Auswahlkriterium herangezogen. In beiden Untersuchungen besteht die dritte Gruppe aus Kühen, welche eine hohe Leistung haben und fünf bis acht bzw. zehn Wochen p. p. sind.

Bei der laktationsabhängigen Gruppeneinteilung sind sich die Autoren einig, dass der Zeitpunkt direkt nach der Kalbung für Stoffwechseluntersuchungen eine hohe Bedeutung aufweist. Dabei werden die ersten drei Tage p. p. von GÜRTLER (1976), SEIDEL und EHRENTRAUT (1976) und FÜRLL (2013a) besonders vermerkt (Tabelle 2.1). Die Trockensteherphase wird von sechs der Autoren in Tabelle 2.1 ebenfalls als wichtigen Zeitpunkt angesehen. DRACKLEY (1999) beschreibt vor allem die Phase drei Wochen a. p. bis drei Wochen p. p. als wichtigen Entstehungszeitpunkt für Krankheiten und diese ist damit von hoher Bedeutung für die Gesundheit, die Produktion und die Rentabilität. 
KIDA (2002a) nennt zusätzlich noch die Zeitpunkte zehn Tage nach dem Trockenstellen und zehn Tage nach der Kalbung als geeignet.

Tabelle 2.1 Übersicht der Gruppeneinteilung von Herden zur Stoffwechseluntersuchung durch verschiedene Autoren

\begin{tabular}{|c|c|c|c|c|c|c|}
\hline Autor & \multirow{2}{*}{\multicolumn{2}{|c|}{$\begin{array}{l}\text { Gruppe a. p. } \\
\text { Ende } \\
\text { Trächtigkeit }\end{array}$}} & \multicolumn{4}{|c|}{ Gruppe p. p. } \\
\hline $\begin{array}{l}\text { SOMMER } \\
(1970)\end{array}$ & & & Puerperium & $\begin{array}{l}\text { Beginn } \\
\text { Trächtigkeit }\end{array}$ & & \\
\hline $\begin{array}{l}\text { SEIDEL u. } \\
\text { EHRENTRAUT } \\
(1976)\end{array}$ & & & ersten $3 \mathrm{~d}$ p.p. & $2-6$ Wo p.p. & $\begin{array}{l}6-10 \text { Wo p. } \\
\text { p. }\end{array}$ & \\
\hline $\begin{array}{l}\text { WILLER } \\
\text { et al. (1976) }\end{array}$ & & & 1. Wo p.p. & $\begin{array}{l}\text { 2. - 4. Wo p. } \\
\text { p. }\end{array}$ & $\begin{array}{l}\text { 5. }-10 \text {. Wo p. } \\
\text { p. }\end{array}$ & \\
\hline $\begin{array}{l}\text { GÜRTLER } \\
\text { (1976) }\end{array}$ & & & 1. - 3. d p.p. & $\begin{array}{l}\text { 2. }-4 \text {. Wo } \\
\text { p.p. }\end{array}$ & $\begin{array}{l}\text { 6. - 10. Wo p. } \\
\text { p. }\end{array}$ & \\
\hline $\begin{array}{l}\text { LOTTHAMMER } \\
\text { (1981) }\end{array}$ & $6-8$ & o a. p. & $1-3$ Wo p. p. & $\begin{array}{l}6 \text { Wo p.p. u. } \\
\text { später }\end{array}$ & & \\
\hline $\begin{array}{l}\text { BRYDL } \\
\text { (1999) }\end{array}$ & $1-2$ & o a.p. & $1-7$ d p.p. & $2-3$ Wo p. p. & $6-8$ Wo p. p. & $\begin{array}{l}\text { mittlere } \\
\text { Laktation }\end{array}$ \\
\hline $\begin{array}{l}\text { KIDA } \\
(2002 b)\end{array}$ & TS & & bis 49 d p.p. & $\begin{array}{l}50-109 \mathrm{~d} p \\
\text { p. }\end{array}$ & $\begin{array}{l}110-209 \mathrm{~d} \\
\text { p.p. }\end{array}$ & $\begin{array}{l}210 \text { d p.p. bis } \\
\text { TS }\end{array}$ \\
\hline $\begin{array}{l}\text { GELFERT u. } \\
\text { STAUFENBIEL } \\
(2007)\end{array}$ & $\begin{array}{l}>3 \\
\text { Wo } \\
\text { a. p. }\end{array}$ & $\begin{array}{l}<3 \\
\text { Wo } \\
\text { a. p. }\end{array}$ & $0-1$ Wo p.p. & $3-5$ Wo p. p. & $\begin{array}{l}15-18 \text { Wo p. } \\
\mathrm{p}\end{array}$ & \\
\hline $\begin{array}{l}\text { SAKOWSKI } \\
\text { et al.(2012) }\end{array}$ & & & $5-30$ d p. p.. & $60-90 d$ p. $p$ & $\begin{array}{l}120-150 \mathrm{~d} \\
\text { p.p. }\end{array}$ & $250 \mathrm{~d}$ p.p. \\
\hline $\begin{array}{l}\text { FÜRLL } \\
\text { (2013a) }\end{array}$ & $1-2$ & o a. p. & 3. d. p. p. & $\begin{array}{l}2-12 \text { Wo p. } \\
\text { p. }\end{array}$ & & \\
\hline
\end{tabular}

Nach einer Futterumstellung ist ebenfalls eine Stoffwechseluntersuchung anzuraten (SEIDEL und EHRENTRAUT 1976, FÜRLL 2013a). Während PAYNE et al. (1970) angeben, mindestens einen Monat nach der Änderung der Fütterung abzuwarten und speziell die Zeit am Ende der Stallperiode im Winter und am Ende der Weidesaison im Sommer nennen, empfiehlt GÜRTLER (1976) schon ein bis zwei Wochen nach Veränderung der Fütterung die Kontrolle durchzuführen.

Neben der Untersuchung der schon genannten Tiere mit klinischen Symptomen (GÜRTLER 1976, ROSSOW et al. 1973) bzw. Herden mit offensichtlichen Leistungseinbußen (FÜRLL 2013a), besteht zusätzlich noch die Möglichkeit Schlachtrinder auszuwählen (ROSSOW et al. 1973).

Wiederholungen der Stoffwechseluntersuchungen sollen beim Auftreten von Leistungsminderungen mit unbekannten Ursachen bzw. beim Auftreten von Stoffwechselstörungen monatlich und bis zum Abklingen der Symptome durchgeführt werden. Bei Herden ohne offensichtliche Probleme ist anzuraten, Untersuchungen im Abstand von drei Monaten durchzuführen (GÜRTLER 1976). Die TGL 
34313 (1988) ordnete Stammkuhherden, Herden mit hoher Tierzahl und Hochleistungsherden ohne erkennbare Erkrankungen bzw. Leistungsbeeinträchtigungen der Kategorie A zu. In diesen Betrieben sollten in Phasen, in denen die Tiere einer hohen Belastung in Bezug auf den Stoffwechsel ausgesetzt sind, Stoffwechseluntersuchungen mindestens zweimal jährlich erfolgen sowie bei speziellen Futterrationen. FÜRLL (2013a) empfiehlt zur Früherkennung von Problemen bzw. zur Bestätigung, dass keine subklinischen Probleme im Bestand bestehen, vierteljährliche Kontrollen.

\section{Anzahl der Tiere}

Während LOTTHAMMER (1981) drei bis vier Tiere je Gruppe zur Stoffwechseluntersuchung auszuwählen beschreibt, sehen ROWLANDS und POCOCK (1971) fünf Tiere je Gruppe als ausreichend an. PAYNE et al. (1970, 1973) und LEE et al. (1978) nennen sieben Tiere je Gruppe. Die Mehrzahl der Autoren empfehlen jedoch zehn Tiere je Gruppe zu untersuchen (ROSSOW et al. 1975, SEIDEL und EHRENTRAUT 1976, WILLER et al. 1976, TGL 34313 1988, GELFERT und STAUFENBIEL 2007, BORCHARD und STAUFENBIEL 2012, FÜRLL 2013a, WATANABE et al 2013).

\subsection{Probenmaterial und Parameter}

\section{Probenmaterial}

Als Probenmaterial eignen sich für Stoffwechseluntersuchungen neben Blut und Harn noch Milch, Haare, Pansensaft, Speichel und Leberbioptate (GELFERT und STAUFENBIEL 2007).

Der Vorteil von Blutproben ist das breite Parameterspektrum, welches mit diesem Substrat ermittelt werden kann (FÜRLL 2013a). Außerdem stellt die Fixierung zur Entnahme von Blutproben bei Rindern keine großen Probleme dar (GELFERT und STAUFENBIEL 2007).

Harnuntersuchungen sind vor allem für die Bestimmung des Säure-Base-Status von Bedeutung. So können im Harn im Gegensatz zum Blut schon sehr zeitig alkalische oder saure Belastungen nachgewiesen werden (BENDER et al. 2003). Die Probenentnahme kann mittels Katheter oder durch manuelle Stimulation erfolgen (GELFERT und STAUFENBIEL 2007).

Die Milch ist bei Milchkühen das am einfachsten zu gewinnende Substrat. So können die tägliche Milchmenge und makroskopische Befunde als Hilfsmittel zur Einschätzung der Eutergesundheit sowie zum Teil als Hinweise zum Vorliegen von Stoffwechselerkrankungen genutzt werden (FÜRLL 2013a). Ein weiterer Vorteil besteht darin, dass alle vier Wochen Milchleistungsprüfungen durchgeführt werden. Dabei werden u. a. die Inhaltsstoffe Milchfett, -eiweiß und -harnstoff ermittelt und lassen dadurch Rückschlüsse auf die Fütterung und den Stoffwechsel zu (SCHOLZ 1990).

Die Haaranalyse dient vor allem dem Nachweis von Spurenelementen. Die Vorteile sind die einfache Probenentnahme, die gute Haltbarkeit und Lagerfähigkeit der Proben, sowie die gute Widerspiegelung 8 
der Versorgungslage (FÜRLL 2013a). Der Nachteil von Haaranalysen sind die höheren Kosten und

die Beeinflussung des Spurenelementgehaltes durch exogene Einflüsse (GELFERT und STAUFENBIEL 2007).

Die Pansensaftuntersuchung ist eine Einzeltieranalyse, welche bei klinisch manifesten Erkrankungen mit Hinweisen auf eine Pansenfermentationsstörung zur speziellen Diagnostik verwendet werden kann (STAUFENBIEL 2011). Der Autor beschreibt für dieses Analyseverfahren jedoch einen zu geringen Aussagewert für die Bestandsbetreuung und dadurch einen Rückgang in der Bedeutung. Dem entgegengesetzt sieht FÜRLL (2014b) die Pansensaftbeurteilung, trotz des größeren Aufwandes in der Probenentnahme, für eine sichere Diagnose in Hinblick auf Pansenfermentationsstörungen als notwendig an. Zudem stehen mittlerweile neue Analyseverfahren für weiterreichende Untersuchungen zur Verfügung (FÜRLL 2014b).

Speichelproben dienen hauptsächlich zur Bestimmung des Natrium- und Kaliumgehaltes (LOTTHAMMER 1981). Allerdings bestehen gegenüber der Untersuchung dieser Parameter im Harn keine Vorteile. Außerdem können die Proben durch Futterreste verunreinigt werden (GELFERT und STAUFENBIEL 2007)

Durch die Entnahme einer Leberbiopsie kann der Fettgehalt dieses Organes und damit Hinweise auf die Funktionsfähigkeit der Leber direkt im Stall ermittelt werden (AHMED et al. 2003).

\section{Parameter}

Bei der Auswahl der zu untersuchenden Parameter gibt es verschiedene Möglichkeiten. So unterteilen GÜRTLER (1976) und FÜRLL (2013 b) die Parameter in drei Gruppen. GÜRTLER (1976) beschreibt die Ketonkörper (KK) als erste Ordnung und empfiehlt diese bei jeder Stoffwechseluntersuchung bestimmen zu lassen. Der zweiten Ordnung sind die Parameter Glucose (Glu), Freie Fettsäuren (FFS), Calzium (Ca), anorganisches Phosphat $\left(\mathrm{P}_{\mathrm{i}}\right)$, Netto-Säure-Basen-Ausscheidung (NSBA), NatriumKalium-Quotient, Magnesium (Mg), Mangan (Mn), Cupfer (Cu), Cadmium, Aschegehalt der Knochen und Leberhistologie zugeordnet und der Autor rät zur Untersuchung in größeren Abständen zusätzlich zu den Ketonkörpern oder beim Auftreten von erhöhten Belastungen z. B. „,sehr hoher Leistung“ oder Futterumstellungen. Die Parameter der dritten Ordnung, Alkalische Phosphatase (AP), AspartatAmino-Transferase (AST), Ornithin-Karbamyltransferase, Bilirubin (Bili) und Proteine, sollen bei weiterführenden Untersuchungen zur Abklärung bestimmter Erkrankungen mit Auftreten von klinischen Symptomen zusätzlich bestimmt werden.

FÜRLL (2013b) ordnet dagegen die FFS der Kategorie A zu, welche einmal pro Laktation zwei bis vier Tage p. p. untersucht werden sollen. Dabei kann dies in großen Herden stichprobenartig erfolgen. Die Parameter der Kategorie B1 gehören zum „Minimal-Standard“ bei verschlechterter Milchleistung bzw. herabgesetzter Nutzungsdauer. Dazu zählen ß-Hydroxybutyrat (BHB), Harnstoff, Cholesterol, Creatinkinase (CK), Selen (Se), $\mathrm{Cu}$ und $\beta$-Carotin (ß-Car) Die Parameter der Kategorie B2 Glucose 
(Glu), $\gamma$-Glutamyl-Transferase (GGT), Glutamat-Dehydrogenase (GLDH), fraktionierte NSBA, Natrium (Na) und Kalium (K) im Harn können zusätzlich beim Auftreten verschiedener Erkrankungen untersucht werden.

Eine Übersicht, welche Parameter verschiedene weitere Autoren empfehlen, ist in Tabelle $2.2 \mathrm{zu}$ sehen. Dabei ist zu erkennen, dass ROSSOW et al. (1978) und SÖLLNER-DONATH (2013) die Parameter in Abhängig des Laktationsstadiums auswählen, während SOMMER (1985) unterscheidet, ob eine Überprüfung der Gesundheit oder der adäquaten Versorgung stattfinden soll.

Neben den bereits genannten Parametern können neue Parameter als Ergänzung zur Frühdiagnostik hinzugezogen werden. Dazu gehören z. B. Akute-Phase-Proteine, Lipoproteine, IGF-1, TNF $\alpha$, RBP-4, weitere Spurenelemente, Carnitinfraktionen, Vitamine, Antioxidantien und Gerinnungsparameter (FÜRLL 2013b).

Tabelle 2.2 Übersicht des empfohlenen Parameterspektrums verschiedener Autoren bei der allgemeinen Stoffwechseluntersuchung

\begin{tabular}{|c|c|}
\hline Autor & Parameterspektrum \\
\hline $\begin{array}{l}\text { PAYNE et al. } 1970 \\
\text { ROWLANDS und POCOCK } 1971\end{array}$ & Hkt, Glu, Hast, $\mathrm{P}_{\mathrm{i}}, \mathrm{Ca}, \mathrm{Mg}, \mathrm{Na}, \mathrm{K}, \mathrm{TP}, \mathrm{Alb}$, Glob, Hb \\
\hline $\begin{array}{l}\text { WUJANZ und LACHNMANN } \\
1972\end{array}$ & Chol, Bili, Ca, $\mathrm{P}_{\mathrm{i}}$, Glu, KK im Harn, Knochenasche \\
\hline ROSSOW et al.1975 & $\begin{array}{l}\text { 1. Wo p. p: } \mathrm{Ca}, \mathrm{P}_{\mathrm{i}}, \mathrm{Glu}, \mathrm{Mg} \\
\text { 2. - 4. Wo p. p: } \mathrm{Ca}, \mathrm{P}_{\mathrm{i}}, \mathrm{Glu}, \mathrm{KK} \text {, Harnazeton } \\
\text { 5. - 10. Wo p. p: } \mathrm{Ca}, \mathrm{P}_{\mathrm{i}} \text {, Glu, KK, Knochenasche aus } \\
\text { Hüfthöckerbiopsie }\end{array}$ \\
\hline ADAMS et al. 1978 & $\begin{array}{l}\text { Hkt, Hb, rote u. weiße Blutzellen, } \mathrm{Ca}, \mathrm{P}_{\mathrm{i}}, \mathrm{Mg}, \mathrm{K}, \mathrm{TP}, \mathrm{Alb} \text {, } \\
\text { Glob, Hast }\end{array}$ \\
\hline LOTTHAMMER 1981 & $\begin{array}{l}\mathrm{P}_{\mathrm{i}}, \mathrm{Cu}, \mathrm{Hast}, \mathrm{Glu}, \text { Bili, AST, GLDH, ß-Carotin } \\
\text { Harn: } \mathrm{Na}, \mathrm{K}, \mathrm{Ca}\end{array}$ \\
\hline SOMMER 1985 & $\begin{array}{l}\text { AST, Chol } \rightarrow \text { Gesundheitskontrolle } \\
\text { Hast, } \mathrm{Ca}, \mathrm{P}_{\mathrm{i}}, \mathrm{Na}, \mathrm{K}, \mathrm{Mg}, \beta_{\text {-Carotin }} \rightarrow \text { Versorgungskontrolle }\end{array}$ \\
\hline KIDA 2002b & Hkt, Alb, GGT, AST, Hast, Glu, Chol, FFS, Cu, $\mathrm{P}_{\mathrm{i}}, \mathrm{Mg}$ \\
\hline SÖLLNER-DONATH 2013 & $\begin{array}{l}\text { a. } p \text { : FFS, Bili, Chol, } \mathrm{P}_{\mathrm{i}}, \mathrm{Mg}, \mathrm{Zn}, \\
\text { Harn: Na, K, NSBA } \\
\text { Frischabkalber: FFS, Bili, Chol, } \mathrm{P}_{\mathrm{i}}, \mathrm{Mg}, \mathrm{Zn}, \mathrm{BHB}, \mathrm{Ca}, \mathrm{Mn} \text {, } \\
\text { Harn: Na, NSBA } \\
\text { Frischmelker: FFS, Bili, Chol, } \mathrm{P}_{\mathrm{i}}, \mathrm{Mg}, \mathrm{Zn}, \mathrm{BHB}, \mathrm{GLDH} \\
\text { Harn: Na, K, NSBA }\end{array}$ \\
\hline WATANABE et al. 2013 & Glu, FFS, Chol, TP, Alb, Hast \\
\hline
\end{tabular}


Tabelle 2.3 Labordiagnostische Untersuchungsschwerpunkte, Kontrollzeiträume sowie wichtige und bewährte Laborparameter (FÜRLL 2013a) (B = Blut, H = Harn, Ha = Haare, L = Leber)

\begin{tabular}{|c|c|c|c|c|c|}
\hline \multirow{3}{*}{$\begin{array}{l}\text { Problem- } \\
\text { kreis }\end{array}$} & \multirow{3}{*}{ Fragestellungen } & \multicolumn{3}{|c|}{ Kontrollschwerpunkte } & \multirow{3}{*}{$\begin{array}{l}\text { wichtige } \\
\text { Laborparameter in Blut } \\
\text { oder anderen Substraten }\end{array}$} \\
\hline & & \multicolumn{3}{|c|}{ Wochen } & \\
\hline & & 1 a.p & 1 p.p. & 3-4 p.p. & \\
\hline $\begin{array}{l}\text { Energie- } \\
\text { versorgung }\end{array}$ & $\begin{array}{l}\text { 1) gesteigerte Lipolyse } \\
\text { 2) Energieunterversorgung }\end{array}$ & $\mathrm{X}$ & $\mathrm{X}$ & $\mathrm{X}$ & $\begin{array}{l}\text { FFS, Bilirubin, BHB, } \\
\text { Cholesterol }\end{array}$ \\
\hline $\begin{array}{l}\text { Proteinver- } \\
\text { sorgung }\end{array}$ & $\begin{array}{l}\text { 1) Proteinüberversorgung } \\
\text { 2) Energieunterversorgung }\end{array}$ & & $\mathrm{X}$ & $\mathrm{X}$ & $\begin{array}{l}\text { Harnstoff, Protein, } \\
\text { (Albumin) }\end{array}$ \\
\hline $\begin{array}{l}\text { Leberstoff- } \\
\text { wechsel }\end{array}$ & „Leberstatus“ & $\mathrm{X}$ & $\mathrm{X}$ & $\mathrm{X}$ & GLDH, GGT, AST \\
\hline Uterus & Endometritis & & $X$ & $X$ & CK (B) \\
\hline $\begin{array}{l}\text { anorg. Pho- } \\
\text { sphat }(\mathrm{Pi})\end{array}$ & $\begin{array}{l}\text { 1) Verdauungsstörung(en) } \\
\text { 2) Azidosen }\end{array}$ & & $X$ & $\mathrm{X}$ & $\mathrm{Pi}(\mathrm{B}, \mathrm{H})$ \\
\hline Calzium & $\begin{array}{l}\text { 1) Verfügbarkeit } \\
\text { 2) Ionisationsgrad }\end{array}$ & & $X$ & $\mathrm{X}$ & {$[\mathrm{Ca}(\mathrm{B}, \mathrm{H})]$} \\
\hline Natrium & Versorgungsstatus & & & $X$ & $\mathrm{Na}(\mathrm{H})$ \\
\hline $\begin{array}{l}\text { Kalium/ } \\
\text { Alkalose }\end{array}$ & $\begin{array}{l}\text { 1) K-Versorgungsstatus } \\
\text { 2)Stoffwechselalkalisierung }\end{array}$ & \multirow[t]{2}{*}{$\mathrm{X}$} & \multirow[t]{2}{*}{$\mathrm{X}$} & \multirow[t]{2}{*}{$\mathrm{X}$} & \multirow[t]{2}{*}{$\begin{array}{l}\mathrm{K}(\mathrm{H}), \text { NSBA, pH-Wert } \\
(\mathrm{H})\end{array}$} \\
\hline Azidose & akute/ chronische Azidose & & & & \\
\hline Jod & \multirow{9}{*}{ Versorgungsstatus } & \multirow{5}{*}{\multicolumn{3}{|c|}{$\begin{array}{l}\text { Frühlaktation } \\
\text { (2 bis } 8 \text { Wo. p.p.) }\end{array}$}} & $\mathrm{J}(\mathrm{B}, \mathrm{Ha})$ \\
\hline Mangan & & & & & $\begin{array}{l}\text { Mn (Voll-B, Ha), } \\
\text { AP (B) }\end{array}$ \\
\hline Cupfer & & & & & $\mathrm{Cu}(\mathrm{B}, \mathrm{Ha})$ \\
\hline Selen & & & & & Se (B), GPX (Voll-B) \\
\hline Zink & & & & & $\mathrm{Zn}(\mathrm{Ha})$ \\
\hline Vitamin A & & \multirow{5}{*}{\multicolumn{3}{|c|}{2 bis 4 Wo. p.p. }} & Vitamin A $(B, L)$ \\
\hline B-Carotin & & & & & B-Carotin $(\mathrm{B}, \mathrm{L})$ \\
\hline Vitamin E & & & & & Vitamin E \\
\hline Vitamin C & & & & & Vitamin C \\
\hline $\begin{array}{l}\text { Antioxidan- } \\
\text { tien }\end{array}$ & $\begin{array}{l}\text { Status an Pro-/Antioxidan- } \\
\text { tien, Futterqualität }\end{array}$ & & & & $\begin{array}{l}\text { TEAC, (ACW, ACL, } \\
\text { SOD, GPX) }\end{array}$ \\
\hline
\end{tabular}

SEIDEL und EHRENTRAUT (1976) sprechen bei der Stoffwechseluntersuchung von der „Objektivierung von Stoffwechselstörungen“ und empfehlen die Auswahl der Parameter anhand von speziellen Krankheitsbildern. Auch die TGL 34313 (1988) sah für spezielle Krankheitsprobleme eigene Untersuchungsspektren vor. FÜRLL (2013a) beschreibt ebenfalls gesonderte Problem- bzw. Organprofile zur Differenzierung spezieller Erkrankungen (Tabelle 2.3 und Tabelle 2.4). 
Tabelle 2.4 Empfohlene Parameter bei bestimmten Krankheitsbildern nach FÜRLL (2013a), modifiziert

\begin{tabular}{|c|c|c|}
\hline Krankheitsbild & Parameter & Zeitpunkt \\
\hline Fettmobilisationssyndrom & $\begin{array}{l}\text { Blut: BHB, Bili, AST, Chol, FFS, Leukozyten } \\
\text { Milch: FEQ, Hast, Protein }\end{array}$ & $\begin{array}{l}<1 \text { Woche a.p. } \\
2-4 \text { d p.p. }\end{array}$ \\
\hline Ketose & Blut: BHB, FFS, Bili, Glu, Leukozyten & $\begin{array}{l}2-1 \text { Wo a.p. } \\
2-12 \text { Wo p.p. }\end{array}$ \\
\hline Gebärparese & $\begin{array}{l}\text { Blut: AP } \\
\text { Harn: NSBA, Basen, BSQ, K, pH-Wert }\end{array}$ & $2-1$ Wo a.p. \\
\hline Labmagenverlagerung & $\begin{array}{l}\text { Blut: } \text { FFS, Chol, CK, Bili, KK, Cl, K, } \\
\quad \text { Leukozyten } \\
\text { Harn: NSBA } \\
\text { Milch: FEQ, Hast }\end{array}$ & $\begin{array}{l}\text { peripartum } \\
\text { 3. d p.p. }\end{array}$ \\
\hline Fruchtbarkeitsstörungen & $\begin{array}{l}\text { Blut: FFS, IGF-1, BHB, Glu, Chol, Bili, Hast, } \\
\text { Protein, B-Car, Ck, AST, GLDH, Pi, Se, J, } \\
\text { Cu, Mn, Co } \\
\text { Harn: } \mathrm{Na}, \mathrm{K}, \mathrm{Pi} \text {, frakt. NSBA, relative Dichte }\end{array}$ & $\begin{array}{l}\text { a. p. } \\
\text { 3. d. p. p. } \\
\text { Frühlaktation }\end{array}$ \\
\hline $\begin{array}{l}\text { Mastitiden } \\
\text { Klauenerkrankungen }\end{array}$ & $\begin{array}{l}\text { Blut: FFS, Bili, BHB, Chol, Hast, Protein, } \\
\text { Leukozyten, Se, TEAC, SD, GPX, ACL, } \\
\text { ACW } \\
\text { Harn: pH-Wert, frakt. NSBA, K, relative Dichte }\end{array}$ & in Problemsituationen \\
\hline $\begin{array}{l}\text { Störung Säure-Base- } \\
\text { Haushalt }\end{array}$ & $\begin{array}{l}\text { Blutserum: } \mathrm{Pi}, \mathrm{Ca}, \mathrm{Cl}, \mathrm{Laktat} \\
\text { Vollblut: } \mathrm{pH}-\text { Wert, } \mathrm{BE}, \mathrm{pCO} 2 \\
\text { Milch: } \mathrm{pH}-\text { Wert, Soxhlet-Henkel-Zahl } \\
\text { Harn: } \mathrm{pH}-\text { Wert, frakt. NSBA, BSQ, K, Na, Pi, } \\
\quad \text { Ca, relative Dichte } \\
\text { Pansensaft: } \mathrm{pH}-\text { Wert, Gesamtazidität, Laktat, } \\
\quad \text { Ammoniak }\end{array}$ & in Problemsituationen \\
\hline
\end{tabular}

Die Konzentrationen verschiedener Parameter sind zum Teil von bestimmten Bedingungen abhängig. Dazu zählen die Abhängigkeit der Jahreszeiten (PAYNE et al. 1970, 1974, ROSSOW et al. 1975, LEE et al. 1978, GHERGARIU et al. 1984, FÜRLL 1989, EICHER 2003, ZAHN 2006), des Laktationsstadiums (u. a. PAYNE et al. 1974, ROSSOW et al. 1975, ROWLANDS et al. 1975, LEE et al. 1978, ZAHN 2006, KRONSCHNABL 2010, FÜRLL 2013a, b), der Milchleistung (PAYNE et al. 1974, ROWLANDS et al. 1975, LEE et al. 1978, SÖLLNER-DONATH 2013), der Fütterung (PAYNE et al. 1970, 1974, LOTTHAMMER 1981, ZAHN 2006), der Rasse (SOMMER 1970) und des Alters (SOMMER 1970, LOTTHAMMER 1981, ACKERMANN et al. 2013b, FÜRLL 2013b). Des Weiteren hat auf die Konzentrationen der Parameter Glucose, BHB, Ca und $\mathrm{P}_{\mathrm{i}}$ die Auswahl des Punktionsortes bei der Probengewinnung einen Einfluss (EICHER 2003). Weitere Unterschiede wurden zum Einen zwischen verschiedenen Untersuchungsjahren zur gleichen Jahreszeit festgestellt (PAYNE et al. 1973) und zum Anderen zwischen verschiedenen Herden (PAYNE et al. 1970, 
ROSSOW et al. 1975). ROSSOW et al. (1975) empfehlen deshalb die Erstellung eines herdenspezifischen Stoffwechselprofiles.

Gesonderte Referenzbereiche werden zwischen der Winter- und Sommerfütterung als nicht notwendig angesehen (PAYNE et al.1974).

Leistungsabhängige bzw. betriebsspezifische Referenzbereiche sind ebenfalls nicht zu empfehlen, da so die Gefahr besteht Mängel zu übersehen. Gesonderte laktationsabhängige Toleranzgrenzen werden dagegen für die Parameter FFS, CK, $P_{i}$ und B-Carotin als sinnvoll erachtet (FÜRLL 2013a).

\subsection{Frühdiagnostik von Krankheiten anhand verschiedener Parameter}

BAUMGÄRTNER (1979) sieht die Früherkennung von Stoffwechselkrankheiten anhand bestimmter Parameter noch als unmöglich an. HACKER und SIERING (1979) konnten ebenfalls keine Veränderungen von Parametern im dritten und vierten bzw. im achten und neunten Trächtigkeitsmonat bei Tieren, die später an Puerperalstörungen erkrankten, feststellen.

Aktuellere Untersuchungen zeigen, dass bei bestimmten Erkrankungen verschiedene Parameter bereits frühzeitig Abweichungen aufweisen.

So konnte bei Kühen mit späterer Labmagenverlagerung (LMV) bereits a. p. erhöhte FFS und erniedrigte Zn-Konzentrationen sowie eine Störung im Säure-Base-Haushalt nachgewiesen werden. In der ersten Woche p. p. zeigten diese Tiere erhöhte Konzentrationen der Parameter FFS, Bilirubin, BHB und AST sowie erniedrigte Konzentrationen bei $\mathrm{Mg}$, Ca und $\mathrm{Zn}$. Bei Kühen mit späterem Nachgeburtsverhalten konnten a. p. ebenfalls erhöhte FFS und niedrige Zn-Konzentrationen sowie niedrige Na-Konzentrationen beobachtet werden. Außerdem war der BSQ im Harn erniedrigt. (SÖLLNER-DONATH 2013).

Kühe mit erniedrigten Glucosekonzentrationen, erhöhten BHB-Konzentrationen und erhöhten Milchacetonkonzentrationen in der ersten Woche p. p. weisen ein erhöhtes Risiko auf, im Laufe der Laktation an Ketose zu erkranken (REIST et al. 2003).

Ein erhöhtes Erkrankungsrisiko für Gebärmutterentzündungen besteht bei veränderten Albumin- und Bilirubinkonzentrationen in der Hochträchtigkeit (STOCK 2009). Eine andere Untersuchung zeigte, dass Kühe bereits acht Wochen vor dem Auftreten von Endometritiden veränderte LDH-Aktivtäten sowie Cholesterol- und Glucosekonzentrationen zeigen (SOMMER 1970).

Nach HARASZTI et al. (1984) ist außerdem die Konzeptionschance p. p. herabgesetzt, wenn die Kühe a. p. erniedrigte Albumin- und Cholesterolkonzentrationen aufweisen.

Weitere geeignete Parameter zur Frühdiagnostik sind in Tabelle 2.5 (FÜRLL 2013a) zusammengestellt. Sie basieren auf den Daten von WILKEN (2003), HOOPS (2006), HÄDRICH (2007) sowie SCHWARTAU (2012). 
Tabelle 2.5 Laborparameter zur Frühdiagnostik der wichtigsten Rinderkrankheiten a. p. (FÜRLL 2013a)

\begin{tabular}{|l|c|c|c|c|c|c|}
\hline & Ovarzysten & Endometritis & Mastitis & Laminitis & LMV & Gebärparese \\
\hline FFS & + & + & + & + & +++ & - \\
\hline BHB & + & ++ & + & + & ++ & - \\
\hline Glucose & + & + & - & + & + & - \\
\hline IGF-1 & +++ & - & - & +++ & - & - \\
\hline Insulin & + & - & - & - & - & - \\
\hline CK & - & +++ & - & - & ++ & - \\
\hline TEAC & - & +++ & +++ & - & - & - \\
\hline Haptoglobin & - & - & - & + & - & - \\
\hline Bilirubin & - & - & - & - & + & - \\
\hline AP & - & - & + & - & - & +++ \\
\hline NSBA & - & - & - & - & - & + \\
\hline
\end{tabular}

\subsection{Referenzbereiche und Auswertung}

Das Wort „refere“ kommt aus dem lateinischen und bedeutet „sich auf etwas beziehen“. Ein Referenzbereich bezieht sich auf die Messwerte einer gesunden Vergleichspopulation (SCHWENDENWEIN 2013).

Der Messwert eines Patienten kann mit dem Referenzbereich verglichen werden. Dabei sollten die Untersuchungsbedingungen des Patienten denen, die bei Erstellung des Referenzbereiches vorlagen, möglichst ähnlich sein. Deshalb müssen diese Bedingungen definiert sein (KRAFT 2005). Dazu zählen

- Angaben zu den Probanden: Zahl, Alter, Rasse, Geschlecht, Gesundheit, Zeit und Methode der Probengewinnung

- Angaben zu der labortechnische Verarbeitung: Beschreibung der Methodik, Aufbewahrungszeit, -art und -temperatur der Probe bis zur Verarbeitung, verwendete Reagenzien, Berechnungsarten, Präzision, Richtigkeit, Qualitätskontrolle

Auf Grund dessen wird empfohlen, dass vor allem große Labore mit laborspezifischen Referenzbereichen arbeiten (SCHWENDENWEIN 2013)

Auch die Erstellung von stallspezifischen Referenzbereichen wird in der Literatur empfohlen. So beschreibt GÜRTLER (1976) die Verwendung von Kühen nach der Dritten und Vierten Laktation mit einer Leistung von mehr als 5000 kg Milch pro Jahr zur Ermittlung von Referenzwerten.

Zur Ermittlung des Referenzbereiches sollte die Mindestzahl an Individuen keinesfalls weniger als 80 sein, jedoch wird zu einer Anzahl von mindestens 120 geraten (SCHWENDENWEIN 2013). 
Bei der statistischen Bearbeitung zur Ermittlung der Referenzgrenzen wird zwischen dem nichtparametrischen und dem parametrischen Verfahren unterschieden. Bei dem erst genannten, welches auch als Perzentil-Methode beschrieben ist, wird ein bestimmter Perzentilbereich als Referenzbereich angesehen. Meistens wird dabei das 95\%-Perzentil-Intervall gewählt. Das bedeutet, dass alle Werte der Größe nach geordnet werden und anschließend bei zweiseitigen Referenzbereichen die obersten und untersten 2,5\% der Werte ausgeschlossen werden. Bei einem einseitigen Referenzbereich, das heißt es gibt eine obere oder eine untere Grenze, werden nur die 2,5\% der Werte auf der Seite ausgeschlossen, wo eine Referenzgrenze von Bedeutung ist. Bei dieser Methode ist eine Normalverteilung der Werte keine Voraussetzung. Im Gegensatz dazu müssen die Konzentrationen bei der Anwendung der parametrischen Methode normal verteilt sein. In diesem Fall wird der Referenzbereich mit Hilfe des Mittelwertes \pm der zweifachen Standardabweichung ermittelt (SCHWENDENWEIN 2013).

ROWLANDS und POCOCK (1971), PAYNE et al. (1973) ROSSOW et al. (1973), WILLER et al. (1976) setzen ebenfalls bei der Einzeltierauswertung die zweifache Standardabweichung ein. Einige andere Autoren sehen die zweifache Standardabweichung um den Mittelwert als zu weit an. So wird zum Teil nur für bestimmte Parameter (ADAMS et al. 1978) oder für alle Parameter die einfache Standardabweichung als sinnvoll erachtet (SOMMER 1970, KIDA 2002b, WATANABE et al. 2013). ADAMS et al. (1978) empfehlen dagegen für die meisten Parameter die 1,3-fache Standardabweichung zu verwenden.

Auf Herdenbasis kann der Vergleich von Ergebnissen anhand von Referenzbereichen u. a. mit Hilfe des Mittelwertes einer Teilgruppe erfolgen. Dabei wird der Herdenmittelwert mit einem Mittelwert verglichen, der repräsentativ für die jeweilige Population ist. Während ROWLANDS und POCOCK (1971) Herden als „normal“ beurteilen, die sich innerhalb des Populationsmittelwertes und der einfachen Standardabweichung befinden, arbeiten WILLER et al. (1976) mit relativen Standardabweichungen, welche parameterabhängig ermittelt werden. PAYNE et al. (1970) bewerten Herden anhand einer Auswertung von 13 Herden mit guten Erfolgen in der Fütterung und im Management. Von diesen Herden wurden für bestimmte Parameter die Mittelwerte und das 95\%-Konfidenzintervall bestimmt und zum Vergleich herangezogen.

Eine Herde gilt als potenziell gefährdet, wenn zwei Mittelwerte außerhalb der Erwartungswerte liegen und/ oder wenn bei mehr als drei bis vier Parametern mehr als $20 \%$ der Tiere Konzentrationen außerhalb des Referenzbereiches aufweisen. In diesem Fall sollte die Herde besonders beobachtet werden und eine Kontrolle der Fütterung und des Managements erfolgen (ADAMS et al. 1978). LAUNER und STORM (1979) bzw. FÜRLL (2013a) nutzen für die Beurteilung von Mittelwerten bzw. Medianwerten Kontrollgrenzen und für die Auswertung von Einzelwerten eines Parameters Toleranzgrenzen. FÜRLL (2013a) geht ebenfalls von einer Leistungs- bzw. Gesundheitsgefährdung aus, wenn der Mittelwert außerhalb der Kontrollgrenzen oder 20\% der Einzelwerte außerhalb der 
Toleranzgrenzen sind. Dabei werden die Kontrollgrenzen als Mittelwert \pm 0,5 Standardabweichung und die Toleranzgrenzen als Mittelwert \pm einfacher Standardabweichung definiert. Für die Parameter FFS und BHB beschreiben OSPINA et al. (2010) bereits 15 - 20\% der Konzentrationen außerhalb der Grenzen als alarmierend in Bezug auf ein erhöhtes Risiko für LMV und Ketosen sowie eine herabgesetzte Trächtigkeitsrate und Milchproduktion.

Bei der Beurteilung von Poolproben müssen die Grenzen ebenfalls etwas enger sein, als bei der Beurteilung von Einzelwerten (BORCHARDT und STAUFNBIEL 2012). Aus diesem Grund wird bei Poolproben als Referenzbereich der Mittelwerte \pm einfache Standardabweichung empfohlen (GELFERT und STAUFENBIEL 2007). VAN SAUN (2010) arbeitet dagegen mit der halben Standardabweichung bei der Auswertung von Poolproben.

Bei dem Vergleich von Ergebnissen mit Referenzbereichen ist jedoch zu beachten, dass nicht alle abnormen Parameter gleichzeitig ein klinische Relevanz aufweisen (ROWLANDS und POCOCK 1971, PAYNE et al. 1973, FÜRLL 2013a). Kühe ohne klinische sichtbare Krankheitssymptome können pathologische Laborwerte aufweisen und im Gegensatz können klinisch kranke Kühe Laborwerte innerhalb der Referenzbereiche haben (BAUMGÄRTNER 1979). Aus diesem Grund ist eine klinische Untersuchung in Verbindung mit Stoffwechseluntersuchungen zur Stellung einer sicheren Krankheitsdiagnose anzuraten (SEIDEL und EHRENTRAUT 1976; BAUMGÄRTNER 1979, HACKER und SIERNG 1979)

Die Bedeutung von Abweichungen einiger Blutparameter wird in Tabelle 2.6 verdeutlicht. 
Tabelle 2.6: Herdendiagnostische Bedeutung einiger abweichender Stoffwechselparameter im Blut (FÜRLL 2013a)

\begin{tabular}{|c|c|c|}
\hline Parameter & & Bedeutung \\
\hline $\begin{array}{l}\text { Ketonkörper } \\
\text { gesamt, ß-Hy- } \\
\text { droxybutyrat }\end{array}$ & $\uparrow$ & $\begin{array}{l}\text { 1) (längerer) Energiemangel im Futter oder eingeschränkte Futteraufnahme } \\
\text { bei Krankheiten (Energiemangelketose) } \\
\text { 2) } \uparrow \text { Buttersäure in Silage, hohe Kraftfuttergaben (alimentäre Ketose) }\end{array}$ \\
\hline \multirow[t]{2}{*}{ Glucose } & $\downarrow$ & $\begin{array}{l}\text { Energiemangel im Futter oder eingeschränkte Futteraufnahme bei } \\
\text { Krankheiten (hpts. Ketose) }\end{array}$ \\
\hline & $\uparrow$ & $\begin{array}{l}\text { 1) starke Belastungen (z. B. Transport), 2) Endotoxämie 3) metabolisches } \\
\text { Syndrom }\end{array}$ \\
\hline FFS & $\uparrow$ & $\begin{array}{l}\text { Energiemangel im Futter oder eingeschränkte Futteraufnahme bei } \\
\text { Krankheiten, Stress (Kalbung, Transport), Fettmobilisationssyndrom, } \\
\text { metabolisches Syndrom }\end{array}$ \\
\hline Bilirubin & $\uparrow$ & $\begin{array}{l}\text { 1) Energiemangel im Futter oder eingeschränkte Futteraufnahme bei } \\
\text { Krankheiten (Inanitionsikterus!), 2) Leberbelastung, 3) Erythrozytenzerfall } \\
\text { (Anämie), häufig als Mikrohämolyse bei Septikämien; korreliert immer } \\
\text { signifikant mit FFS }\end{array}$ \\
\hline Cholesterol & $\downarrow$ & $\begin{array}{l}\text { eingeschränkte Futteraufnahme (Transitphase!) und Darmverdauung } \\
\text { (Diarrhö); systematischer Anstieg p.p. ist Zeichen für gutes Futtermanage- } \\
\text { ment: } 1 \text { Woche p.p. }>2 \text { mmol/l, } 4 \text { Wochen p.p. }>3 \text { mmol/l, } 8 \text { Wochen p.p. > } \\
4 \text { mmol/l }\end{array}$ \\
\hline \multirow[t]{2}{*}{ Protein } & 个 & $\begin{array}{l}\text { 1) wichtiger Entzündungsmarker (Mastitis, Metritis, Klauen, Fremdkörper, } \\
\text { Pneumonien), 2) Proteinüberversorgung }\end{array}$ \\
\hline & $\downarrow$ & $\begin{array}{l}\text { 1) Proteinverlust (Nieren, Darm, Bauchhöhle, Uterus), } \\
\text { 2) starker Proteinmangel im Futter (Unterernährung) }\end{array}$ \\
\hline \multirow[t]{2}{*}{ Harnstoff } & $\uparrow$ & $\begin{array}{l}\text { 1) Energiemangel im Futter, 2) Kreislaufstörungen (Schock!), 3) } \\
\text { Nierenkrankheiten (hpts. prärenal) }\end{array}$ \\
\hline & $\downarrow$ & $\begin{array}{l}\text { 1) Proteinmangel im Futter, 2) reduzierte Futteraufnahme bei Krankheiten, 3) } \\
\text { chronische Krankheiten }\end{array}$ \\
\hline Kreatinin & $\uparrow$ & 1) Nierenkrankheiten, 2) starker Körpermasseabbau und Unterernährung \\
\hline \multirow[t]{2}{*}{ Fibrinogen } & $\uparrow$ & Akute-Phasen-Reaktion/Entzündungen \\
\hline & $\downarrow$ & Blutgerinnungsstörungen/Thrombosen \\
\hline Haptoglobin & $\uparrow$ & $\begin{array}{l}\text { Akute-Phasen-Reaktion/Entzündungen, bes. bei Pneumonien und Enteritiden; } \\
\text { wesentlich sensibler als Fibrinogen }\end{array}$ \\
\hline AST & $\uparrow$ & Muskel- (Uterus-!!!, Labmagen-), Leberschäden; akute Endometritis \\
\hline GLDH & $\uparrow$ & $\begin{array}{l}\text { 1) Leber-, (starke) Nierenschäden } \\
\text { 2) intensiver Stoffwechsel- und Harnstoffumsatz }\end{array}$ \\
\hline \multirow[t]{2}{*}{$\gamma$-GT } & $\uparrow$ & $\uparrow$ Leberschäden, - korreliert eng mit Leberfett und -volumenzunahme \\
\hline & $\downarrow$ & unzureichende Kolostrumaufnahme (Kälber) \\
\hline CK & $\uparrow$ & Muskel-, (Uterus-!!!, Labmagen-) schäden; akute Endometritis \\
\hline \multirow[t]{2}{*}{ AP } & $\uparrow$ & 1) Knochenweiche (Rachitis); 2) Gebärpareserisiko wenn $<45$ U/l \\
\hline & $\downarrow$ & Mangan-, Zinkmangel, azidotische Belastungen \\
\hline LDH & $\uparrow$ & sensibler Indikator für Störungen im Körper (ohne genauere Lokalisation) \\
\hline $\mathrm{Ca}$ & $\downarrow$ & Gebärparese, (Rachitis), subklinisch: Retentio sec, LMV, Mastitis \\
\hline
\end{tabular}




\begin{tabular}{|l|l|l|}
\hline \multirow{2}{*}{ Fortsetzung Tabelle 2.6 } \\
\hline \multirow{2}{*}{ Pi } & $\uparrow$ & Pansen- u. a. Azidosen, Calzinose \\
\cline { 2 - 3 } & $\downarrow$ & $\begin{array}{l}\text { 1) chronische Pansen- u. a. Azidosen, 2) starke Belastungen, 3) gestörte } \\
\text { Verdauung, z. B. Diarrhö oder Ileus, 4) Pi-Binder (Zeolith) }\end{array}$ \\
\hline \multirow{2}{*}{ Mg } & $\uparrow$ & starke Stressreaktion \\
\hline Na & $\downarrow$ & 1) Weide-, Stall-, Transporttetanie, Tetanie der Kälber, 2) Gebärparese \\
\hline K & $\downarrow$ & starker Diarrhö; $\downarrow$ Versorgungslage $\rightarrow$ Harn!, $\downarrow$ Fruchtbarkeit \\
\hline $\mathrm{Cl}$ & $\downarrow$ & Diarrhö, eingeschränkte Futteraufnahme bei Krankheiten, $\uparrow$ Stress \\
\hline Cu & $\downarrow$ & $\begin{array}{l}\text { Dislocatio abomasi, Diarrhö, Stase des Vormagen-Labmagen-Systems } \\
\text { (Indigestionen), Labmagengeschwüre }\end{array}$ \\
\hline Se & $\downarrow$ & $\begin{array}{l}\text { Unterversorgung, } \downarrow \text { Leistung, } \downarrow \text { Fruchtbarkeit, Anämie, Abmagerung, } \\
\text { Bewegungsstörungen, Haarveränderungen, Herzschwäche }\end{array}$ \\
\hline Zn & $\downarrow$ & $\begin{array}{l}\text { Unterversorgung, } \downarrow \text { Leistung, } \downarrow \text { Fruchtbarkeit, Abmagerung, Bewegungsstö- } \\
\text { rungen/Muskeldystrophie, Herzschwäche }\end{array}$ \\
\hline Mn & $\downarrow$ & $\begin{array}{l}\text { Unterversorgung, } \downarrow \text { Leistung, Haar- und Hautveränderungen (Parakeratose), } \\
\text { Horninstabilität }\end{array}$ \\
\hline Fe & $\downarrow$ & $\begin{array}{l}\text { Unterversorgung, } \downarrow \text { Leistung, } \downarrow \text { Fruchtbarkeit, Abmagerung, Bewegungsstö- } \\
\text { rungen, } \uparrow \text { männliche Kälber }\end{array}$ \\
\hline B-Carotin & $\downarrow$ & Unterversorgung, $\downarrow$ Leistung, $\downarrow$ Resistenz, Kümmern, Anämie \\
\hline Vitamin A & $\downarrow$ & Unterversorgung, schlechte Fruchtbarkeit und Resistenz (Diarrhöen) \\
\hline Vitamin E & $\downarrow$ & Unterversorgung, schlechte Fruchtbarkeit und Resistenz (Diarrhöen) \\
\hline SOD & $\downarrow$ & Anterversorgung, analog wie bei Se \\
\cline { 2 - 3 } & $\uparrow$ & akute Belastungen, z.B. rechtsseitige LMV \\
\hline GPX & $\downarrow / \uparrow$ & i. d. Regel invers zu SOD bei Rindern; bei Se-Mangel $\downarrow ;$ \\
\hline TEAC & $\downarrow / \uparrow$ & $\begin{array}{l}\text { analog wie SOD für Summe wasserlöslicher Antioxidantien und Vitamin-E; } \\
\downarrow \text { z.B. bei Retentio sec., Mastitiden, LMV }\end{array}$ \\
\hline ACL & $\downarrow$ & chronischer Mangel wasserlöslicher Antioxidantien, z.B. bei Mastitiden \\
\hline
\end{tabular}




\section{Tiere, Material und Methoden}

In der Zeit von Oktober 2006 bis März 2011 wurden insgesamt 840 eingesendete Proben aus 60 verschiedenen Betrieben einer Tierärztlichen Gemeinschaftspraxis im Emsland analysiert. Es gab 122 Einsendungen mit durchschnittlich 6,9 Einzelproben. In $32 \%$ der Fälle wurde die höchste Anzahl von zehn Proben je Einsendung untersucht. Bei den Proben handelt es sich in 793 Fällen um Blutserum und in den restlichen 47 um Harnuntersuchungen. Elf der Blutproben wurden gepoolt und bestanden aus zwei bis zehn Einzelproben.

Die untersuchten Kühe und Färsen wurden stichprobenartig ausgewählt und gehörten deshalb unterschiedlichen Alters-, Leistungs- und Laktationsgruppen an. Im Untersuchungsauftrag sind in der Regel zu den jeweiligen Tieren Angaben zum Laktationsstadium vermerkt. Anhand dieser Angaben können die Kühe in verschiedene Gruppen eingeteilt werden (Tabelle 3.1).

Tabelle 3.1: Definition der Laktationsstadien und Anzahl der Tiere je Laktationsstadium von eingesendeten Proben einer tierärztlichen Gemeinschaftspraxis im EL

\begin{tabular}{|c|l|c|c|}
\hline Laktationsstadium & Definition & n Tiere & $\begin{array}{c}\text { rel. } \\
\text { Häufigkeit } \\
\text { in \% }\end{array}$ \\
\hline a.p. & 8 Wo a.p./ 56 d a.p. bis 1 d a.p. & 321 & 38,2 \\
\hline 0-1 Wo p. p. & 0-1 Wo p. p./ 0-7 d p. p. & 109 & 13,0 \\
\hline bis 8 Wo p. p. & $\begin{array}{l}\text { 2 Wo p. p./ > 7 d p. p. bis 8 Wo p. p./ 2 Mo p. p./ } \\
\text { 60 d p. p, Frühlaktation, frischmelk }\end{array}$ & 206 & 24,5 \\
\hline bis 14 Wo p. p. & $\begin{array}{l}\text { > 2 Mo p. p./ 9 Wo p. p. bis 3 1/2 Mo p. p./ 14 Wo p. p./ } \\
\text { 100 d p. p., Hochlaktation }\end{array}$ & 46 & 5,5 \\
\hline >100d p. p. & $\begin{array}{l}\text { > 100d p. p./ > 14 Wo p. p., mittlere Laktation, } \\
\text { Spätlaktation, altmelk }\end{array}$ & 57 & 6,8 \\
\hline Färse & Färse, Rind a.p. & 50 & 6,0 \\
\hline ohne Angabe & ohne Angabe bzw. nicht eindeutig zuzuordnen & 51 & 6,1 \\
\hline & Gesamt & 840 & 100,0 \\
\hline
\end{tabular}

An alle Betriebe, die nur einmal eingesendet haben, sind Fragebögen verteilt worden. Betriebe, welche mehrmals Proben eingeschickt haben, sind persönlich besucht worden. Es wurden Angaben zur Größe des Betriebes, Rasse der Rinder, Milchleistung mit Inhaltstoffen, Haltung, Fütterung und Fruchtbarkeitskennzahlen erfragt. Außerdem wurden die Hauptursachen für Abgänge im Betrieb und die Gründe für die Probeneinsendung notiert. Insgesamt haben 53 Betriebe an der Befragung teilgenommen.

Die Betriebe halten zwischen 24 und 270 Milchkühe und haben eine Leistung von 5800 bis 11600 Milch-kg/ Jahr. Eine genaue Aufteilung der Betriebe anhand ihrer Anzahl von Milchkühen spiegelt die Tabelle 3.2 wider. 43 Betriebe halten ausschließlich Schwarzbunte Deutsche Holstein zur 
Milchgewinnung. Acht Landwirte züchten Schwarz- und Rotbunte Holsteins. Einer davon hat zusätzlich noch Braunvieh im Bestand. Ein Betrieb mit Schwarzbunten Holstein Kühen gibt an, ab dem dritten Versuch mit Fleckvieh zu besamen. Nur ein Landwirt hält ausschließlich Limousins zur Fleischgewinnung. Zum Teil befinden sich zusätzlich noch Zuchtbullen oder Mastrinder auf den Höfen.

Tabelle 3.2: Gruppeneinteilung der Betriebe einer tierärztlichen Gemeinschaftspraxis im EL anhand der Anzahl Milchkühe

\begin{tabular}{|c|c|}
\hline Anzahl Milchkühe & Anzahl Betriebe \\
\hline $1-50$ & 8 \\
\hline $51-75$ & 19 \\
\hline $76-100$ & 11 \\
\hline $101-150$ & 11 \\
\hline$>150$ & 3 \\
\hline
\end{tabular}

In 45 Beständen werden die Milchkühe im Laufstall gehalten. Bei sechs Betrieben ist Anbindehaltung angegeben und bei zwei Landwirten werden die Kühe in Boxen gehalten. Im Durchschnitt haben die Rinder 161 Tage Weidegang.

Die Proben wurden im Labor der Medizinischen Klinik untersucht. Je nach Einsendungsgrund wurden verschiedene Parameter zur Untersuchung vom Tierarzt in Abstimmung mit dem Landwirt ausgewählt. Zum Teil folgten nach Rücksprache mit dem Labor weitere Untersuchungen auf einzelne Parameter. Daraus folgend ist eine unterschiedliche Anzahl von Ergebnissen der einzelnen Parameter vorhanden. Die Analyse der Parameter erfolgte mit den Methoden in Tabelle 3.3 und Tabelle 3.4. Anschließend sind die Einzelwerte anhand der Toleranzbereiche (Tabelle 3.3 und Tabelle 3.4) und die Mittelwerte bzw. Mediane anhand der Kontrollbereiche (FÜRLL 2013a) bewertet worden. Wenn zur Auswertung der Mittelwerte bzw. Mediane keine Kontrollgrenze vorhanden war, wurde in diesem Fall ebenfalls die Toleranzgrenze herangezogen.

Aus dem Blut wurden die Parameter des Energie-Fett-Leberstoffwechsels Glucose, FFS, BHB, AST, GGT, GLDH, Bilirubin, Gallensäuren (GS), Cholesterol und des Eiweißstoffwechsels Gesamteiweiß (Totales Protein, TP), Albumin, Kreatinin, Harnstoff, sowie das Muskelenzym CK, ß-Carotin und Coeruloplasmin $(\mathrm{Cpl})$ bestimmt. Des Weiteren liegen Ergebnisse zu Parametern des Mineralstoffwechsels, wie Na, K, Chlorid $(\mathrm{Cl}), \mathrm{Ca}$, anorganisches Phosphat $\left(\mathrm{P}_{\mathrm{i}}\right)$, Eisen $(\mathrm{Fe}), \mathrm{Mg}$, AP und der Spurenelemente $\mathrm{Cu}, \mathrm{Se}, \mathrm{Zn}$ und $\mathrm{Mn}$ vor. Bei vorhandenen Rückstellproben wurde zusätzlich noch die Trolox äquivalente antioxidative Kapazität (TEAC) ermittelt.

Aus dem Harn wurden die Konzentrationen von $\mathrm{Na}, \mathrm{K}, \mathrm{Cl}, \mathrm{Mg}, \mathrm{Ca}, \mathrm{P}_{\mathrm{i}}$, sowie Basen, Säuren, Ammonium (NH4+), NSBA und der pH-Wert bestimmt. Anhand der Ergebnisse ist anschließend der Basen-Säure-Quotient (BSQ) ermittelt worden. 
Tabelle 3.3: Analysemethoden, Variationskoeffizienten, Geräte, Toleranzbereiche (FÜRLL 2013a) der

Blutserumparameter

\begin{tabular}{|c|c|c|c|c|c|}
\hline $\begin{array}{l}\text { Blutserumparameter } \\
\text { (Einheit) }\end{array}$ & Methoden & $\begin{array}{l}\text { Toleranz- } \\
\text { bereich }\end{array}$ & $\begin{array}{l}\mathrm{VKS} \\
(\%)\end{array}$ & $\begin{array}{l}\text { VKT } \\
(\%)\end{array}$ & $\begin{array}{l}\text { Gerät/ } \\
\text { Firma }\end{array}$ \\
\hline $\mathrm{FFS}(\mu \mathrm{mol} / \mathrm{l})$ & Kinetischer UV-Test & $\begin{array}{c}\mathrm{a} \leq 150, \mathrm{~b} \leq 620 \\
\mathrm{c}=\leq 340\end{array}$ & 0,38 & 2,57 & \multirow{3}{*}{$\begin{array}{c}\text { Randox } \\
\text { Laboratories } \\
\text { GmbH } \\
\text { Krefeld }\end{array}$} \\
\hline Bilirubin $(\mu \mathrm{mol} / \mathrm{l})$ & JENDRASSIK und GROF & $\leq 5,3$ & 0,50 & 2,14 & \\
\hline $\mathrm{BHB}(\mathrm{mmol} / \mathrm{l})$ & UV-Methode & $\leq 0,62$ & 4,31 & 1,57 & \\
\hline Glucose (mmol/l) & Hexokinase-Methode & $2,22-3,30$ & 0,65 & 1,15 & \multirow{17}{*}{$\begin{array}{c}\text { Hitachi 912, } \\
\text { Automatic } \\
\text { Analyser/ } \\
\text { Boehringer } \\
\text { Mannheim }\end{array}$} \\
\hline Cholesterol (mmol/l) & CHOD-PAP-Methode & $\geq 1,5$ & 0,76 & 1,28 & \\
\hline CK (U/l) & $\begin{array}{l}\text { NAC aktivierte optimierte } \\
\text { Standard-Methode der DGKC }\end{array}$ & $\begin{array}{l}\mathrm{a}, \mathrm{c} \leq 150 \\
\mathrm{~b} \leq 200\end{array}$ & 0,49 & 1,64 & \\
\hline AST (U/l) & \multirow{2}{*}{$\begin{array}{l}\text { optimierte Standard-Methode der } \\
\text { DGKC }\end{array}$} & $\leq 80$ & 0,50 & 2,51 & \\
\hline GLDH (U/l) & & $\leq 41$ & 1,9 & 2,3 & \\
\hline GGT (U/l) & Methode nach SZASZ & $\leq 50$ & 0,91 & 3,37 & \\
\hline AP U/l & p-Nitrophenyl-phosphat & $45-120$ & 0,64 & 1,66 & \\
\hline $\mathrm{TP}(\mathrm{g} / \mathrm{l})$ & Biuret-Methode & $68-82$ & 0,35 & 1,90 & \\
\hline Albumin (g/l) & Bromcresolgrün & $30-39$ & 1,20 & 2,20 & \\
\hline Harnstoff (mmol/l) & Kinetischer UV Test & $2,0-5,0$ & 2,80 & 3,50 & \\
\hline Kreatinin $(\mu \mathrm{mol} / \mathrm{l})$ & Methode nach Jaffé & $55-150$ & 2,80 & 3,50 & \\
\hline $\mathrm{Mg}(\mathrm{mmol} / \mathrm{l})$ & Xylidylblau-Methode & $0,9-1,32$ & 0,98 & 2,85 & \\
\hline $\mathrm{Fe}(\mu \mathrm{mol} / \mathrm{l})$ & Ferrozin (ohne Enteiweißung) & $13-33$ & 0,60 & 2,23 & \\
\hline $\mathrm{Ca}(\mathrm{mmol} / \mathrm{l})$ & Kresolphtalein & $2,0-2,54$ & 0,41 & 1,21 & \\
\hline $\mathrm{P}_{\mathrm{i}}(\mathrm{mmol} / \mathrm{l})$ & Molybdat-Reaktion & $\begin{array}{l}\text { a, c } 1,55-2,29 \\
\text { b } 1,26-2,13\end{array}$ & 0,60 & 1,75 & \\
\hline $\mathrm{TEAC} \mu \mathrm{mol} / 1$ & MILLER et al. (1996) & $180-320$ & 3,8 & 6,4 & \\
\hline Coeruloplasmin (mg/l) & SUNDERMAN u. NOMOTO (1970) & $200-300$ & & & \\
\hline $\mathrm{Na}(\mathrm{mmol} / \mathrm{l})$ & \multirow{2}{*}{$\mathrm{KNa} 2$ : ionensensitive Elektrode } & $135-157$ & 0,31 & 0,76 & \multirow{2}{*}{$\begin{array}{r}\text { Radiometer } \\
\text { Kopenhagen }\end{array}$} \\
\hline $\mathrm{K}(\mathrm{mmol} / \mathrm{l})$ & & $3,9-5,2$ & 0,59 & 1,45 & \\
\hline $\mathrm{Cl}(\mathrm{mmol} / \mathrm{l})$ & Coulorimetrische Titration - & $95-110$ & 0,22 & 1,12 & A \\
\hline $\mathrm{Se}(\mu \mathrm{mol} / \mathrm{l})$ & \multirow{4}{*}{$\begin{array}{l}\text { Massenspektrometrie } \\
\text { mit induktiv } \\
\text { gekoppeltem Plasma }\end{array}$} & $0,40-0,88$ & & & \multirow{4}{*}{$\begin{array}{c}\text { Analysen- } \\
\text { gerät ICP- } \\
\text { MS } 820 \\
\text { Varian }\end{array}$} \\
\hline $\mathrm{Cu}(\mu \mathrm{mol} / \mathrm{l})$ & & $8,0-32,8$ & & & \\
\hline $\mathrm{Mn}(\mu \mathrm{mol} / \mathrm{l})$ & & $>0,4$ & & & \\
\hline $\mathrm{Zn}(\mu \mathrm{mol} / \mathrm{l})$ & & $12-25$ & & & \\
\hline Gallensäuren $(\mu \mathrm{mol} / \mathrm{l})$ & KOMIYAMA et al. (1982) & $15-88$ & & & B \\
\hline B-Carotin $(\mu \mathrm{mol} / \mathrm{l})$ & chromatographisch mit HPLC & $\mathrm{a}, \mathrm{c}>7,4 \mathrm{~b}>4,02$ & & & \\
\hline
\end{tabular}

VKS $(\%)=$ Präzisionskontrollen in der Serie; VKT $(\%)=$ Präzisionskontrollen von Tag zu Tag $\mathrm{a}=\mathrm{a} . \mathrm{p}, \mathrm{b}=1$. Woche p. $\mathrm{p}, \mathrm{c}=>1$ Woche p. $\mathrm{p}$.

$\mathrm{A}=\mathrm{Ciba}$ Corning Chloride Analyser 925, B = Test-kit 5.Gen. von Labor+Technik 
Tabelle 3.4: Analysemethoden, Variationskoeffizienten, Geräte, Toleranzbereiche (FÜRLL 2013a) der Harnparameter

\begin{tabular}{|c|c|c|c|c|c|}
\hline $\begin{array}{l}\text { Harnparameter } \\
\text { (Einheit) }\end{array}$ & Methoden & $\begin{array}{l}\text { Referenz- } \\
\text { bereich }\end{array}$ & $\begin{array}{l}\text { VKS } \\
(\%)\end{array}$ & $\begin{array}{l}\mathrm{VKT} \\
(\%)\end{array}$ & $\begin{array}{l}\text { Gerät/ } \\
\text { Firma }\end{array}$ \\
\hline $\mathrm{pH}$ & elektrisches pH-Meter & $7,8-8,4$ & 0,07 & & TM 5 \\
\hline Basen (mmol/l) & \multirow{4}{*}{$\begin{array}{c}\text { Titration nach } \\
\text { LACHMANN (1981) }\end{array}$} & $150-250$ & & & \\
\hline Säuren (mmol/l) & & $50-100$ & & & \\
\hline $\mathrm{NH} 4+(\mathrm{mmol} / \mathrm{l})$ & & $<10$ & & & \\
\hline NSBA (mmol/l) & & $83-215$ & 2,62 & & \\
\hline BSQ & Formel: Basen/(Säuren + NH4+) & $1,8-4,6$ & & & \\
\hline $\mathrm{Na}(\mathrm{mmol} / \mathrm{l})$ & \multirow{2}{*}{$\mathrm{KNa} 2$ : ionensensitive Elektrode } & $>2,2$ & 4,1 & 4,8 & \multirow{2}{*}{$\begin{array}{r}\text { Radiometer } \\
\text { Kopenhagen }\end{array}$} \\
\hline $\mathrm{K}(\mathrm{mmol} / \mathrm{l})$ & & $150-300$ & 3,9 & 4,7 & \\
\hline $\mathrm{Cl}(\mathrm{mmol} / \mathrm{l})$ & coulorimetrische Titration & $40-160$ & & & $\mathrm{~A}$ \\
\hline $\mathrm{Mg}(\mathrm{mmol} / \mathrm{l})$ & Xylidylblau-Methode & $3,7-16,5$ & 3,5 & 4,5 & B \\
\hline $\mathrm{Ca}(\mathrm{mmol} / \mathrm{l})$ & Titration mit Eriochromblau & $\leq 2,5$ & 3,2 & 4,1 & \\
\hline $\mathrm{Pi}(\mathrm{mmol} / \mathrm{l})$ & $\begin{array}{l}\text { Molybdänblau-Methode } \\
\text { (Taussky und Shorr) }\end{array}$ & $0,1-3,3$ & 3,1 & 3,6 & $\mathrm{C}$ \\
\hline
\end{tabular}

VKS $(\%)=$ Präzisionskontrollen in der Serie; VKT $(\%)=$ Präzisionskontrollen von Tag zu Tag $\mathrm{A}=$ Ciba Corning Chloride Analyser 925

$\mathrm{B}=$ Hitachi 912, AutomaticAnalyser/ Boehringer Mannheim

$\mathrm{C}=$ Eppendorf-Photometer $1101 \mathrm{M}$

Die statistische Auswertung erfolgte mit Microsoft Office Excel 2007. Mithilfe des Statistik Programmes WinSTAT für Microsoft Excel Version 2012.1 wurden die Parameter auf Normalverteilung und signifikante Unterschiede zwischen den Jahren untersucht. Die Überprüfung auf Normalverteilung erfolgte mit dem Kolmogorov-Smirnov-Test (KST) und wurde für die Parameter als Gesamtheit und bei ausgewählten Parametern für die einzelnen Jahre sowie die Laktationsstadien innerhalb der Jahre durchgeführt. Die Nullhypothese wurde bei einem $\mathrm{p}$-Wert $\leq \alpha$ mit einem Signifikanzniveau $\alpha=5 \%$ abgelehnt. Bei Normalverteilung der Konzentrationen folgte die Auswertung zwischen den Jahren mit dem unabhängigen T-Test, um zu überprüfen, ob ein signifikanter Unterschied zwischen den Mittelwerten $(\bar{x}, \mathrm{MW})$ besteht. Bei Parametern, die nicht normalverteilt sind, wurde der Mann-Whitney-U-Test angewandt um signifikante Unterschiede in der Konzentrationsverteilung (KV) zwischen den Untersuchungsjahren herauszufinden. Als signifikant unterschiedlich galt hierbei ebenfalls wenn $\mathrm{p} \leq 0,05$ ist.

Die Ergebnisse werden, neben tabellarischer Darstellung, anhand von Kreis- und Säulendiagrammen veranschaulicht. Bei normalverteilten Konzentrationen der Parameter werden außerdem die Mittelwerte mit Standardabweichung $(\bar{x} \pm \mathrm{SD})$ und bei nichtnormalverteilten Konzentrationen der Median mit 1. und 3. Quartil (Q1, Q3) gezeigt. 


\section{$4 \quad$ Ergebnisse}

\subsection{Betriebsanamnese}

Von 53 Betrieben liegen Angaben u. a. zur Betriebsgröße, Leistung, Haltung, Fütterung, Fruchtbarkeit und Abgangsursachen vor.

In den Betrieben werden entweder ausschließlich (81\%) Deutsche Schwarzbunte Holsteins gehalten oder diese in Verbindung mit Rotbunten Holsteins (13\%) bzw. mit einer anderen Rasse (2\%). Es ist nur ein reiner Mastbetrieb mit Limousin-Rindern darunter.

Die durchschnittliche Milchleistung der Betriebe liegt bei $8718 \mathrm{~kg} / \mathrm{Jahr}$. Eine Aufteilung der Betriebe nach ihrer Leistung ist in Abbildung $4.1 \mathrm{zu}$ sehen. Dabei ist ersichtlich, dass $80 \%$ eine Leistung zwischen 7000 und $10000 \mathrm{~kg} / \mathrm{Jahr}$ erzielen.

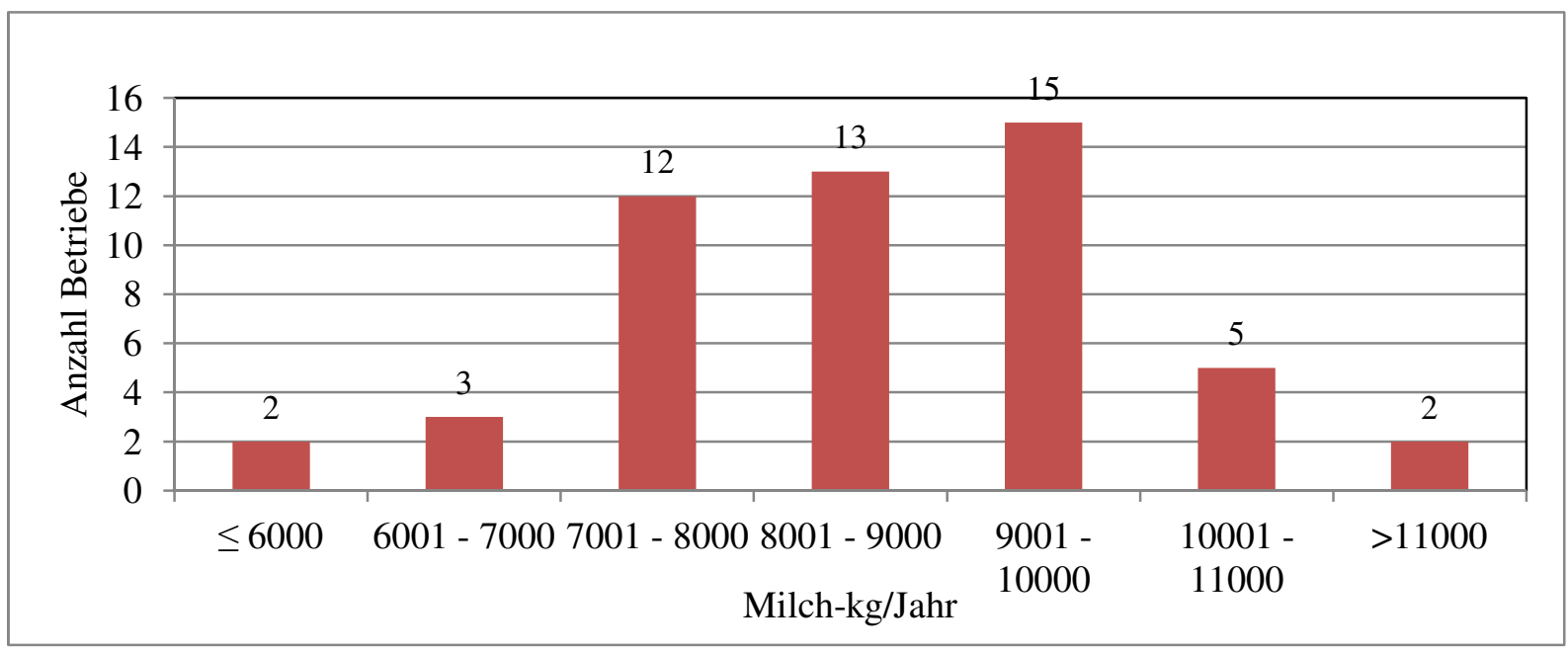

Abbildung 4.1: Einteilung der Betriebe einer tierärztlichen Gemeinschaftspraxis im EL nach Milchleistung pro Jahr

In 44 Betrieben (88 \%) sind die Kühe in den wärmeren Monaten auf der Weide. Die Zeitspanne liegt zwischen vier und acht Monaten im Jahr. Der Durchschnitt beträgt ca. sechs Monate/Jahr. Ausschließliche Stallhaltung findet bei sechs Betrieben (12\%) statt.

Bei 56,6\% der Betriebe wird die künstliche Besamung zur Bedeckung durchgeführt. Neun Landwirte (17\%) lassen ausschließlich einen Bullen decken. In 14 Ställen (26,4 \%) findet sowohl die künstliche Besamung als auch der Sprung durch Deckbullen statt. Der durchschnittliche Besamungsindex der Betriebe, die künstliche Besamungen durchführen, liegt bei 1,89. 96,7 \% der Betriebe haben einen Besamungsindex unterhalb der von HOEDEMAKER et al. (2014) empfohlenen Zielgröße $\leq 2,2$. Nur ein Unternehmen liegt darüber und weist einen Index von 4,8 auf. 
Die Zwischenkalbezeit (ZKZ) liegt bei $58 \%$ der Betriebe bei $\leq 410$ Tagen. Der Rest von $42 \%$ (19 Betriebe) weist eine höhere ZWK auf. Wie in Abbildung 4.2 zu sehen, können dem Zeitraum 401 bis 410 Tage die meisten Betriebe zugeordnet werden. Diese zwölf Betriebe entsprechen $27 \%$ der Landwirte, die zu diesem Punkt Angaben gemacht haben.

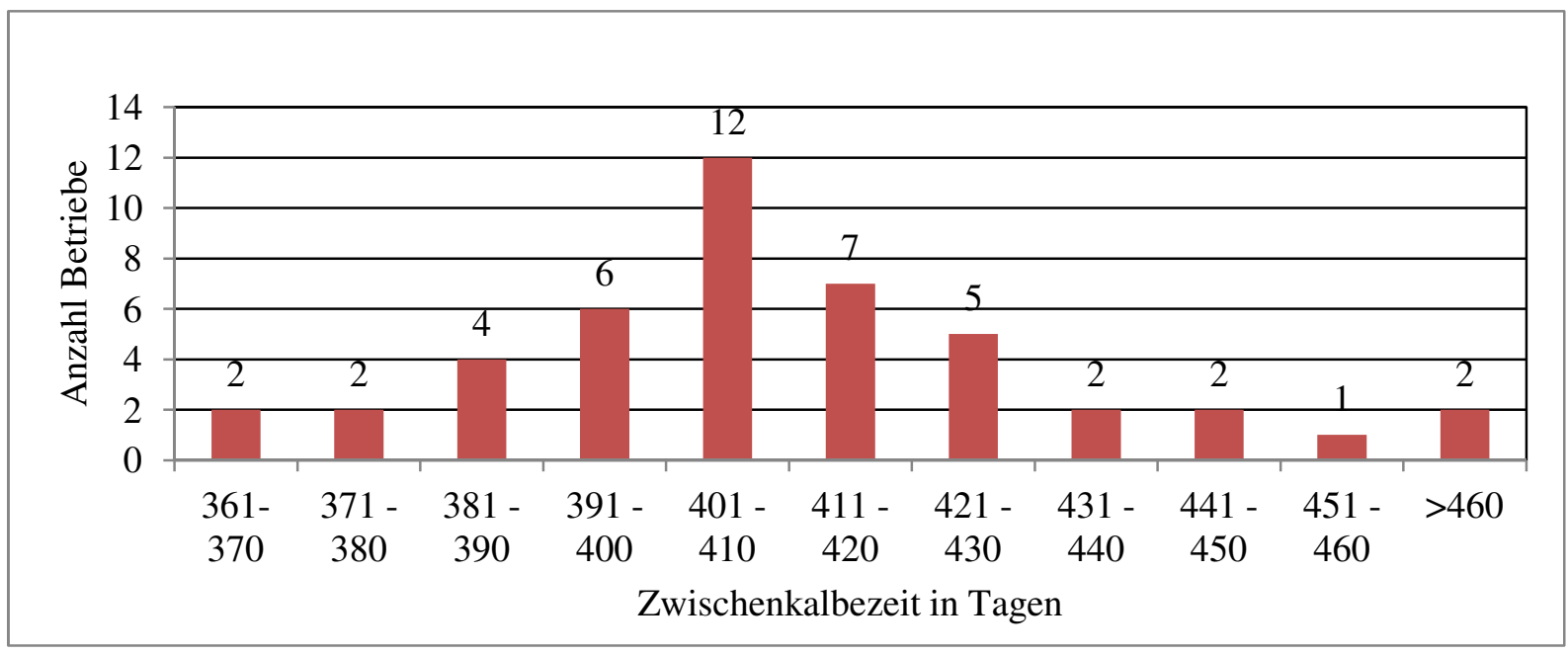

Abbildung 4.2: Zwischenkalbezeiten in Betrieben einer tierärztlichen Gemeinschaftspraxis im EL

\subsubsection{Fütterung}

Insgesamt lassen 47 Landwirte (89\%) das Futter auf verschiedene Inhaltstoffe analysieren und 46 führen eine Futterrationsberechnung durch. In 44 Betrieben (83\%) wird sowohl die Analyse als auch die Berechnung durchgeführt. Zwei Betriebe geben an, ihr Silo nur zu analysieren und keine Rationsberechnung durchzuführen und drei Landwirte berechnen Ihre Ration ohne vorher zu untersuchen. Vier Betriebe geben weder das Eine noch das Andere in Auftrag.

Im Durchschnitt bekommen die Kühe 1,5-mal frisches Futter vorgelegt. In $58 \%$ der Betriebe wird einmal gefüttert und in $37 \%$ zweimal. Die restlichen drei Herden werden mithilfe des WeelinkSystem gefüttert und bekommen deshalb zwischen drei und viermal frisches Silo. Bei dem WeelinkSystem werden die Siloblöcke auf den Futtertisch gestellt. Die Fressgitter sind beweglich und werden je nach Siloaufnahme der Rinder an die Siloblöcke herangefahren.

Als Hauptfutter bekommen die Rinder in allen Betrieben Grassilage. $89 \%$ der Betriebe (47 Betriebe) füttern Maissilage als zweite Hauptfutterkomponente. Von diesen Betrieben bieten 19 Landwirte jahreszeitenabhängig ihren Kühen zusätzlich frisches Gras an. Ausschließliche Grassilage bekommen die Rinder in drei Betrieben vorgelegt. Die restlichen drei Betriebe füttern neben Gassilage frisches Gras dazu. Als zusätzliche Komponente wird in 12 Betrieben (19\%) Heu, in 14 Betrieben (22 \%) Stroh und in fünf Betrieben ( $8 \%$ ) sowohl Heu als auch Stroh dazugegeben. 13 Landwirte (20\%) geben an, keine weitere Hauptfutterkomponenten zu füttern. 20 Betriebe setzen noch zusätzliche Komponenten ein, wie z. B. Kartoffelreibsel, Zuckerrübenschnitzel, Grünmais, Rapsschrot, Melasse, 
Möhrentrester, Pülpe, Maiskleber, Kartoffeln, Trockenschnitzel, Futterraps, Soja, Maiskolbenschrot, Luzerneheu, Biertreber und Soja-Raps-Mischung. Hierbei ist zu beachten, dass zum Teil Mehrfachnennungen vorliegen.

Die Kraftfutterzuteilung findet in den Betrieben an unterschiedlichen Stellen des Stalles statt. In 26 Betrieben (49\%) haben die Kühe einen Ort zur Kraftfutteraufnahme. Diese erfolgt entweder über die Ration, im Melkstand oder über einen Transponder an einem Automaten. Die anderen 27 Herden bekommen an mehreren Plätzen im Stall das Kraftfutter zugeteilt. Insgesamt wird die Zuteilung bei 32 Betrieben im Melkstand, bei 31 Betrieben über einen Automat und bei 19 Betrieben über die Ration durchgeführt. Eine genaue Aufteilung mit den verschiedenen Kombinationen der Kraftfutterzuteilung ist in Abbildung $4.3 \mathrm{zu}$ sehen.

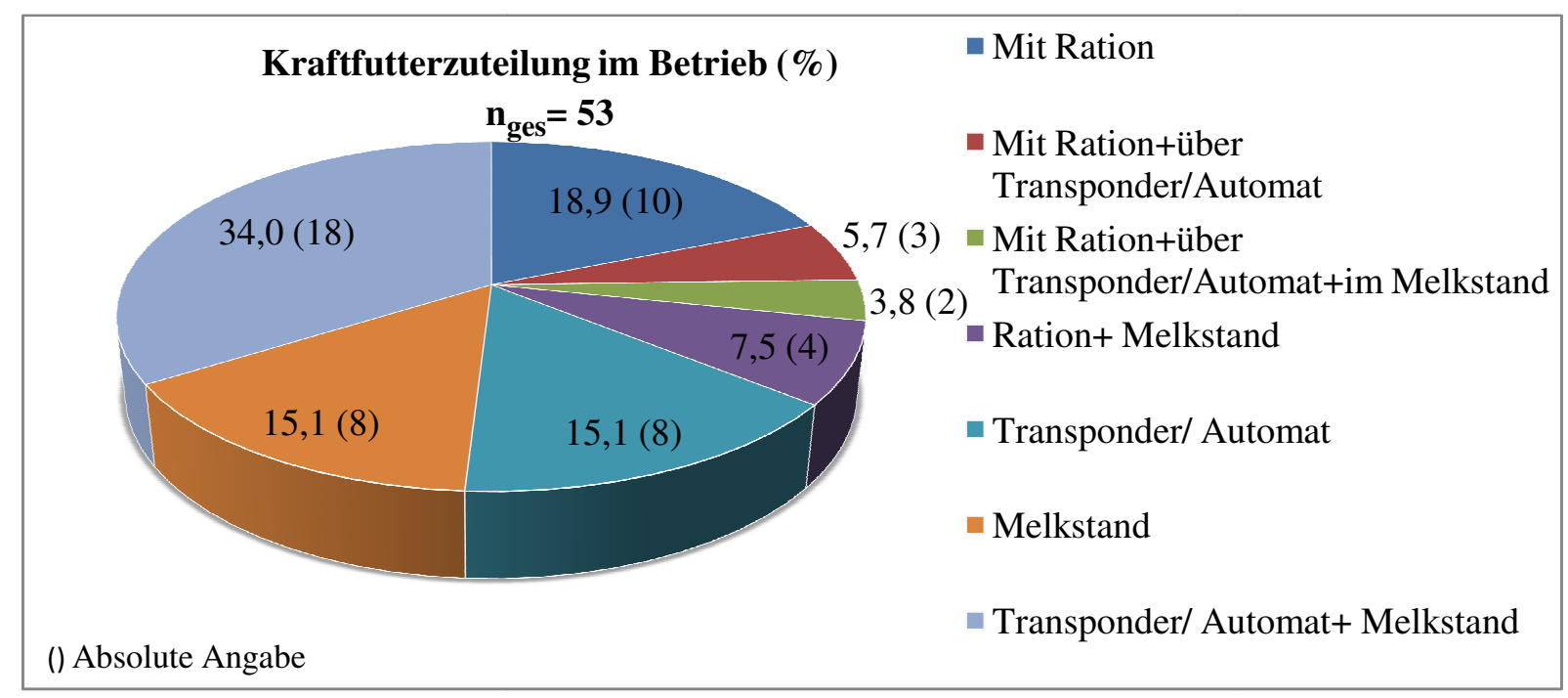

Abbildung 4.3: Art der Kraftfutterzuteilung in den Betrieben einer tierärztlichen Gemeinschaftspraxis im EL

Ein weiterer Punkt, der in den Fragebögen behandelt wurde, ist die Mineralstoffversorgung der Kühe. Hierbei liegen Angaben über die Zuteilung und die Mineralfutterarten vor. Die Auswertung der Zuteilung ergab, dass die Mineralstoffversorgung zum größten Teil (76 \%) über die Ration erfolgt. Von diesen 42 Betrieben stellen neun Betriebe Ihren Kühen zusätzlich noch Lecksteine bzw. Leckschalen zur freien Aufnahme zur Verfügung. Ausschließliche Versorgung über Lecksteine bzw. Leckschalen erfolgt in acht Herden (15\%). Vier Landwirte $(7 \%)$ geben an, mit Mineralstoffen angereichertes Kraftfutter zu füttern, welches nicht der Ration zugesetzt ist. In nur einem Betrieb wird kein Mineralfutter gefüttert bzw. zur Verfügung gestellt.

Die meisten Landwirte bedienen sich verschiedener Fertigmischungen für die Mineralstoffversorgung ihrer Kühe. Zum Teil geben sie zusätzlich noch Viehsalz und/ oder Futterkalk dazu. Vier Befragte geben an, ausschließlich Viehsalz und/ oder Futterkalk zu füttern. In acht Betrieben wird mit Mineralstoffen versetztes Ausgleichsfutter bzw. Milchleistungsfutter verwendet, welches entweder 
über die Ration, im Melkstand oder einen Automat verabreicht wird. In drei Betrieben erfolgt die Mineralstoffversorgung ausschließlich über das Ausgleichs- bzw. Milchleistungsfutter. Ein Betrieb füttert zusätzlich noch Viehsalz und zwei Betriebe Fertigmischung, Viehsalz und Futterkalk. Deshalb ist es hier zu Mehrfachnennung gekommen, welche das Diagramm über die verschiedenen Kombinationen der Mineralfutter (Abbildung 4.4) zwar mit beinhaltet, aber nicht extra ausweist.

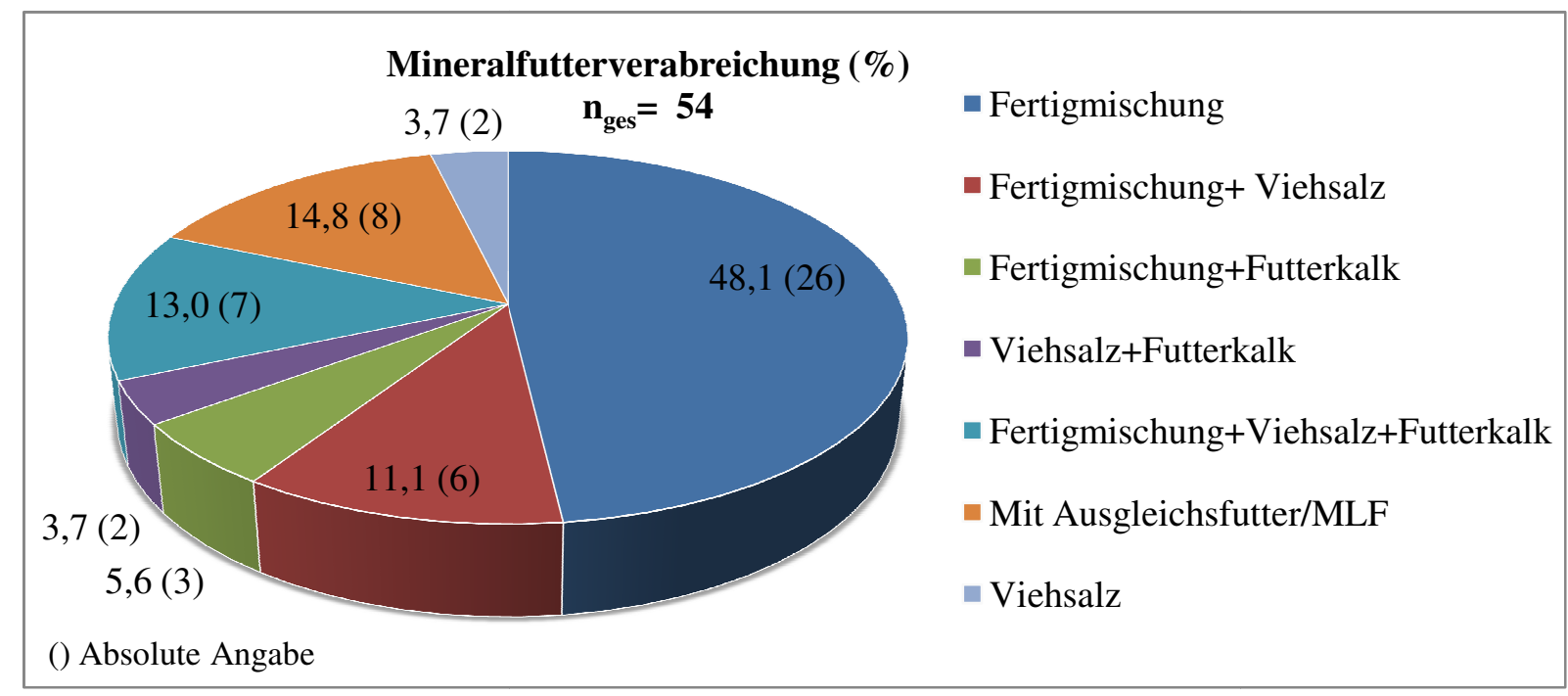

Abbildung 4.4: Häufigkeiten von Kombinationen verschiedener Mineralfutter in Betrieben einer tierärztlichen Gemeinschaftspraxis im EL

Mehr als die Hälfte der Betriebe (53,6 \%) geben an, keine weiteren Zusätze zu verfüttern. $32 \%$ der anderen Betriebe versorgen ihre Kühe mit Propylenglykol. Davon setzen die Hälfte der Betriebe das Propylenglykol regulär der Ration bzw. dem Kraftfutter zu, zum Teil bei bestimmten Gruppen, und die andere Hälfte je nach Bedarf bei bestimmten Kühen. Acht Betriebe nennen weitere Zusatzstoffe, wie Todhefen, Lebendhefen, Melasse, Natriumbicarbonat, Futterharnstoff, Flüssigzucker und Glycerin. Auch hier kommen dreimal andere Zusatzstoffe in Kombination mit Propylenglykol vor, so dass es auch bei diesem Punkt Mehrfachnennungen gibt.

\subsubsection{Gründe für Abgänge im Betrieb und Einsendungen der Proben}

In den Fragenbögen haben die Landwirte Angaben zu den Ursachen für Abgänge in ihren Betrieben gemacht. Dabei sollten sie die möglichen Ursachen mit Hilfe von Ziffern in der bestandsspezifischen Reihenfolge markieren. Mögliche Antworten waren Euterkrankheiten, Fruchtbarkeitsstörungen, Klauenerkrankungen/ Gliedmaßenerkrankungen, Stoffwechselkrankheiten, Infektionskrankheiten, schlechte Melkbarkeit, Leistungsmangel und Alter. Bei Sonstiges bestand die Möglichkeit weitere Ursachen zu ergänzen.

Insgesamt gab es achtmal Mehrfachnennung an erster Stelle, d. h. mehrere Ursachen waren für die Abgänge im Bestand verantwortlich. Wie in Abbildung $4.5 \mathrm{zu}$ erkennen, sind als Hauptursachen an 
erster Stelle Euterkrankheiten, Fruchtbarkeitsstörungen, Klauenerkrankungen und Gliedmaßenerkrankungen und Alter sowie einmal Sonstiges angegeben. Die anderen Ursachen folgen in der Rangfolge erst ab zweiter Stelle. Als Sonstiges ist in diesem Fall die Infektiöse Bovine Rhinotracheitis-Sanierung genannt.

Mit 40,6 \% sind Fruchtbarkeitsstörungen in dieser Umfrage mit deutlichem Abstand die Hauptursache für Abgänge in den untersuchten Betrieben. Darauf folgen die Klauen- und Gliedmaßenerkrankungen mit 29,7 \%, die Euterkrankheiten mit 21,9\% und das Alter mit 6,3.

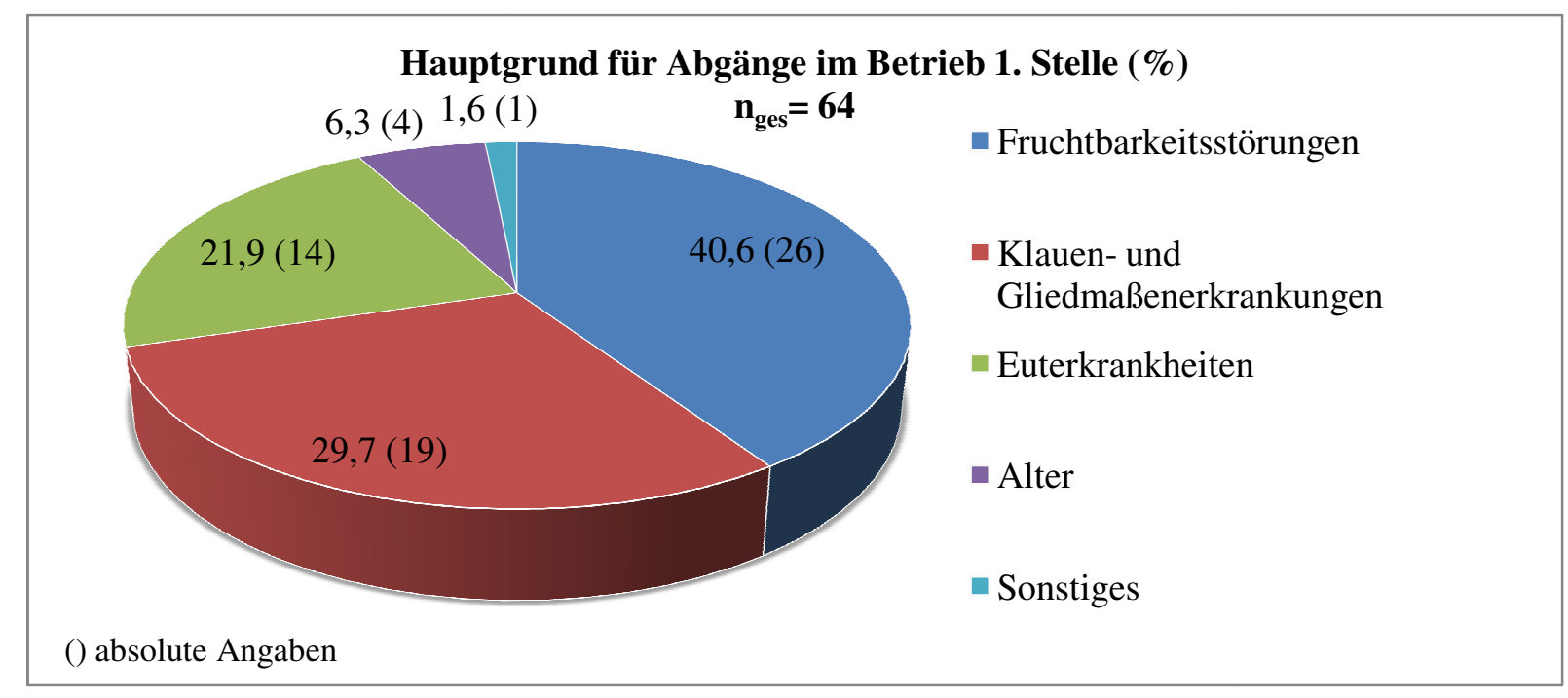

Abbildung 4.5: Hauptgründe für Abgänge an 1. Stelle in den Betrieben einer tierärztlichen Gemeinschaftspraxis im EL

Bei den Gründen, die von den Landwirten in der Rangfolge an zweiter Stelle angegeben wurden, sind auch Fruchtbarkeitsstörungen am häufigsten genannt. Das bedeutet, in den Betrieben, in denen Fruchtbarkeitsstörungen nicht der Hauptgrund für Abgänge sind, werden diese trotzdem zu 27,1 \% als zweithäufigster Grund angegeben. Mit fast gleichem Prozentsatz von 25,0 \% folgen hier die Euterkrankheiten und dann mit geringem Abstand die Klauen- und Gliedmaßenerkrankungen. Deutlich weniger sind das Alter und Stoffwechselkrankheiten mit jeweils 8,3\% genannt. Leistungsmangel bzw. Sonstiges mit je 4,2 \% und Infektionskrankheiten mit 2,1 \% ist nur zwei- bzw. einmal angegeben.

An letzter Stelle der Anamnese stehen Fragen zur Probeneinsendung und Maßnahmen, die nach Erhalt der Ergebnisse durchgeführt wurden. 33 von 51 Landwirten haben bei der Frage zum Einsendungsgrund mehrere Antworten gegeben, sodass sich hier eine höhere Gesamtanzahl von Angaben ergibt.

$\mathrm{Zu}$ 21,4 \% sind Proben eingeschickt worden, um u. a. den Stoffwechselstatus der Herde zu erfahren (Abbildung 4.6). Ausschließliche Stoffwechselstatusabfrage erfolgte bei fünf Einsendern. Bei den meisten Betrieben sind bestimmte Erscheinungen verstärkt beobachtet worden, weshalb daraufhin der Landwirt Stoffwechseluntersuchungen angefordert hat. Der häufigste Grund waren auch hier die 
Fruchtbarkeitsprobleme mit 20,4 \%. Darauf folgen mit größerem Abstand mit jeweils 9,2 \% verstärktes Auftreten von Ketosen, Festliegern und Euterproblemen und mit 6,1 \% Durchfall. Leistungsabfall wurde zu 2,0 \% genannt. Ein großer Teil von 22,4 \% beschreibt Sonstiges. Dabei werden u. a. magere Erstkalbinnen bzw. Kühe, zu viele kranke Kühe, Verkalbungen, Frühgeburten, Schwergeburten, vermehrt Nachgeburtsverhalten, zu schwache neugeborene Kälber, Kälbersterben kurz nach der Kalbung, vermehrt Labmagenverlagerungen, Todesfälle bei den Kühen, Verdacht auf $\mathrm{Cu}$ - bzw. Selenmangel, Azidose, Klauenerkrankungen und zum Zweck einer Meisterarbeit genannt.

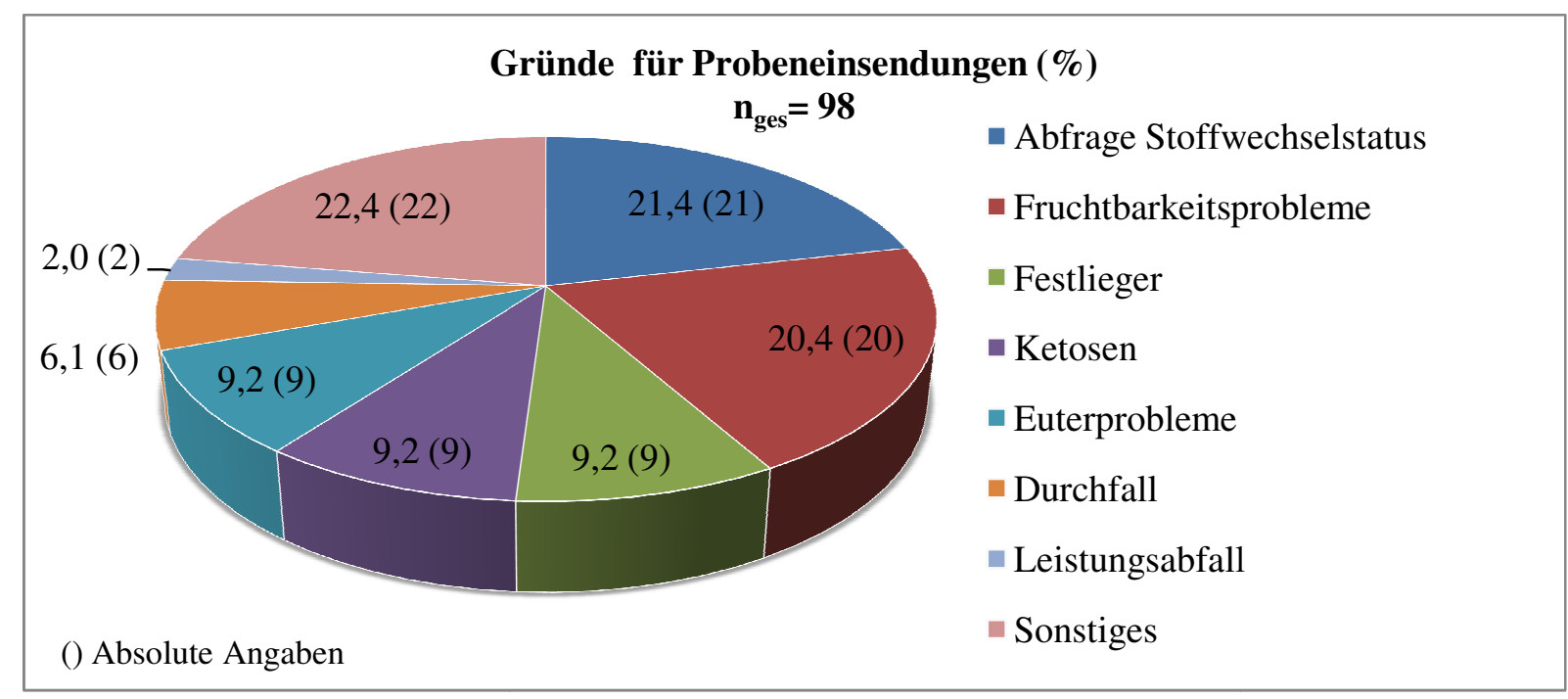

Abbildung 4.6: Gründe für die Einsendung der Proben in den Betrieben einer tierärztlichen Gemeinschaftspraxis im EL

50 von 53 Landwirten haben Angaben zu den durchgeführten Maßnahmen nach dem Erhalt der Ergebnisse der Stoffwechseluntersuchungen gemacht, welche in Abbildung 4.7 (Diagramm A) gezeigt werden. Auch bei dieser Frage gibt es durch die freie Antwortmöglichkeit der Landwirte Mehrfachnennungen.

Die meisten Veränderungen erfolgten in der Fütterung $(42,4 \%)$, wobei hier nochmal unterschieden werden kann zwischen dem Mineral-, Kraft- und Grundfutter (Abbildung 4.7 Diagramm B) In ungefähr der Hälfte der Fälle (47,1 \%) kam es zur Anpassung in der Mineralstofffütterung. Mit fast gleicher Anzahl an Nennungen folgen die Veränderungen im Kraftfutter $(20,6 \%)$ und im Grundfutter $(17,6 \%)$. Die restlichen Angaben von 14,7\% in der Futterumstellung sind nicht genau definiert wurden bzw. können nicht eindeutig zugeordnet werden. Da es von einigen Landwirten mehrere Angaben zur Veränderung in der Fütterung gibt, besteht eine Differenz zwischen der Anzahl im Punkt „Futterumstellung“ (Abbildung 4.7 Diagramm A) und der Gesamtanzahl an Nennungen in der Unterteilung in die verschiedenen Futterarten (Abbildung 4.7 Diagramm B). 
Eine weitere Maßnahme, die zu 15,2 \% genannt wurde (Abbildung 4.7 Diagramm A), ist die parenterale Verabreichung von Selen. Die 27,3 \% sonstigen Veränderungen sind in Abbildung 4.7 (Diagramm C) aufgeschlüsselt. Dabei sind zu einem Drittel verschiedene Mineralboli verabreicht und zu einem weiteren Drittel verschiedene Behandlungen durchgeführt worden. Das letzte Drittel setzt sich zusammen aus 11,1 \% Veränderung in der Wasserversorgung, 5,6 \% Propylenglykolgabe und $16,7 \%$ Sonstiges.

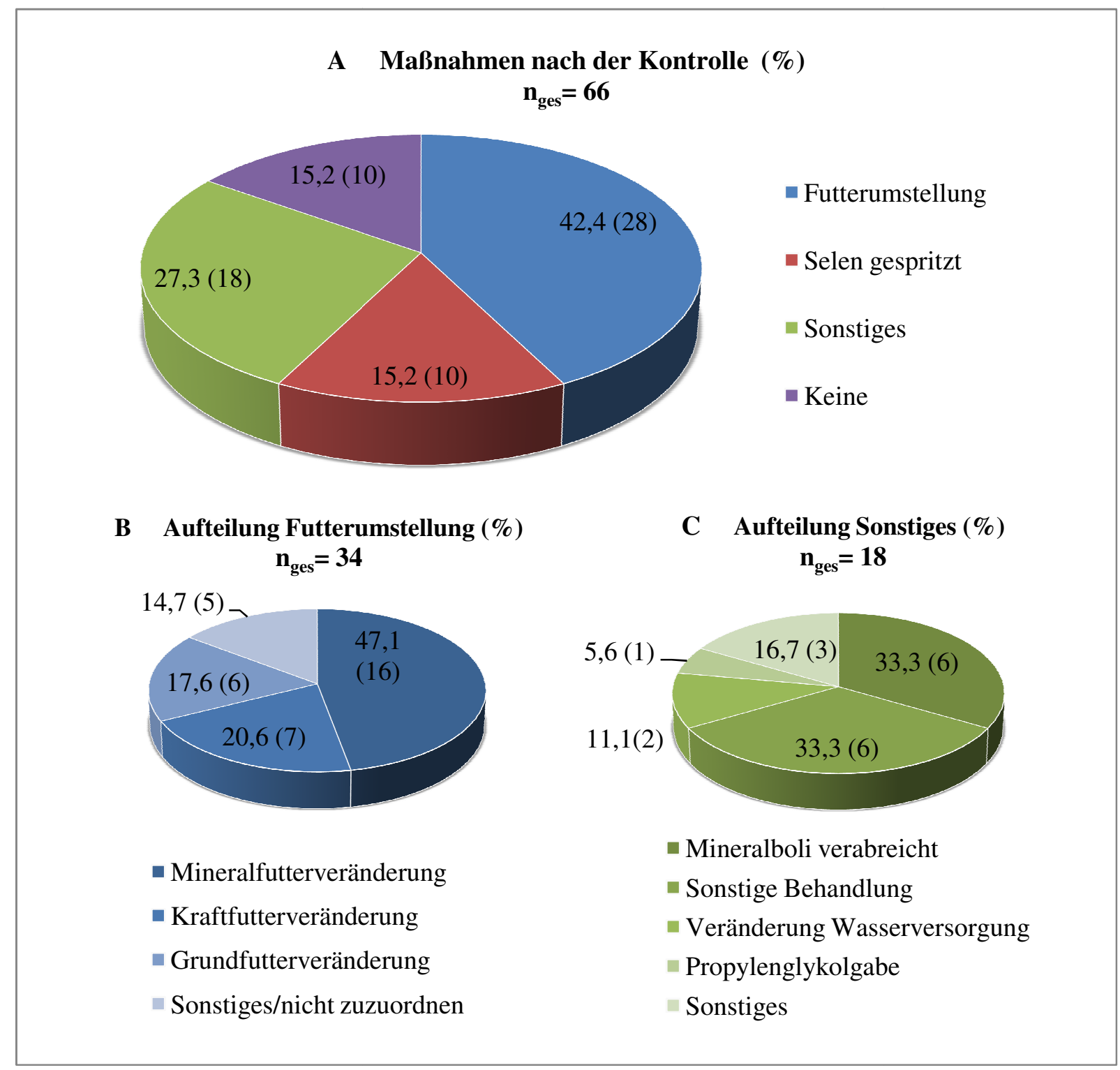

Abbildung 4.7: Maßnahmen nach Erhalt der Probenergebnisse in den Betrieben einer tierärztlichen Gemeinschaftspraxis im EL 
Insgesamt haben 25 von 53 Landwirten mindestens eine Maßnahme genannt, die im Zusammenhang mit der Mineralstoffversorgung steht. Die alleinige Veränderung an der Mineralstofffütterung und die ausschließlich parenterale Gabe von Mineralstoffen sind jeweils insgesamt neunmal beschrieben. Eine Kombination aus Anpassung der Mineralstofffütterung, Eingeben eines Mineralbolus und/oder einer parenteralen Verabreichung von Mineralstoffen wird siebenmal beschrieben.

Zehn (19\% von 53) Befragte haben aufgrund der Ergebnisse keine Maßnahmen bzw. Veränderungen durchgeführt.

\subsection{Ergebnisse der Proben als Gesamtheit}

\subsubsection{Allgemeine Auswertung der Einsendungen, Proben- und Parameteranzahl}

Insgesamt sind 122-mal Proben zur Untersuchung eingeschickt worden. Im Durchschnitt wurden dabei 6,9 Proben je Einsendung untersucht. Am Häufigsten sind jedoch zehn Proben (39-mal, entspricht $32 \%$ ) eingesendet worden (Abbildung 4.8). Wie in der Abbildung zu sehen, besteht ein deutlicher Abstand zu den Probenanzahlen neun bis zwei. Die Poolproben sind als eine Probe gezählt.

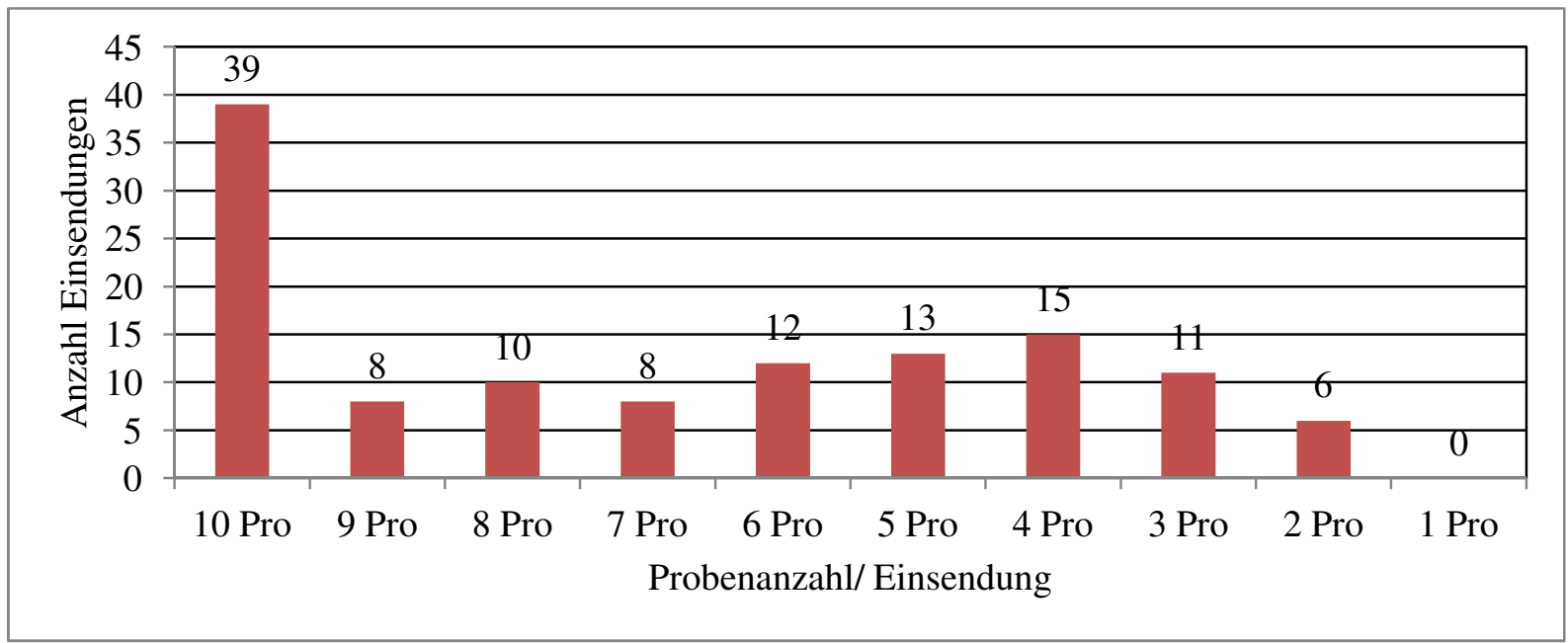

Abbildung 4.8: Anzahl an Einzelproben je Einsendung von Betrieben einer tierärztlichen Gemeinschaftspraxis im EL

Die Gesamtzahl der Proben variiert innerhalb der Jahre. Im Jahr 2007 sind mit 226 Proben die meisten Untersuchungen durchgeführt worden. Darauf folgen die Jahre 2009 mit 173 Proben, 2008 mit 161 Proben und 2010 mit 128 Proben. Da im Jahr 2006 erst ab Oktober und im Jahr 2011 nur bis März Ergebnisse vorliegen, ist ein Vergleich mit den anderen Jahren nicht sinnvoll. Von dem Jahr 2006 liegen insgesamt 58 und von 201194 Untersuchungsergebnisse vor.

Deutlich zu erkennen ist die Tatsache, dass die durchschnittliche Probenanzahl je Einsendung im Laufe der Jahre abnimmt (Abbildung 4.9). So sind 2006 im Durchschnitt 9,7 Proben je Einsendung zu verzeichnen und 2010 nur noch 5,1 Proben. 2011 ist ein geringer Anstieg auf 6,3 zu sehen, wobei die 
Jahre 2006 und 2011 auch hier wieder mit Beachtung der verkürzten Untersuchungszeiträume gelesen werden müssen. Aber auch in den Jahren 2007 bis 2010 ist der Trend deutlich zu sehen.

Das ist auch die Ursache, warum kein Zusammenhang sichtbar ist zwischen der Probengesamtanzahl und den Einsendungen in den einzelnen Jahren. So sind die meisten Einsendungen im Jahr 2009 mit 30 verzeichnet (Abbildung 4.9). Darauf folgen mit je 25 Einsendungen die Jahre 2007 und 2010. Die wenigsten Einsendungen in einem ganzen Jahr erfolgten 2008 mit 21. Die Jahre 2011 mit 15 und 2006 mit sechs Einsendungen bilden den Schluss.

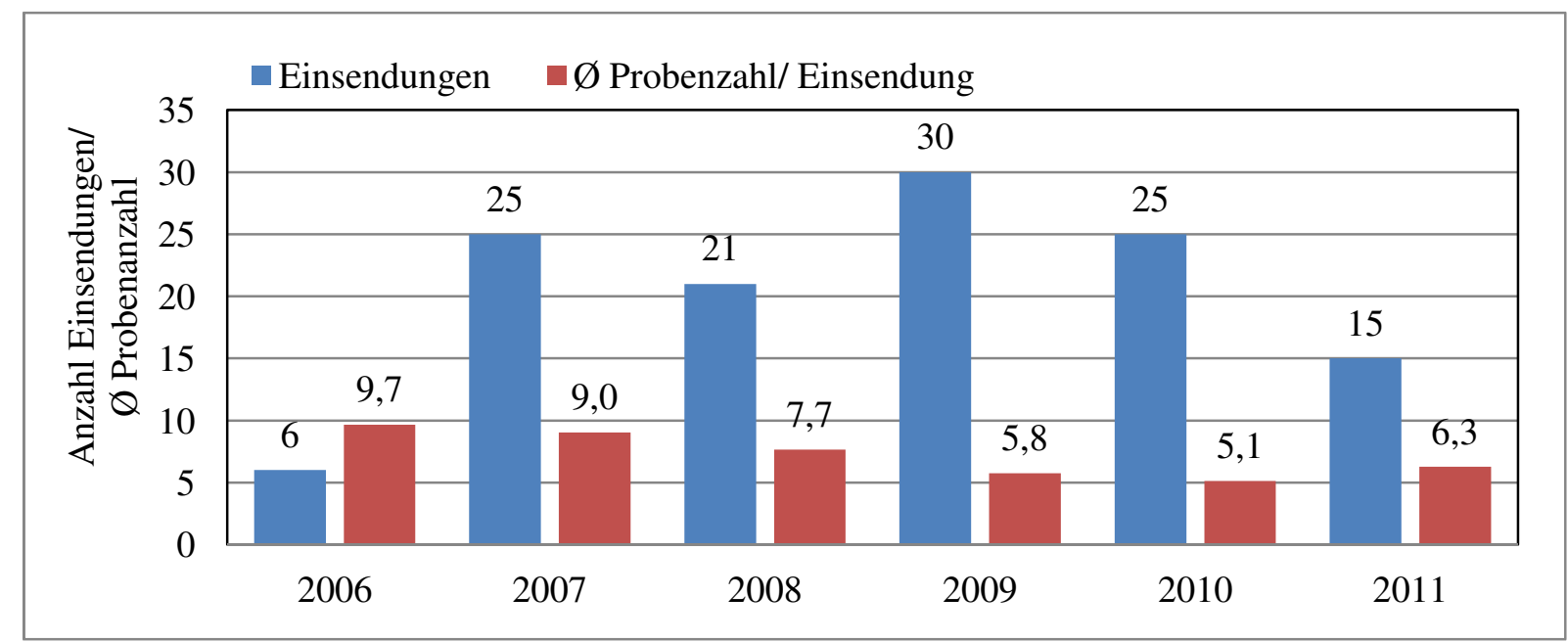

Abbildung 4.9: Anzahl an Einsendungen und durchschnittliche Probenanzahl/ Einsendung einer tierärztlichen Gemeinschaftspraxis im EL im Jahresvergleich

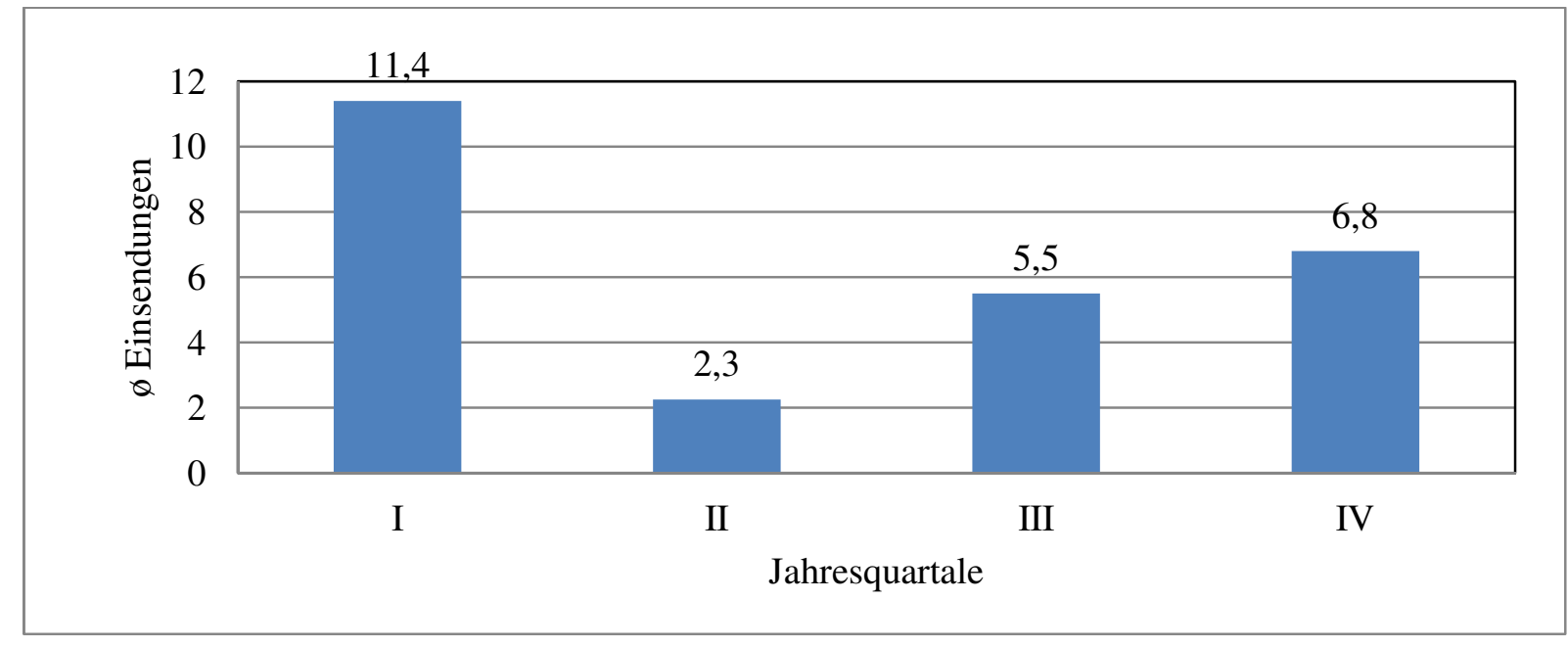

Abbildung 4.10: Durchschnittliche Einsendungen von 2006 bis 2011 innerhalb der Jahresquartale einer tierärztlichen Gemeinschaftspraxis im EL

Um einen Überblick über die jahreszeitliche Abhängigkeit der Einsendungen zu bekommen, sind aus den jährlichen Summen der einzelnen Quartale die Durchschnittswerte gebildet worden (Abbildung 4.10). Dabei wird deutlich, dass im ersten Quartal mit einer durchschnittlichen Anzahl von 11,4 
Einsendungen mit Abstand die meisten Untersuchungen erfolgten. Im zweiten Quartal sinken die durchschnittlichen Einsendungen auf 2,3 ab. In diesem Zeitraum fand im Laufe der Jahre in der Regel pro Monat entweder eine oder keine Untersuchung statt. Ab Juli kommt es dann wieder zu vermehrten Einsendungen, was im dritten und vierten Quartal mit 5,5 bzw. 6,8 Einsendungen deutlich wird. Diese jahreszeitliche Varianz ist, bis auf das Jahr 2008, auch innerhalb der einzelnen Jahre zu beobachten. 2008 sind die meisten Einsendungen im dritten Quartal.

Für die eingesendeten Blut- und Harnproben liegen Ergebnisse von im Durchschnitt 9,9 Parametern vor. Eine genaue Verteilung der Parameteranzahl wird in Abbildung 4.11 gezeigt. Dabei ist ersichtlich, dass für 50 Einsendungen die Parameteranzahl neun beträgt. Das entspricht $41 \%$. Mit großem Abstand folgen die Anzahlen zehn und 13.

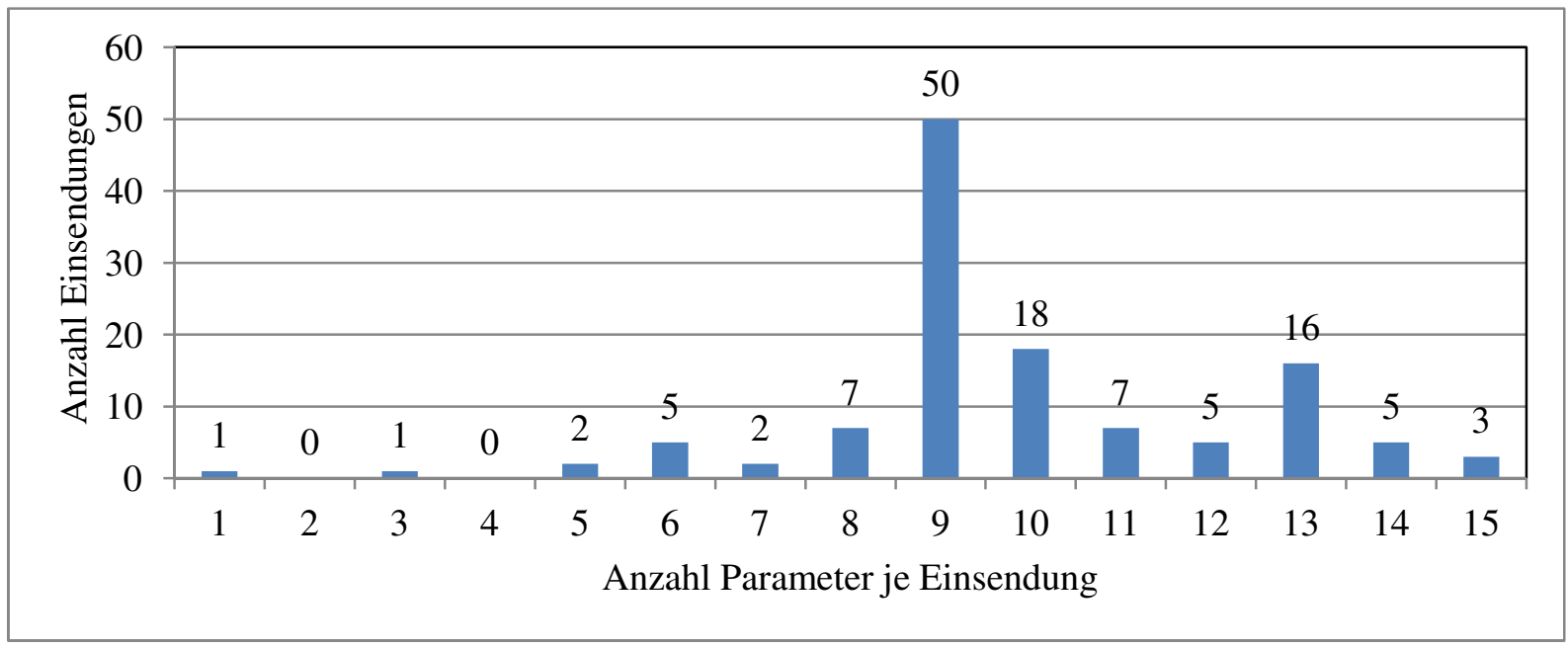

Abbildung 4.11: Untersuchte Parameteranzahl je Einsendung einer tierärztlichen Gemeinschaftspraxis im EL.

Innerhalb der einzelnen Einsendungen sind die verschiedenen Parameter auf Hinweise für eine Gefährdung des Gesundheitsstatus untersucht worden. Nach FÜRLL (2013a) kann man von einer Gesundheitsgefährdung der Gruppe sprechen, wenn mehr als $20 \%$ der Einzelwerte Ergebnisse oberbzw. unterhalb der Toleranzgrenzen aufweisen. Darauf aufbauend wurde jeder Parameter innerhalb einer Einsendung als gesund oder gesundheitsgefährdend gekennzeichnet. Anschließend wurden die jeweiligen Einsendungen Klassen zugeordnet, welche bestimmte Anzahlen an gesundheitsgefährdenden Parametern aufweisen.

Die Ergebnisse sind in Abbildung 4.12 zu sehen. Diese Abbildung zeigt, dass z. B. 32 Einsendungen zwischen 40,1\% und $50 \%$ Parameter aufweisen, welche als gesundheitsgefährdend gekennzeichnet wurden. Mit etwas Abstand folgen die Klassen 60,1 - $70 \%$ mit 26 Einsendungen und 50,1-60\% mit 23 Einsendungen. Daraus ergibt sich, dass $78,7 \%$ der Einsendungen zwischen 40,1 und $70 \%$ Parameter aufweisen, welche als gesundheitsgefährdend gelten. Es gibt keine Einsendung, die weniger 
als $20 \%$ gesundheitsgefährdende Parameter aufweist. Die Einsendung mit $100 \%$ wurde nur auf einen Parameter untersucht, welcher als gesundheitsgefährdend gilt.

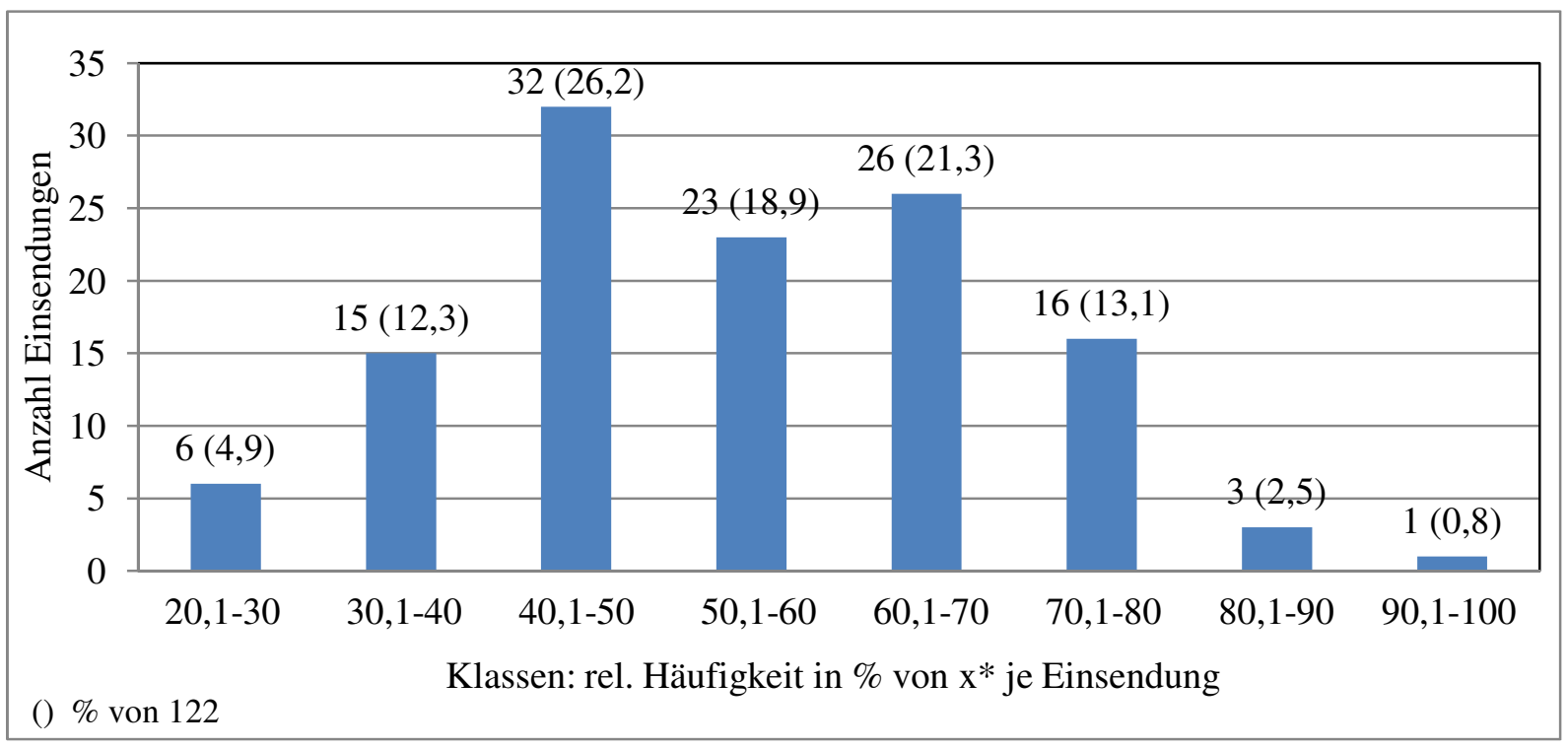

Abbildung 4.12: Häufigkeit von Parametern mit Hinweisen auf eine Gefährdung des Gesundheitsstatus $\left(x^{*}\right)$ (je Einsendung) einer tierärztlichen Praxis im EL. $x^{*}=>20 \%$ der Einzelwerte eines Parameters befinden sich außerhalb der Toleranzgrenzen (FÜRLL 2013a)

\subsubsection{Blutproben}

793 Blutproben sind insgesamt untersucht worden. In dieser Anzahl sind elf Poolproben enthalten. Dabei wurden die Poolproben zu je dreimal aus fünf und drei Einzelproben, zweimal aus neun Einzelproben und zu je einmal aus zehn, sechs und zwei Einzelproben zusammen gestellt.

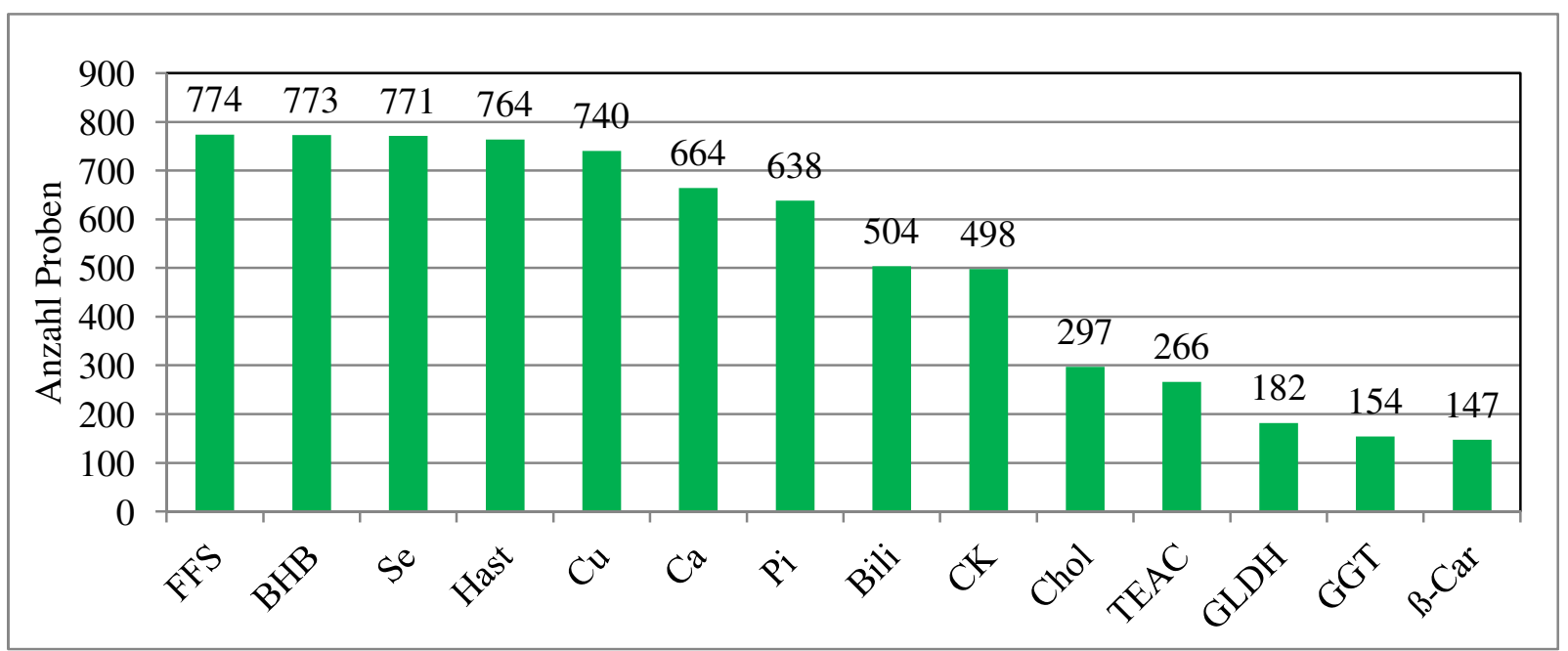

Abbildung 4.13: Gesamtprobenanzahl je Parameter mit $n>100$ eingesendet von einer tierärztlichen Gemeinschaftspraxis im EL 
$\mathrm{Zu}$ den einzelnen Einsendungen sind verschiedene Parameter in Abhängigkeit des Einsendungsgrundes von der Tierarztpraxis zur Untersuchung angefordert worden. Eine Übersicht, wie oft die Blutproben auf die einzelnen Parameter insgesamt untersucht wurden, zeigen Abbildung 4.13 und Abbildung 4.14. Dabei ist zu erkennen, dass für die meisten Proben Ergebnisse der Parameter FFS, BHB, Se, Harnstoff und Cu vorhanden sind. (Abbildung 4.13).

Wird für einen Vergleich, wie oft ein Parameter untersucht wurde, anstelle der Einzelproben die Einsendungen verwendet, besteht der bedeutendste Unterschied darin, dass Selen an erster Stelle steht und in 97,4\% der Einsendungen untersucht wurde. Darauf folgen mit jeweils 96,5\% die FFS und BHB. Die weitere Reihenfolge der Parameter ist mit den Angaben in Abbildung 4.13 identisch. Auch die Werte stehen ungefähr im gleichen Verhältnis und sind somit vergleichbar.

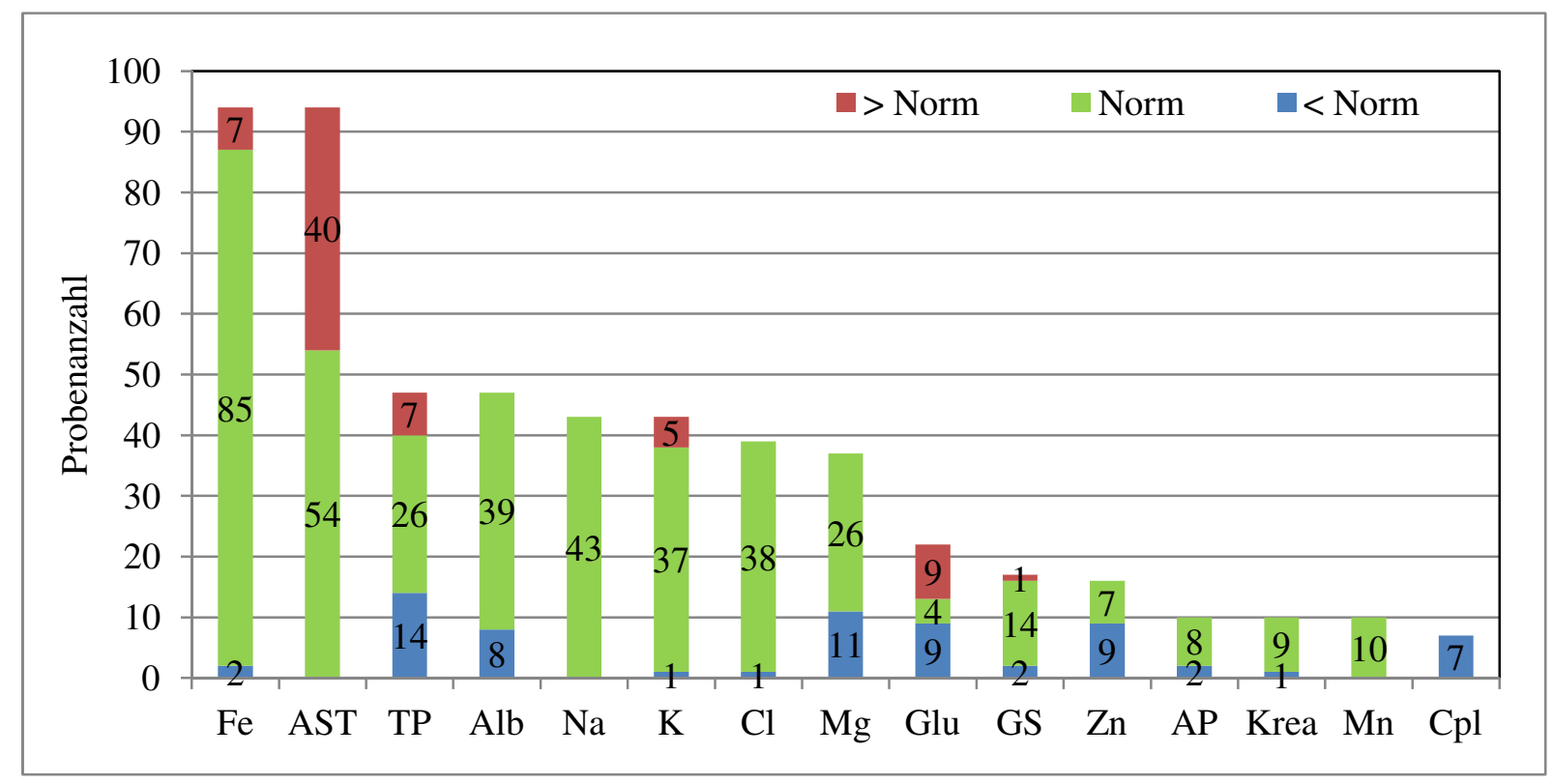

Abbildung 4.14: Gesamtprobenanzahl mit $\mathrm{n}<100$ und Werteverteilung der Parameter eingesendeter Proben einer tierärztlichen Gemeinschaftspraxis im EL

\subsubsection{Parameter des Energie-Fett-Leber-Stoffwechsels (Glucose, FFS, BHB, AST, GGT, GLDH, Gallensäuren, Bilirubin, Cholesterol)}

\section{Glucose}

Zu dem Parameter Glucose gibt es 22 Untersuchungsergebnisse (Abbildung 4.14). Davon liegen vier $(18,2 \%)$ im physiologischen Bereich von 2,22 - 3,30 mmol/l (FÜRLL 2013a). Sowohl über dem Normbereich, als auch unterhalb des Normbereiches sind jeweils 40,9\% (absolut neun Proben) zu verzeichnen. Der Mittelwert befindet sich bei 2,56 mmol/l (Anhang Tabelle 9.1) und liegt damit unterhalb des Kontrollbereiches von 2,61 - 3,10 mmol/l (FÜRLL 2013a). Eine Aufspaltung in die einzelnen Laktationsstadien ist aufgrund der geringen Gesamtanzahl nicht sinnvoll. 


\section{Freie Fettsäuren (FFS)}

Die FFS sind mit 774 Ergebnissen der mit am häufigsten untersuchte Parameter. Da bei diesem Parameter je nach Laktationsstadium unterschiedliche physiologische Bereiche vorliegen, sind die Ergebnisse aufgeteilt. Insgesamt befinden sich 62,1\% (absolut 481 Proben) innerhalb und 37,9\% (absolut 293 Proben) oberhalb der Toleranzgrenzen. Die Toleranzgrenzen nach FÜRLL (2013a) liegen ante partum bei $150 \mu \mathrm{mol} / \mathrm{l}$, in der ersten Woche p. p. zwischen zehn und $620 \mu \mathrm{mol} / \mathrm{l}$ und ab der zweiten Woche p. p. bei $340 \mu \mathrm{mol} / \mathrm{l}$.

Die FFS spielen bei dieser Untersuchung vor allem von a. p. bis acht Wochen p. p. eine größere Rolle. Wie in Abbildung $4.15 \mathrm{zu}$ sehen, sind in diesem Zeitraum die meisten Abweichungen vom physiologischen Bereich zu verzeichnen. Bei den folgenden Laktationsstadien und auch bei den Färsen liegen die Probenergebnisse zu 89,1 \% oder mehr innerhalb des Normbereiches.

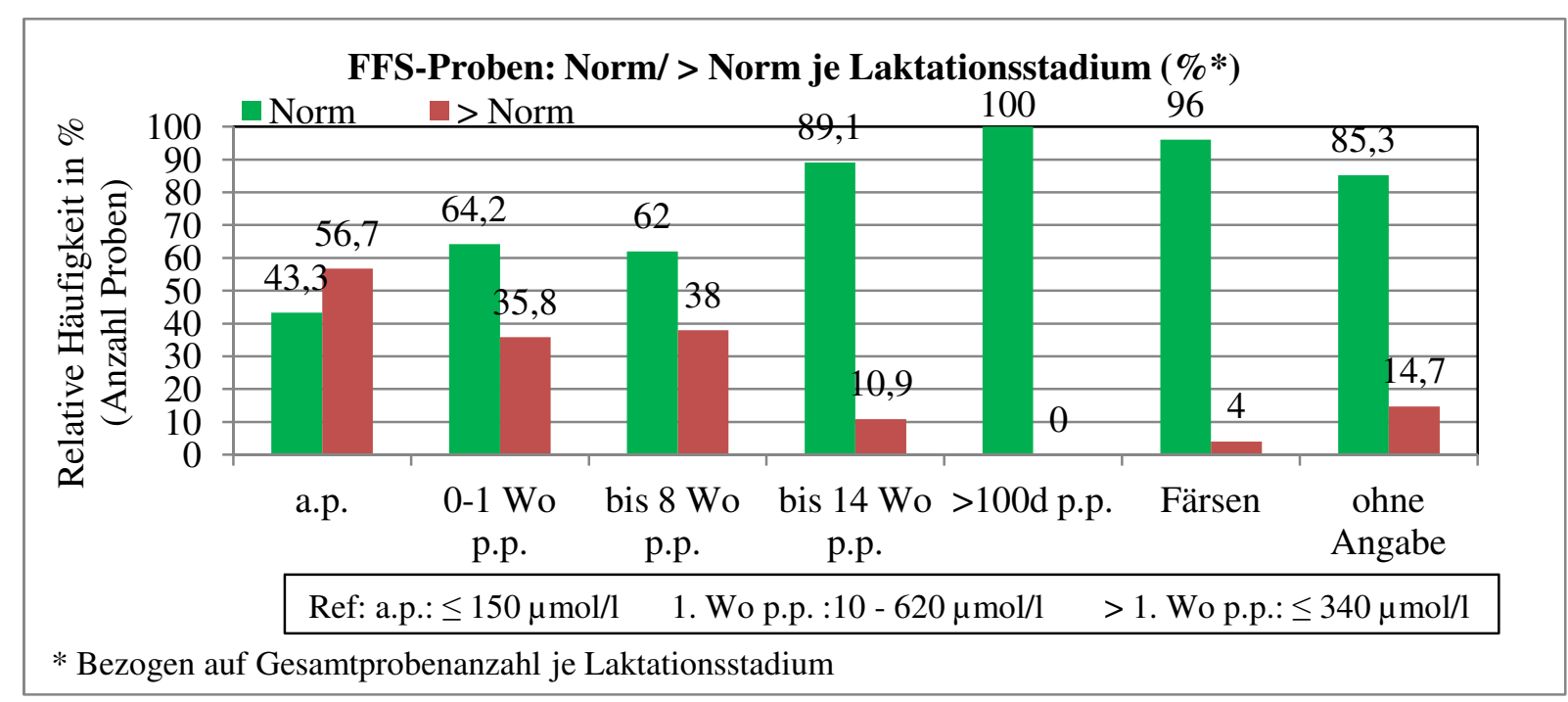

Abbildung 4.15: FFS: Probenanzahl mit Konzentrationen innerhalb und oberhalb des Normbereiches je Laktationsstadium eingesendet von einer tierärztlichen Gemeinschaftspraxis im EL

Abbildung 4.15 zeigt, dass mehr als die Hälfte der Proben (56,7 \%), die von Kühen a. p. stammen, oberhalb der Toleranzgrenzen liegen. Die Proben eine bis acht Wochen p. p. befinden sich nur noch zu $35,8 \%$ und $38 \%$ über dem Normbereich. Es ist somit ein deutlicher und kontinuierlicher Anstieg der Anzahl an Proben mit physiologischen Konzentrationen im Verlauf der Laktation zu beobachten.

Beim Vergleich der Medianwerte (Tabelle 4.1) der einzelnen Laktationsstadien ist festzustellen, dass der Median a. p. mit $168 \mu \mathrm{mol} / \mathrm{l}$ der einzige Wert außerhalb der Kontrollgrenzen $(\leq 90 \mu \mathrm{mol} / \mathrm{l}$, 1. Woche p. p. 40 - $500 \mu \mathrm{mol} / \mathrm{l}$ nach FÜRLL 2013a) ist. P. p. sind die Mediane bei $438 \mu \mathrm{mol} / \mathrm{l}$ in der ersten Woche p.p, bei $269 \mu \mathrm{mol} / \mathrm{l}$ zwei bis acht Wochen p. p, bei $136 \mu \mathrm{mol} / \mathrm{l}$ neun bis 14 Wo p. p. und bei $128 \mu \mathrm{mol} / \mathrm{l}$ mehr als 14 Wochen p. p. Die Färsen weisen einen Median von $108 \mu \mathrm{mol} / \mathrm{l}$ auf. Somit liegen die Mediane sowohl p. p. als auch bei den Färsen jeweils im Normbereich. 
Tabelle 4.1: FFS, BHB, Cholesterol: Mediane, 1. und 3. Quartil im Laktationsstadienvergleich von Proben einer tierärztlichen Gemeinschaftspraxis im EL

\begin{tabular}{|c|c|c|c|c|c|c|}
\hline \multirow{2}{*}{ LS } & \multicolumn{2}{|c|}{ FFS } & \multicolumn{2}{c|}{ BHB } & \multicolumn{2}{c|}{ Cholesterol } \\
\cline { 2 - 7 } & $\begin{array}{c}\text { Median in } \\
\mu \mathrm{mol} / \mathrm{l}\end{array}$ & $\begin{array}{c}\mathrm{Q} 1 ; \mathrm{Q} 3 \\
\text { in } \mu \mathrm{mol} / \mathrm{l}\end{array}$ & $\begin{array}{c}\text { Median in } \\
\mathrm{mmol} / \mathrm{l}\end{array}$ & $\begin{array}{c}\text { Q1; Q3 } \\
\text { in } \mathrm{mmol} / 1\end{array}$ & $\begin{array}{c}\text { Median in } \\
\mathrm{mmol} / 1\end{array}$ & $\begin{array}{c}\text { Q1; Q3 } \\
\text { in } \mathrm{mmol} / 1\end{array}$ \\
\hline a. p. & 168,0 & $108 ; 313$ & 0,59 & 0,$47 ; 0,77$ & 2,71 & 2,$20 ; 3,45$ \\
\hline 0-1Wo p. p. & 438,0 & $215 ; 765$ & 0,86 & 0,$62 ; 1,21$ & 2,16 & 1,$83 ; 2,71$ \\
\hline bis 8 Wo p. p. & 268,5 & $155 ; 447$ & 0,76 & 0,$59 ; 1,07$ & 3,7 & 2,$22 ; 4,6$ \\
\hline bis 14 Wo p. p. & 135,5 & $101 ; 164$ & 0,67 & 0,$57 ; 0,84$ & 4,8 & 3,$93 ; 5,36$ \\
\hline >100d p. p. & 128,0 & $95 ; 162$ & 0,77 & 0,$58 ; 0,98$ & 4,64 & 3,$82 ; 5,30$ \\
\hline Färsen & 107,5 & $82 ; 145$ & 0,44 & 0,$32 ; 0,62$ & 2,66 & 2,$28 ; 3,13$ \\
\hline ohne Angabe & 137,0 & $96 ; 226$ & 0,62 & 0,$52 ; 0,84$ & 3,7 & 2,$70 ; 4,25$ \\
\hline
\end{tabular}

\section{B-Hydroxybutyrat (BHB)}

Von den Untersuchungen auf den Ketonkörper BHB sind insgesamt 773 Ergebnisse vorhanden. Für die 773 Proben liegen sowohl Ergebnisse für den Parameter BHB als auch für FFS vor. Diese zwei Parameter sind, bis auf eine Probe, immer zusammen untersucht worden.

Eine gesicherte Korrelation zwischen den beiden Parametern kann nicht nachgewiesen werden. Der Korrelationskoeffizient nach Pearson von BHB und FFS beträgt 0,07.

Von den 773 BHB-Ergebnissen befinden sich 340 Proben (44 \%) innerhalb der Toleranzgrenze von $\leq$ 0,62 mmol/l (FÜRLL 2013a). Die restlichen 433 Proben (56 \%) liegen oberhalb der Grenze. Das bedeutet, dass mehr als die Hälfte der Ergebnisse außerhalb des physiologischen Bereiches liegen. Der Median beträgt 0,66 mmol/l (Anhang Tabelle 9.1) und ist aufgrund der hohen Abweichungen erwartungsgemäß oberhalb der Kontrollgrenze von 0,53 mmol/l (FÜRLL 2013a).

Die Verteilung der Ergebnisse von BHB innerhalb und außerhalb des physiologischen Bereiches in den einzelnen Laktationsstadien zeigt Abbildung 4.16. Auch hier ist dieser große Anteil an Proben über $0,62 \mathrm{mmol} / \mathrm{l}$ in den verschiedenen Laktationsstadien deutlich zu erkennen. Ausschließlich die Färsen zeigen einen geringeren Anteil von $24 \%$.

BHB verhält sich gegensätzlich zu den FFS. Hier befinden sich p. p. die meisten Abweichungen. So ist zwar ein geringer Abfall der Abweichungen im Laufe der Laktation zu erkennen und damit ein geringer Anstieg der Probenanzahl im Normbereich, aber die Abweichungen sinken bis zum Ende der Laktation nicht unter 68,9\%. Somit befinden sich immer über zwei Drittel der Ergebnisse außerhalb der Toleranzgrenze.

A. p. sind mehr Konzentrationen unterhalb der Toleranzgrenze als oberhalb. So liegt die reichliche Hälfte der Konzentrationen von 56,7 \% unterhalb der Toleranzgrenze und damit im Normbereich. 


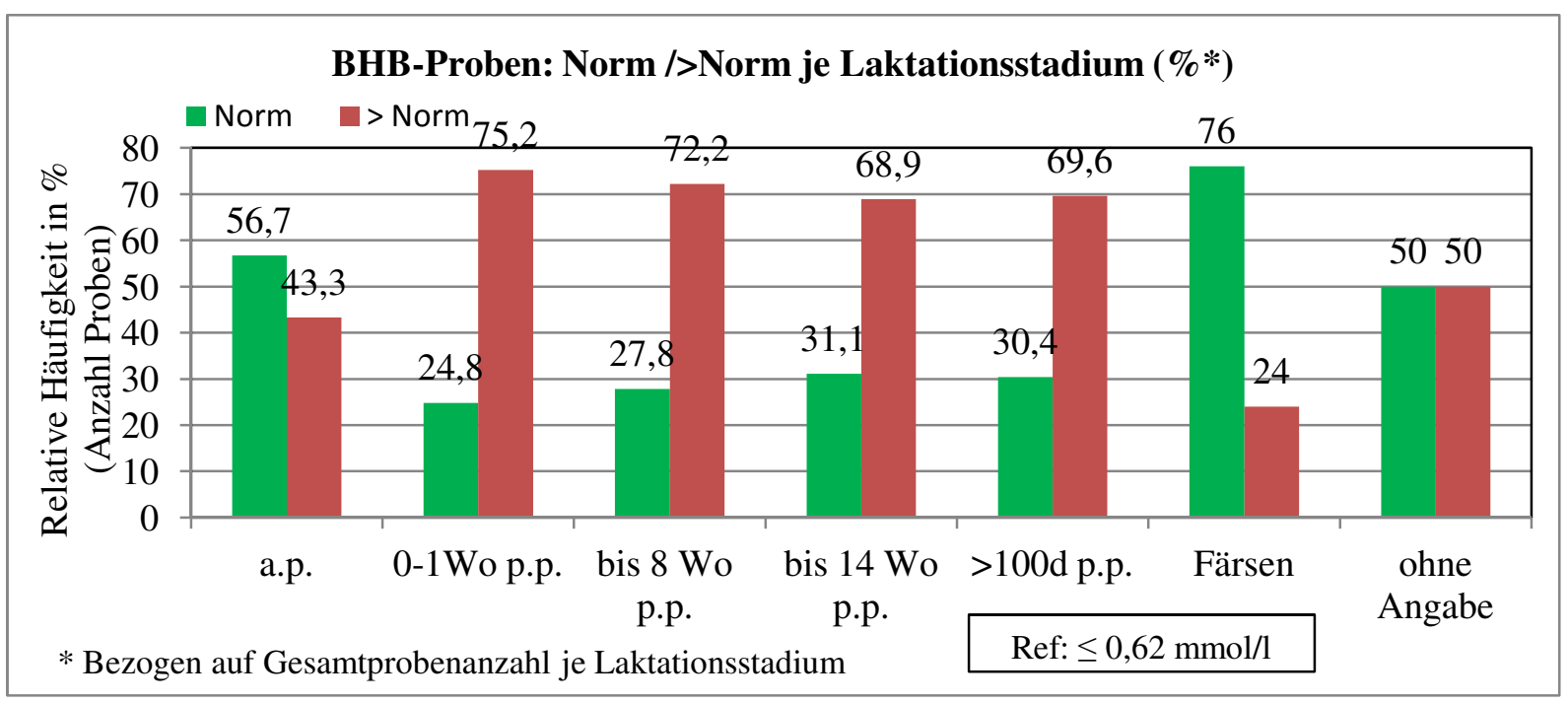

Abbildung 4.16: BHB: Probenzahl mit Konzentrationen innerhalb und oberhalb des Normbereiches je Laktationsstadium eingesendet von einer tierärztlichen Gemeinschaftspraxis im EL

Beim Vergleich der Mediane innerhalb der Laktationsstadien (Tabelle 4.1) zeigt sich ein ähnliches Bild. So haben auch hier die Färsen mit $0,44 \mathrm{mmol} / \mathrm{l}$ den einzigen Wert kleiner als $0,53 \mathrm{mmol} / \mathrm{l}$. Sowohl a. p. als auch p. p. befinden sich die Mittelwerte oberhalb der Kontrollgrenze. A. p. liegt der Median von 0,59 mmol/l nur knapp über der Grenze. In der ersten Woche p. p. erhöht sich der Median auf $0,86 \mathrm{mmol} / \mathrm{l}$ und verzeichnet im Laufe der Laktation Konzentrationen zwischen $0,67 \mathrm{mmol} / \mathrm{l}$ und $0,77 \mathrm{mmol} / 1$.

Es zeigt sich also, dass es um die Kalbung zu einem starken Anstieg der BHB-Konzentrationen kommt und die Anzahl der Abweichungen sowie die Mediane von Laktationsbeginn an bis zum Ende auf erhöhtem Niveau verbleiben.

\section{Aspartat-Amino-Transferase (AST)}

Von dem Enzym AST sind insgesamt 94 Ergebnisse vorhanden (Abbildung 4.14). Diese haben zu 57,4 \% Aktivitäten $\leq 80$ U/l, was die obere Toleranzgrenze (FÜRLL 2013a) darstellt. 42,6 \% liegen darüber und sind somit außerhalb des physiologischen Bereiches (Abbildung 4.17).

Da fast die Hälfte der Aktivitäten außerhalb des Normbereiches sind, wäre die Aufteilung in die einzelnen Laktationsstadien von Interesse. Aufgrund der geringeren Gesamtprobenanzahl und somit auch je Laktationsstadium ist diese Aufsplittung jedoch nicht sinnvoll.

Der Median beträgt 76,1 U/l (Anhang Tabelle 9.1) und befindet sich damit oberhalb der Kontrollgrenze von $\leq 69$ U/l (FÜRLL 2013a).

Eine Korrelation zu anderen Parametern mit einem Korrelationskoeffizient von $>0,5$ ist nicht nachzuweisen. 


\section{$\gamma$-Glutamyl-Transferase (GGT)}

Es gibt 154 Ergebnisse der GGT (Abbildung 4.13). Davon liegen 150 der Aktivitäten (97,4 \%) im Normbereich von $\leq 50$ U/l (FÜRLL 2013a) (Abbildung 4.17). Das heißt, dass nur vier Proben $(2,6 \%)$ darüber liegen.

Eine Aufteilung in die einzelnen Laktationsstadien liegt wegen der geringen Anzahl an Proben, die vom Normbereich abweichen, nicht vor.

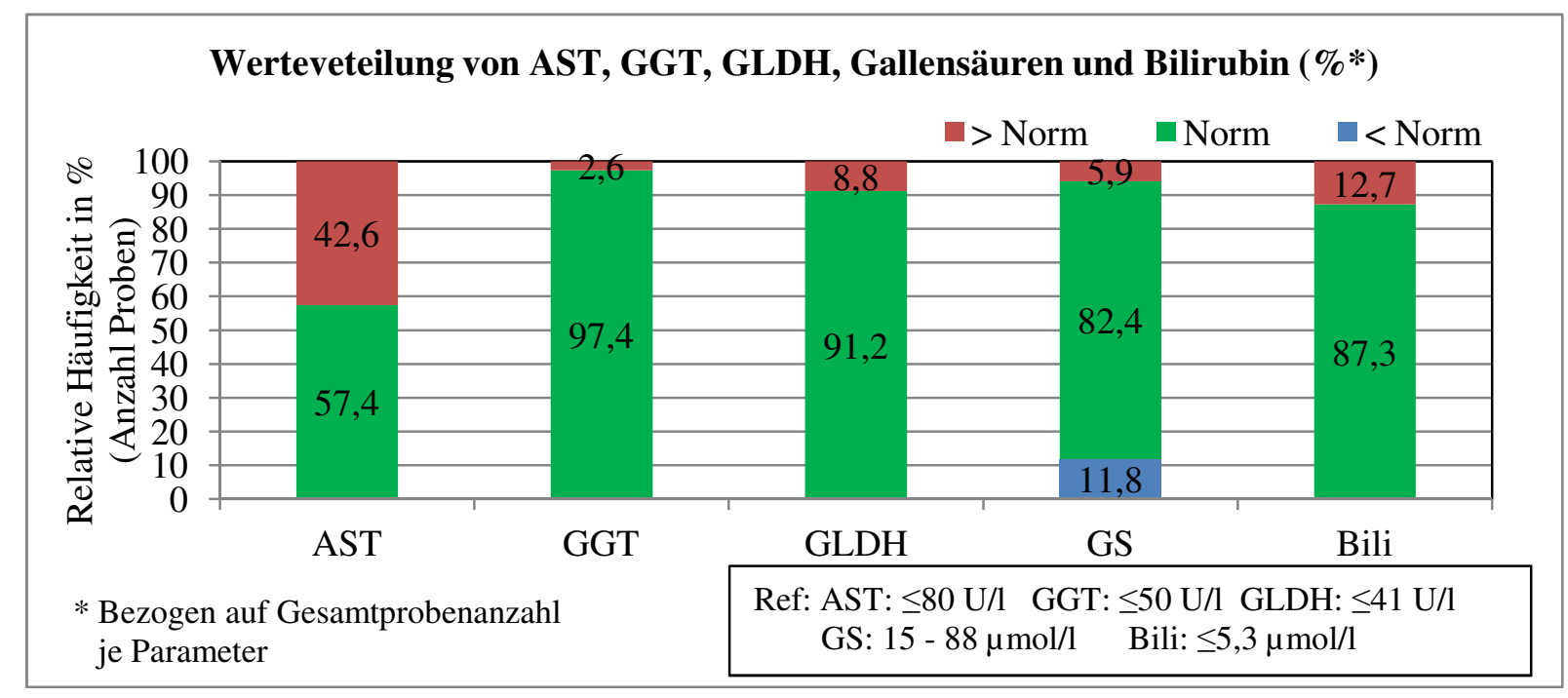

Abbildung 4.17: Werteverteilung von AST, GGT, GLDH, Gallensäuren und Bilirubin von eingesendeten Proben einer tierärztlichen Gemeinschaftspraxis im EL

\section{Glutamat-Dehydrogenase (GLDH)}

Die Aktivitäten des Leberenzyms GLDH weisen, wie schon die GGT, nur einen geringen Prozentsatz von $8,8 \%$ an Proben auf, die vom Normbereich abweichen (Abbildung 4.17). Das entspricht bei 182 Proben (Abbildung 4.13) 16 Abweichungen. Der physiologische Bereich wird von FÜRLL (2013a) als $\leq 41 \mathrm{U} / 1$ definiert.

\section{Gallensäuren (GS)}

Die Ergebnisse des Parameters Gallensäuren sollen in dem Bereich von 15 - $88 \mu \mathrm{mol} / \mathrm{l}$ liegen (FÜRLL 2013a). 14 von insgesamt 17 Konzentrationen befinden sich in diesem Bereich (Abbildung 4.17). Nur zwei Proben $(11,8 \%)$ weisen niedrigere und eine Probe $(5,9 \%)$ höhere Konzentrationen auf. 


\section{Bilirubin}

504 Proben sind auf Bilirubin untersucht worden (Abbildung 4.13). Die Ergebnisse befinden sich zu 87,3\% (Abbildung 4.17) innerhalb der von FÜRLL (2013a) beschriebenen Toleranzgrenze von $\leq 5,3 \mu \mathrm{mol} / \mathrm{l}$.

Tabelle 4.2: Bilirubin: Probenanzahl mit Konzentrationen innerhalb und außerhalb des Normbereiches je Laktationsstadium, sowie deren Mediane und Quartile (1. und 3.), eingesendet von einer tierärztlichen Gemeinschaftspraxis im EL (Ref: $\leq 5,3 \mu \mathrm{mol} / \mathrm{l})$

\begin{tabular}{|c|c|c|c|c|c|c|c|}
\hline Bilirubin & $\mathrm{n}_{\text {ges }}$ & n Norm & $\begin{array}{c}\% \text { von } \mathrm{n}_{\text {ges }} \\
(\text { Norm })\end{array}$ & $\mathrm{n}>$ Norm & $\begin{array}{c}\% \text { von } \mathrm{n}_{\text {ges }} \\
(>\text { Norm })\end{array}$ & $\begin{array}{c}\text { Median } \\
\text { in } \mu \mathrm{mol} / 1\end{array}$ & $\begin{array}{c}\mathrm{Q} 1 ; \mathrm{Q} 3 \\
\text { in } \mu \mathrm{mol} / 1\end{array}$ \\
\hline a.p. & 196 & 174 & 88,8 & 22 & 11,2 & 2,6 & 1,$7 ; 3,5$ \\
\hline 0-1Wo p. p. & 65 & 43 & 66,2 & 22 & 33,8 & 4,3 & 2,$8 ; 6,7$ \\
\hline bis 8 Wo p. p. & 104 & 85 & 81,7 & 19 & 18,3 & 3,8 & 2,$7 ; 4,9$ \\
\hline bis 14 Wo p. p. & 44 & 43 & 97,7 & 1 & 2,3 & 3,0 & 2,$3 ; 3,6$ \\
\hline >100d p. p. & 45 & 45 & 100,0 & 0 & 0,0 & 2,5 & 1,$9 ; 3,2$ \\
\hline Färsen & 41 & 41 & 100,0 & 0 & 0,0 & 2,2 & 1,$7 ; 2,6$ \\
\hline ohne Angabe & 9 & 9 & 100,0 & 0 & 0,0 & 2,5 & 1,$8 ; 3,1$ \\
\hline Gesamt & 504 & 440 & 87,3 & 64 & 12,7 & 2,9 & 2,$0 ; 4,1$ \\
\hline
\end{tabular}

Bei der Aufteilung in die einzelnen Laktationsstadien ist zu erkennen, dass es nennenswerte Abweichungen vom Normbereich in dem Zeitraum a. p. bis acht Wochen p. p. gibt (Tabelle 4.2). Die folgenden Laktationsstadien und auch die Färsen weisen 97,7 \% bzw. 100 \% der Proben innerhalb des Referenzbereiches auf. Die meisten Abweichungen sind in der ersten Woche p. p. mit 33,8\% zu finden. In diesem Zeitraum ist auch der höchste Median von 4,3 $\mu \mathrm{mol} / 1 \mathrm{zu}$ verzeichnen. Alle Medianwerte befinden sich aber unterhalb der oberen Kontrollgrenze von 4,6 $\mu \mathrm{mol} / \mathrm{l}$ (FÜRLL 2013a). Die Zeiträume a. p. und zwei bis acht Wochen p. p. weisen eine geringere Anzahl an Abweichungen von $11,2 \%$ und $18,3 \%$ auf (Tabelle 4.2 ).

Einen gesicherten Korrelationskoeffizient nach Pearson von 0,63 lässt sich für Bilirubin und FFS berechnen.

\section{Cholesterol}

Von Cholesterol sind 297 Proben in die Auswertung mit eingeflossen (Abbildung 4.13). Davon befinden sich zehn Proben (3,4\%) unterhalb des physiologischen Bereiches von $\geq 1,5 \mathrm{mmol} / \mathrm{l}$ (FÜRLL 2013a). Bei der Aufteilung in die verschiedenen Laktationsstadien ist zu beobachten, dass der Median von 2,71 mmol/l a. p. auf 2,16 mmol/l in der ersten Woche p. p. absinkt und anschließend mit zunehmender Laktationsdauer wieder stark ansteigt (Tabelle 4.1). In der Periode neun bis 14 
Wochen p. p. wird der höchste Wert von 4,80 mmol/l erreicht. Danach fällt er wieder leicht auf 4,64 mmol/l ab. Die Färsen weisen einen Medianwert von 2,66 mmol/l auf.

\title{
4.2.2.2 Parameter des Eiweißstoffwechsels (TP, Albumin, Kreatinin, Harnstoff)
}

\section{Totales Protein (TP)}

Von dem Parameter Totales Protein, welcher das Gesamteiweiß bezeichnet, sind insgesamt 47 Konzentrationen vorhanden (Abbildung 4.14). Diese befinden sich zur reichlichen Hälfte (55,3\%) im physiologischen Bereich von 68 - 82 g/l (FÜRLL 2013a). 14 Ergebnisse (29,8 \%) sind unterhalb und sieben Ergebnisse (14,9\%) sind oberhalb des Bereiches einzuordnen.

Wenn Daten für Totales Protein vorliegen, sind immer von der gleichen Probe auch Daten für Albumin vorhanden. Aufgrund der geringen Gesamtanzahl gibt es keine weiteren Auswertungen.

\begin{abstract}
Albumin
Wie oben schon vermerkt, kann die gleiche Anzahl Proben (47) wie beim Totalen Protein zur Auswertung herangezogen werden (Abbildung 4.14). Auch hier befindet sich der größere Teil (83\%) von Ergebnissen innerhalb der Toleranzgrenzen. Diese sind bei FÜRLL (2013a) als 30 - 39 g/l angegeben. Abweichungen sind nur unterhalb dieser Grenzen zu verzeichnen und betragen $17 \%$.
\end{abstract}

\section{Kreatinin}

Bei einer Einsendung von zehn Einzelproben ist auf Kreatinin untersucht worden (Abbildung 4.14). Dabei befindet sich ein Wert außerhalb des Referenzbereiches von 55 - 150 ㅆmol/l (FÜRLL 2013a).

\section{Harnstoff}

Harnstoff ist mit einer Gesamtprobenanzahl von 764 der am viert häufigste untersuchte Parameter (Abbildung 4.13). 246 Ergebnisse, welche 34,6 \% bedeuten, können nicht innerhalb der Toleranzgrenzen von 2,0 - 5,0 mmol/l (FÜRLL 2013a) eingeordnet werden. Es befinden sich 6,0 \% der Konzentrationen unterhalb und 28,5\% oberhalb dieser Grenzen (Tabelle 4.3).

Die meisten Proben stammen von Kühen, die sich a. p. bis acht Woche p. p. befinden. Die Abweichungen unterhalb des Normbereiches sind a. p. mit 8,8 \% am höchsten. In den Zeiträumen neun bis 14 Wochen p. p. und über 100 Tagen p. p. sind die Abweichungen oberhalb der Toleranzgrenze bei 51,1 bzw. 42,3\%. Bei den Färsen betragen die unteren Abweichungen 8,0 \% und die oberen $16 \%$.

Beim Vergleich der Mittelwerte innerhalb der verschiedenen Laktationsperioden ist von a. p. bis zum Ende der Laktation immer ein stetig leichter Anstieg der Durchschnitte zu erkennen. So beträgt der 
Mittelwert a. p. 4,02 mmol/l und am Laktationsende 4,87 mmol/l. Den geringsten Mittelwert weisen die Färsen mit 3,71 mmol/l auf.

Tabelle 4.3: Harnstoff: Probenanzahl mit Konzentrationen innerhalb und außerhalb des Normbereiches je Laktationsstadium, sowie deren Mittelwerte mit Standardabweichung (SD), eingesendet von einer tierärztlichen Gemeinschaftspraxis im EL (Ref: 2,0 - 5,0 mmol/l)

\begin{tabular}{|l|c|c|c|c|c|c|c|c|}
\hline Harnstoff & $\mathrm{n}_{\text {ges }}$ & $\begin{array}{c}\mathrm{n} \\
<\text { Norm }\end{array}$ & $\begin{array}{c}\% \text { von } \mathrm{n}_{\text {ges }} \\
(<\text { Norm })\end{array}$ & $\begin{array}{c}\mathrm{n} \\
\text { Norm }\end{array}$ & $\begin{array}{c}\% \text { von } \mathrm{n}_{\text {ges }} \\
(\text { Norm) }\end{array}$ & $\begin{array}{c}\mathrm{n} \\
>\text { Norm }\end{array}$ & $\begin{array}{c}\% \text { von } \mathrm{n}_{\text {ges }} \\
(>\text { Norm })\end{array}$ & $\begin{array}{c}\bar{x} \pm \mathrm{SD} \\
\text { in mmol/1 }\end{array}$ \\
\hline a. p. & 319 & 28 & 8,8 & 214 & 67,1 & 77 & 24,1 & $4,02 \pm 1,39$ \\
\hline 0-1Wo p. p. & 108 & 3 & 2,8 & 81 & 75,0 & 24 & 22,2 & $4,18 \pm 1,16$ \\
\hline bis 8 Wo p. p. & 156 & 8 & 5,1 & 101 & 64,7 & 47 & 30,1 & $4,33 \pm 1,39$ \\
\hline bis 14 Wo p. p. & 45 & 2 & 4,4 & 20 & 44,4 & 23 & 51,1 & $4,88 \pm 1,79$ \\
\hline$>$ 100d p. p. & 52 & 1 & 1,9 & 29 & 55,8 & 22 & 42,3 & $4,87 \pm 1,70$ \\
\hline Färsen & 50 & 4 & 8,0 & 38 & 76,0 & 8 & 16,0 & $3,71 \pm 1,27$ \\
\hline ohne Angabe & 34 & 0 & 0,0 & 17 & 50,0 & 17 & 50,0 & $5,11 \pm 1,61$ \\
\hline Gesamt & 764 & 46 & 6,0 & 500 & 65,4 & 218 & 28,5 & $4,24 \pm 1,45$ \\
\hline
\end{tabular}

\subsubsection{Parameter des Mineralstoffwechsels ( $\mathrm{Na}, \mathrm{K}, \mathrm{Cl}, \mathrm{Ca}, \mathrm{P}_{\mathrm{i}}, \mathrm{Fe}, \mathrm{Mg}, \mathrm{AP}$ ) und des Muskelstoffwechsels (CK)}

\section{Natrium (Na)}

Von dem Mineral Na liegen insgesamt 43 Ergebnisse vor (Abbildung 4.14). Dieser Parameter ist der Einzige, bei dem die Konzentrationen zu $100 \%$ in den physiologischen Bereich von 135 - 157 mmol/l (FÜRLL 2013a) einzuordnen sind.

\section{Kalium (K)}

Alle Proben, die auf K untersucht wurden, weisen ebenfalls ein Ergebnis von Natrium auf. Somit ist auch hier eine Gesamtprobenanzahl von 43 zu verzeichnen (Abbildung 4.14). Die Kaliumkonzentrationen sind zu $86 \%$ innerhalb der Toleranzgrenzen. Diese sind von FÜRLL (2013a) als 3,9 und $5,2 \mathrm{mmol} / \mathrm{l}$ beschrieben. Ein Ergebnis (2,3\%) weist eine Konzentration unterhalb von 3,9 mmol/l und fünf Ergebnisse (11,6\%) weisen Konzentrationen oberhalb von 5,2 mmol auf und befinden sich somit außerhalb des physiologischen Bereiches. 


\section{Chlorid (Cl)}

Bei der Cl-Auswertung von insgesamt 39 Untersuchungsergebnissen ist ein abweichender Wert $(2,6 \%)$ vorhanden (Abbildung 4.14). Der Normbereich befindet sich zwischen 95 und 110 mmol/l (FÜRLL 2013a).

\section{Calzium (Ca)}

664 Ergebnisse sind von dem Parameter Ca vorhanden (Tabelle 4.4). Für Ca ist der Normbereich zwischen 2,00 und 2,54 mmol/l definiert (FÜRLL 2013a). So ergibt sich eine Gesamtabweichung von $10,7 \%$, die sich aus den Konzentrationen 2,3\% unterhalb des Normbereiches und 8,4\% oberhalb des Normbereiches zusammensetzt.

Tabelle 4.4: Ca: Probenanzahl mit Konzentrationen innerhalb und außerhalb des Normbereiches je Laktationsstadium, eingesendet von einer tierärztlichen Gemeinschaftspraxis im EL (Ref: $2,0-2,54 \mathrm{mmol} / \mathrm{l})$

\begin{tabular}{|c|c|c|c|c|c|c|c|}
\hline Ca & $\mathrm{n}_{\text {ges }}$ & $\mathrm{n}<$ Norm & $\begin{array}{c}\% \text { von } \mathrm{n}_{\text {ges }} \\
(<\text { Norm })\end{array}$ & $\mathrm{n}$ Norm & $\begin{array}{c}\text { \% von } \mathrm{n}_{\text {ges }} \\
(\text { Norm })\end{array}$ & $\mathrm{n}>$ Norm & $\begin{array}{c}\text { \% von } \mathrm{n}_{\text {ges }} \\
(>\text { Norm })\end{array}$ \\
\hline a.p. & 275 & 3 & 1,1 & 253 & 92,0 & 19 & 6,9 \\
\hline 0-1Wo p. p. & 76 & 10 & 13,2 & 58 & 76,3 & 8 & 10,5 \\
\hline bis 8 Wo p. p. & 137 & 1 & 0,7 & 124 & 90,5 & 12 & 8,8 \\
\hline bis 14 Wo p. p. & 46 & 0 & 0,0 & 40 & 87,0 & 6 & 13,0 \\
\hline >100d p. p. & 53 & 1 & 1,9 & 47 & 88,7 & 5 & 9,4 \\
\hline Färsen & 46 & 0 & 0,0 & 40 & 87,0 & 6 & 13,0 \\
\hline ohne Angabe & 31 & 0 & 0,0 & 31 & 100,0 & 0 & 0,0 \\
\hline Gesamt & 664 & 15 & 2,3 & 593 & 89,3 & 56 & 8,4 \\
\hline
\end{tabular}

In Tabelle 4.4 sind die Ergebnisse nach den einzelnen Laktationsstadien aufgegliedert. Hierbei ist zu erkennen, dass außer in der ersten Woche p. p. fast keine Unterversorgungen an $\mathrm{Ca}$ zu verzeichnen sind. In der ersten Woche p. p. sind mit 13,2 \% die meisten Konzentrationen unter dem Normbereich gemessen worden. Auch bei den Gesamtabweichungen ist in diesem Stadium prozentual der höchste Wert erreicht. Absolut die meisten Konzentrationen oberhalb des physiologischen Bereiches sind in den Stadien a. p. mit 19 und von der zweiten bis achten Woche p. p. mit 12 zu verzeichnen. Prozentual wurden dagegen, aufgrund der hohen Gesamtprobenanzahl in dem jeweiligen Laktationsstadium, niedrigere Ergebnisse berechnet.

Die Mediane der einzelnen Laktationsphasen (Tabelle 4.5) liegen, wie durch die geringen Anzahlen an Abweichungen nicht anders zu erwarten, innerhalb der Kontrollgrenzen von 2,12 - 2,46 mmol/l (FÜRLL 2013a). Aber auch hier wurde ein deutlich geringerer Wert, im Gegensatz zu den anderen Phasen, von 2,27 mmol/l in der ersten Woche p. p. berechnet, welcher mit den 13,2\% der 
Konzentrationen unterhalb des Normbereiches zusammenhängt. Die anderen Mediane weisen Werte zwischen 2,35-2,41 mmol/l auf.

Tabelle 4.5: Ca und $\mathrm{P}_{\mathrm{i}}$ : Mediane und Quartile (1. und 3.) im Laktationsstadienvergleich von Proben einer tierärztlichen Gemeinschaftspraxis im EL

\begin{tabular}{|c|c|c|c|c|}
\hline \multirow{2}{*}{ LS } & \multicolumn{2}{|c|}{$\mathrm{Ca}$} & \multicolumn{2}{c|}{$\mathrm{P}_{\mathrm{i}}$} \\
\cline { 2 - 5 } & $\begin{array}{c}\text { Median } \\
\text { in mmol/1 }\end{array}$ & $\begin{array}{c}\text { Q1; Q3 } \\
\text { in mmol/1 }\end{array}$ & $\begin{array}{c}\text { Median } \\
\text { in mmol/1 }\end{array}$ & $\begin{array}{c}\text { Q1; Q3 } \\
\text { in mmol/l }\end{array}$ \\
\hline a. p. & 2,37 & 2,$28 ; 2,45$ & 2,03 & 1,$85 ; 2,29$ \\
\hline 0-1Wo p. p. & 2,27 & 2,$15 ; 2,43$ & 1,88 & 1,$67 ; 2,10$ \\
\hline bis 8 Wo p. p. & 2,35 & 2,$25 ; 2,45$ & 1,90 & 1,$68 ; 2,09$ \\
\hline bis 14 Wo p. p. & 2,36 & 2,$31 ; 2,46$ & 1,92 & 1,$78 ; 2,14$ \\
\hline >100d p. p. & 2,41 & 2,$31 ; 2,49$ & 1,96 & 1,$70 ; 2,18$ \\
\hline Färsen & 2,41 & 2,$35 ; 2,49$ & 2,39 & 2,$20 ; 2,67$ \\
\hline ohne Angabe & 2,29 & 2,$23 ; 2,38$ & 1,86 & 1,$64 ; 1,99$ \\
\hline
\end{tabular}

\section{anorganisches Phosphat $\left(\mathbf{P}_{\mathrm{i}}\right)$}

Für den Referenzbereich von $P_{i}$ werden in der ersten Woche p. p. 1,26-2,13 mmol/l und in allen anderen Laktationsphasen 1,55 - 2,29 mmol/l genannt (FÜRLL 2013a). Von den 638 Proben, die auf $\mathrm{P}_{\mathrm{i}}$ untersucht worden, können 70,4 \% innerhalb des Referenzbereiches eingeordnet werden (Tabelle 4.6). Bei den Gesamtabweichungen verursachen die Konzentrationen oberhalb des Normbereiches mit 21,6 \% den größeren Anteil. So ist hier vor allem die Zeit a. p. zu nennen mit 24,9\%. Auch die absolute Anzahl von 63 Proben ist mit Abstand die Höchste der oberen Abweichungen.

In der ersten Woche p. p. fällt die Anzahl über dem Normbereich auf 22,4 \% und die Anzahl unter dem Normbereich steigt auf 6,6 \% an. In den Phasen zwei bis acht Wochen und neun bis 14 Wochen p. p. verzeichnen die Ergebnisse mehr Konzentrationen unterhalb der Toleranzgrenze wie oberhalb. Am Ende der Laktation steigt die Anzahl oberhalb des Referenzbereiches wieder auf 15,1\% an, wobei in dieser Zeit auch 11,3\% der Proben Konzentrationen unterhalb von 1,55 mmol/l aufweisen.

Auffallend ist die geringe Anzahl an Proben innerhalb der physiologischen Grenzen bei den Färsen. Hier ist der höchste Wert an Abweichungen oberhalb des Normbereiches zu verzeichnen. Der Wert beträgt $63 \%$. Auch der Median von 2,39 mmol/l (Tabelle 4.5) ist mit Abstand der Höchste und der einzige Wert außerhalb der Kontrollbereiche von 1,71 - 2,13 mmol/l bzw. 1,45 - 1,94 mmol/l in der ersten Woche p. p. (FÜRLL 2013a). Alle Medianwerte von a. p. bis zum Ende der Laktation sind innerhalb des Kontrollbereiches einzuordnen. Die Mediane sinken von a. p. mit 2,03 mmol/l auf 1,88 $\mathrm{mmol} / \mathrm{l}$ in der ersten Woche p. p. Im Verlauf der Laktation steigen diese Werte wieder kontinuierlich an und erreichen einen Median von 1,96 mmol/l. 
Tabelle 4.6: $\mathrm{P}_{\mathrm{i}}$ : Probenanzahl mit Konzentrationen innerhalb und außerhalb des Normbereiches je Laktationsstadium, eingesendet von einer tierärztlichen Gemeinschaftspraxis im EL (Ref: $1,55-2,29 \mathrm{mmol} / \mathrm{l} ; 1$. Wo p. p. $1,26-2,13 \mathrm{mmol} / \mathrm{l})$

\begin{tabular}{|c|c|c|c|c|c|c|c|}
\hline$\underline{\mathbf{P}}_{\mathbf{i}}$ & $\mathrm{n}_{\text {ges }}$ & $\mathrm{n}<$ Norm & $\begin{array}{c}\% \text { von } \mathrm{n}_{\text {ges }} \\
(<\text { Norm })\end{array}$ & $\mathrm{n}$ Norm & $\begin{array}{c}\% \text { von } \mathrm{n}_{\text {ges }} \\
(\text { Norm })\end{array}$ & $\mathrm{n}>$ Norm & $\begin{array}{c}\% \text { von } \mathrm{n}_{\text {ges }} \\
(>\text { Norm })\end{array}$ \\
\hline a. p. & 253 & 12 & 4,7 & 178 & 70,4 & 63 & 24,9 \\
\hline 0-1Wo p. p. & 76 & 5 & 6,6 & 54 & 71,1 & 17 & 22,4 \\
\hline bis 8 Wo p. p. & 134 & 17 & 12,7 & 104 & 77,6 & 13 & 9,7 \\
\hline bis 14 Wo p. p. & 46 & 5 & 10,9 & 37 & 80,4 & 4 & 8,7 \\
\hline >100d p. p. & 53 & 6 & 11,3 & 39 & 73,6 & 8 & 15,1 \\
\hline Färsen & 46 & 0 & 0,0 & 17 & 37,0 & 29 & 63,0 \\
\hline ohne Angabe & 30 & 6 & 20,0 & 20 & 66,7 & 4 & 13,3 \\
\hline Gesamt & 638 & 51 & 8,0 & 449 & 70,4 & 138 & 21,6 \\
\hline
\end{tabular}

\section{Eisen $(\mathbf{F e})$}

Von dem Parameter Fe sind 94 Untersuchungsergebnisse vorhanden (Abbildung 4.14). 90,4 \% der Konzentrationen liegen innerhalb des physiologischen Bereiches. Dieser ist laut FÜRLL (2013a) als 12 - $33 \mu \mathrm{mol} / \mathrm{l}$ definiert. Neun Untersuchungsergebnisse befinden sich außerhalb dieses Bereiches, wobei sieben Ergebnisse (7,4 \%) Konzentrationen über der oberen Grenze aufweisen.

\section{Magnesium (Mg)}

Auf $\mathrm{Mg}$ wurden 37 Proben untersucht (Abbildung 4.14). Der Referenzbereich wird mit 0,9 - 1,32 mmol/l beschrieben (FÜRLL 2013a). 70,3 \% der Proben befinden sich innerhalb dieses Bereiches. Die Abweichungen von $29,7 \%$ sind nur unterhalb des Referenzbereiches zu verzeichnen.

\section{Alkalische Phosphatase (AP)}

Von der AP liegen, wie schon beim Kreatinin, ausschließlich von einer Einsendung Ergebnisse vor. Von den zehn Proben sind acht in den physiologischen Bereich von 45 - 120 U/L (FÜRLL 2013a) einzuordnen (Abbildung 4.14). Zwei Proben weisen niedrigere Ergebnisse auf.

\section{Creatinkinase (CK)}

Von dem Muskelenzym CK sind in die Auswertung insgesamt 498 Untersuchungsergebnisse mit einbezogen (Abbildung 4.13). Bei diesem Parameter sind die Referenzwerte nach FÜRLL (2013a) vom Laktationsstadium abhängig. So sind die Ergebnisse in der ersten Woche p. p. bis $200 \mathrm{U} / 1$ und in der restlichen Zeit bis $100 \mathrm{U} / \mathrm{l}$ als physiologisch einzuordnen. Unter Berücksichtigung dieser Grenzen ergibt sich eine Anzahl der Proben außerhalb der Normbereiche von 68,9\%. Das bedeutet, dass weniger als ein Drittel sich unterhalb der oberen Toleranzgrenzen befindet. 
Die Werteverteilung innerhalb der einzelnen Laktationsstadien ist in Abbildung $4.18 \mathrm{zu}$ sehen. In dieser Abbildung wird die hohe Anzahl an Abweichungen deutlich. So sind a. p. 60,4 \% Abweichungen zu verzeichnen. In der ersten Woche p. p. sinkt die Anzahl auf 40,9\% und ist somit die einzige Periode mit einem Wert unter $50 \%$. Anschließend steigen die Anzahlen an Abweichungen wieder stark an und verzeichnen Werte von 73,6 \%, 81,4 \% und am Ende der Laktation sogar 90,9\%. Die 36 Proben von Färsen haben in dieser Untersuchung zu 100 \% erhöhte CK-Aktivitäten.

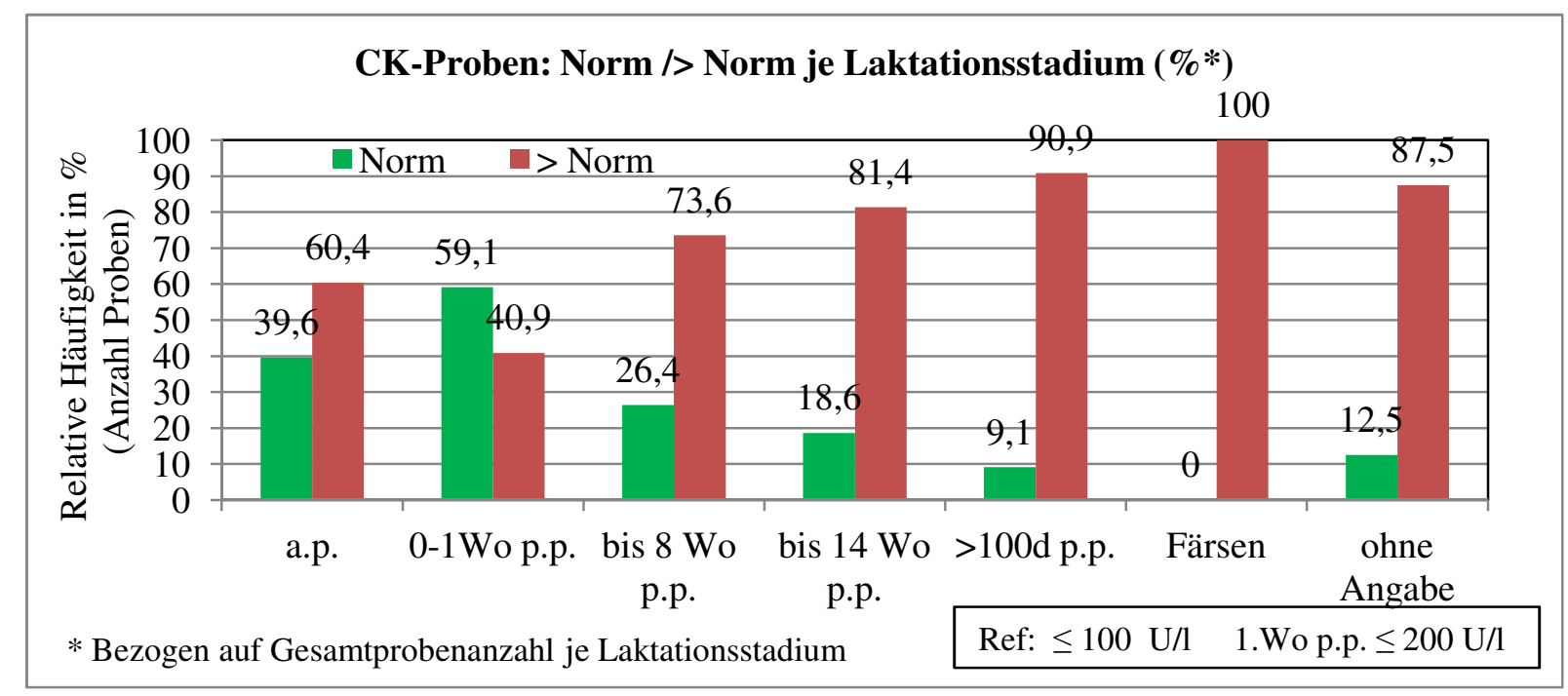

Abbildung 4.18: CK: Probenanzahl mit Aktivitäten innerhalb und oberhalb des Normbereiches je Laktationsstadium eingesendet von einer tierärztlichen Gemeinschaftspraxis im EL

Auch bei dem Vergleich der Mediane in den einzelnen Laktationsperioden spiegelt sich die hohe Anzahl an Abweichungen in den Werten a. p. und mehr als zwei Wochen p. p. wieder. So betragen die Mediane a. p. 114,0 U/l, von der zweiten bis zur achten Woche p. p. 125,7 U/l, von der neunten bis zur 14. Woche p. p. 131,3 U/l und am Ende der Laktation 130,3 U/l (Tabelle 4.7). Damit befinden sich alle über der oberen Toleranzgrenze. Der Medianwert in der ersten Woche p. p. ist mit 175,6 U/l der höchste, befindet sich aber unterhalb der Toleranzgrenze für dieses Laktationsstadium. Außerdem ist hier der größte Quartilsabstand mit 139,0 U/l vorzufinden. Die Färsen weisen mit 172,8 U/l ebenfalls einen Median >100 U/l auf.

Bei diesem Parameter besteht außerdem eine sehr große Spannweite zwischen dem Minimum von 31,7 U/L und dem Maximum von 12491,0 U/1 (Anhang Tabelle 9.1). 
Tabelle 4.7: CK: Mediane und Quartile (1. und 3.) im Laktationsstadienvergleich von Proben einer tierärztlichen Gemeinschaftspraxis im EL

\begin{tabular}{|c|c|c|c|c|c|c|c|}
\hline LS & a.p. & $\begin{array}{c}0-1 \text { Wo p. } \\
\text { p. }\end{array}$ & $\begin{array}{c}\text { bis } 8 \text { Wo p. } \\
\text { p. }\end{array}$ & $\begin{array}{c}\text { bis } 14 \text { Wo } \\
\text { p. p. }\end{array}$ & $>100$ d p. p. & Färsen & $\begin{array}{c}\text { ohne } \\
\text { Angabe }\end{array}$ \\
\hline $\begin{array}{c}\text { Median } \\
\text { in U/I }\end{array}$ & 114,0 & 175,6 & 125,7 & 131,3 & 130,3 & 154,8 & 161,0 \\
\hline Q1;Q3 & 83,$3 ; 167,9$ & 120,$7 ; 259,7$ & 99,$6 ; 175,3$ & 115,$9 ; 168,8$ & 113,$7 ; 182,1$ & 122,$9 ; 189,1$ & 124,$6 ; 172,3$ \\
\hline
\end{tabular}

\subsubsection{Spurenelemente ( $\mathrm{Cu}$, Se, $\mathrm{Zn}, \mathrm{Mn})$, B-Carotin, Coeruloplasmin und die Trolox äquivalente Antioxidative Kapazität (TEAC)}

\section{Cupfer (Cu)}

Auf $\mathrm{Cu}$ sind insgesamt 740 Proben untersucht wurden (Tabelle 4.8). Für dieses Spurenelement wird der physiologische Bereich von 8,0 - 32,8 $\mu$ mol/l definiert (FÜRLL 2013a). Nur 10,7 \% der Ergebnisse weisen Konzentrationen unterhalb dieses Bereiches auf. Es sind keine Konzentrationen über $32,8 \mu \mathrm{mol} / \mathrm{l}$ vorhanden.

Tabelle 4.8: $\mathrm{Cu}$ : Probenanzahl mit Konzentrationen innerhalb und unterhalb des Normbereiches je Laktationsstadium, eingesendet von einer tierärztlichen Gemeinschaftspraxis im EL (Ref: 8,0 - 32,8 $\mu \mathrm{mol} / \mathrm{l})$

\begin{tabular}{|c|c|c|c|c|c|}
\hline$\underline{\mathbf{C u}}$ & $\mathrm{n}_{\text {ges }}$ & $\mathrm{n}<$ Norm & $\begin{array}{c}\text { \% von } \mathrm{n}_{\text {ges }} \\
(<\text { Norm })\end{array}$ & n Norm & $\begin{array}{c}\% \text { von } \mathrm{n}_{\text {ges }} \\
(\text { Norm })\end{array}$ \\
\hline a.p. & 296 & 37 & 12,5 & 259 & 87,5 \\
\hline 0-1Wo p. p. & 102 & 9 & 8,8 & 93 & 91,2 \\
\hline bis 8 Wo p. p. & 156 & 7 & 4,5 & 149 & 95,5 \\
\hline bis 14 Wo p. p. & 44 & 1 & 2,3 & 43 & 97,7 \\
\hline >100d p. p. & 54 & 8 & 14,8 & 46 & 85,2 \\
\hline Färsen & 47 & 10 & 21,3 & 37 & 78,7 \\
\hline ohne Angabe & 41 & 7 & 17,1 & 34 & 82,9 \\
\hline Gesamt & 740 & 79 & 10,7 & 661 & 89,3 \\
\hline
\end{tabular}

Im Laufe der Laktation ist von a. p. bis 14 Wochen p. p. eine sinkende Anzahl an Abweichungen von $12,5 \%$ auf 2,3 \% zu beobachten (Tabelle 4.8). Am Ende der Laktation steigt die Anzahl der Konzentrationen unter dem Normbereich wieder auf $14,8 \%$ an. Im Vergleich zu den Kühen sind die Abweichungen bei den Färsen mit 21,3 \% deutlich höher.

Die Mediane bewegen sich zwischen 10,7 $\mu$ mol und 13,1 $\mu \mathrm{mol} / 1$ und sind damit alle innerhalb der Toleranzgrenzen einzuordnen (Tabelle 4.9). 
Für $\mathrm{Cu}$ und Coeruloplasmin ist ein nennenswerter Korrelationskoeffizient nach Pearson von 0,76 berechenbar. Allerdings gibt es nur sieben gültige Fälle, woraus die Korrelation bestimmt werden kann. Somit ist dieser Wert aufgrund der geringen Anzahl an Fällen nur bedingt aussagekräftig.

Tabelle 4.9: $\mathrm{Cu}$, B-Carotin, Se und TEAC: Mediane und Quartile (1. und 3.) bzw. Mittelwerte und Standardabweichungen im Laktationsstadienvergleich von Proben einer tierärztlichen Gemeinschaftspraxis im EL

\begin{tabular}{|c|c|c|c|c|c|c|}
\hline \multirow{2}{*}{ LS } & \multicolumn{2}{|c|}{$\mathrm{Cu}$} & \multicolumn{2}{c|}{ ß-Carotin } & Se & TEAC \\
\cline { 2 - 7 } & $\begin{array}{c}\text { Median } \\
\text { in } \mu \mathrm{mol} / 1\end{array}$ & $\mathrm{Q} 1 ; \mathrm{Q} 3$ & $\begin{array}{c}\text { Median } \\
\text { in } \mu \mathrm{mol} / 1\end{array}$ & $\mathrm{Q} 1 ; \mathrm{Q} 3$ & $\begin{array}{c}\bar{x} \pm \mathrm{SD} \\
\text { in } \mu \mathrm{mol} / 1\end{array}$ & $\begin{array}{c}\bar{x} \pm \mathrm{SD} \\
\mu \mathrm{mol} / 1\end{array}$ \\
\hline a.p. & 11,7 & 9,$6 ; 14,6$ & 7,35 & 5,$30 ; 11,09$ & $0,61 \pm 0,26$ & $308,6 \pm 41,9$ \\
\hline 0-1Wo p. p. & 13,1 & 10,$6 ; 15,6$ & 4,34 & 2,$83 ; 5,44$ & $0,73 \pm 0,29$ & $295,0 \pm 48,9$ \\
\hline bis 8 Wo p. p. & 12,6 & 10,$4 ; 15,6$ & 4,82 & 3,$75 ; 6,65$ & $0,76 \pm 0,31$ & $343,1 \pm 43,9$ \\
\hline bis 14 Wo p. p. & 10,7 & 9,$8 ; 13,0$ & \multicolumn{2}{|c|}{ nur ein Wert } & $0,81 \pm 0,21$ & $383,1 \pm 50,5$ \\
\hline >100d p. p. & 11,1 & 9,$2 ; 13,0$ & \multicolumn{2}{|c|}{ nur ein Wert } & $0,78 \pm 0,25$ & $341,8 \pm 50,5$ \\
\hline Färsen & 11,6 & 8,$4 ; 14,9$ & 4,77 & 4,$73 ; 6,84$ & $0,69 \pm 0,30$ & $306,5 \pm 9,9$ \\
\hline ohne Angabe & 11,9 & 9,$0 ; 14,0$ & 7,40 & 7,$25 ; 7,80$ & $0,69 \pm 0,31$ & $317,1 \pm 34,7$ \\
\hline
\end{tabular}

\section{Selen (Se)}

Se ist mit 771 Ergebnissen der am dritthäufigsten untersuchte Parameter (Abbildung 4.13). Davon befinden sich fast zwei Drittel $(60,6 \%)$ innerhalb der Toleranzgrenzen. Diese beschreibt FÜRLL (2013a) mit 0,4 - 0,88 $\mu$ mol/1. Die 39,4 \% Abweichungen teilen sich in Konzentrationen, die zu 15,8\% unterhalb und 23,6\% oberhalb der Toleranzgrenzen liegen.

In Abbildung 4.19 sind die Abweichungen innerhalb der verschiedenen Laktationsperioden sichtbar. Hier wird deutlich, dass die Anzahl der Tiere, welche Konzentrationen unter dem Normbereich haben, im Laufe der Laktation deutlich weniger werden. Im Gegensatz dazu steigt die Anzahl von Ergebnissen über 0,88 $\mu \mathrm{mol}$ ab dem Zeitpunkt der Kalbung stark an und erreicht in der Phase neun bis 14 Wochen p. p. den höchsten Wert der Laktation von $37 \%$. Bei den Färsen ist das Verhältnis Abweichungen unterhalb des physiologischen Bereiches mit $20 \%$ und oberhalb mit $26 \%$ relativ ausgewogen.

Für die Mittelwerte innerhalb der einzelnen Perioden lassen sich Konzentrationen zwischen 0,61 $\mu \mathrm{mol} / \mathrm{l}$ (a. p.) und 0,81 $\mu \mathrm{mol} / \mathrm{l}$ (bis 14 Wochen p. p.) berechnen (Tabelle 4.9). Sie folgen dem Verlauf der Abweichung oberhalb des Normbereiches. Der Mittelwert in dem Stadium neun bis 14 Wochen p. p. liegt als Einziger oberhalb der Kontrollgrenze von 0,80 $\mu$ mol/l (FÜRLL 2013a).

Auch für Se und Coeruloplasmin ist ein relativ hoher Korrelationskoeffizient nach Pearson mit 0,62 bestimmbar. Aber wie schon bei $\mathrm{Cu}$ gibt es zusammen mit Coeruloplasmin nur sieben gültige Fälle. 


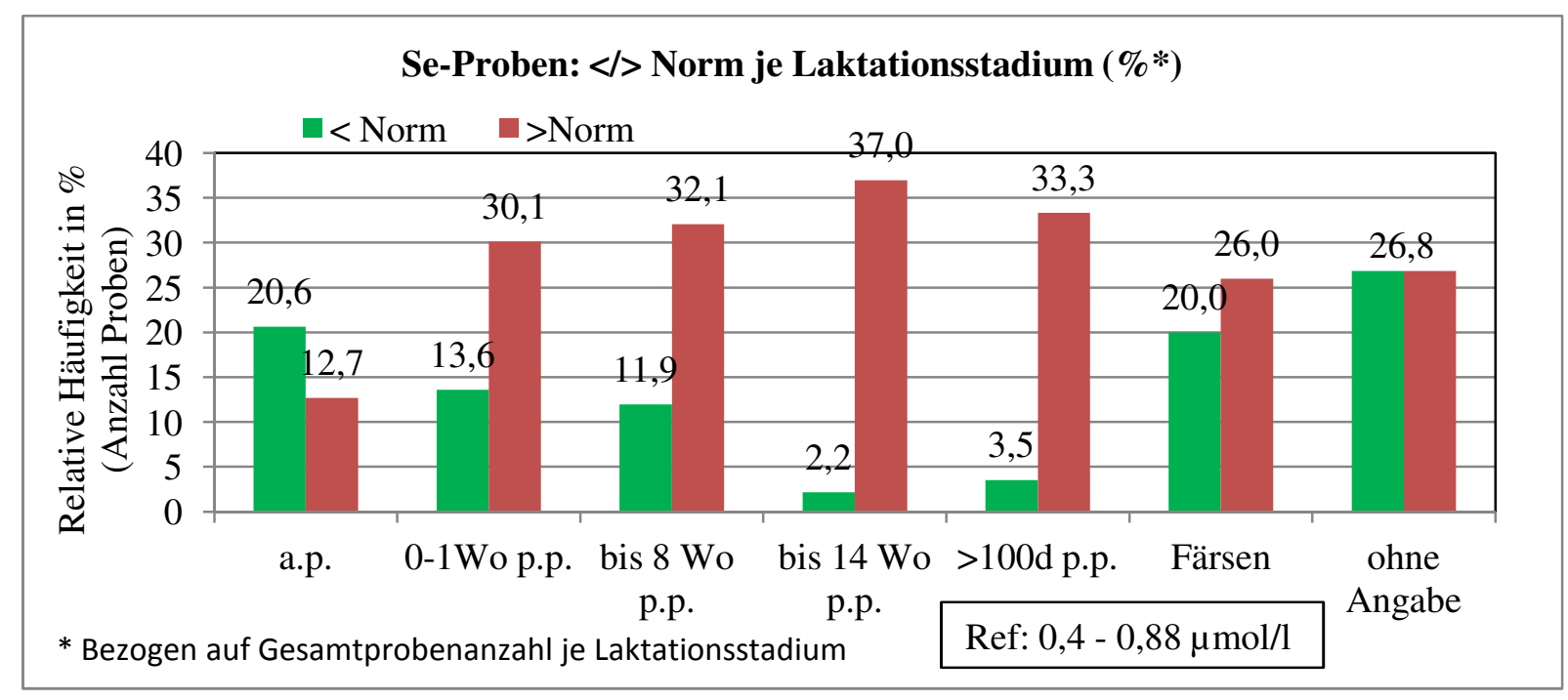

Abbildung 4.19: Se: Probenanzahl mit Konzentrationen innerhalb und oberhalb des Normbereiches je Laktationsstadium, eingesendet von einer tierärztlichen Gemeinschaftspraxis im EL

\section{Zink (Zn)}

Von $\mathrm{Zn}$ liegen 16 Ergebnisse vor (Abbildung 4.14). Davon befinden sich sieben Konzentrationen (43,8 \%) innerhalb des Normbereiches von 12 - $25 \mu \mathrm{mol} / \mathrm{l}$ (FÜRLL 2013a) und neun Konzentrationen $(56,3 \%)$ darüber.

\section{Mangan (Mn)}

Auf das Spurenelement Mn wurde eine Einsendung mit zehn Einzelproben untersucht (Abbildung 4.14). Alle Ergebnisse sind innerhalb des physiologischen Bereiches von $\geq 0,4 \mu \mathrm{mol} / \mathrm{l}$ (FÜRLL 2013a) einzuordnen.

\section{B-Carotin}

Es liegen 174 Ergebnisse zu ß-Carotin vor (Tabelle 4.10). Diese werden anhand des Referenzbereiches von $\geq 7,4 \mu \mathrm{mol} / \mathrm{l}$ und in der ersten Woche p. p. $\geq 4,02 \mu \mathrm{mol} / \mathrm{l}$ (FÜRLL 2013a) bewertet. Danach können 42,9\% der Proben diesem Bereich zugeordnet werden. Die restlichen 57,1 \% weisen Konzentrationen unterhalb des Normbereiches auf.

Bei der Aufteilung in die verschiedenen Laktationsstadien (Tabelle 4.10) sind aussagefähige Angaben nur in dem Zeitraum a. p. bis acht Wochen p. p. und bei den Färsen sinnvoll. In den anderen Zeiträumen liegt jeweils nur ein Ergebnis vor und sie sind somit nicht vergleichbar.

Sowohl a. p, als auch in der ersten Woche p. p. ist das Verhältnis von Konzentrationen innerhalb und außerhalb des physiologischen Bereiches etwa gleich. So zeigen die Ergebnisse, dass $50 \%$ bzw. $52,9 \%$ der Proben Konzentrationen innerhalb des Normbereiches aufweisen. Von der zweiten bis zur achten Woche p. p. kommt es dann zu einem starken Anstieg auf 77,8 \% der Konzentrationen 
unterhalb des Normbereiches. Auffallend ist auch der große Anteil an Abweichungen von 86,7 \% bei den Färsen.

Tabelle 4.10: ß-Carotin: Probenanzahl mit Konzentrationen innerhalb und unterhalb des Normbereiches je Laktationsstadium, eingesendet von einer tierärztlichen Gemeinschaftspraxis im EL (Ref: $\geq 7,4 \mu \mathrm{mol} / 1 ; 1$.Wo p. p. $\geq 4,02 \mu \mathrm{mol} / \mathrm{l}$ )

\begin{tabular}{|c|c|c|c|c|c|}
\hline B-Carotin & $\mathrm{n}_{\text {ges }}$ & $\mathrm{n}<$ Norm & $\begin{array}{c}\% \text { von } \mathrm{n}_{\text {ges }} \\
(<\text { Norm })\end{array}$ & n Norm & $\begin{array}{c}\% \text { von } \mathrm{n}_{\text {ges }} \\
(\text { norm })\end{array}$ \\
\hline a. p. & 66 & 33 & 50,0 & 33 & 50,0 \\
\hline 0-1Wo p. p. & 34 & 16 & 47,1 & 18 & 52,9 \\
\hline bis 8 Wo p. p. & 27 & 21 & 77,8 & 6 & 22,2 \\
\hline bis 14 Wo p. p. & 1 & 0 & 0,0 & 1 & 100,0 \\
\hline >100d p. p. & 1 & 0 & 0,0 & 1 & 100,0 \\
\hline Färsen & 15 & 13 & 86,7 & 2 & 13,3 \\
\hline ohne Angabe & 3 & 1 & 33,3 & 2 & 66,7 \\
\hline Gesamt & 147 & 84 & 57,1 & 63 & 42,9 \\
\hline
\end{tabular}

In den Bereichen, wo die Anzahl an Abweichungen sehr hoch ist, wird ein Median unterhalb der Toleranzgrenze errechnet. Dies trifft für die Laktationsphase zwei bis acht Wochen p. p. mit 4,82 $\mu \mathrm{mol} / \mathrm{l}$ und für die Färsen mit 4,77 $\mu \mathrm{mol} / \mathrm{l}$ zu (Tabelle 4.9). Nur ganz knapp unter der Toleranzgrenze ist der Median a. p. mit 4,35 $\mu \mathrm{mol} / \mathrm{l}$ einzuordnen. Die anderen Mediane befinden sich oberhalb der Toleranzgrenze und sind unauffällig.

\section{Coeruloplasmin}

Für das Plasmaprotein Coeruloplasmin liegen insgesamt sieben Ergebnisse aus zwei Einsendungen mit einmal vier und einmal drei Einzelproben vor (Abbildung 4.14). Die Ergebnisse weisen alle Konzentrationen unterhalb der Toleranzgrenze von 0,2 - 0,3 g/l (FÜRLL 2013a) auf.

\section{Trolox Äquivalente Antioxidative Kapazität (TEAC)}

Von 266 Rückstellproben wurde die TEAC bestimmt. Die Proben stammen aus dem Zeitraum Januar 2009 bis März 2011. Diese Proben befinden sich zu 54,5 \% innerhalb des Referenzbereiches von $180-320 \mu \mathrm{mol} / \mathrm{l}$ (FÜRLL 2013a).

Bei der Verteilung in die einzelnen Laktationsstadien sind auswertbare Probenanzahlen in den Phasen a. p. mit 150 Proben, in der ersten Woche p. p. mit 36 Proben und in der zweiten bis achten Woche p. p. mit 41 Proben vorhanden. Die folgenden Laktationsperioden beinhalten entweder drei oder zehn Proben. Zwei Proben von Färsen und 24 Proben ohne Angaben bilden den Rest.

In Abbildung 4.20 wird deutlich, dass sowohl a. p, als auch in der ersten Woche p. p. über $60 \%$ der Proben im physiologischen Bereich liegen. In der Zeit zwei bis acht Woche p. p. steigt die Anzahl an 
Abweichungen stark an und erreicht einen Wert von 70,7 \%. Diese Erhöhung spiegelt sich auch im Mittelwert wieder, welcher in diesem Stadium 343,1 $\mu \mathrm{mol} / 1$ beträgt (Tabelle 4.9). Von den drei aussagekräftigen Laktationsperioden ist diese die Einzige mit einem Mittelwert über $320 \mu \mathrm{mol} / \mathrm{l}$.

Eine nennenswerte Korrelation zu einem anderen Parameter mit einem Korrelationskoeffizient nach Pearson > 0,5 ist in dieser Auswertung nicht nachweisbar.

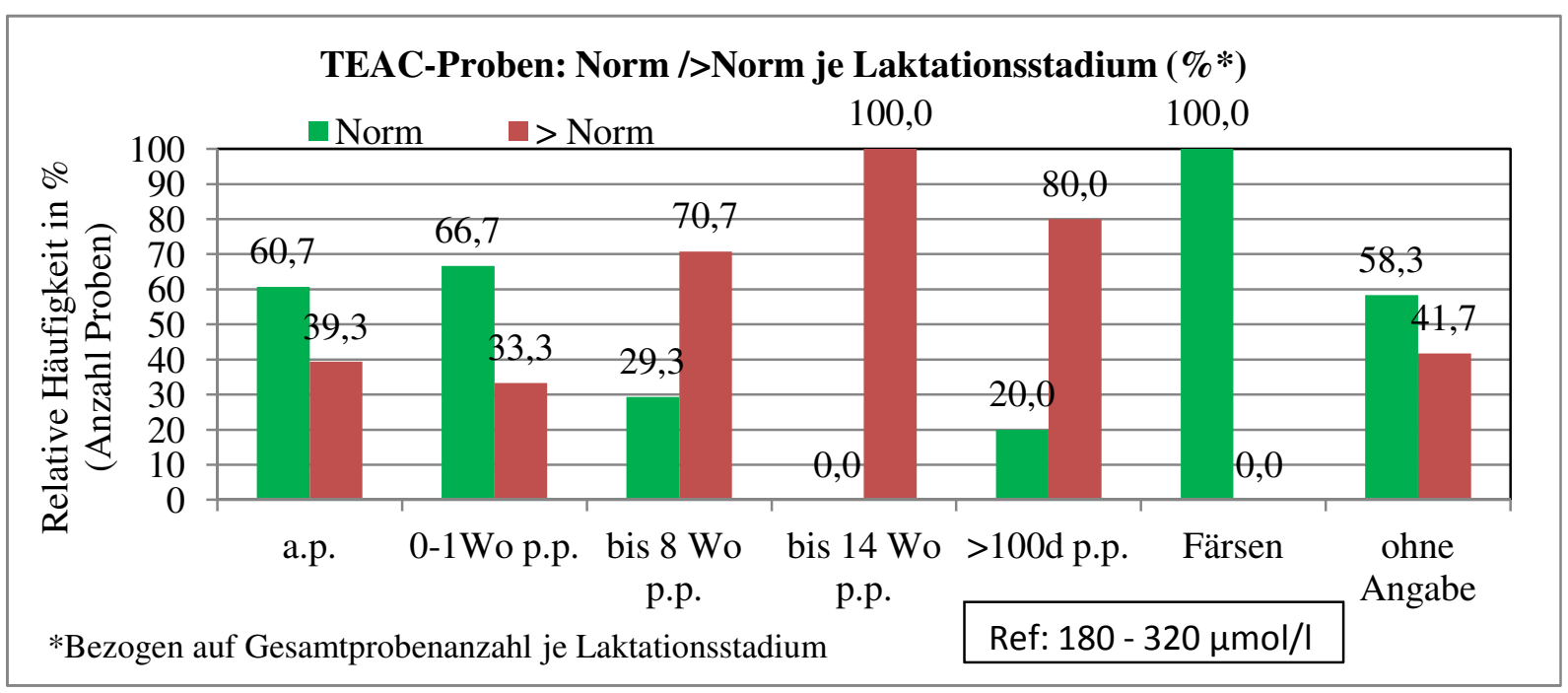

Abbildung 4.20: TEAC: Probenanzahl mit Konzentrationen innerhalb und oberhalb des Normbereiches je Laktationsstadium, eingesendet von einer tierärztlichen Gemeinschaftspraxis im EL

\subsubsection{Harnproben}

47 Harnproben in acht Einsendungen sind im Laufe des Untersuchungszeitraumes eingesendet worden. Die erste Einsendung ist März 2009 und die letzte im Juni 2010 verzeichnet. Die Einsendungen bestehen sechsmal aus fünf Einzelproben und jeweils einmal aus sieben bzw. zehn Einzelproben.

Die Proben stammen alle von Kühen, die zwischen drei und sechs Wochen p. p. waren. So lauten die Angaben zum Laktationsstadium fünfmal sechs Wochen p.p, fünfmal vier bis sechs Wochen p. p. und bei den restlichen 37 Fällen drei bis vier Wochen p. p.

Für alle 47 Proben liegen Ergebnisse zu den Parametern Na, K, Basen, Säuren und NH4+ sowie zum pH-Wert, der NSBA und dem BSQ vor. Die Parameter $\mathrm{Cl}, \mathrm{Mg}, \mathrm{Ca}$ und $\mathrm{P}_{\mathrm{i}}$ wurden bei verschiedenen Einsendungen in unterschiedlicher Anzahl untersucht. Detaillierte Angaben, sowie die Werteverteilung der verschiedenen Harnparameter werden in Abbildung 4.21 gezeigt.

Zur Auswertung der einzelnen Parameter werden erneut die Toleranzgrenzen von FÜRLL (2013a) herangezogen (Tabelle 3.4). 


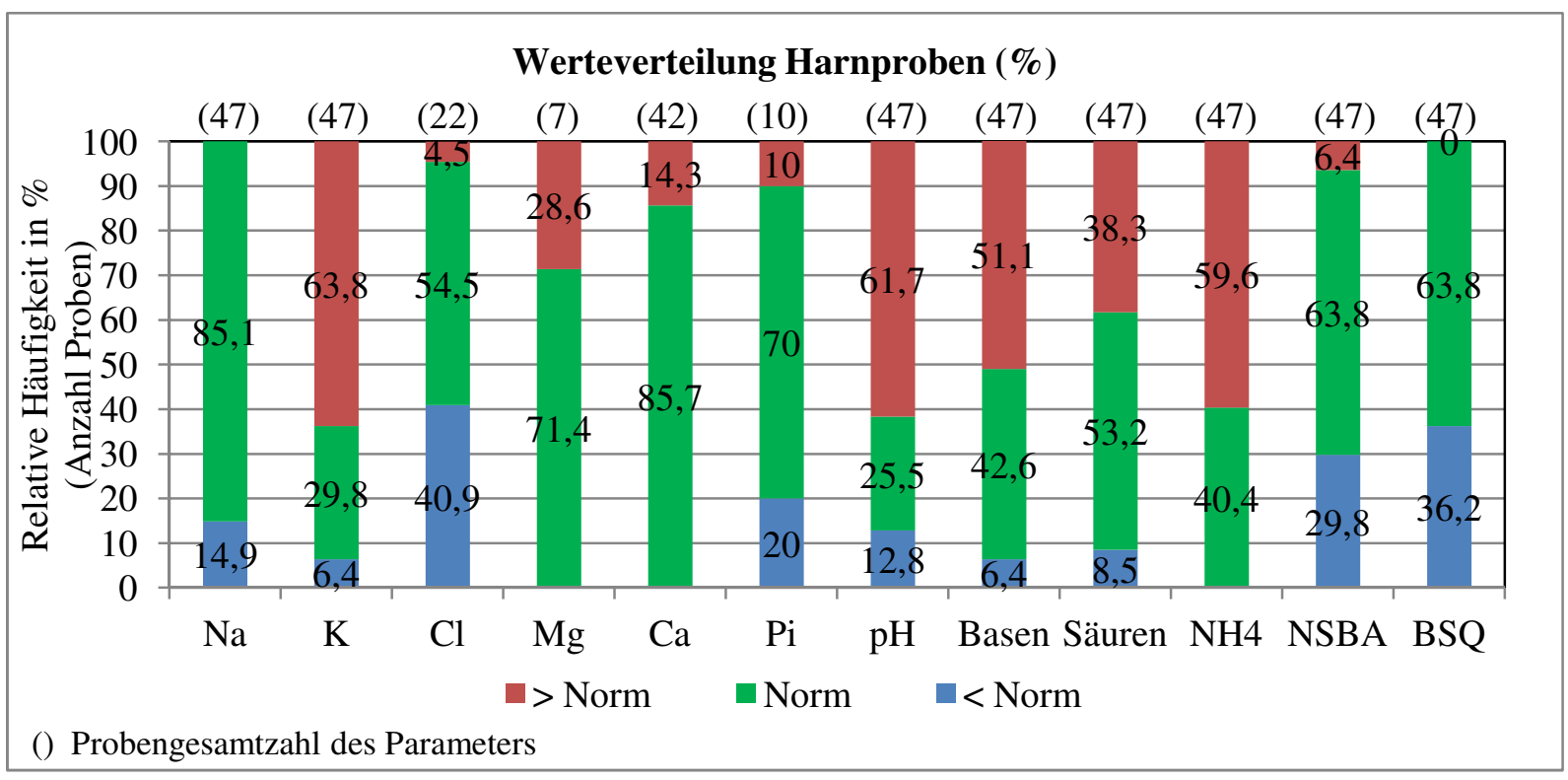

Abbildung 4.21: Probengesamtanzahl und Werteverteilung von Parametern in Harnproben, eingesendet von einer tierärztlichen Gemeinschaftspraxis im EL

In Abbildung 4.21 wird deutlich, dass $\mathbf{K}$ mit 29,8 \% der Konzentrationen im Normalbereich und der pH-Wert mit 25,5\% die Parameter mit den meisten Abweichungen sind (Ref: K: 150 - 300 mmol/l; pH: 7,8 - 8,4). Bei beiden Parametern ist der Anteil an Ergebnissen über dem Normbereich mehr als $60 \%$, das sind somit auch die höchsten Werte im Vergleich aller Harnparameter. Die unteren Abweichungen sind mit 6,4 \% bei Kalium und 12,8 \% bei dem pH-Wert sehr gering.

Sowohl die Basen, als auch das $\mathbf{N H}_{\mathbf{4}}$ mit Anzahlen an Proben innerhalb der Referenzgrenzen (Basen: 150 - $250 \mathrm{mmol} / \mathrm{l} ; \mathrm{NH}_{4}:<10 \mathrm{mmol} / \mathrm{l}$ ) um die $40 \%$ folgen in der Reihenfolge. Auch diese zwei Parameter weisen mit 51,1\% bzw. 59,6\% relativ viele Abweichungen oberhalb der Toleranzgrenzen auf. Konzentrationen unterhalb der Toleranzgrenze sind nur bei den Basen vorhanden. Diese sind aber mit $6,4 \%$ sehr gering.

Mehr als $50 \%$ der Ergebnisse von Cl (54,5\%) und den Säuren (53,2 \%) können innerhalb der Referenzbereiche (Cl: 40 - 160 mmol/l; Säuren: 50 - 100 mmol/l) eingeordnet werden. Bei dem Elektrolyt Chlorid ist der Anteil an Abweichungen oberhalb des Referenzbereiches mit 4,5\% sehr gering. Dagegen weist der Parameter mit 40,9 \% die meisten Abweichungen unterhalb auf. Bei den Säuren sind die Anteile dagegen wie bei den vorher genannten Parametern verteilt. Hier ist der Anteil an Abweichungen über dem Normbereich mit 38,3 \% um ein vielfaches höher als die Abweichungen unter dem Normbereich.

Mit jeweils 63,8 \% Konzentrationen innerhalb der Toleranzgrenzen ähnelt sich die Werteverteilung von der NSBA und dem BSQ sehr stark (Ref: NSBA: 83 - 215 mmol/l; BSQ: 1,8 - 4,6). Der Unterschied besteht darin, dass der BSQ kein und die NSBA nur einen geringen Anteil an Ergebnissen 
oberhalb der Toleranzgrenze aufweisen. Die Abweichungen unterhalb der Grenze liegen mit 29,8 \% und $36,2 \%$ sehr eng beieinander.

Die zwei Parameter mit den geringsten Gesamtprobenanzahlen $\mathbf{M g}$ und $\mathbf{P}_{\mathbf{i}}$ haben Ergebnisse im Normbereich (Mg: 3,7 - 16,5 mmol/1; $\mathrm{P}_{\mathrm{i}}:$ 0,1 - 3,3 mmol/l) von 71,4 \% und $70 \%$. Bei Magnesium sind nur Abweichungen oberhalb der Grenze vorhanden. Die Abweichungen des $\mathrm{P}_{\mathrm{i}}$ teilen sich in $10 \%$ oberhalb und $20 \%$ unterhalb der Grenzen.

Na und Ca weisen mit über $85 \%$ die meisten physiologischen Konzentrationen auf (Ref: Na: $\geq 2,2$ $\mathrm{mmol} / \mathrm{l} \mathrm{Ca}: \leq 2,5 \mathrm{mmol} / \mathrm{l})$. Der Unterschied liegt bei den Abweichungen, welche bei Natrium nur unterhalb und bei Calzium nur oberhalb der Normbereiche vorhanden sind.

\subsection{Ergebnisse der Proben im Jahresvergleich}

Für die Parameter mit einer Gesamtprobenanzahl größer als 100, außer GGT und GLDH, wurde eine Auswertung und Vergleich der einzelnen Jahre vorgenommen.

Für die Parameter GGT und GLDH liegen nur in den Jahren 2009 bis 2011 Ergebnisse vor, wobei nur 2010 und 2011 eine entsprechende Probenanzahl zugeordnet werden kann. Innerhalb dieser zwei Jahre liegt aber die Anzahl an Abweichungen zwischen 2,6\% und 11,9\% und ist somit als sehr gering einzustufen.

Von jedem auswertbaren Parameter liegen die Ergebnisse für die verschiedenen Jahre vor. Die Ergebnisse eines Jahres der einzelnen Parameter, sowie die Ergebnisse der Jahre innerhalb der verschiedenen Laktationsstadien, werden mithilfe des KST auf Normalverteilung untersucht. Bei einem p-Wert > 0,05 wird von einer Normalverteilung ausgegangen und die Jahre werden mithilfe des unabhängigen t-Tests auf signifikante Unterschiede der Mittelwerte untersucht. Bei $\mathrm{p} \leq 0,05$ wird davon ausgegangen, dass keine Normalverteilung der Werte vorliegt und die Jahre werden mit dem Mann-Whitney-U-Test auf signifikanten Unterschiede in der Konzentrationsverteilung weiter verglichen.

\subsubsection{Parameter des Energie-Fett-Leber-Stoffwechsels (FFS, BHB, Bilirubin, Cholesterol)}

\section{Freie Fettsäuren}

Aufgrund der hohen Gesamtanzahl an Untersuchungsergebnissen und den relativ starken Abweichungen in den Laktationsperioden a. p. bis acht Woche p. p. liegt für die FFS sowohl eine Aufteilung in die verschiedenen Jahre als auch eine Aufteilung in diese drei Laktationsperioden innerhalb der Jahre vor. 
Die Abweichungen der einzelnen Jahre zeigen bis 2010 einen steigenden Trend (Tabelle 4.11). 2011 sinkt die Anzahl dann gering ab und erreicht einen Wert von 39,1\%. Die meisten Abweichungen sind dem Jahr 2010 mit 46,8 \% zu zuordnen, dicht gefolgt von 2009 mit 45,5\%.

Tabelle 4.11: FFS: Jahresvergleich der Probenanzahl und der Abweichungen von eingesendeten Proben einer tierärztlichen Gemeinschaftspraxis im EL (Ref: a. $\quad$ p. $\quad>\quad 150 \mu \mathrm{mol} / \mathrm{l}$; 1. Wo p. p. $>620 \mu \mathrm{mol} / \mathrm{l} ;>1$ Wo p. p. $>340 \mu \mathrm{mol} / \mathrm{l})$

\begin{tabular}{|c|c|c|c|}
\hline FFS & $\mathrm{n}_{\text {ges }}$ & $\mathrm{n}>$ Norm & \% von $\mathrm{n}_{\text {ges }}(>$ Norm) \\
\hline 2006 & 58 & 13 & 22,4 \\
\hline 2007 & 226 & 68 & 30,1 \\
\hline 2008 & 151 & 62 & 41,1 \\
\hline 2009 & 143 & 65 & 45,5 \\
\hline 2010 & 109 & 51 & 46,8 \\
\hline 2011 & 87 & 34 & 39,1 \\
\hline
\end{tabular}

Bei der Aufteilung in die verschiedenen Laktationsperioden gibt es a. p. Abweichungen mit Werten von 37,8 \% bis 68,8\% (Abbildung 4.22). Dabei ist ein steigender Trend von 2006 bis $2010 \mathrm{zu}$ verzeichnen. Die Jahre 2006 und 2011 weisen die geringsten Abweichungen auf. Hierbei ist aber wieder zu beachten, dass von diesen Jahren nur drei Monate in die Auswertung mit einbezogen wurden und deshalb die Probenanzahl geringer ist, als in den anderen Jahren. Signifikante Unterschiede a. p. sind zum einem zwischen den Jahren 2006 und 2010 zu verzeichnen und zum Anderen weisen die Jahre 2007, 2008, 2009 und 2010 zu 2011 signifikante Unterschiede auf.

Der Laktationsperiode erste Woche p. p. können auf Grund der relativ kurzen Periodendauer von nur sieben Tagen geringere Probenanzahlen zu den verschiedenen Jahren $\mathrm{zu}$ geordnet werden (Anhang Tabelle 9.3). In der ersten Woche p. p. betragen die Abweichungen in den Jahren 2006 und 2007 ca. 17 \% (Abbildung 4.22). In den folgenden Jahren liegen diese Werte deutlich höher. Im Jahr 2008 sind die meisten Abweichungen mit 57,1\% zu verzeichnen. Bei den folgenden Jahren betragen die Abweichungen $50 \%$ (2009 und 2011) bzw. 41,2 \% (2010). Beim Vergleich der Jahre liegen signifikante Unterschiede zwischen 2007 und 2008, 2009 und 2011 vor.

Von der zweiten bis zur achten Woche p. p. weisen die Jahre 2006 und 2009 eine geringere Anzahl an Abweichungen, 14,3\% bzw. 17,9 \%, auf, als die restlichen Jahre. Die anderen Jahre haben Werte zwischen $37,5 \%$ (2007) und $50 \%$ (2011). In dieser Laktationsperiode sind mehr signifikante Unterschiede zwischen den Jahren zu verzeichnen. So ist der Mittelwert von dem Jahr 2006 signifikant unterschiedlich zu den Werten der Jahre 2007, 2008, 2010 und 2011. Des Weiteren lassen sich zwischen den Jahren 2008 und 2009 bzw. 2009 und 2011 ebenfalls signifikante Unterschiede feststellen. 


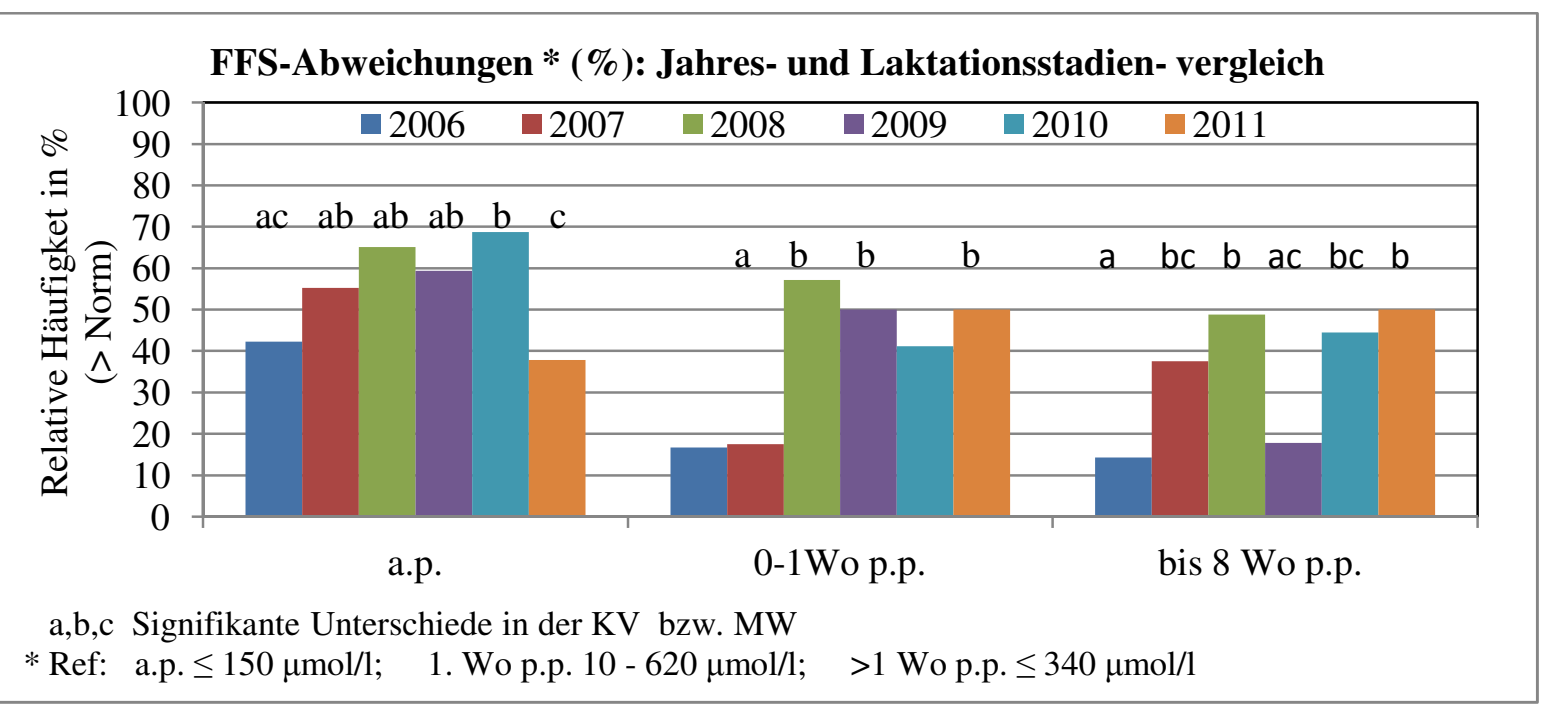

Abbildung 4.22: Abweichungen der FFS a. p. bis 8. Woche p. p. im Jahresvergleich und signifikante Unterschiede $(\mathrm{p} \leq 0,05)$ zwischen den Jahren eines Laktationsstadiums von eingesendet Proben einer tierärztlichen Gemeinschaftspraxis im EL

\section{B-Hydroxybutyrat}

Die relativ hohe Anzahl an Abweichungen in der Gesamtauswertung von BHB lässt sich auch innerhalb der einzelnen Jahre nachweisen. Die Werte der Jahre 2006 bis 2010 unterscheiden sich nur gering und weisen Werte zwischen 51,3\% und 57,5 \% auf (Tabelle 4.12). Das Jahr 2011 zeigt mit Abstand die meisten Abweichungen mit 67,8 \% und auch den höchsten Medianwert von 0,75 mmol/l. Die Medianwerte liegen alle oberhalb der Kontrollgrenze von 0,53 mmol/l (FÜRLL 2013a).

Signifikante Unterschiede können zwischen dem Jahr 2011 und den Jahren 2006, 2008, 2009 und 2010 nachgewiesen werden. Zu dem Jahr 2007 liegt kein Unterschied vor. Dafür besteht aber für das Jahr 2007 ein signifikanter Unterschied zum Jahr 2008.

Tabelle 4.12: BHB: Jahresvergleich der Probenanzahl (Verteilung anhand KST), der Abweichungen und der Mediane mit den Quartilen (1. und 3.), sowie signifikante Unterschiede $(\mathrm{p} \leq 0,05)$ in der KV zwischen den Jahren von eingesendeten Proben einer tierärztlichen Gemeinschaftspraxis im EL (Ref: $\leq 0,62 \mathrm{mmol} / \mathrm{l}$; Verteilung: no = normal verteilt; $\mathrm{nn}=$ nicht normal verteilt)

\begin{tabular}{|c|c|c|c|c|c|}
\hline BHB & $\begin{array}{c}\mathrm{n}_{\text {ges }} \\
\text { (Verteilung) }\end{array}$ & $\mathrm{n}>$ Norm & $\begin{array}{c}\text { \% von } \mathrm{n}_{\text {ges }} \\
(>\text { Norm })\end{array}$ & $\begin{array}{c}\text { Median } \\
\text { in mmol/l }\end{array}$ & Q1; Q3 \\
\hline 2006 & $58(\mathrm{no})$ & 32 & 55,2 & $0,66^{\mathrm{ab}}$ & 0,$51 ; 0,88$ \\
\hline 2007 & $226(\mathrm{nn})$ & 130 & 57,5 & $0,70^{\mathrm{cb}}$ & 0,$50 ; 0,96$ \\
\hline 2008 & $150(\mathrm{nn})$ & 77 & 51,3 & $0,63^{\mathrm{a}}$ & 0,$49 ; 0,85$ \\
\hline 2009 & $143(\mathrm{nn})$ & 75 & 52,4 & $0,64^{\mathrm{ab}}$ & 0,$48 ; 0,85$ \\
\hline 2010 & $109(\mathrm{nn})$ & 60 & 55,0 & $0,65^{\mathrm{ab}}$ & 0,$52 ; 0,80$ \\
\hline 2011 & $87(\mathrm{nn})$ & 59 & 67,8 & $0,75^{\mathrm{c}}$ & 0,$59 ; 1,06$ \\
\hline
\end{tabular}


Bei dem Jahresvergleich innerhalb der verschiedenen Laktationsstadien sind bis zur achten Woche p. p. aussagefähige Probenanzahlen vorhanden (Anhang Tabelle 9.3). Die Probenanzahlen von Kühen, welche mehr als acht Wochen nach der Kalbung waren, sind zum Teil sehr gering. Da aber auch hier nennenswerte Abweichungen vorliegen, sind diese Proben für den Jahresvergleich zu dem Laktationsstadium „,mehr als acht Wochen p. p.“ zusammen gefasst.

In Abbildung 4.23 wird der Unterschied zwischen den Abweichungen vor und nach der Kalbung wieder deutlich, welcher bereits in Kapitel 4.2.2.1 geschildert wurde. Nur bei einer Betrachtung von dem Jahr 2006 kann diese Aussage nicht bestätigt werden.

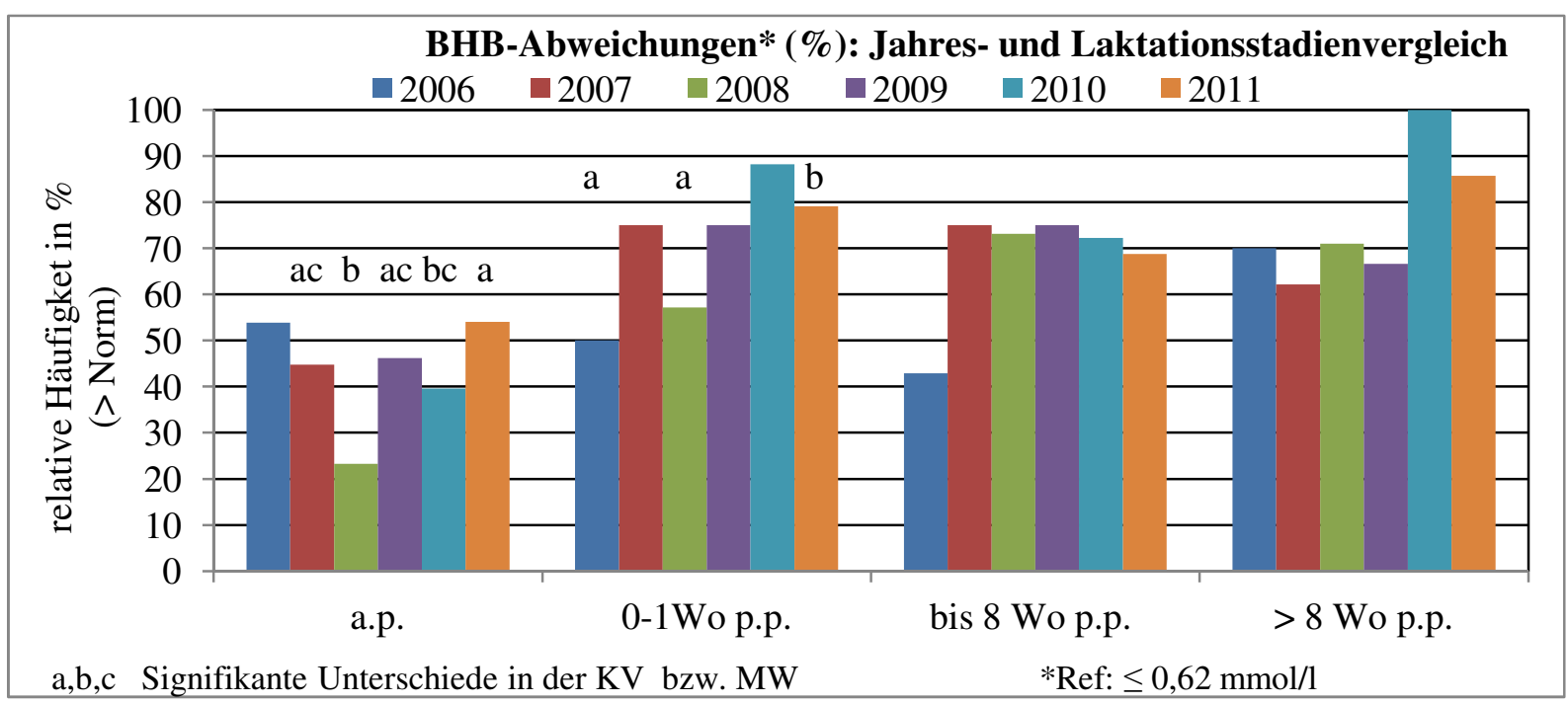

Abbildung 4.23: BHB-Abweichungen der Laktationsstadien im Jahresvergleich und signifikante Unterschiede $(\mathrm{p} \leq 0,05)$ zwischen den Jahren eines Laktationsstadiums von eingesendeten Proben einer tierärztlichen Gemeinschaftspraxis im EL

A. p. verzeichnet das Jahr 2008 mit 23,3\% die geringsten Abweichungen (Abbildung 4.23). Die anderen Jahre weisen Werte zwischen 39,6 \% und 54,1 \% auf. Ein p-Wert $\leq$ 0,05 kann zwischen dem Jahr 2008 und den Jahren 2007, 2009 und 2011 berechnet werden. Ebenfalls besteht ein signifikanter Unterschied zwischen den Jahren 2010 und 2011.

In der ersten Woche p. p. wird für 2010 eine Abweichung von 88,2\% nachgewiesen und ist damit deutlich höher im Vergleich zu den anderen Jahren. Die Jahre 2007 (75 \%), 2009 (75\%) und $2011(79,2 \%)$ befinden sich in Bezug auf die Abweichungen auf einem Niveau. Für die Jahre 2006 und 2008 liegen deutlich geringere Anzahlen an Abweichungen vor. Diese zwei Jahre sind die einzigen, für die ein signifikanter Unterschied zu 2011 berechnet werden kann.

Für die Laktationsperiode zwei bis acht Woche p. p. liegen im Verlauf der Jahre konstant hohe Abweichungen zwischen 68,8 \% und $75 \%$ vor. Nur das Jahr 2006 unterscheidet sich von den anderen Jahren. Hier beträgt die Abweichung 42,9\%. Signifikante Unterschiede sind zwischen den einzelnen Jahren jedoch nicht nachweisbar. 
Dies trifft ebenso für die Laktationsperiode mehr als acht Wochen p. p. zu. Hier sind die hohen Abweichungen in den Jahren 2010 und 2011 auffallend. 2010 sind $100 \%$ der Proben außerhalb des physiologischen Bereiches und 2011 nur 85,7\%.

\section{Bilirubin}

Von Bilirubin liegen hauptsächlich Daten aus den Jahren 2006 bis 2009 vor (Tabelle 4.13). In den Jahren 2010 wurden nur zwei und 2011 wurden keine Proben auf diesen Parameter untersucht.

Tabelle 4.13: Bilirubin: Jahresvergleich der Probenanzahl (Verteilung anhand KST), der Abweichungen und der Mediane mit den Quartilen (1. und 3.), sowie signifikante Unterschiede $(\mathrm{p} \leq 0,05)$ in der $\mathrm{KV}$ zwischen den Jahren von eingesendeten Proben einer tierärztlichen Gemeinschaftspraxis im EL (Ref: $\leq 5,3 \mu \mathrm{mol} / \mathrm{l}$; Verteilung: no = normalverteilt; $\mathrm{nn}=$ nicht normal verteilt)

\begin{tabular}{|c|c|c|c|c|c|}
\hline Bilirubin & $\begin{array}{c}\mathrm{n}_{\text {ges }} \\
\text { (Verteilung) }\end{array}$ & $\mathrm{n}>$ Norm & $\begin{array}{c}\text { \% von } \mathrm{n}_{\text {ges }} \\
(>\text { Norm })\end{array}$ & $\begin{array}{c}\text { Median } \\
\text { in } \mu \text { mol/1 }\end{array}$ & Q1; Q3 \\
\hline 2006 & $48(\mathrm{no})$ & 4 & 8,3 & $3,0^{\mathrm{a}}$ & 2,$0 ; 3,7$ \\
\hline 2007 & $206(\mathrm{nn})$ & 23 & 11,2 & $2,7^{\mathrm{a}}$ & 1,$9 ; 3,7$ \\
\hline 2008 & $143(\mathrm{nn})$ & 25 & 17,5 & $3,2^{\mathrm{b}}$ & 2,$3 ; 4,6$ \\
\hline 2009 & $105(\mathrm{nn})$ & 10 & 9,5 & $2,8^{\mathrm{a}}$ & 1,$9 ; 3,8$ \\
\hline
\end{tabular}

Wie in Tabelle $4.13 \mathrm{zu}$ sehen ist, erreichen die Abweichungen in den verschiedenen Jahren Werte zwischen $8,3 \%$ und $17,5 \%$. Die Mediane sind alle kleiner als 4,6 $\mu \mathrm{mol} / \mathrm{l}$ und befinden sich damit innerhalb des Kontrollbereiches (FÜRLL 2013). Signifikante Unterschiede bestehen ausschließlich zwischen dem Jahr 2008 und den anderen Jahren.

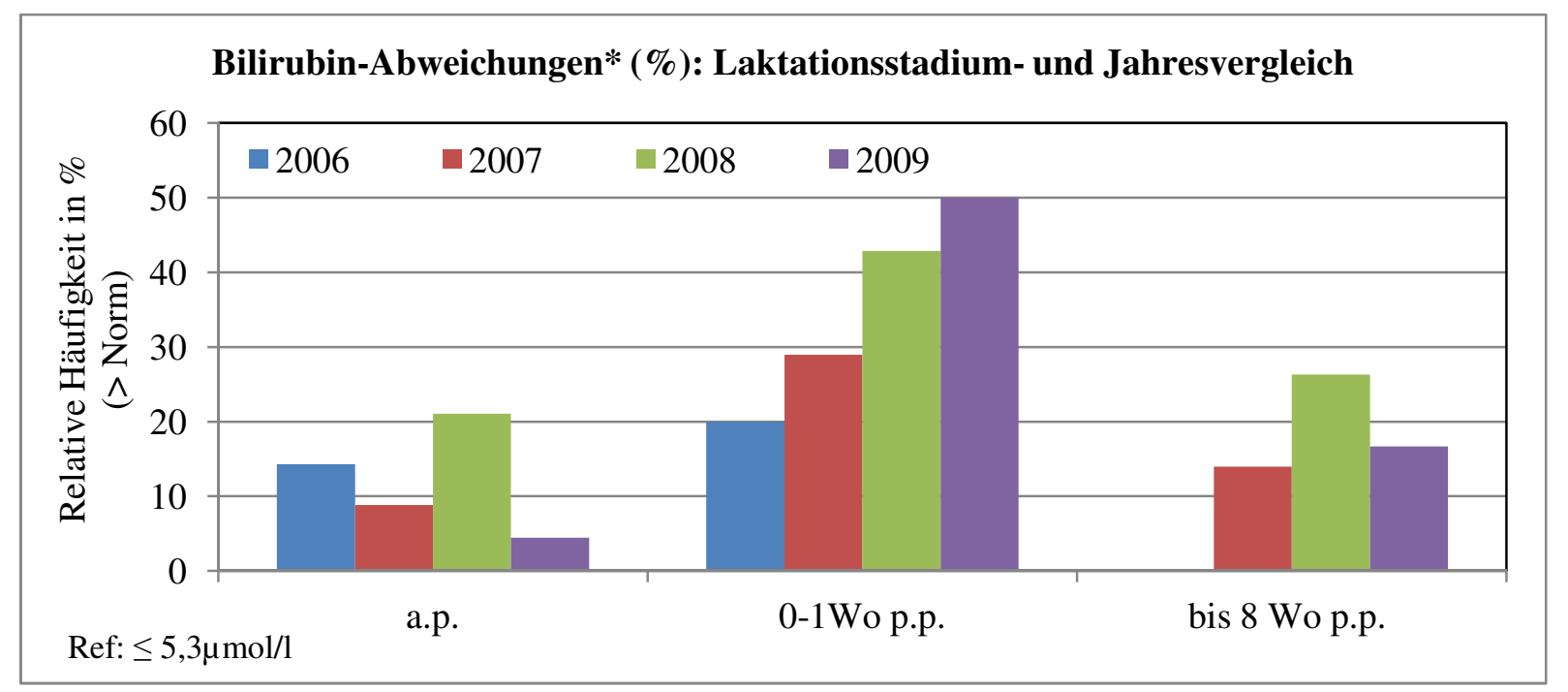

Abbildung 4.24: Bilirubin-Abweichungen der Laktationsstadien im Jahresvergleich von eingesendeten Proben einer tierärztlichen Gemeinschaftspraxis im EL 
Die Aufteilung in die verschiedenen Laktationsstadien (Abbildung 4.24) ist nur für den Zeitraum a. p. bis acht Woche p. p. sinnvoll, da zum Einen in den verbliebenen Stadien in der Regel keine Abweichungen zu verzeichnen sind und zum Anderen meist nur eine geringe und damit nicht sehr aussagefähige Probenanzahl vorhanden ist.

Abbildung 4.24 zeigt, dass auch im Jahresvergleich in der ersten Woche p. p. vermehrt Abweichungen mit steigendem Trend im Verlauf der Jahre vorhanden sind. Die Mittelwerte (Tabelle 4.14) zeigen einen ähnlichen Trend und erreichen in den Jahren 2007 mit 4,8 $\mu \mathrm{mol} / 1,2008$ mit 6,7 $\mu \mathrm{mol} / 1$ und 2009 mit 9,88 $\mu \mathrm{mol} / \mathrm{l} \mathrm{Konzentrationen} \mathrm{über} \mathrm{der} \mathrm{Kontrollgrenze} \mathrm{von} \mathrm{4,6} \mu \mathrm{mol} / \mathrm{l}$. Außerdem sind in diesen Jahren hohe Standardabweichungen zu vermerken. Signifikante Unterschiede zwischen den Jahren sind aber nicht vorhanden.

Sowohl a. p. als auch in der zweiten bis achten Woche p. p. sind ebenfalls keine signifikanten Unterschiede zwischen den Jahren nachweisbar. Bei beiden Laktationsperioden gibt es Schwankungen in der Anzahl der Abweichungen zwischen den Jahren (Abbildung 4.24). Dabei fällt auf, dass für beide Perioden im Jahr 2008 die häufigsten Abweichungen zu verzeichnen sind. Der Mittelwert von dem Jahr 2008 in dem Laktationsstadium zwei bis acht Wochen p. p. befindet sich zusätzlich oberhalb der Kontrollgrenze (Tabelle 4.14).

Tabelle 4.14: Bilirubin: Mittelwerte mit Standardabweichung (*Ausnahme: Median (Q1; Q3)) in $\mu \mathrm{mol} / \mathrm{l}$ im Jahres- und Laktationsstadienvergleich von eingesendeten Proben einer tierärztlichen Gemeinschaftspraxis im EL.

\begin{tabular}{|l|c|c|c|c|}
\hline \multicolumn{1}{|c|}{ Bilirubin } & 2006 & 2007 & 2008 & 2009 \\
\hline a.p. & $3,0 \pm 2,2$ & $2,6(1,6 ; 3,3)^{*}$ & $3,4 \pm 2,1$ & $2,8 \pm 1,3$ \\
\hline 0-1 Wo p. p. & $3,8 \pm 1,8$ & $4,8 \pm 3,7$ & $6,7 \pm 5,3$ & $9,9 \pm 7,8$ \\
\hline bis 8 Wo p. p. & $3,5 \pm 1,0$ & $3,8 \pm 2,4$ & $4,7 \pm 2,7$ & $3,8 \pm 1,7$ \\
\hline
\end{tabular}

\section{Cholesterol}

Bei Cholesterol zeigen die Werte im Jahresvergleich maximal 5,7\% Abweichungen (Tabelle 4.15). Keine Abweichungen verzeichnen die Jahre 2007 und 2011. Die Mittelwerte befinden sich auf einem Niveau und es können keine signifikanten Unterschiede der Mittelwerte zwischen den Jahren nachgewiesen werden. 
Tabelle 4.15: Cholesterol: Jahresvergleich der Probenanzahl, der Abweichungen und der Mittelwerte mit Standardabweichung von eingesendeten Proben einer tierärztlichen Gemeinschaftspraxis im EL (Ref: $\geq 1,5 \mathrm{mmol} / \mathrm{l})$

\begin{tabular}{|c|c|c|c|c|}
\hline Cholesterol & $\mathrm{n}_{\text {ges }}$ & $\mathrm{n}<$ Norm & $\begin{array}{c}\% \text { von } \mathrm{n}_{\text {ges }} \\
(<\text { Norm })\end{array}$ & $\begin{array}{c}\bar{x} \pm \mathrm{SD} \\
\text { in } \mathrm{mmol} / 1\end{array}$ \\
\hline 2006 & 20 & 1 & 5,0 & $3,46 \pm 1,71$ \\
\hline 2007 & 10 & 0 & 0,0 & $3,55 \pm 1,38$ \\
\hline 2008 & 53 & 3 & 5,7 & $2,97 \pm 1,18$ \\
\hline 2009 & 84 & 4 & 4,8 & $3,34 \pm 1,19$ \\
\hline 2010 & 92 & 2 & 2,2 & $3,01 \pm 1,19$ \\
\hline 2011 & 38 & 0 & 0,0 & $3,04 \pm 0,99$ \\
\hline
\end{tabular}

\subsubsection{Parameter des Eiweißstoffwechsels (Harnstoff)}

\section{Harnstoff}

Für Harnstoff sind die Abweichungen unterhalb der Toleranzgrenze deutlich geringer als die Abweichungen oberhalb. So treten Werte $<2,0 \mathrm{mmol} / \mathrm{l} \mathrm{zu}$ maximal 7,9 \% auf (Tabelle 4.16). Ausgenommen davon ist das Jahr 2006, welches mit 25,9\% Werte unterhalb des Normbereiches einen deutlichen Unterschied zu den anderen Jahren zeigt. Dieses Jahr ist auch das Einzige mit einer höheren Anzahl an unteren Abweichungen als oberen Abweichungen (12,1 \%). In den Jahren 2007 bis 2011 traten die meisten Abweichungen über dem Referenzbereich auf. Dabei steht 2008 mit 39,1\% an der Spitze. Die anderen Jahre weisen Werte zwischen 25,5\% und 31,0 \% auf.

Bei den Mittelwerten bestehen signifikante Unterschiede ebenfalls nur zwischen 2006 und den Jahren 2007 bis 2011.

Tabelle 4.16: Harnstoff: Jahresvergleich der Probenanzahl, der Abweichungen und der Mittelwerte mit Standardabweichung, sowie signifikante Unterschiede $(p \leq 0,05)$ der Mittelwerte von eingesendeten Proben einer tierärztlichen Gemeinschaftspraxis im EL (Ref: 2,0 - 5,0 mmol/l)

\begin{tabular}{|c|c|c|c|l|l|c|}
\hline Harnstoff & $\mathrm{n}_{\text {ges }}$ & $\mathrm{n}<$ Norm & $\begin{array}{c}\text { \% von } \mathrm{n}_{\text {ges }} \\
(<\text { Norm })\end{array}$ & $\mathrm{n}>$ Norm & $\begin{array}{c}\% \text { von } \mathrm{n}_{\text {ges }} \\
(>\text { Norm })\end{array}$ & $\begin{array}{c}\bar{x} \pm \mathrm{SD} \\
\text { in mmol/1 }\end{array}$ \\
\hline 2006 & 58 & 15 & 25,9 & 7 & 12,1 & $3,38^{\mathrm{a}} \pm 1,47$ \\
\hline 2007 & 216 & 3 & 1,4 & 55 & 25,5 & $4,31^{\mathrm{b}} \pm 1,25$ \\
\hline 2008 & 151 & 12 & 7,9 & 59 & 39,1 & $4,47^{\mathrm{b}} \pm 1,67$ \\
\hline 2009 & 143 & 6 & 4,2 & 37 & 25,9 & $4,16^{\mathrm{b}} \pm 1,31$ \\
\hline 2010 & 109 & 8 & 7,3 & 33 & 30,3 & $4,24^{\mathrm{b}} \pm 1,65$ \\
\hline 2011 & 87 & 2 & 2,3 & 27 & 31,0 & $4,42^{\mathrm{b}} \pm 1,27$ \\
\hline
\end{tabular}


Auch bei diesem Parameter wurden aufgrund der geringen Probenanzahlen die Werte von Kühen, welche mehr als acht Wochen p. p. sind, für den Jahresvergleich innerhalb der Laktationsstadien zusammengelegt. Die Abbildung 4.25 gibt die Mittelwerte der verschiedenen Laktationsstadien wieder. Dabei ist zu sehen, dass in dem Jahr 2006 in allen Laktationsstadien die geringsten Mittelwerte auftreten. Mittelwerte $>$ 5,0 mmol/l treten insgesamt dreimal auf und sind ausschließlich dem Stadium mehr als acht Wochen p. p. zugeordnet. Davon sind die Werte im Jahr 2008 mit 5,05 mmol/l und im Jahr 2011 mit 5,01 mmol/l nur knapp über dem Grenzbereich. Der deutlich erhöhte Wert von 7,35 mmol/1 im Jahr 2010 ist nur bedingt aussagekräftig, da in diesem Jahr nur drei Ergebnisse diesem Laktationsstadium zugeordnet werden können.

Signifikante Unterschiede bestehen im Laktationszeitraum a. p. zwischen dem Jahr 2006 und den Jahren 2007, 2008, 2009 und 2011. Außerdem ist das Jahr 2010 signifikant verschieden zu den Jahren 2007 und 2011. In der ersten Woche p. p. sind signifikante Unterschiede zwischen den Jahren 2006 und 2007 zu jeweils 2009 und 2011 vorhanden. Ein weiterer signifikanter Unterschied ist für die Jahre 2009 und 2010 nachweisbar. Im Stadium mehr als acht Wochen p. p. treten die signifikanten Unterschiede zwischen den Jahren 2006 und 2007 bzw. 2008 auf. Des Weiteren sind die Werte aus dem Jahr 2010 zu denen der anderen Jahre signifikant verschieden.

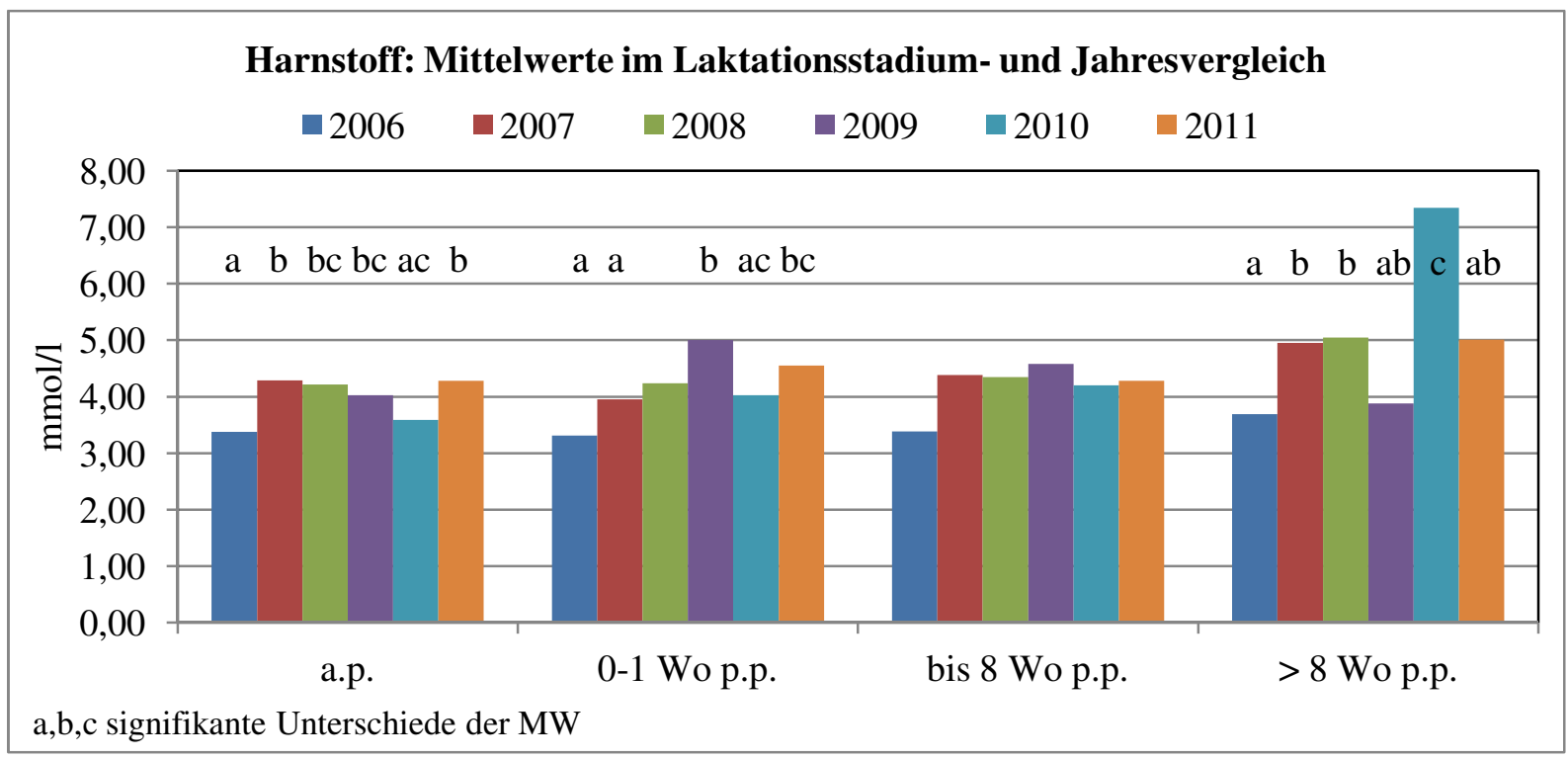

Abbildung 4.25: Harnstoff: Mittelwerte der Laktationsstadien im Jahresvergleich und signifikante Unterschiede $(p \leq 0,05)$ von Proben, eingesendet durch eine tierärztlichen Gemeinschaftspraxis im EL 


\subsubsection{Parameter des Mineralstoffwechsels $\left(\mathrm{Ca}, \mathrm{P}_{\mathrm{i}}\right)$ und des Muskelstoffwechsels $(\mathrm{CK})$}

\section{Calzium}

Für Ca liegen die meisten Ergebnisse in den Jahren 2007 bis 2009 vor (Tabelle 4.17). Mit Ausnahme des Jahres 2010 sind die Abweichungen oberhalb der Toleranzgrenze höher als unterhalb der Grenze. Die oberen Abweichungen in den Jahren 2006 bis 2009 befinden sich nahezu auf gleichem Niveau und erreichen Werte zwischen 8,3\% und 10,6\%. Allerdings ist die geringere Probenanzahl im Jahr 2006 zu beachten. Keine Abweichungen vom Normbereich traten 2011 auf. Signifikante Unterschiede der Mittelwerte können zwischen den Jahren 2010 und 2011 jeweils zu den Jahren 2006 bis 2009 nachgewiesen werden. Zwischen 2010 und 2011 besteht kein Unterschied.

Tabelle 4.17: Ca: Jahresvergleich der Probenanzahl, der Abweichungen und der Mittelwerte mit Standardabweichung, sowie signifikante Unterschiede $(\mathrm{p} \leq 0,05)$ der Mittelwerte von eingesendeten Proben einer tierärztlichen Gemeinschaftspraxis im EL (Ref: 2,00 - 2,54 mmol/l)

\begin{tabular}{|c|c|c|c|c|c|c|}
\hline $\mathrm{Ca}$ & $\mathrm{n}_{\text {ges }}$ & $\mathrm{n}<$ Norm & $\begin{array}{c}\% \text { von } \mathrm{n}_{\text {ges }} \\
(<\text { Norm })\end{array}$ & $\mathrm{n}>$ Norm & $\begin{array}{c}\% \text { von } \mathrm{n}_{\text {ges }} \\
(>\text { Norm })\end{array}$ & $\begin{array}{c}\bar{x} \pm \mathrm{SD} \\
\text { in } \mathrm{mmol} / 1\end{array}$ \\
\hline 2006 & 58 & 2 & 3,4 & 6 & 10,3 & $2,35^{\mathrm{a}} \pm 0,17$ \\
\hline 2007 & 226 & 5 & 2,2 & 21 & 9,3 & $2,37^{\mathrm{a}} \pm 0,15$ \\
\hline 2008 & 151 & 3 & 2,0 & 16 & 10,6 & $2,36^{\mathrm{a}} \pm 0,16$ \\
\hline 2009 & 132 & 2 & 1,5 & 11 & 8,3 & $2,37^{\mathrm{a}} \pm 0,16$ \\
\hline 2010 & 74 & 3 & 4,4 & 2 & 2,9 & $2,29^{\mathrm{b}} \pm 0,15$ \\
\hline 2011 & 23 & 0 & 0 & 0 & 0 & $2,27^{\mathrm{b}} \pm 0,13$ \\
\hline
\end{tabular}

Zum Vergleich der Laktationsperioden innerhalb der Jahre (Abbildung 4.26) werden bei diesem Parameter, aufgrund der geringen Abweichungen, die Mittelwerte benutzt, welche in allen Stadien überwiegend innerhalb der Kontrollgrenzen von 2,12 - 2,46 mmol/1 (FÜRLL 2013a) liegen. Eine Ausnahme bildet der Mittelwert von dem Jahr 2009 in der ersten Woche p. p. mit 2,09 mmol/1 und 2010 in dem Stadium mehr als acht Wochen p. p. mit 2,48 mmol/1. Die Mittelwerte in der ersten Woche p. p. sind, wie schon in der Gesamtauswertung, auch beim Jahresvergleich geringer, als in den anderen Laktationsphasen. Ebenso wie in der Phase mehr als acht Wochen p. p. sind hier verstärkt Schwankungen der Werte zwischen den Jahren vorhanden.

Signifikante Unterschiede zwischen den Jahren treten vor allem vor der Kalbung auf. So sind die Jahre 2006 und 2007 signifikant unterschiedlich zu 2011. Für das Jahr 2009 können signifikante Unterschiede zu den Jahren 2008, 2010 und 2011 nachgewiesen werden. In der ersten Woche p. p. unterscheiden sich nur die Jahre 2007 und 2009 signifikant und von der zweiten bis zur achten Woche p. p. unterscheiden sich die Jahre 2007 und 2009. In der Zeit mehr als acht Wochen p. p. sind die Jahre 2006 zu 2008 bzw. 2007 und 2010 zu 2009 signifikant unterschiedlich. 


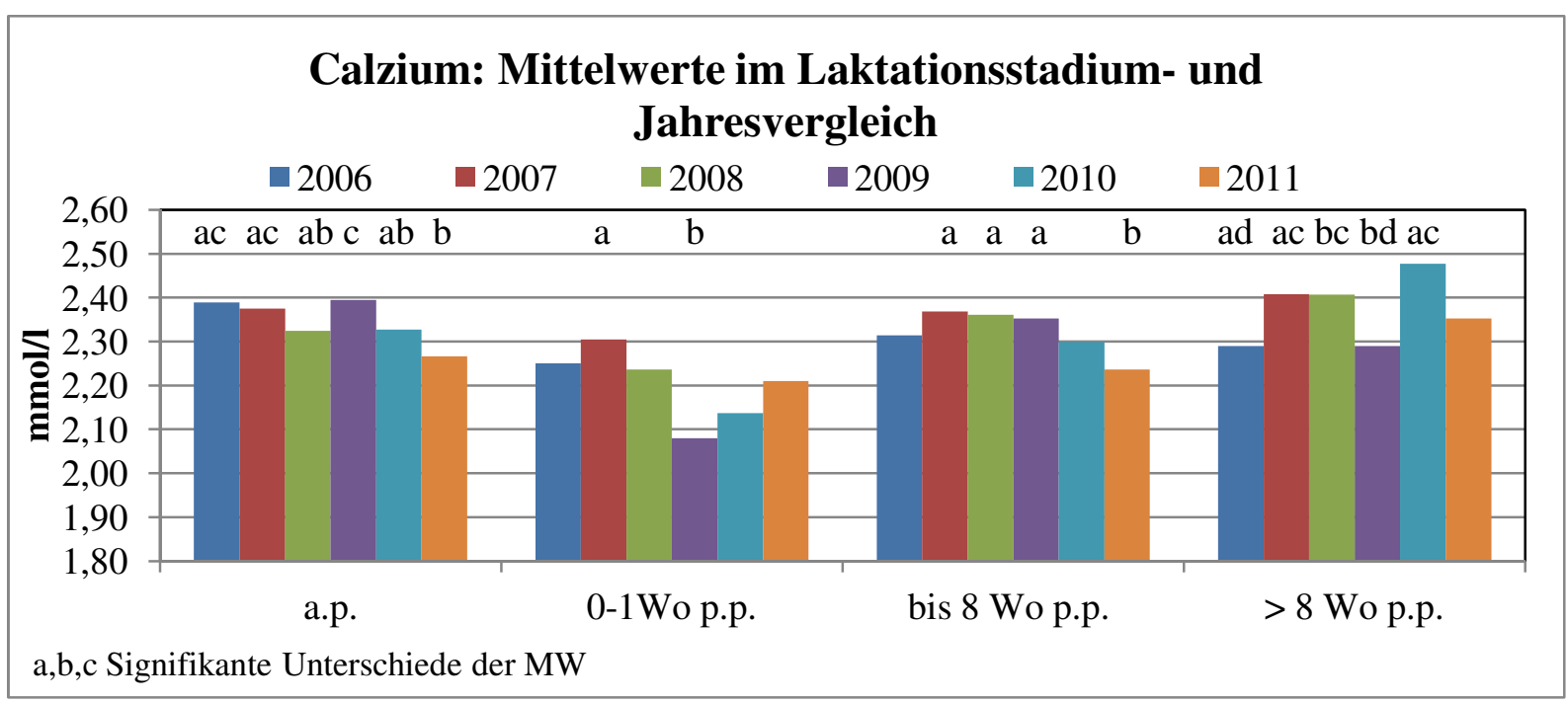

Abbildung 4.26: Ca: Mittelwerte der Laktationsstadien im Jahresvergleich und signifikante Unterschiede $(p \leq 0,05)$ von Proben, eingesendet durch eine tierärztlichen Gemeinschaftspraxis im EL

\section{Anorganisches Phosphat}

Auf das Elektrolyt $P_{\mathrm{i}}$ wurde vor allem in den Jahren 2007 bis 2009 untersucht. In der Regel sind die Abweichungen oberhalb des Toleranzbereiches größer als die unterhalb (Tabelle 4.18). Eine Ausnahme davon bildet das Jahr 2010. Dieses Jahr weist 13,5 \% Abweichungen unter der Norm und 10,8 \% Abweichungen über der Norm auf. Die geringsten Abweichungen vom physiologischen Bereich sind dem Jahr 2009 mit 4,7 \% unterhalb und 13,2 \% oberhalb zu zuordnen. Die meisten Abweichungen zeigten sich dagegen im Jahr 2006 (10,3\% < Norm; 39,7 \% > Norm). Für die verbleibenden Jahre 2007, 2008 und 2011 können Abweichungen unterhalb des Normbereiches zwischen $6,6 \%$ und $8,7 \%$ und oberhalb zwischen $17,4 \%$ und $27,2 \%$ beschrieben werden.

Tabelle 4.18: $\mathrm{P}_{\mathrm{i}}$ : Jahresvergleich der Probenanzahl und der Abweichungen von eingesendeten Proben einer tierärztlichen Gemeinschaftspraxis im EL (Ref: a. p./>1.Wo p.p: 1,55-2,29 mmol/l; 1. Wo p.p: $1,26-2,13 \mathrm{mmol} / \mathrm{l})$

\begin{tabular}{|c|c|c|c|c|c|}
\hline $\mathrm{P}_{\mathrm{i}}$ & $\mathrm{n}_{\text {ges }}$ & $\mathrm{n}<$ Norm & $\begin{array}{c}\% \text { von } \mathrm{n}_{\text {ges }} \\
(<\text { Norm })\end{array}$ & $\mathrm{n}>$ Norm & $\begin{array}{c}\% \text { von } \mathrm{n}_{\text {ges }} \\
(>\text { Norm })\end{array}$ \\
\hline 2006 & 58 & 6 & 10,3 & 23 & 39,7 \\
\hline 2007 & 226 & 18 & 8,0 & 48 & 21,2 \\
\hline 2008 & 151 & 10 & 6,6 & 41 & 27,2 \\
\hline 2009 & 106 & 5 & 4,7 & 14 & 13,2 \\
\hline 2010 & 74 & 10 & 13,5 & 8 & 10,8 \\
\hline 2011 & 23 & 2 & 8,7 & 4 & 17,4 \\
\hline
\end{tabular}


Bedeutende Abweichungen sind fast ausschließlich a. p. zu verzeichnen. Aus diesem Grund werden auch bei diesem Parameter die Mittelwerte der Jahre innerhalb der Laktationsperioden zum Vergleich herangezogen (Abbildung 4.27).

Die Mittelwerte der verschiedenen Jahre in den einzelnen Laktationsperioden befinden sich überwiegend innerhalb der Kontrollgrenzen (1,71 - 2,13 mmol/l; 1 . Woche p. p: 1,45 - 1,94 mmol/l nach FÜRLL 2013a). Die Ausnahme stellen die Mittelwerte von 2006 in der 1. Woche p. p. mit 2,09 $\mathrm{mmol} / \mathrm{l}, 2007$ a. p mit 2,14 mmol/l und 2011 sowohl a. p. mit ebenfalls $2,14 \mathrm{mmol} / \mathrm{l}$ als auch in der 1 . Woche p. p. mit 2,21 mmol/l dar.

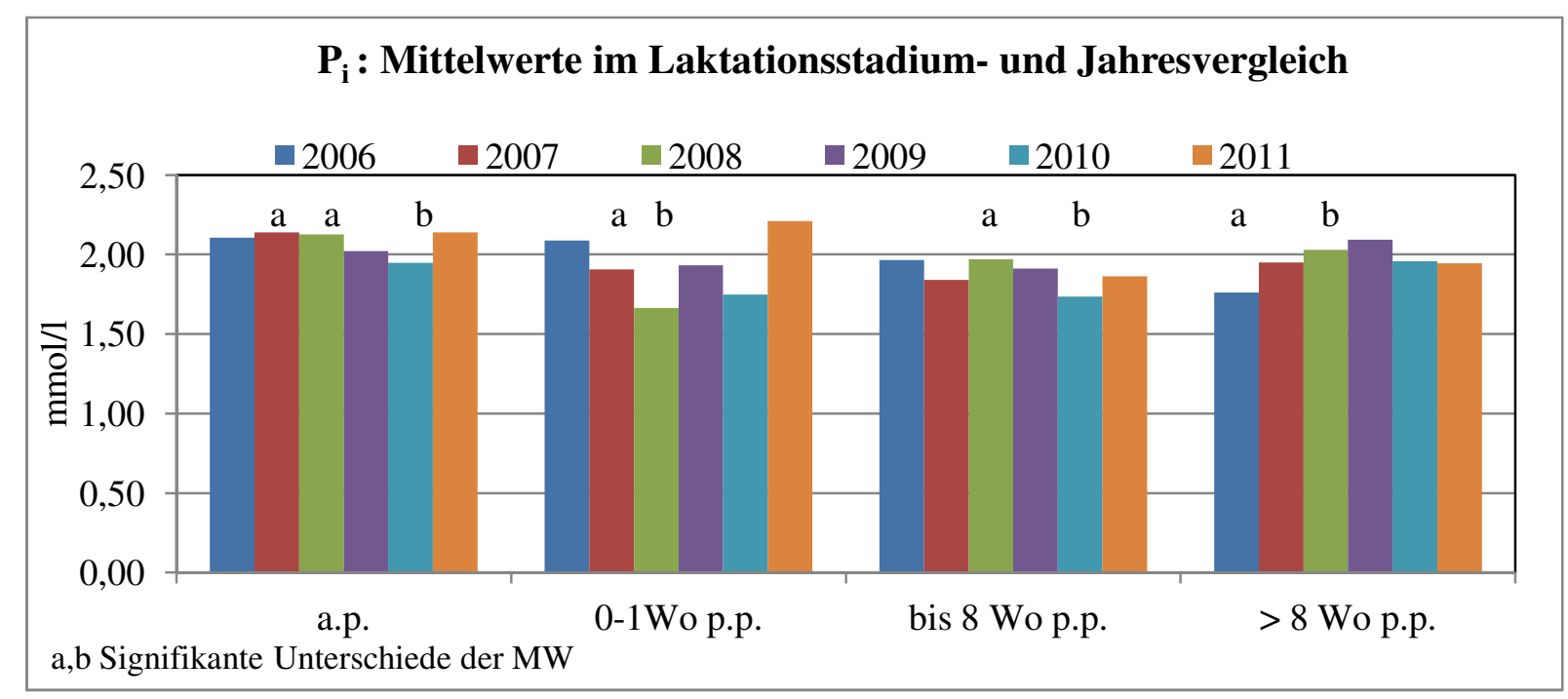

Abbildung 4.27: $\mathrm{P}_{\mathrm{i}}$ : Mittelwerte der Laktationsstadien im Jahresvergleich und signifikante Unterschiede $(p \leq 0,05)$ von Proben, eingesendet durch eine tierärztlichen Gemeinschaftspraxis im EL

Wie aus der Abbildung 4.27 hervorgeht, sind die meisten Schwankungen der Mittelwerte zwischen den Jahren in dem Zeitraum erste Woche p. p. vorhanden. Ansonsten fällt auf, dass die Mittelwerte a. p. überwiegend $>2,00 \mathrm{mmol} / \mathrm{l}$ betragen und p. p. in den meisten Fällen kleiner als 2,00 mmol/l sind.

Signifikante Unterschiede bestehen a. p. zwischen den Jahren 2006 und 2007 jeweils zu 2010, in der ersten Woche p. p. zwischen den Jahren 2007 und 2008, von der zweiten bis achten Woche p. p. zwischen den Jahren 2008 und 2010 und nach der achten Woche p. p. zwischen den Jahren 2006 und 2008.

\section{Creatinkinase}

Für die CK liegen im Verlauf der Jahre 2006 bis 2010 unterschiedliche Gesamtprobenanzahlen vor. 2011 wurden keine Proben auf diesen Parameter untersucht. Die Abweichungen über dem physiologischen Bereich der Jahre 2006 und 2008 bis 2010 schwanken zwischen 72,5 und 76,3\% (Tabelle 4.19). Deutlich weniger Abweichungen sind für das Jahr 2007 mit 63,7 \% zu verzeichnen 
Tabelle 4.19: CK: Jahresvergleich der Probenanzahl und der Abweichungen von eingesendeten Proben einer tierärztlichen Gemeinschaftspraxis im EL (Ref: a. p./>1. Wo p.p: $\leq 100 \mathrm{U} / \mathrm{l}$; 1. Wo p.p: $\leq 200 \mathrm{U} / \mathrm{l})$

\begin{tabular}{|c|c|c|c|}
\hline $\mathrm{CK}$ & $\mathrm{n}_{\text {ges }}$ & $\mathrm{n}>$ Norm & $\begin{array}{c}\text { \% von } \mathrm{n}_{\text {ges }} \\
(>\text { Norm })\end{array}$ \\
\hline 2006 & 38 & 29 & 76,3 \\
\hline 2007 & 226 & 144 & 63,7 \\
\hline 2008 & 138 & 100 & 72,5 \\
\hline 2009 & 73 & 53 & 72,6 \\
\hline 2010 & 23 & 17 & 73,9 \\
\hline
\end{tabular}

Bei der Aufteilung in die verschiedenen Laktationsstadien sind die Proben von Kühen, die mehr als acht Wochen p. p. sind, aufgrund der geringen Probenanzahlen wieder zusammen gefasst (Abbildung 4.28).

Der Verlauf mit dem geringen Absenken der Abweichungen in der ersten Woche p. p. und dem darauf anschließenden Wiederanstieg bis zum Ende der Laktation, welcher in Kapitel 4.2.2.2 beschrieben wird, ist hier in den meisten Jahren auch nachvollziehbar. Eine Ausnahme zeigt sich im Jahr 2009, in dem ein kontinuierlicher Anstieg der Abweichungen von vor der Kalbung bis zum Ende der Laktation zu erkennen ist. Die größten Unterschiede bei den Abweichungen zwischen den Jahren treten in der ersten Woche p. p. auf.

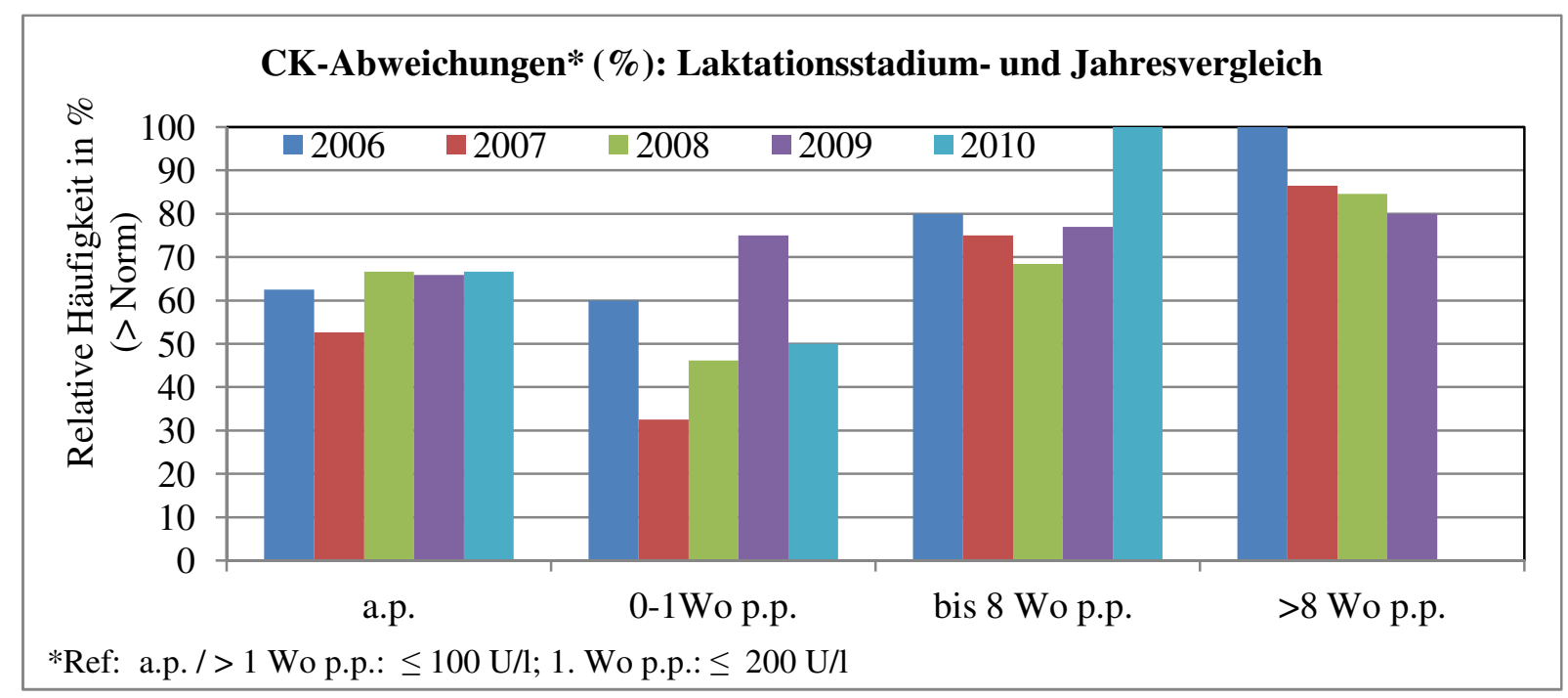

Abbildung 4.28: CK-Abweichungen der Laktationsstadien im Jahresvergleich von eingesendeten Proben einer tierärztlichen Gemeinschaftspraxis im EL

Signifikante Unterschiede zwischen den Jahren in der Verteilung der Grundgesamtheit sind jedoch in keinem Laktationsstadium nachweisbar. Bei den 100 \% Abweichungen im Jahr 2010 im Stadium zwei 
bis acht Wochen p. p. und im Jahr 2006 mehr als acht Wochen p. p. sind die geringen Probenanzahlen von zwei bzw. sechs (Anhang Tabelle 9.3) zu beachten.

Die Mediane der einzelnen Jahre innerhalb der Laktationsstadien befinden sich überwiegend oberhalb der Toleranzgrenzen (Tabelle 4.20). Innerhalb des Toleranzbereiches sind ausschließlich die Werte der Jahre 2007 mit 169,4 U/l und 2008 mit 159,6 U/l in der 1. Woche p. p.

Tabelle 4.20: CK: Mediane und Quartile (1. und 3.) in U/l im Jahres und Laktationsstadienvergleich von eingesendeten Proben einer tierärztlichen Gemeinschaftspraxis im EL.

\begin{tabular}{|c|c|c|c|c|c|c|c|c|c|c|}
\hline \multirow[b]{2}{*}{ CK } & \multicolumn{2}{|c|}{2006} & \multicolumn{2}{|c|}{2007} & \multicolumn{2}{|c|}{2008} & \multicolumn{2}{|c|}{2009} & \multicolumn{2}{|c|}{2010} \\
\hline & $\begin{array}{l}\text { Me- } \\
\text { dian }\end{array}$ & $\begin{array}{l}\text { Q1; } \\
\text { Q3 }\end{array}$ & $\begin{array}{l}\text { Me- } \\
\text { dian }\end{array}$ & $\begin{array}{l}\text { Q1; } \\
\text { Q3 }\end{array}$ & $\begin{array}{l}\text { Me- } \\
\text { dian }\end{array}$ & $\begin{array}{l}\text { Q1; } \\
\text { Q3 }\end{array}$ & $\begin{array}{l}\text { Me- } \\
\text { dian }\end{array}$ & $\begin{array}{l}\text { Q1; } \\
\text { Q3 }\end{array}$ & $\begin{array}{l}\text { Me- } \\
\text { dian }\end{array}$ & $\begin{array}{l}\text { Q1; } \\
\text { Q3 }\end{array}$ \\
\hline a.p & 123,3 & $\begin{array}{l}88,2 ; \\
161,8\end{array}$ & 102,5 & $\begin{array}{c}75,4 ; \\
166,6\end{array}$ & 116,6 & $\begin{array}{c}90,9 \\
180,6\end{array}$ & 126,5 & $\begin{array}{l}86,8 ; \\
161,0\end{array}$ & 138,0 & $\begin{array}{l}96,0 ; \\
252,8\end{array}$ \\
\hline 0-1 Wo p. p. & 202,9 & $\begin{array}{l}149,3 ; \\
320,4\end{array}$ & 169,4 & $\begin{array}{l}119,6 \\
232,7\end{array}$ & 159,6 & $\begin{array}{c}109,0 \\
407,4\end{array}$ & 228,0 & $\begin{array}{c}205,0 ; \\
295,8\end{array}$ & 237,5 & $\begin{array}{l}169,0 ; \\
293,8\end{array}$ \\
\hline bis 8 Wo p. p. & 124,9 & $\begin{array}{c}121,6 \\
156,9\end{array}$ & 130,8 & $\begin{array}{c}101,9 ; \\
176,1\end{array}$ & 119,3 & $\begin{array}{c}96,2 ; \\
158,3\end{array}$ & 132,0 & $\begin{array}{c}102,0 ; \\
138,0\end{array}$ & 273,0 & $\begin{array}{l}255,0 ; \\
291,0\end{array}$ \\
\hline$>8$ Wo p. p. & 131,8 & $\begin{array}{l}118,0 \\
145,1\end{array}$ & 127,2 & $\begin{array}{c}113,9 ; \\
167,5\end{array}$ & 134,3 & $\begin{array}{l}118,2 ; \\
201,9\end{array}$ & 126,0 & $\begin{array}{c}108,0 \\
170,0\end{array}$ & & \\
\hline
\end{tabular}

\subsubsection{Spurenelemente ( $\mathrm{Cu}, \mathrm{Se})$, B-Carotin und die Trolox äquivalente Antioxidative Kapazität (TEAC)}

\section{Cupfer}

Tabelle 4.21: $\mathrm{Cu}$ : Jahresvergleich der Probenanzahl (mit Verteilung anhand des KST), der Abweichungen und der Mittelwerte mit Standabweichung (* Ausnahme: Median mit Quartilen (1. und 3.)), sowie signifikante Unterschiede $(\mathrm{p} \leq 0,05)$ der Mittelwerte von eingesendeten Proben einer tierärztlichen Gemeinschaftspraxis im EL (Ref: 8,0 - 32,8 $\mu \mathrm{mol} / 1$; Verteilung: no = normal verteilt; nn $=$ nicht normal verteilt)

\begin{tabular}{|c|c|c|c|c|}
\hline $\mathrm{Cu}$ & $\mathrm{n}_{\text {ges }}$ (Verteilung) & $\mathrm{n}<$ Norm & $\begin{array}{c}\% \text { von } \mathrm{n}_{\text {ges }} \\
(<\text { Norm })\end{array}$ & $\begin{array}{c}\bar{x} \pm \mathrm{SD} \\
\text { in } \mu \mathrm{mol} / 1\end{array}$ \\
\hline 2006 & $38(\mathrm{no})$ & 1 & 2,6 & $12,2^{\mathrm{ac}} \pm 3,0$ \\
\hline 2007 & $225(\mathrm{no})$ & 31 & 13,8 & $11,4^{\mathrm{a}} \pm 3,2$ \\
\hline 2008 & $151(\mathrm{nn})$ & 9 & 6,0 & $11,8^{\mathrm{c}}(10,2 ; 14,3)^{*}$ \\
\hline 2009 & $143(\mathrm{no})$ & 6 & 4,2 & $15,9^{\mathrm{b}} \pm 5,7$ \\
\hline 2010 & $89(\mathrm{no})$ & 10 & 11,2 & $12,6^{\mathrm{c}} \pm 4,0$ \\
\hline 2011 & $94(\mathrm{no})$ & 22 & 23,4 & $11,2^{\mathrm{a}} \pm 4,0$ \\
\hline
\end{tabular}


Bei $\mathrm{Cu}$ sind die Abweichungen in den einzelnen Jahren sehr verschieden. So werden Werte zwischen 2,6 \% und 23,4 \% erreicht (Tabelle 4.21). In den Jahren 2006 und 2008 bis 2010 sind die absoluten Anzahlen $\leq 10$. Aus diesem Grund wird auf die Unterteilung in die verschiedenen Laktationsstadien verzichtet.

Der höchste Mittelwert lässt sich für 2009 mit 15,9 $\mu$ mol/l errechnen. Dieser Wert ist zu allen anderen Jahren signifikant verschieden. Weitere signifikante Unterschiede bestehen zwischen 2007 und 2008 bzw. 2010. Die beiden zuletzt genannten Jahre sind ebenfalls zu 2011 signifikant unterschiedlich.

\section{Selen}

Se zeigt im Jahresvergleich deutliche Unterschiede. So sind die Jahre 2006 und 2007 durch hohe Abweichungen über dem physiologischen Bereich gekennzeichnet. Die Werte betragen für diese Jahre 36,2 \% bzw. 36,7 \% (Tabelle 4.22). Abweichungen unter dem Normbereich sind für das Jahr 2006 keine und für das Jahr 2007 sehr geringe 1,8 \% beschrieben. In den Jahren 2008, 2010 und 2011 sind die Abweichungen über und unter dem Referenzbereich, als auch im Jahresvergleich relativ ähnlich. Das Jahr 2009 steht im starken Kontrast zu den anderen Jahren. Hier ist der Anteil an Abweichungen unter dem physiologischen Bereich mit einem Wert von $35 \%$ stark erhöht. Dafür sind die Abweichungen über der oberen Toleranzgrenze mit 8,4\% im Vergleich zu den anderen Jahren gering.

Tabelle 4.22: Se: Jahresvergleich der Probenanzahl (mit Verteilung anhand des KST), der Abweichungen und der Mittelwerte mit Standardabweichung (*Ausnahme: Median mit Quartilen (1. und 3.)), sowie signifikante Unterschiede $(\mathrm{p} \leq 0,05)$ der Mittelwerte von eingesendeten Proben einer tierärztlichen Gemeinschaftspraxis im EL (Ref: 0,40 - 0,88 $\mu \mathrm{mol} / \mathrm{l}$; Verteilung: no= normal verteilt; $\mathrm{nn}=$ nicht normal verteilt)

\begin{tabular}{|c|c|c|c|c|c|c|}
\hline Se & $\begin{array}{c}\mathrm{n}_{\text {ges }} \\
(\text { Verteilung) }\end{array}$ & $\mathrm{n}<$ Norm & $\begin{array}{c}\% \text { von } \mathrm{n}_{\text {ges }} \\
(<\text { Norm })\end{array}$ & $\mathrm{n}>$ Norm & $\begin{array}{c}\% \text { von } \mathrm{n}_{\text {ges }} \\
(>\text { Norm })\end{array}$ & $\begin{array}{c}\bar{x} \pm \mathrm{SD} \\
\text { in } \mu \mathrm{mol} / 1\end{array}$ \\
\hline 2006 & $58(\mathrm{nn})$ & 0 & 0,0 & 21 & 36,2 & $0,82^{\mathrm{a}}(0,69 ; 1,05)^{*}$ \\
\hline 2007 & $226(\mathrm{no})$ & 4 & 1,8 & 83 & 36,7 & $0,82^{\mathrm{a}} \pm 0,23$ \\
\hline 2008 & $151(\mathrm{no})$ & 27 & 17,9 & 30 & 19,9 & $0,64^{\mathrm{b}} \pm 0,24$ \\
\hline 2009 & $143(\mathrm{no})$ & 50 & 35,0 & 12 & 8,4 & $0,52^{\mathrm{c}} \pm 0,23$ \\
\hline 2010 & $99(\mathrm{no})$ & 19 & 19,2 & 16 & 16,2 & $0,63^{\mathrm{b}} \pm 0,27$ \\
\hline 2011 & $94(\mathrm{no})$ & 22 & 23,4 & 20 & 21,3 & $0,65^{\mathrm{b}} \pm 0,34$ \\
\hline
\end{tabular}

Die vorangegangenen Erkenntnisse spiegeln sich ebenfalls bei der Untersuchung auf signifikante Unterschiede in der Gesamtheit wider. So sind die Jahre 2006 und 2007 jeweils zu den anderen Jahren verschieden, untereinander aber nicht (Tabelle 4.22). Für das Jahr 2009 lassen sich signifikante Unterschiede zu allen anderen Jahren nachweisen. Die Jahre 2008, 2010 und 2011 unterscheiden sich untereinander nicht signifikant, aber zu den bereits genannten Jahren. 
Der Medianwert von 2006 und der Mittelwert von 2007 befindet sich oberhalb des Kontrollbereiches von $0,50-0,80 \mu \mathrm{mol} / \mathrm{l}$ (FÜRLL 2013a)

Bei diesem Spurenelement sind die Abweichungen sowohl oberhalb als auch unterhalb der Toleranzgrenzen von Bedeutung. Aus diesem Grund erfolgt auch im Jahresvergleich eine Aufteilung der Abweichungen in die verschiedenen Laktationsstadien.

Wie schon zuvor beim allgemeinen Jahresvergleich beschrieben, unterscheiden sich die Jahre ebenfalls sehr stark innerhalb der verschiedenen Laktationsstadien. Der in Kapitel 4.2.2.4 beschriebene Verlauf in den Laktationsstadien, in denen a. p. die unteren Abweichungen überwiegen und p. p. die oberen Abweichungen stark ansteigen, kann nicht für alle Jahre im Einzelnen nachgewiesen werden.

In dem Zeitraum a. p. überwiegen in den Jahren 2006 und 2007 die Abweichungen über dem Normbereich und in den folgenden Jahren die Abweichungen unterhalb dessen (Tabelle 4.23). Die Mittelwerte der ersten beiden Jahre unterscheiden sich erwartungsgemäß ebenfalls signifikant zu den folgenden Jahren. Außerdem besteht ein Unterschied zwischen den Jahren 2006 und 2007. Für die Jahre 2009 und 2011 kann ein weiterer Mittelwertunterschied nachgewiesen werden. Der Mittelwert von 2006 ist mit $0,91 \mu \mathrm{mol} / 1$ in diesem Laktationsstadium der einzige Wert oberhalb der Kontrollgrenze.

In der Laktationsperiode erste Woche p. p. sind zum Teil nur geringe Probenanzahlen in den einzelnen Jahren vorhanden. Daraus folgen zum Teil hohe Prozentwerte, obwohl die absoluten Abweichungen sehr gering sind. In den ersten drei Jahren überwiegen die oberen Abweichungen. In den Jahren 2009 und 2011 sind mehr Abweichungen unterhalb des Referenzbereiches zu verzeichnen und 2010 ist das Verhältnis gleich. Zwischen den Jahren 2007 und 2009, 2010 bzw. 2011 liegen signifikante Unterschiede der Mittelwerte vor.

In dem Stadium zwei bis acht Wochen p. p. ragen die Jahre 2009 und 2010 heraus, indem sie mehr untere Abweichungen wie obere Abweichungen aufweisen. Bei den restlichen Jahren überwiegen die Abweichungen oberhalb der Referenzgrenze. Signifikante Unterschiede können zwischen den Jahren 2006, 2007 und 2008 jeweils zu den Jahren 2009 und 2010 nachgewiesen werden. Ebenfalls signifikant unterschiedlich sind die Jahre 2007 und 2008. Zwischen den Jahren 2006 und 2007 bzw. zwischen 2009 und 2010 liegen keine Unterschiede vor. Das Jahr 2011 ist in dieser Laktationsperiode zu keinem anderen Jahr signifikant verschieden.

Die letzte Laktationsperiode zeichnet sich, trotz des Zusammenfassens, wieder durch meist sehr geringe Probenanzahlen in den Jahren aus. So können bis auf 2007 und 2008 den Jahren 10 oder weniger Proben zugeordnet werden. Wie schon in der ersten Woche p. p. überwiegen in den ersten drei Jahren die oberen Abweichungen. Dagegen sind 2010 überhaupt keine Abweichungen zu registrieren und $2011 \mathrm{im}$ gleichen Verhältnis von jeweils 14,3\%. Auch für diesen Zeitraum sind signifikante Unterschiede nachweisbar. So unterscheiden sich die Jahre 2006 und 2007 jeweils zu 
2008, 2009 und 2011. Ein weiterer Unterschied besteht zwischen den Ergebnissen aus den Jahren 2008 und 2009. Die Ergebnisse von 2010 sind zu keinem anderen Jahr signifikant verschieden.

Die Mittelwerte von 2006 und 2007 befinden sich p. p. alle oberhalb des Kontrollbereiches. Nur knapp über diesem Bereich liegt mit $0,81 \mu \mathrm{mol} / \mathrm{l}$ ebenfalls der Wert von $2011 \mathrm{im}$ Laktationsstadium zwei bis acht Wochen p. p.

Tabelle 4.23: Se: Probenanzahl, Abweichungen und Mittelwerte mit Standardabweichung der Laktationsstadien im Jahresvergleich, sowie signifikante Unterschiede $(\mathrm{p} \leq 0,05)$ der Mittelwerte von eingesendeten Proben einer tierärztlichen Gemeinschaftspraxis im EL (Ref: 0,40 - 0,88 $\mu \mathrm{mol} / \mathrm{l}$ )

\begin{tabular}{|c|c|c|c|c|c|c|c|}
\hline \multicolumn{2}{|c|}{$\mathrm{Se}$} & 2006 & 2007 & 2008 & 2009 & 2010 & 2011 \\
\hline \multirow{4}{*}{$\stackrel{\dot{0}}{\dot{\sigma}}$} & $\mathrm{n}_{\mathrm{ges}}$ & 26 & 76 & 43 & 91 & 42 & 37 \\
\hline & $\begin{array}{c}<\text { Norm } \\
\left(\% \text { von } n_{\text {ges }}\right)\end{array}$ & 0 & 1,3 & 30,2 & 34,1 & 28,6 & 21,6 \\
\hline & $\begin{array}{c}>\text { Norm } \\
\left(\% \text { von } n_{\text {ges }}\right)\end{array}$ & 38,5 & 21,1 & 4,7 & 5,5 & 7,1 & 10,8 \\
\hline & $\begin{array}{c}\bar{x} \pm \text { SD } \\
\text { sign. US }\end{array}$ & $\begin{array}{c}0,91 \pm 0,27 \\
a \\
\end{array}$ & $\begin{array}{c}0,74 \pm 0,21 \\
b\end{array}$ & $\begin{array}{c}0,5 \pm 0,19 \\
\mathrm{~cd}\end{array}$ & $\begin{array}{c}0,5 \pm 0,19 \\
c \\
\end{array}$ & $\begin{array}{c}0,55 \pm 0,24 \\
\mathrm{~cd}\end{array}$ & $\begin{array}{c}0,6 \pm 0,26 \\
d\end{array}$ \\
\hline \multirow{4}{*}{$\begin{array}{l}\dot{0} \\
\dot{2} \\
0 \\
3 \\
\dot{3} \\
\dot{0}\end{array}$} & $\mathrm{n}_{\text {ges }}$ & 6 & 40 & 14 & 8 & 11 & 24 \\
\hline & $\begin{array}{c}<\text { Norm } \\
\left(\% \text { von } n_{\text {ges }}\right)\end{array}$ & 0 & 2,5 & 14,3 & 25 & 18,2 & 29,2 \\
\hline & $\begin{array}{c}>\text { Norm } \\
\left(\% \text { von } n_{\text {ges }}\right)\end{array}$ & 33,3 & 42,5 & 28,6 & 12,5 & 18,2 & 20,8 \\
\hline & $\begin{array}{c}\bar{x} \pm \text { SD } \\
\text { sign. US }\end{array}$ & $0,87 \pm 0,29$ & $\begin{array}{c}0,82 \pm 0,21 \\
a\end{array}$ & $0,76 \pm 0,25$ & $\begin{array}{c}0,60 \pm 0,21 \\
b\end{array}$ & $\begin{array}{c}0,61 \pm 0,28 \\
b\end{array}$ & $\begin{array}{c}0,63 \pm 0,39 \\
b\end{array}$ \\
\hline \multirow{4}{*}{$\begin{array}{c}\dot{0} \\
\dot{0} \\
0 \\
\vdots \\
\infty \\
\frac{\mathfrak{n}}{0}\end{array}$} & $\mathrm{n}_{\mathrm{ges}}$ & 7 & 48 & 41 & 28 & 19 & 16 \\
\hline & $\begin{array}{c}<\text { Norm } \\
\left(\% \text { von } n_{\text {ges }}\right)\end{array}$ & 0 & 2,1 & 9,8 & 32,1 & 15,8 & 12,5 \\
\hline & $\begin{array}{c}>\text { Norm } \\
\left.\text { (\% von } n_{\text {ges }}\right)\end{array}$ & 28,6 & 50 & 29,3 & 17,9 & 10,5 & 37,5 \\
\hline & $\begin{array}{c}\bar{x} \pm \text { SD } \\
\text { sign. US } \\
\end{array}$ & $\begin{array}{c}0,87 \pm 0,27 \\
a b\end{array}$ & $\begin{array}{c}0,89 \pm 0,27 \\
a \\
\end{array}$ & $\begin{array}{c}0,75 \pm 0,27 \\
b\end{array}$ & $\begin{array}{c}0,61 \pm 0,28 \\
c \\
\end{array}$ & $\begin{array}{c}0,59 \pm 0,23 \\
c \\
\end{array}$ & $0,81 \pm 0,47$ \\
\hline \multirow{4}{*}{$\begin{array}{l}\dot{2} \\
\dot{2} \\
0 \\
\dot{3} \\
\infty \\
\wedge\end{array}$} & $\mathrm{n}_{\text {ges }}$ & 10 & 37 & 39 & 6 & 4 & 7 \\
\hline & $\begin{array}{c}<\text { Norm } \\
\left(\% \text { von } n_{\text {ges }}\right)\end{array}$ & 0 & 2,7 & 0 & 16,7 & 0 & 14,3 \\
\hline & $\begin{array}{c}>\text { Norm } \\
\left(\% \text { von } n_{\text {ges }}\right)\end{array}$ & 50 & 45,9 & 30,8 & 0 & 0 & 14,3 \\
\hline & $\begin{array}{c}\bar{x} \pm \text { SD } \\
\text { sign. US }\end{array}$ & $\begin{array}{c}0,93 \pm 0,22 \\
a\end{array}$ & $\begin{array}{c}0,88 \pm 0,22 \\
a\end{array}$ & $\begin{array}{c}0,75 \pm 0,21 \\
b\end{array}$ & $\begin{array}{c}0,53 \pm 0,19 \\
c\end{array}$ & $0,69 \pm 0,17$ & $\begin{array}{c}0,67 \pm 0,23 \\
\text { bc }\end{array}$ \\
\hline
\end{tabular}




\section{B-Carotin}

Für ß-Carotin liegen Ergebnisse ab dem Jahr 2008 vor. Wie schon in der Gesamtauswertung sind auch im Jahresvergleich die Abweichungen sehr hoch (Tabelle 4.24). So ist 2009 das einzige Jahr mit Abweichungen unter $50 \%$. Die meisten Abweichungen mit 63,8 \% liegen für 2011 vor. 2008 und 2010 sind mit 54,1\% bzw. 56,5\% Abweichungen auf ähnlichem Niveau.

Tabelle 4.24: ß-Carotin: Jahresvergleich der Probenanzahl und der Abweichungen von eingesendeten Proben einer tierärztlichen Gemeinschaftspraxis im EL (Ref: a. p./> 1.Wo p. p. $\geq 7,4 \mu \mathrm{mol} / \mathrm{l} ; 1$.Wo p. p. $\geq 4,02 \mu \mathrm{mol} / \mathrm{l})$

\begin{tabular}{|c|c|c|c|}
\hline B-Carotin & $\mathrm{n}_{\text {ges }}$ & $\mathrm{n}<$ Norm & $\begin{array}{c}\% \text { von } \mathrm{n}_{\text {ges }} \\
(<\text { Norm })\end{array}$ \\
\hline 2008 & 37 & 20 & 54,1 \\
\hline 2009 & 29 & 14 & 48,3 \\
\hline 2010 & 23 & 13 & 56,5 \\
\hline 2011 & 58 & 37 & 63,8 \\
\hline
\end{tabular}

\section{TEAC}

Zur TEAC liegen nur für die Jahre 2009 bis 2011 Ergebnisse vor. Abweichungen sind ausschließlich oberhalb des Referenzbereiches vorhanden. Wie in Tabelle $4.25 \mathrm{zu}$ sehen, betragen diese Werte zwischen 43,7 \% und $50 \%$. Die Mittelwerte von 2009 und 2010 sind sehr ähnlich. Der Wert von 2011 ist mit 308,3 $\mu \mathrm{mol} / \mathrm{l}$ etwas niedriger als die, aus den Vergleichsjahren. Signifikante Unterschiede können zwischen den Jahren nicht nachgewiesen werden.

Tabelle 4.25: TEAC: Jahresvergleich der Probenanzahl, der Abweichungen und der Mittelwerte mit Standardabweichung von eingesendeten Proben einer tierärztlichen Gemeinschaftspraxis im EL (Ref: 180 - $320 \mu \mathrm{mol} / \mathrm{l})$

\begin{tabular}{|c|c|c|c|c|}
\hline TEAC & $\mathrm{n}_{\text {ges }}$ & $\mathrm{n}>$ Norm & $\begin{array}{c}\text { \% von } \mathrm{n}_{\text {ges }} \\
(>\text { Norm })\end{array}$ & $\begin{array}{c}\bar{x} \pm \mathrm{SD} \\
\text { in } \mu \mathrm{mol} / 1\end{array}$ \\
\hline 2009 & 108 & 54 & 50,0 & $318,8 \pm 38,6$ \\
\hline 2010 & 71 & 29 & 40,8 & $317,1 \pm 43,7$ \\
\hline 2011 & 87 & 38 & 43,7 & $308,3 \pm 53,3$ \\
\hline
\end{tabular}




\subsection{Ergebnisse ausgewählter Betriebe}

Für 30 Betriebe, das bedeutet die Hälfte aller Betriebe, können zwei oder mehr Einsendungen verzeichnet werden. Die genaue Verteilung wird in Abbildung 4.29 abgebildet. Den größten Anteil davon stellen mit 56,7 \% die Betriebe dar, welche zweimal eingesendet haben.

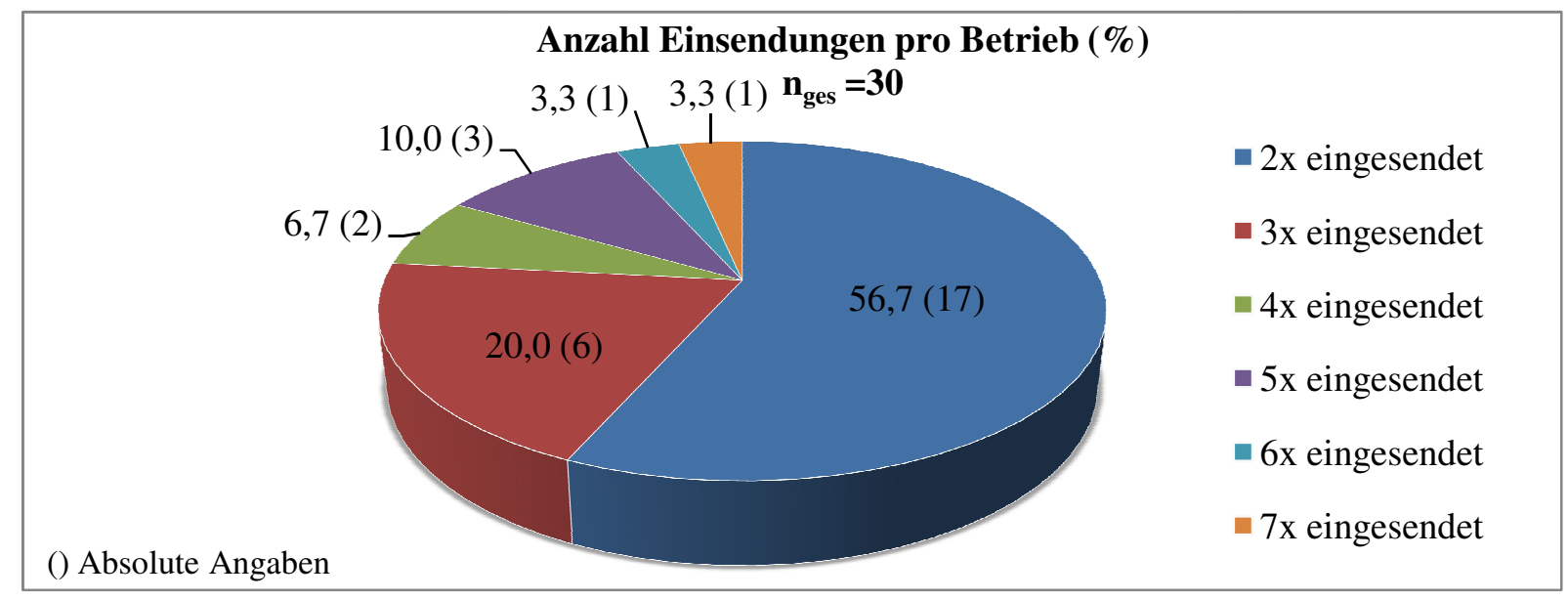

Abbildung 4.29: Relative Anzahl von Einsendungen pro Betrieb einer tierärztlichen Gemeinschaftspraxis im EL

Die Ergebnisse von 24 Betrieben werden nochmal im Einzelnen verglichen. Bei den übrigen sechs wird ein Verlauf aus verschiedenen Ursachen als nicht sinnvoll erachtet. Die Ursachen sind u. a. die Einsendung von einmal Blut und einmal Harn, die Einsendung in einem Abstand von weniger als einem Monat, zu geringe Probenanzahlen in einer Einsendung oder keine gleichen untersuchten Parameter zwischen den Einsendungen.

\subsubsection{Betriebliche Veränderungen}

Die verbliebenen 24 Betriebe werden zum Einen auf eine positive bzw. negative Veränderung der Ergebnisse im Verlauf der aufeinanderfolgenden Einsendungen untersucht und zum Anderen auf Einzeltiere, welche mehrmals untersucht wurden.

Die Überprüfung auf Veränderungen im Einsendungsverlauf erfolgt auf zwei verschiedenen Wegen. Hierbei werden ausschließlich die Blutparameter beachtet. Die Harnparameter werden in diese Auswertung nicht mit einbezogen.

Bei der ersten Herangehensweise wird die relative Häufigkeit von Einzelwerten, die innerhalb der Toleranzgrenze liegen, bezogen auf die Probenanzahl je Einsendung für jeden einzelnen untersuchten Parameter ermittelt. Die Ergebnisse werden anschließend im Verlauf der Einsendungen beurteilt. Sind diese Ergebnisse der Parameter bei $100 \%$ bzw. $90 \%$ geblieben oder haben sich im Verlauf der Einsendungen verbessert, wird der Parameter als positiv gewertet. Gleichbleibende Häufigkeit wird als neutral und somit weder als Verbesserung noch Verschlechterung angesehen. Eine Ausnahme davon 
besteht, wenn die relative Häufigkeit von physiologischen Werten $0 \%$ entspricht. In diesem Fall und wenn es zu einer Verschlechterung der Werte kommt, wird von einer negativen Veränderung ausgegangen. Bei nicht eindeutigen bzw. stark schwankenden Verläufen der Ergebnisse wird eine Grafik und der An- bzw. Abstieg der Trendlinie als Ergebnis für die Veränderung genutzt. Anschließend wird die Anzahl an Parametern, die sich verbessert haben mit den Parametern, welche sich verschlechtert haben, verglichen. Somit kann für die Betriebe eine Aussage getroffen werden, ob diese sich im Verlauf der Einsendungen in Bezug auf die untersuchten Parameter positiv oder negativ entwickelt haben.

Die Parameter, welche nur in einer Einsendung untersucht wurden, werden bei diesem Verfahren, im Gegensatz zu dem im Folgenden beschriebenen Weg, nicht mit berücksichtigt.

In Kapitel 4.2.1 wird bereits die Kennzeichnung der Parameter einer Einsendung als gesundheitsgefährdend beschrieben. Das heißt, dass mehr als $20 \%$ der Einzelwerte zu Ergebnisse führen, die sich außerhalb des Toleranzbereiches befinden (FÜRLL 2013a). Diese Ergebnisse werden für die zweite Herangehensweise zur Untersuchung auf eine Verbesserung der Betriebe herangezogen. Die Anzahl an nicht-gesundheitsgefährdenden Parametern wird ins Verhältnis zu der Gesamtanzahl an untersuchten Parametern der jeweiligen Einsendung gesetzt. Diese Häufigkeit wird anschließend im Verlauf der Einsendung bewertet. Kommt es zu einer Steigerung der relativen Häufigkeit an nicht gesundheitsgefährdenden Parametern, wird davon ausgegangen, dass sich der Betrieb in Bezug auf die Ergebnisse der Blutparameter verbessert hat. Wenn keine eindeutige Aussage über eine positive oder negative Veränderung getroffen werden kann, wird auch in diesem Fall der An- bzw. Abstieg einer Trendlinie in einer Grafik zu Hilfe genommen.

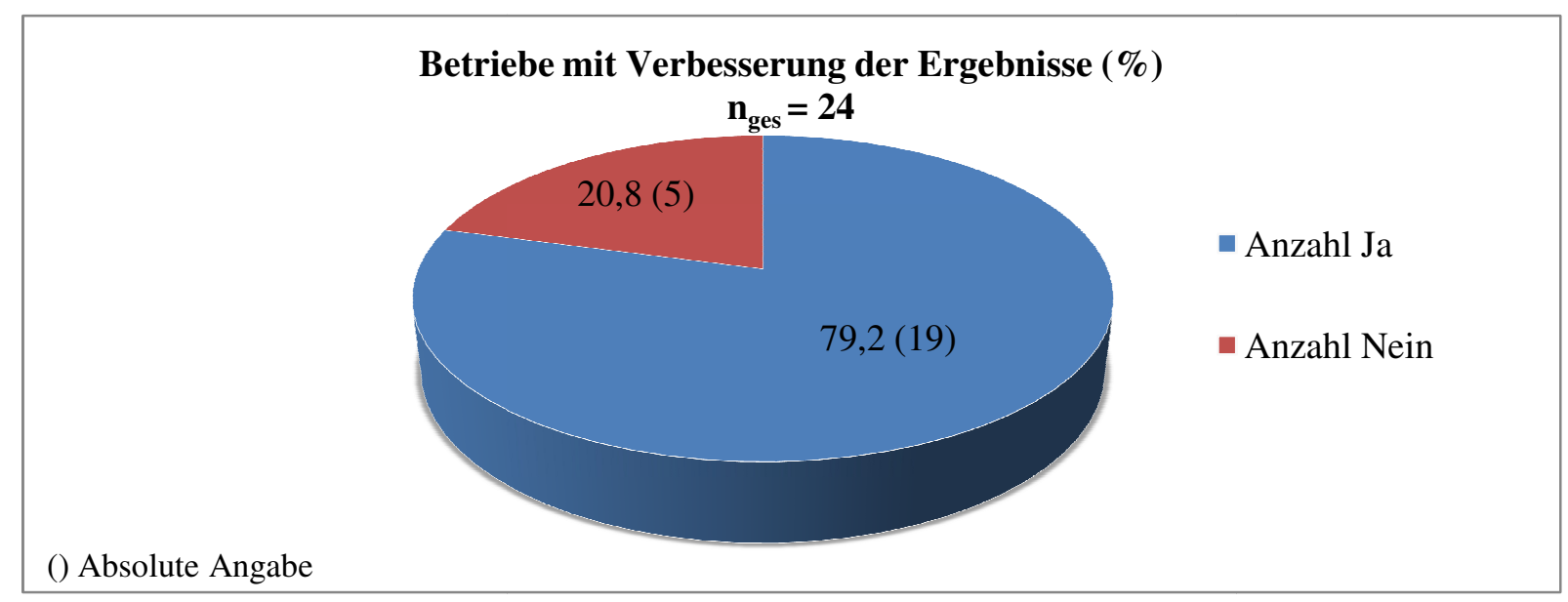

Abbildung 4.30: Anzahl Betriebe mit einer Verbesserung der Ergebnisse von einer tierärztlichen Gemeinschaftspraxis im EL 
Bei sechs Betrieben werden mithilfe dieser zwei beschriebenen Herangehensweisen unterschiedliche Endergebnisse ermittelt. Bei den anderen Betrieben gelangt man auf beiden Wegen zu den gleichen Schlussfolgerungen. Die sechs verschiedenen Ergebnisse heben sich bei der Gesamtbetrachtung gegenseitig auf, sodass die Gesamtergebnisse des einen, als auch des anderen Weges, identisch sind.

Anhand dieser Auswertung kann bei insgesamt 19 Betrieben (79,2 \% von 24) eine Verbesserung der Ergebnisse nachgewiesen werden (Abbildung 4.30). Nur 5 Betriebe (20,8 \%) weisen eine Verschlechterung der Ergebnisse im Verlauf der Einsendungen auf.

\subsubsection{Veränderungen der Parameter}

Um herauszufinden, ob bestimmte Parameter sich im Einsendungsverlauf vermehrt positiv oder negativ entwickeln, wird neben der Betrachtung des gesamten Betriebes auch die Untersuchung auf Veränderungen im Verlauf der Einsendung, auf die einzelnen Parameter bezogen, durchgeführt. Für diese Betrachtung werden ebenfalls ausschließlich die Blutparameter herangezogen, da es nur einen Betrieb gibt, der in dem Untersuchungszeitraum zweimal Harnproben eingesendet hat.

Für die betriebliche Auswertung sind die untersuchten Parameter, je nach Veränderung im Einsendungsverlauf, bereits als positiv, negativ bzw. neutral (bei keiner Veränderung) für jeden Betrieb eingestuft wurden. Die Anzahl der Betriebe mit den jeweils eingestuften Parametern zeigt Tabelle 4.26.

Tabelle 4.26: Vergleich einzelner Parameter mit positiven (P+), negativen (P -) bzw. keinen (neutrale) (P \pm ) Veränderungen im Einsendungsverlauf ausgewählter Betriebe einer tierärztlichen Gemeinschaftspraxis im EL ( $\mathrm{P} 1 \mathrm{x}=$ Betrieb hat Parameter nur bei einer Einsendung untersuchen lassen)

\begin{tabular}{|l|c|c|c|c|c|c|c|c|c|c|}
\hline $\begin{array}{c}\text { Para- } \\
\text { meter } \\
(\mathrm{P})\end{array}$ & $\begin{array}{c}\mathrm{n} \text { Betr. } \\
\mathrm{P}+\end{array}$ & $\begin{array}{c}\% \text { von } \\
\text { gesamt } \\
(\mathrm{P}+)\end{array}$ & $\begin{array}{c}\mathrm{n} \text { Betr. } \\
\mathrm{P}-\end{array}$ & $\begin{array}{c}\% \text { von } \\
\text { gesamt } \\
(\mathrm{P}-)\end{array}$ & $\begin{array}{c}\mathrm{n} \text { Betr. } \\
\mathrm{P} \pm\end{array}$ & $\begin{array}{c}\text { \% von } \\
\text { gesamt } \\
(\mathrm{P} \pm)\end{array}$ & $\begin{array}{c}\text { n Betr. } \\
\mathrm{P} 1 \mathrm{x}\end{array}$ & $\begin{array}{c}\text { \% von } \\
\text { gesamt } \\
(\mathrm{P} 1 \mathrm{x})\end{array}$ & Gesamt & $\begin{array}{c}\% \\
\text { Gesamt } \\
\text { von 24 } \\
\text { Betr. }\end{array}$ \\
\hline $\mathrm{Ca}$ & 16 & 72,7 & 3 & 13,6 & 0 & 0 & 3 & 13,6 & 22 & 91,7 \\
\hline $\mathrm{Pi}$ & 9 & 39,1 & 6 & 26,1 & 1 & 4,3 & 7 & 30,4 & 23 & 95,8 \\
\hline Hast & 18 & 75,0 & 6 & 25,0 & 0 & 0 & 0 & 0,0 & 24 & 100,0 \\
\hline $\mathrm{Chol}$ & 7 & 38,9 & 1 & 5,6 & 0 & 0 & 10 & 55,6 & 18 & 75,0 \\
\hline $\mathrm{BHB}$ & 14 & 58,3 & 7 & 29,2 & 2 & 8,3 & 1 & 4,2 & 24 & 100,0 \\
\hline FFS & 9 & 37,5 & 13 & 54,2 & 2 & 8,3 & 0 & 0,0 & 24 & 100,0 \\
\hline $\mathrm{Bili}$ & 8 & 36,4 & 7 & 31,8 & 0 & 0 & 7 & 31,8 & 22 & 91,7 \\
\hline $\mathrm{CK}$ & 6 & 28,6 & 4 & 19,0 & 0 & 0 & 11 & 52,4 & 21 & 87,5 \\
\hline $\mathrm{Cu}$ & 17 & 70,8 & 7 & 29,2 & 0 & 0 & 0 & 0,0 & 24 & 100,0 \\
\hline $\mathrm{Se}$ & 10 & 41,7 & 13 & 54,2 & 1 & 4,2 & 0 & 0,0 & 24 & 100,0 \\
\hline
\end{tabular}


Die Ergebnisse (Tabelle 4.26) belegen, dass alle ausgewählten Betriebe auf Harnstoff, FFS, Cu und Se mehrfach untersucht haben und somit für diese Parameter 24 Einsendungsverläufe zur Auswertung vorliegen. Auf BHB haben auch alle Betriebe untersuchen lassen. Bei einem Betrieb erfolgte die Untersuchung jedoch nur bei einer Einsendung, so dass für diesen Parameter 23 Verläufe vorhanden sind.

FFS und Se sind die beiden Parameter, welchen mehr Betriebe mit negativen Veränderungen als positive Veränderungen zugeordnet werden können. Das bedeutet, dass sich die Anzahl an Werten, welche außerhalb der Toleranzgrenzen liegen, im Verlauf der Einsendungen bei mehr als $50 \%$ der Betriebe erhöhen. Die anderen Parameter verzeichnen mehr Betriebe mit positiven Verläufen. Hierbei sind vor allem die Parameter Harnstoff, $\mathrm{Cu}$ und $\mathrm{Ca}$ zu nennen, die mit 18, 17 bzw. 16 Betrieben bei über $70 \%$ an positiven Verläufen liegen.

Den Parametern CK und Cholesterol können elf bzw. zehn Betriebe zugeordnet werden, welche auf diese Parameter nur in einer Einsendung untersucht haben. Darauf folgen $\mathrm{P}_{\mathrm{i}}$ und Bilirubin mit jeweils sieben Betrieben.

Die in Tabelle 4.26 nicht genannten Parameter sind von der Mehrzahl der Betriebe nur bei einer Einsendung oder insgesamt von nur wenigen Betrieben untersucht worden. Relativ häufig treten dabei noch die Parameter ß-Carotin bei 16 Betrieben, GLDH bei 15 und GGT bei 13 Betrieben auf. Für B-Carotin lassen sich zwei positive Verläufe und für GGT sowie GLDH jeweils drei positive Verläufe vermerken, wobei sich allerdings für GGT auch ein negativer Verlauf feststellen ließ. Eine genaue Verteilung der verbliebenen Parameter wird in Tabelle 9.4 (Anhang) deutlich.

\subsubsection{Mehrfach untersuchte Kühe}

29 Kühe aus 16 verschiedenen Betrieben sind mehrfach untersucht wurden. Ob diese Kühe zufällig oder bewusst zur Nachkontrolle wiederholt ausgesucht wurden, ist nicht mehr nachvollziehbar.

Für zwei Kühe liegen die Ergebnisse von vier Einsendungen und für eine Kuh von drei Einsendungen vor. Von den verbliebenen Kühen sind jeweils zwei Untersuchungsergebnisse vorhanden.

Für jede Kuh und Einsendung wird die relative Häufigkeit der Anzahl an Parametern, die sich innerhalb der Toleranzgrenzen befinden, bezogen auf die Parameteranzahl je Einsendung, ermittelt. Anschließend werden die Häufigkeiten der Einsendungen einer Kuh verglichen und bei einem Anstieg als Verbesserung bzw. bei einem Abfall als Verschlechterung bewertet.

Insgesamt kann auf diese Weise bei 15 Kühen (51,7 \%) eine Verbesserung nachgewiesen werden. Bei 13 Kühen $(44,8 \%)$ wird eine Verschlechterung und bei einer Kuh eine gleichbleibende Häufigkeit vermerkt (Tabelle 4.27). 
Tabelle 4.27: Veränderung der relativen Häufigkeit an physiologischen Parametern von bestimmten Kühen ausgewählter Betriebe einer tierärztlichen Gemeinschaftspraxis NWD

\begin{tabular}{|c|c|c|}
\hline $\begin{array}{c}\text { Veränderung der rel. Häufigkeit an } \\
\text { physiologischen Parametern }\end{array}$ & n Kühe & \% von 29 \\
\hline verbessert & 15 & 51,7 \\
\hline verschlechtert & 13 & 44,8 \\
\hline gleich & 1 & 3,4 \\
\hline Summe & 29 & \\
\hline
\end{tabular}

Im Folgenden werden für jede Kuh im Einzelnen, die untersuchten Parameter auf eine Veränderung untersucht. Für diese Auswertung werden drei Kühe ausgegrenzt, da von diesen Tieren die Ergebnisse von jeweils einmal Harn und einmal Blut vorliegen und somit ein Verlauf nicht sinnvoll ist.

Für diese 26 Kühe beträgt die Gesamtanzahl an untersuchten Parametern zwischen 9 und 18. Im Durchschnitt liegen für diese Tiere die Untersuchungsergebnisse von 12,9 Parametern vor.

Können die Werte eines Parameters in allen Einsendungen einer Kuh innerhalb der Toleranzgrenzen eingeordnet werden, so wird dieser Parameter als neutral gewertet. Sind die Werte erst innerhalb des physiologischen Bereiches und in folgenden Einsendungen außerhalb dessen, dann gilt der Parameter als negativ. Ist der Verlauf gegensätzlich, das bedeutet erst außerhalb und dann innerhalb des Referenzbereiches wird dies als positive Veränderung angesehen. Des Weiteren werden die Parameter gekennzeichnet, für welche die Ergebnisse von nur einer Einsendung vorliegen.

Tabelle 4.28: Anzahl Kühe, mit entsprechend relativer Häufigkeit an neutralen Parametern bzw. an nur einmal untersuchten Parametern, ausgewählter Betriebe einer tierärztlichen Gemeinschaftspraxis im EL

\begin{tabular}{|c|c|c|}
\hline rel. Häufigkeit & $\begin{array}{c}\text { n Kühe mit rel. Häufigkeit an } \\
\text { neutrale Parameter }\end{array}$ & $\begin{array}{c}\text { n Kühe mit rel. Häufigkeit an nur } \\
1 \times \text { untersuchten Parametern }\end{array}$ \\
\hline 0 & 1 & 4 \\
\hline $0,1-25 \%$ & 12 & 3 \\
\hline $25,1-50 \%$ & 10 & 9 \\
\hline $50,1-75 \%$ & 3 & 1 \\
\hline$>75 \%$ & & \\
\hline
\end{tabular}

Bei dieser Auswertung gibt es eine Kuh, welche weniger als $25 \%$ neutrale Parameter aufweist (Tabelle 4.28). Bei zwölf Kühen werden zwischen $25 \%$ und $50 \%$ der Parameter als neutral bewertet und für zehn Kühe liegen für 50 - $75 \%$ der Parameter Werte vor, die sich in allen Einsendungen innerhalb der Toleranzgrenzen befinden. Drei Kühe weisen mehr als $75 \%$ der Parameter mit diesen Voraussetzungen auf. 
Ein Parameter mit einer positiven Veränderung wird bei 12 Kühen gezeigt und zwei positiv veränderte Parameter liegen bei zwei Kühen vor. Bei insgesamt 12 Kühen können keine positiven Veränderungen innerhalb eines Parameters nachgewiesen werden (Tabelle 4.29).

Negative Veränderungen treten insgesamt 34-Mal auf und werden für 13 Kühe bei einem Parameter, für sechs Kühe bei zwei Parametern und für drei Kühe bei drei Parametern vermerkt.

Tabelle 4.29: Anzahl Kühe, mit jeweiligen Anzahlen an verbesserten bzw. verschlechterten Parametern, ausgewählter Betriebe einer tierärztlichen Gemeinschaftspraxis im EL

\begin{tabular}{|c|c|c|}
\hline $\mathrm{n}$ Parameter & $\begin{array}{c}\mathrm{n} \text { Kühe mit jeweiliger Anzahl an } \\
\text { verbesserten Parametern }\end{array}$ & $\begin{array}{c}\mathrm{n} \text { Kühe mit jeweiliger Anzahl an } \\
\text { verschlechterten Parametern }\end{array}$ \\
\hline 0 & 12 & 4 \\
\hline 1 & 12 & 6 \\
\hline 2 & 2 & 3 \\
\hline 3 & 0 & 13 \\
\hline
\end{tabular}

Für die einzelnen Kühe werden außerdem die Parameter gekennzeichnet, welche nur bei einer Einsendung untersucht wurden. Von insgesamt vier Kühen liegen für alle Parameter die Ergebnisse von mehreren Einsendungen vor. Wobei drei von diesen Kühen aus einem Betrieb stammen. Bei drei Kühen wurden zwischen $10 \%$ und $20 \%$ der Parameter nur einmal untersucht (Tabelle 4.28). Zu den zwei Kategorien 25 - 50\% der Parameter mit einer Einsendung bzw. 50 - $75 \%$ dieser Parameter können jeweils neun Kühe zugeordnet werden. Nur bei einer Kuh sind für mehr als $75 \%$ der Parameter die Ergebnisse von nur einer Einsendung vorhanden.

Tabelle 4.30 Anzahl Kühe mit Veränderungen ausgewählter Parameter von Betrieben einer tierärztlichen Gemeinschaftspraxis im EL $(+=$ verbessert; - =verschlechtert; $\pm=$ gleich; $1 \mathrm{x}=$ einmal untersucht $)$

\begin{tabular}{|c|c|c|c|c|c|c|c|c|c|c|c|c|c|}
\hline & $\mathrm{Ca}$ & $\mathrm{P}_{\mathrm{i}}$ & Hast & Chol & BHB & FFS & GGT & GLDH & Bili & CK & Cu & Se & TEAC \\
\hline+ & & 4 & 4 & & & 3 & & & & 3 & & & \\
\hline- & & 6 & 10 & & & 13 & & & & 5 & & & \\
\hline \pm & 18 & 8 & 9 & 5 & 26 & 10 & 2 & 2 & 12 & 2 & 22 & 23 & 7 \\
\hline $1 \mathrm{x}$ & 7 & 5 & 1 & 14 & 0 & 0 & 11 & 13 & 9 & 11 & 4 & 3 & 9 \\
\hline $\mathrm{n}_{\text {ges }}$ & 25 & 23 & 26 & 19 & 26 & 26 & 13 & 15 & 21 & 21 & 26 & 26 & 16 \\
\hline
\end{tabular}


Werden die untersuchten Parameter der einzelnen Kühe verglichen so stellt sich heraus, dass alle Kühe auf Harnstoff, FFS, BHB, Cu und Se untersucht worden sind (Tabelle 4.30). Wobei jede Kuh für BHB und FFS auch einen Verlauf vorweisen kann. Bei BHB sind die Verläufe zu $100 \%$ neutral. Sowohl die positiven, als auch die negativen Veränderungen werden ausschließlich von den vier Parametern $\mathrm{P}_{\mathrm{i}}$, Harnstoff, FFS und CK verursacht. Alle vier Parameter weisen mehr Kühe mit negativen als positiven Veränderungen auf. Dabei sind die FFS mit 13 negativen und drei positiven Verläufen besonders auffällig. Eine Mehrzahl an Kühen mit neutralen Verläufen können neben BHB für die Parameter Se (23) und $\mathrm{Cu}(22)$ gezeigt werden.

Die hier nicht aufgeführten Parameter sind bei diesen Kühen entweder gar nicht oder nur bei einer Einsendung pro Kuh untersucht worden. 


\section{Diskussion}

\subsection{Ergebnisse der Betriebsanamnese}

Das Ziel war es, einen Überblick zu den Betrieben zu erhalten. Dazu sollten die Landwirte neben Fragen zu Betriebsdaten, Fütterung und Leistungskennzahlen, Angaben zu den Hauptgründen für Abgänge in ihren Betrieben, sowie Gründe für die Einsendung und im Betrieb erfolgte Maßnahmen machen.

Für die Zwischenkalbezeit (ZKZ) wird ein Sollwert von 400 Tagen beschrieben (HOEDEMAKER et al. 2014). In der vorliegenden Untersuchung hätten damit $31 \%$ der Betriebe diesen Wert erreicht. Die meisten Betriebe weisen eine ZKZ zwischen 401 und 410 Tagen auf. Eine verlängerte Zwischenkalbezeit führt vor allem zu wirtschaftlichen Verlusten. So wird für einen Tag längere Zwischenkalbezeit ein Verlust von ein bis zwei Euro pro Tier, zum Teil sogar bis vier Euro pro Tier, beschrieben (HOEDEMAKER et al. 2014). Dabei müssen jedoch die Milchleistung und das Laktationsalter mit berücksichtigt werden.

Die zwei Hauptfutterkomponenten in den Betrieben sind Maissilage (89\% der Betriebe) und Grassilage (100\%). Zum Teil wird den Kühen jahreszeitenbedingt frisches Gras angeboten, welches entweder in Form des Weidebetriebes oder als Zusatz in der Ration erfolgt. Das Kraftfutter bekommen die Kühe hauptsächlich im Melkstand oder über eine Transponderfütterung angeboten und nur zu 35\% über die Ration. Dagegen erfolgt die Mineralfutterzuteilung vor allem über die Ration und wird zum Teil durch Lecksteine oder über das Kraftfutter ergänzt. Eine genaue Verteilung bzw. Mengenangabe der einzelnen Futterkomponenten wurde bei der Erhebung nicht mitgeteilt. Aus diesem Grund konnten auch keine Zusammenhänge zwischen einzelnen Futtermitteln und den Ergebnissen der eingesendeten Proben hergestellt werden.

An erster Stelle bei den Hauptabgangsursachen stehen Fruchtbarkeitsprobleme mit $41 \%$, gefolgt von den Klauen- und Gliedmaßenerkrankungen mit $30 \%$ und den Eutererkrankungen mit $22 \%$. Diese drei Problemkreise stehen auch in anderen Untersuchungen zu den Abgangsursachen immer an den ersten Stellen, variieren jedoch zum Teil in der Reihenfolge. Während in den Jahresberichten vom LKV WESER-EMS $(2008,2010)$ und von VIT (2013) sowie von WHITAKER et al. (2000) ebenfalls die Unfruchtbarkeit als häufigste Abgangsursache ermittelt wurde, stehen bei ANACKER (2009), WANGLER und HARMS (2009) und NAUMANN (2011) die Eutererkrankungen an erster Stelle und weisen Werte zwischen $18 \%$ bis $30 \%$ auf. Die Klauen- und Gliedmaßenerkrankungen stehen bei ANACKER (2009) wie in den eigenen Untersuchungen an zweiter Stelle. Dagegen werden sie von WHITAKER et al. (2000), WANGLER und HARMS (2009), NAUMANN (2011) und im Jahresbericht von VIT (2013) an dritter Stelle beschrieben. Die Reihenfolge ist außerdem von der Laktationszahl abhängig. So verlassen Jungkühe wegen Unfruchtbarkeit verstärkt den Bestand, 
während ältere Tiere eher wegen Klauen- und Gliedmaßen- bzw. Euterproblemen geschlachtet werden (ACKERMANN et al. 2013b).

Sowohl Fruchtbarkeitsprobleme als auch die Eutergesundheit stellen bei Tierärzten, welche eine Integrierte Bestandsbetreuung (ITB) durchführen, die mit am häufigsten vorkommenden Tätigkeitsbereiche dar. Damit wird ebenfalls die hohe Bedeutung dieser Krankheiten für Landwirte verdeutlicht. Während Tierärzte bei der ITB nur zu $60 \%$ auf Klauengesundheit beratend einwirken, ist die Betreuung in Hinsicht auf Stoffwechselerkrankungen mit über 70 prozentigem Anteil von großer Bedeutung (KRINN 2004). Deshalb war nicht zu erwarten, dass Stoffwechselkrankheiten von keinem der Betriebe als Hauptursache genannt wurde. Jedoch nannten 8,3 \% der Landwirte Stoffwechselstörungen an zweiter Stelle für Abgangsursachen. Auch bei WANGLER und HARMS (2009) beträgt die Zahl an Abgängen wegen Stoffwechselstörungen gerade $4 \%$ und in den Jahresberichten vom LKV WESER-EMS $(2008,2010)$ ebenfalls nur $3 \%$. Nun stellt sich die Frage, warum diese Zahl so gering ist. Das ist damit zu erklären, dass die genannten Hauptursachen, Fruchtbarkeitsprobleme, Klauenund Gliedmaßenerkrankungen und Eutererkrankungen, in enger Beziehung zur Energie-, Protein-, Vitamin-, Mengenelement- und Spurenelementsituation stehen und damit Stoffwechselstörungen bzw. -abweichungen diese Krankheiten meist mit verursachen (FÜRLL und FÜRLL 2008).

Bei den Gründen für die Probeneinsendung wurden beim vermehrten Auftreten eines Bestandsproblemes ebenfalls Fruchtbarkeitsprobleme am häufigsten genannt. Dies war aufgrund der häufigen Nennung bei der Hauptabgangsursache zu erwarten. Insgesamt ist jedoch mit $21,4 \%$ die Nachfrage nach dem allgemeinen Stoffwechselstatus der Herde als Einsendungsgrund genannt wurden. Das vermehrte Auftreten von Festliegern und Ketosen gehört ebenfalls in die Rubrik der Stoffwechselstörungen. Da sowohl Eutererkrankungen, als auch Durchfall mit Stoffwechselimbalancen in enger Beziehung stehen (FÜRLL und FÜRLL 2008), summieren sich somit die Gründe, welche im Zusammenhang mit dem Stoffwechsel stehen, auf 75,5\%.

Bei den Maßnahmen nach den Ergebnisauswertungen ist der große Anteil von 42,2 \% Futterumstellung nennenswert. Damit bestätigt sich, dass die Fütterung eine große Bedeutung in der Rinderhaltung hat und bei Abweichungen neben verschiedenen Erregern und Umweltfaktoren die wichtigste Ursache bei der Entstehung von Krankheiten darstellt (BUSCH et al. 2004). Außerdem zeichnet sich die Bedeutung des Mineralstoffwechsels ab. So erfolgte bei der Hälfte der befragten Landwirte mindestens eine Maßnahme, die in Verbindung mit der Mineralstoffversorgung steht. Diese fanden in Form der zusätzlichen enteralen und bzw. oder parenteralen Verabreichung von Mineralen statt, bzw. in der Anpassung des aktuellen Mineralfutters. Dies spiegelt ebenfalls die Bedeutung der Mineralversorgung für einige Erkrankungen wider. So hat die Mineralstoffversorgung Einfluss auf die Fruchtbarkeit und begünstigt u. a. Eutererkrankungen, Klauenerkrankungen, Verdauungsstörungen, LMV und das Auftreten von Gebärparese (FÜRLL und FÜRLL 2008). Außerdem ist die Änderung 
bzw. Anpassung des Mineralfutters oder zusätzliches Anbieten von Leckmassen eine einfache und schnell umzusetzende Maßnahme für den Landwirt.

\subsection{Entwicklung der Einsendungen und Probenanzahlen sowie Auswahl der Parameter}

Bei der Probenanzahl je Einsendung zeigen sich im Laufe der Jahre einige Entwicklungen in verschiedene Richtungen. So bestand die Probenanzahl bei einem Drittel aus zehn Proben je Betrieb. Bei $42 \%$ der Einsendungen betrug die Anzahl zwischen drei und sechs Proben. Im Jahresverlauf wird sichtbar, dass sich die durchschnittliche Probenanzahl je Einsendung von neun Proben auf 5,1 Proben verringert. Das erklärt auch, warum im Jahr 2007 die meisten Proben eingesendet wurden, jedoch im Jahr 2009 die häufigsten Einsendungen erfolgten und zwischen der Gesamtanzahl und der Anzahl an Einsendungen kein Zusammenhang erkennbar ist. Dieser Trend der Verringerung der Probenanzahl je Einsendung ist damit entgegengesetzt der Empfehlungen aktueller Veröffentlichungen (GELFERT und STAUFENBIEL 2007, BORCHARD und STAUFENBIEL 2012, FÜRLL 2013a, WATANABE et al. 2013), welche zehn Tiere je Untersuchungsgruppe anraten. Der Einsatz von Poolproben kann dabei als nur sehr geringer Einflussfaktor angesehen werden, da 2009 nur in einer Einsendung und 2010 in vier Einsendungen Poolproben enthalten waren. Gründe für diesen Rückgang, sowie die geringere Anzahl Tiere je Untersuchungsgruppe können zum einen die geringeren Bestandsgrößen sein, weshalb nicht zu jedem Zeitpunkt ausreichend passende Tiere zur Verfügung stehen und zum anderen können auch Kosteneinsparungsmaßnahmen dafür mit verantwortlich sein.

Eine weitere Auffälligkeit kristallisiert sich bei der Häufigkeit der Einsendungen im Jahresverlauf heraus. So wurden in den Monaten Januar bis März verstärkt Proben eingesendet, während zwischen April und Juni sehr wenige oder gar keine Proben eingeschickt wurden. Zum Ende des Jahres erhöhte sich die Einsendungsrate wieder. Dies ist mit einer erhöhten Abkalbungsrate im Frühjahr und Herbst und der hauptsächlich peripartal erfolgten Probenentnahme zu erklären.

Bei der Parameterauswahl wurden in $41 \%$ der Einsendungen neun verschiedene Parameter ausgewählt. Dabei wurde über 700-Mal FFS, BHB, Se, Hast und Cu ausgewählt sowie über 600-Mal Ca und $\mathrm{P}_{\mathrm{i}}$. Die Parameter, welche über 700-Mal untersucht wurden, sind auch alle in Kategorie A und B1 des empfohlenen Parameterspektrums von FÜRLL (2013b) enthalten. Ca und $\mathrm{P}_{\mathrm{i}}$ werden ebenfalls von verschiedenen Autoren als Parameter des Routinespektrums aufgeführt (PAYNE et al. 1970, ROWLANDS und POCOCK 1971, WUJANZ und LACHMANN 1972, ROSSOW et al. 1975, ADAMS et al. 1978, SOMMER 1985, SÖLLNER-DONATH 2013).

Von allen Einsendungen weisen $66 \%$ bei $40-70 \%$ der Parameter einen Hinweis auf eine Gesundheitsgefährdung auf. Nur $17 \%$ der Einsendungen zeigten weniger als $40 \%$ an Parametern, die auf eine Gesundheitsgefährdung hindeuten. Daraus kann abgeleitet werden, dass in vielen Betrieben die Stoffwechselsituation nicht optimal ist bzw. eine zu späte Risikoerkennung erfolgt. 


\subsection{Ergebnisse der Blutprobenanalyse}

Im Folgenden werden ausgewählte Blutparameter in Hinblick auf den Laktationsverlauf sowie den Jahresverlauf diskutiert. Für die Harnprobenparameter liegen maximal 47 Ergebnisse vor. Deshalb wurde eine weiterführende Analyse nicht durchgeführt. Harnproben wurden von der Gemeinschaftspraxis nur in einem kurzen Zeitraum von März 2009 bis Juni 2010 eingesendet. Anscheinend hatten die Ergebnisse der Harnproben einen zu geringen Informationsgehalt im Sinne vorhandener Abweichungen, um diese weiter zu untersuchen.

\subsubsection{Parameter des Energie-Fett-Leber-Stoffwechsels}

Bei den FFS traten vor allem a. p. bis acht Wochen p. p. bedeutende Abweichungen auf, wobei die meisten Abweichungen ( $\geq 150 \mu \mathrm{mol} / \mathrm{l})$ mit $57 \%$ bereits vor der Kalbung festzustellen waren. Daraus kann geschlossen werden, dass eine große Anzahl der untersuchten Kühe schon a. p. eine gesteigerte Lipolyse in Folge eines Energiemangels in Kombination mit Überkonditionierung hatten. Der Anstieg der FFS bis zum Zeitpunkt der Kalbung konnte ebenfalls von EVERTZ (2006) sowie bei Braunviehrindern in Österreich von HAGMÜLLER (2002) beobachtet werden. SÖLLNER-DONATH (2013) berichtete über das Auftreten von FFS-Konzentrationen oberhalb des Referenzbereiches a. p. vor allem bei Färsen, welches auf eine vermehrte Verfettung bzw. die noch nicht abgeschlossene Entwicklung zurückzuführen ist. Auch bei RABELO et al. (2005) zeigten Färsen im Vergleich zu den Kühen a. p. höhere FFS-Konzentrationen. Die erhöhten Konzentrationen a.p. sind prädisponierend für verschiedene Erkrankungen um und nach der Kalbung, wie Geburtsstörungen, Nachgeburtsverhalten, Ketosen, LMV und Eutererkrankungen (DYK et al. 1995). Das Erkrankungsrisiko erhöht sich auf das 1,5-Fache, wenn die FFS-Konzentrationen a. p. bzw. in den ersten 30 Tagen p. p. über 0,4 mmol/l liegen (VAN SAUN 2004). Auch HÄDRICH (2007) konnte zeigen, dass Kühe mit späteren Mastitiden und Endometritiden, sowie Tot-, Früh- und Zwillingsgeburten bereits zehn Tage a. p. Medianwerte $>0,2 \mathrm{mmol}$ aufwiesen. KÖNYVES et al. (2009) beschreiben ebenfalls ein erhöhtes Risiko für Gebärmuttererkrankungen, wenn 14 Tage a. p. Konzentrationen $>$ 0,2 mmol/l vorliegen. LEBLANC et al (2004) berichten von einer Risikoerhöhung für Nachgeburtsverhalten um $80 \%$ bei FFS-Konzentrationen $\geq 0,5 \mathrm{mmol} / \mathrm{l}$ in den letzten Wochen vor der Kalbung, während QUIROZROCHA et al. (2009) eine Risikoerhöhung um fünf Prozent für jede 0,1 mmol/l Erhöhung der FFSKonzentration beschreiben. Des Weiteren ist die Wahrscheinlichkeit, dass Kühe eine LMV bekommen, um 3,6-Mal höher, wenn die Konzentration in den letzten Tagen a. p. über 0,5 mmol/1 steigt (LEBLANC et al. 2005). Außerdem produzieren Kühe in den ersten vier Monaten p. p. deutlich weniger Milch (LEBLANC 2010) und das Risiko für das Verlassen des Bestandes innerhalb der ersten 60 Tage p. p. ist erhöht (LEBLANC 2010, ROBERTS et al. 2012), wenn a. p. Konzentrationen > 0,4 $\mathrm{mmol} / \mathrm{l}$ vorliegen. 
In der ersten Woche p. p. ist mit Abstand der höchste FFS-Medianwert von $438 \mu \mathrm{mol} / \mathrm{l}$ ermittelt worden. Dieser befindet sich jedoch innerhalb der Kontrollgrenzen von 40 bis $620 \mu \mathrm{mol} / \mathrm{l}$ (WILKEN 2003, FÜRLL 2013a), welche physiologischer weise in der ersten Woche nach der Kalbung höher angesetzt werden als im weiteren Verlauf der Laktation sowie vor der Kalbung. Diese stark erhöhten Konzentrationen kurz nach der Kalbung konnten ebenfalls von KIRCHNER et al. (1977), BRYDL et al. (2003b, 2006), EVERTZ (2006), GLINDEMANN (2006), HÄDRICH (2007), HOOPS (2007), STEINKE (2009), ACKERMANN et al. (2013b), SÖLLNER-DONATH (2013) und ILLEK (2014) gezeigt werden. Der massive Anstieg der FFS zur Kalbung ist auf den erhöhten Energiebedarf während und nach der Kalbung zurückzuführen und die damit verbundene Mobilisierung von Körperfett (DRACKLEY 2005). Bei in der Trockensteherphase überkonditionierten Kühen ist die postpartale Fettmobilisation bedeutend höher (RUKKWAMSUK et al. 2000). Zusätzlich trägt der Stress durch die Kalbung (GRUMMER 1995) sowie die geringere Futteraufnahme zu einer Erhöhung der FFS-Konzentrationen bei. Der Autor beschreibt außerdem, dass die Konzentrationen nach der Kalbung wieder stark absinken, aber auf einem höheren Niveau als vor der Kalbung verbleiben. Aus der vorliegenden Untersuchung geht jedoch hervor, dass die Anzahl an Tieren, welche in der ersten Woche p. p. Konzentrationen $>620 \mu \mathrm{mol} / \mathrm{l}$ aufweisen, bei 35,8 \% und an Tieren, welche in der zweiten bis achten Woche p. p. Konzentrationen $\geq 340 \mu \mathrm{mol} / \mathrm{l}$ aufweisen, bei $38 \%$ liegt. Damit zeigten ein Drittel der untersuchten Kühe eine gesteigerte Fettmobilisation, welche das Risiko in Bezug auf LMV (HÄDRICH 2007, OSPINA et al. 2010, SÖLLNER-DONATH 2013) sowie klinische Ketosen (OSPINA et al. 2010, SEIFI et al. 2011) und frühzeitigen Abgang vor dem 60. Tag p. p. (SEIFI et al. 2011, ROBERTS et al. 2012) erhöhen. Außerdem steigt mit höheren FFSKonzentrationen das Risiko einer verzögerten Uterusrückbildung (SCHMAUßER 2006), sowie einer schlechteren Fruchtbarkeit (FÜRLL 2013a). Eine Erhöhung der FFS zeigt außerdem eine Verringerung der Insulinsensitivität (HAYIRLI 2006), was ebenfalls eine negative Auswirkung auf die Fruchtbarkeit hat (GOERIGK et al. 2011).

Beim Jahresvergleich waren von 2008 bis 2010 die meisten Abweichungen zu beobachten. Außerdem ist ein kontinuierlicher Anstieg an Abweichungen bis 2010 von $22 \%$ auf $47 \%$ zu erkennen, während sich im Jahr 2011 ein leicht rückläufiger Trend beobachten lässt. Innerhalb der einzelnen Laktationsstadien sind a. p. ebenfalls 2008 bis 2010 durch Abweichungen $\geq 59 \mu \mathrm{mol} / \mathrm{l}$ auffällig. In der ersten Woche p. p. weisen die Jahre 2008 bis 2011 Abweichungen zwischen $40 \%$ und $60 \%$ auf und sind damit deutlich niedriger als a. p. Auffällig ist, dass in den Jahren 2006 und 2007 weniger als $20 \%$ Abweichungen vorlagen. Signifikante Unterschiede können in der ersten Woche jedoch nur zwischen den Jahren 2008, 2009 und 2011 zu 2007 nachgewiesen werden. Die meisten Abweichungen in der zweiten bis achten Woche p. p. traten wiederum 2008 sowie 2010 und 2011 auf. Somit ist bei dem Parameter FFS 2008 in allen drei Laktationsstadien auffällig. 
Die BHB-Konzentrationen zeigen ab der Kalbung die gesamte Laktation hindurch eine hohe Anzahl an Abweichungen mit Konzentrationen größer als 0,62 mmol/l. So sind in der ersten Woche p. p. $75 \%$ der Konzentrationen erhöht und sinken dann zum Ende der Laktation leicht ab auf 69 \%. Der höchste Medianwert mit 0,86 mmol/l wird ebenfalls in der ersten Woche p.p. erreicht. Diese Erhöhung kurz nach der Kalbung wurde auch von KIRCHNER et al. (1977), BRYDL et al. (2003b, 2006), REIST et al. (2003), EVERTZ (2006), GLINDEMANN (2006), ZAHN (2006), SÖLLNER-DONATH (2013) und ILLEK (2014) beschrieben. Der Anstieg des BHB nach der Kalbung deutet auf ein Energiedefizit hin (SÖLLNER-DONATH 2013). Bei Kühen mit höherer Körperkondition, sowohl während des Trockenstellens als auch zur Kalbung, ist der Anstieg der Ketonkörper im Blut zum Zeitpunkt der Kalbung stärker (DAETZ 2009). Während die BHB-Konzentrationen bei EVERTZ (2006) bis zum 14. Tag und bei ZAHN (2006) bzw. HAGMÜLLER (2002) bis vier Wochen p.p. wieder absinken, verbleiben die BHB-Konzentrationen in der vorliegenden Untersuchung während der gesamten Laktation auf einem erhöhten Niveau und die Medianwerte befinden sich in allen Laktationsstadien über der Toleranzgrenze von 0,62 mmol/l (FÜRLL 2013a). WILKEN (2003) konnte jedoch an gesunden Kühen zeigen, dass dieser Referenzbereich im Allgemeinen nicht überschritten wurde und eine Referenzwertanpassung nicht notwendig ist. Eine länger bestehende Erhöhung der Konzentrationen p. p. konnte auch von SÖLLNER-DONATH (2013) im Gegensatz zu den Färsen bei den Kühen in der zweiten Laktation beobachtet werden. Als Begründung dafür werden die Steigerung der Milchleistung und der damit verbundene erhöhte Energiebedarf genannt. Auch BIJMHOLT et al. (2012) konnten insgesamt eine höhere Inzidenz von Ketosen bei pluriparen Fleckviehkühen als bei primiparen Kühen feststellen. HAGHIGHAT-JAROMI und NAHID (2011) konnten einen Peak von Hyperketonämien bei Kühen verzeichnen, die vier Wochen p. p. waren. In den eigenen untersuchten Betrieben kann davon ausgegangen werden, dass während der gesamten Laktation subklinische Ketosen von großer Bedeutung waren. Man unterscheidet klinische und subklinische Ketosen. Kühe mit klinischer Ketose weisen meist Konzentrationen größer al $3 \mathrm{mmol} / \mathrm{l}$ auf und zeigen Symptome wie Inappetenz und Apathie (OETZEL 2007). Von einer subklinischen Ketose spricht man, wenn keine klinischen Symptome sichtbar sind und BHB-Konzentrationen größer als 1,2 mmol/l (SAKHA et al. 2007, VOYVODA und ERDOGAN 2010, GARRO et al. 2013, Schulz et al 2014) bzw. zwischen 1,2 bis $2,9 \mathrm{mmol} / \mathrm{l}$ (MCART et al. 2012) vorliegen. Bei einem Anstieg der BHB-Konzentrationen über 1,2 $\mathrm{mmol} / \mathrm{l}$ in der ersten Woche p. p. erhöht sich das Risiko einer LMV auf das 2,6-Fache (DUFFIELD et al. 2009) bzw. 3,4-Fache (LEBLANC et al. 2005). Außerdem steigt das Risiko für das Auftreten von Klinischen Ketosen auf das vier- bis sechsfache an, wenn in den ersten zwei Wochen Konzentrationen $\geq 1,4 \mathrm{mmol} / \mathrm{l}$ erreicht werden (DUFFIELD et al. 2009) bzw. auf das 4,7-fache, wenn die Konzentrationen in der ersten Woche p. p. $\geq 1,2 \mathrm{mmol} / \mathrm{l}$ sind (SEIFI et al 2011). HOOPS (2007) konnte nachweisen, dass Kühe mit späteren Klauenerkrankungen 28 Tage p. p. ebenfalls signifikant höhere BHB-Konzentrationen aufwiesen und HÄDRICH (2007) berichtet von einem Anstieg in diesem Zeitraum bei Kühen mit Ovarialzysten. Des Weiteren haben Kühe mit Konzentration 
$\geq 0,68 \mathrm{mmol} / \mathrm{l}$ am ersten Tag p. p. ein erhöhtes Risiko für Gebärmutterentzündungen (EULER 2009). Zusätzlich erhöht sich durch subklinische Ketosen infolge einer herabgesetzten Abwehrfunktion das Risiko für einen verzögerten Ovulationsbeginn, schwerere Mastitiden (LEBLANC 2010) sowie geringere Milchproduktion (LEBLANC 2010, HOSTENS et al. 2012, MCART et al. 2012, ILLEK 2014) und frühzeitiges Verlassen des Bestandes (MCART et al 2012). Außerdem kommt es mit steigendem Energiedefizit in der Milch zu einem Anstieg der Somatischen Zellen, Makrophagen und Lymphozyten sowie zu einem Absinken der polymorphkernigen Granulozyten (MARTIN et al. 2012). Das Risiko für Sekundärerkrankungen ist umso größer, je früher p. p. eine subklinische Ketose auftritt (MCART et al. 2012).

Während HÄDRICH (2007) eine starke Korrelation zwischen BHB und den FFS nachweisen konnte, ist in dieser Untersuchung kein gesicherter Zusammenhang herstellbar.

Im Jahresvergleich sind vor allem die Medianwerte von $2007 \mathrm{mit}$ 0,70 mmol/l und $2011 \mathrm{mit}$ 0,75 $\mathrm{mmol} / \mathrm{l}$ auffällig. Bei der Aufteilung in die verschiedenen Laktationsstadien sind in der ersten Woche p. p. und in dem Stadium > 8 Wochen p. p. neben dem Jahr 2011 insbesondere das Jahr 2010 mit Abweichungen über $80 \%$ zu nennen. Gesicherte Unterschiede zwischen den Jahren konnten jedoch außer a. p. ausschließlich in der ersten Woche p. p. zwischen 2006 und 2008 zu 2011 nachgewiesen werden. Im weiteren Laktationsverlauf sind keine signifikanten Unterschiede zwischen den Jahren nachweisbar. Ein allgemeiner Trend im Jahresverlauf ist bei diesem Parameter nicht zu erkennen. Bei HEROLD (1989) zeigte sich zwischen den Jahren 1983 bis 1987 ein ansteigender Trend der Anzahl an Konzentrationen > 0,5 mmol/l, wobei 1984 die wenigsten Abweichungen mit $25 \%$ und 1986 die meisten Abweichungen mit $72 \%$ zu verzeichnen waren. Dem entgegengesetzt wurde in den Untersuchungen von LOBER (2005) in dem Zeitraum 1998 bis 2002 ein Absinken der Ketoseprävalenz von 26,4 \% auf 17,6 \% festgestellt. FÜRLL (1989) konnte außerdem in den Monaten Februar und September ein erhöhtes Auftreten von Konzentrationsabweichungen und damit eine Jahreszeitenabhängigkeit feststellen.

Für Bilirubin zeigten sich in der ersten Woche p. p. die meisten Abweichungen ( $>5,3 \mu \mathrm{mol} / \mathrm{l})$ von $33,8 \%$, sowie der höchste Medianwert mit 4,3 $\mu \mathrm{mol} / \mathrm{l}$. Insgesamt ist der Anteil an Konzentrationen größer als 5,3 $\mu \mathrm{mol} / 1$ mit $13 \%$ sehr gering. WILKEN (2003) überprüfte den Referenzbereich von $<5 \mu \mathrm{mol} / \mathrm{l}$ bei gesunden Kühen und konnte diesen als ausreichend bestätigen. Von einem Anstieg der Konzentrationen in der ersten Woche p.p. berichten ebenfalls BAUMGÄRTNER (1979), HÄDRICH (2007), HECKEL (2009), STEINKE (2009) und SÖLLNER-DONATH (2013). Bei Kühen der 1. Laktation ist dieser Anstieg höher als bei Kühen in den folgenden Laktationen (ACKERMANN et al. 2013b). EVERTZ (2006) beschreibt den Anstieg von Bilirubin direkt zur Kalbung und bereits am dritten Tag p. p. das Wiederabsinken der Konzentrationen. Da in der vorliegenden Untersuchung die Kalbung bis sieben Tage p. p. zu einem Zeitraum zusammengefasst wurde, konnten die ersten drei Tage p. p. nicht gesondert überprüft werden. ZAHN (2006) berichtet in der ersten bis zweiten Woche 
p .p. von einem Anstieg des Bilirubins. Erhöhte Bilirubinkonzentrationen weisen wegen der Transportkonkurrenz mit den FFS auf einen Energiemangel im Futter oder eine zu geringe Futteraufnahme bzw. auf Leberbelastungen hin (FÜRLL 2013a). Bei einer höheren Körperkondition zum Trockenstellen sowie zur Kalbung ist der Anstieg der Bilirubinkonzentrationen zur Kalbung größer (DAETZ 2009). GLINDEMANN (2006) konnte außerdem nachweisen, dass sich bei einer Erhöhung der Bilirubinkonzentrationen das Differentialzellbild in der Milch verändert und somit dieser Parameter in enger Beziehung zur Eutergesundheit steht. Außerdem haben Kühe, welche vier Tage p. p Bilirubinkonzentrationen $\geq 7,05 \mu \mathrm{mol} / \mathrm{l}$ aufweisen, ein erhöhtes Risiko für Gebärmutterentzündungen (EULER 2009). Zusätzlich zeigten Kühe mit erhöhten Bilirubinkonzentrationen innerhalb des Zeitraumes zwei Wochen a. p. bis sechs Wochen p.p. eine Verzögerung des Zyklusbeginn (SCHMAUßER 2006). Die Korrelation zwischen Bilirubin und den FFS, welche bereits von HÄDRICH (2007) nachgewiesen wurde, konnte in dieser Untersuchung bestätigt werden. Dieser Zusammenhang ist auf einen Inanitionsikterus zurückzuführen (FÜRLL und SCHÄFER 1992).

Im Jahresvergleich weisen 2006 mit 3,0 $\mu \mathrm{mol} / 1$ und 2008 mit 3,2 $\mu \mathrm{mol} / \mathrm{l}$ die höchsten Medianwerte auf. Diese sind jedoch innerhalb des Referenzbereiches. Ein signifikanter Unterschied kann aber nur für das Jahr $2008 \mathrm{zu}$ den anderen Jahren nachgewiesen werden. Ein deutlicher Trend im Jahresverlauf ist in dieser Untersuchung, wie auch bei HEROLD (1989), nicht zu beobachten. In der ersten Woche p. p. ist ein stetiger Anstieg der Abweichungen zu sehen und vor allem 2008 und 2009 zeigen Abweichungen über $40 \%$. FÜRLL (1989) konnte außerdem eine jahreszeitliche Abhängigkeit, mit einer erhöhten Anzahl an Abweichungen im Mai feststellen.

Die Cholesterol-Konzentrationen sind relativ unauffällig mit nur 3,4\% Abweichungen $(<1,5 \mathrm{mmol} / \mathrm{l})$. Im Laktationsverlauf verhalten sich die Mediane im Verlauf ähnlich wie bei KAPPEL et al. (1984), KIDA (2002b) SEIFI et al. (2003), STAUFENBIEL et al. (2004), ZAHN (2006) und QUIROZROCHA et al. (2009). So ist a.p. ein niedriger Wert von 2,71 mmol/l, welcher in der ersten Woche p. p. auf 2,16 mmol/l weiter absinkt und dann ab der zweiten Woche p. p. verstärkt ansteigt und im Laufe der Laktation über 3,7 mmol/l verbleibt. Die Konzentrationen sind jedoch alle oberhalb der unteren Kontrollgrenze. Niedrige Konzentrationen deuten auf einen Energiemangel durch eine schlechte Energieversorgung bzw. Futteraufnahme hin (STAUFENBIEL et al. 2004). Außerdem konnte bei Kühen mit niedrigen Cholesterolkonzentrationen eine verkürzte Nutzungsdauer nachgewiesen werden (ACKERMANN et al. 2013a). Bei Kühen der ersten Laktation sind die Konzentrationen im Allgemeinen niedriger (ACKERMANN et al. 2013b).

Im Jahresverlauf verzeichnet 2008 den niedrigsten Mittelwert von 2,97 mmol/l. Es sind keine signifikanten Unterschiede nachweisbar, jedoch ist ein leicht abfallender Trend der Mittelwerte zu beobachten. 
Für die AST wäre eine Aufteilung in die Laktationsphasen interessant gewesen, da dieser Parameter $43 \%$ Abweichungen aufweist. Jedoch wurde dieser Parameter zu wenig untersucht, um aussagefähige Einschätzungen im Laktationsverlauf zu erhalten. Nach BOSTEDT (1974) kommt es kurz vor und nach einer normalen Kalbung zu einer Aktivitätssteigerung. Die AST wird vor allem in der Herz- und Skelettmuskulatur sowie in der Leber nachgewiesen (KRAFT und DÜRR 2005). Somit deuten erhöhte Aktivitäten auf Muskel- bzw. Leberschäden hin. Da eine Aktivitätssteigerung keine eindeutige Interpretation zulässt, sollte die Bestimmung der AST-Aktivität immer in Kombination mit der CKAktivität erfolgen (FÜRLL 2013a). Bei LMV (SATTLER und FÜRLL 2004, HÄDRICH 2007) und bei Endometritiden (SATTLER und FÜRLL 2004) sowie bei Tieren mit Schwergeburten, Gebärparese und Klauenerkrankungen (HÄDRICH 2007) können ebenfalls erhöhte Aktivitäten nachgewiesen werden. SAFFAF (2014) konnte zeigen, dass es bei entzündlichen Prozessen zu einer Leberverfettung kommt, was mit einem Anstieg der AST-Aktivität verbunden ist.

Im Gegensatz zur AST wurden die Parameter GGT und GLDH jeweils über 150-Mal untersucht. Doch diese zwei Parameter mit Abweichungen von 2,6 \% bzw. 8,8\% sowie die Gallensäuren, auf welche nur 17 Proben getestet wurden, sind ohne besondere Befunde. Da sowohl die GGT als auch die GLDH als leberspezifisch gelten (KRAFT und DÜRR 2005) und nur sehr geringe Abweichungen zu sehen waren, kann davon ausgegangen werden, dass in dieser Untersuchung keine bedeutenden Leberveränderungen vorlagen. Gleiche Befunde konnten auch von EVERTS (2006), HÄDRICH (2007) und SAFFAF (2014) gezeigt werden. Die Gallensäuren haben anscheinend einen zu geringen Informationsgehalt, weshalb diese einen unbedeutenden Stellenwert bei der Parameterauswahl hatten.

\subsubsection{Parameter des Eiweißstoffwechsels}

Bei der Auswertung der Harnstoff-Konzentrationen sind die meisten Abweichungen unter dem Normbereich von 2,0 - 5,0 mmol/l mit 8,8\% a. p. zu verzeichnen. Für diese niedrigen Konzentrationen kann die Trockensteherration in Verbindung mit einem nicht bedarfsgerechten Proteingehalt eine Ursache darstellen. Auch die Trockensteherration sollte einen ausgewogenen und bedarfsgerechten Anteil an Protein aufweisen, welches Einfluss auf die Energieversorgung sowie die Milchproteinsynthese nach der Kalbung hat und sich positiv auf das Immunsystem auswirkt (DRACKLEY 2005). Von größerem Ausmaße sind jedoch in dieser Untersuchung die Abweichungen über dem Normbereich. Dabei sind die Abweichungen von 22,2\% in der erste Woche p. p. nur geringgradig niedriger als a. p. $(24,1 \%)$. Im Verlauf der Laktation steigen die Abweichungen kontinuierlich auf bis zu 51,1\% an und verbleiben auf über 42,3\% bis zum Ende der Laktation. Bei den Mittelwerten ist a. p. der niedrigste Wert mit 4,02 mmol/l zu sehen. Einige Autoren berichten von einem Abfall der Harnstoffkonzentrationen um die Kalbung. So beschreiben ROWLANDS et al. (1975) niedrigere Konzentrationen in den ersten Monaten nach der Kalbung. Während EVERTZ (2006) und ILLEK (2014) einen Abfall der Konzentrationen direkt zur Kalbung und einen Wiederanstieg bis zum dritten Tag p.p. beobachten, beschränkt HÄDRICH (2007) die geringeren Konzentrationen auf den ersten Monat p. p. Diese 
Verläufe können durch die vorliegenden Ergebnisse nicht bestätigt werden. In diesem Fall verhalten sich die Mittelwerte entsprechend den Abweichungen und werden im Laktationsverlauf immer größer, überschreiten jedoch nicht den Referenzbereich, welcher von WILKEN (2003) an gesunden Kühen bestätigt werden konnte. Somit kann vor allem in der Mittel- und der Spätlaktation von einem Harnstoffüberschuss ausgegangen werden. Harnstoffüberschuss kann durch Energiemangel in der Ration, Kreislaufstörungen oder Nierenkrankheiten entstehen (FÜRLL 2013a). Des Weiteren treten erhöhte Harnstoffwerte bei Rohproteinüberversorgung auf, welche zwar einen milchleistungssteigernden Effekt hat, aber auch negative Auswirkung auf die Pansenfermentation sowie die Fruchtbarkeit haben kann (STAUFENBIEL et al. 2004). So konnte BERNHARD (1992) zeigen, dass es bei Harnstoffkonzentrationen $>5,0 \mathrm{mmol} / \mathrm{l}$ zu einem sprunghaften Anstieg von Fruchtbarkeitsstörungen kommt. Bei Untersuchungen in Ungarn wird ebenfalls ab der Kalbung bis 100 Tage p. p. von $40 \%$ bis $70 \%$ Proteinüberversorgungen berichtet, während in der Trockenstehperiode Proteinüberschuss zwischen $23 \%$ und 25,5\% und Proteinmangel zwischen $25 \%$ und $35 \%$ nachgewiesen wurde (BRYDL et al. 2003a, b, 2006). Diese Ergebnisse gleichen somit den eigenen Untersuchungen.

Im Jahresvergleich ist ausschließlich 2006 mit einem Mittelwert von 3,38 mmol/l signifikant niedriger zu den anderen Jahren. In diesem Jahr konnten auch deutlich mehr untere Abweichungen (25,9 \%) im Vergleich zu den anderen Jahren $(1,4-7,9 \%)$ gezeigt werden, während obere Abweichungen $(12,1 \%)$ weniger auftraten. In den anderen Jahren waren zwischen 25,5\% und 39,1 \% (2008) Konzentrationen über dem Referenzbereich zu verzeichnen. Bei LOBER (2005) waren die Prävalenzen für erhöhten Harnstoff in den Jahren 1998 bis 2002 zwischen 47,7 \% und $56 \%$ und damit deutlich höher als in der eigenen Untersuchung. Bei der Aufteilung in die Laktationsstadien weist ebenfalls 2006 immer die niedrigsten Mittelwerte auf und ist zum Teil auch gesichert unterschiedlich zu einigen anderen Jahren. Mittelwerte nahe der oberen Kontrollgrenze waren in der ersten Woche p. p. 2009 sowie bei den Kühen, welche mehr als acht Wochen p. p. waren, 2007, 2008 und $2011 \mathrm{zu}$ beobachten. In dem Stadium der Spätlaktation ist das Jahr 2010 signifikant verschieden zu den anderen Jahren und weist den einzigen Mittelwert auf, der deutlich über dem Kontrollbereich liegt.

Die Parameter Totales Protein, Albumin und Kreatinin wurden in dieser Untersuchung nur mit sehr geringen Anzahlen, zwischen 10 und 47 Proben, untersucht und sind dadurch in diesem Fall nicht fundiert interpretierbar. Diese Parameter haben aber eine gute Aussagekraft, z. B. über chronische Entzündungen bei Laminitis und Mastitis.

\subsubsection{Parameter des Mineralstoffwechsels und des Muskelstoffwechsels}

Bei Ca waren meist keine bedeutenden Referenzwertabweichungen zu sehen. Nur in der ersten Woche p. p. waren mit 13,2 \% verstärkt Unterversorgungen, d. h. Konzentrationen $<2,0 \mathrm{mmol} / \mathrm{L}$, zu erkennen. Das spiegelt sich auch im Median wider. Während alle anderen Mittelwerte zwischen 2,35 $\mathrm{mmol} / \mathrm{l}$ und 2,41 mmol/l liegen und ein leichter Anstieg im Laktationsverlauf zu sehen ist, ist der Median in der ersten Woche p. p. $(2,27 \mathrm{mmol} / \mathrm{l})$ mit Abstand der Niedrigste, jedoch innerhalb des 
Kontrollbereiches. Somit deckt sich das mit den Angaben von ROSSOW et al. (1975), ROWLANDS et al. (1975), KIRCHNER et al. (1977), HAGMÜLLER (2002), KIDA (2002b), SEIFI et al. (2003), SEVINC und ASLAN (2003) und SÖLLNER-DONATH (2013), welche ebenfalls in der ersten Woche p. p. die niedrigsten Ca-Konzentrationen im Laktationsverlauf beobachteten. Dies ist durch den hohen $\mathrm{Ca}-$ Verbrauch für die Bildung von Kolostrum zu erklären, welcher weder durch die Futteraufnahme noch durch die Mobilisation aus dem Knochen so schnell ausgeglichen werden kann (GOFF et al. 2002). Bei ZAHN (2006) wurden die niedrigsten Konzentrationen dagegen in der ersten Woche a.p. gemessen. Eine subklinische Hypocalzämie liegt vor, wenn keine klinischen Symptome sichtbar sind und die Kühe Serum-Ca-Konzentrationen < 2,0 mmol/l (REINHARDT et al 2011, GOFF 2008) bzw. Ca-Ionenkonzentrationen $<1,0 \mathrm{mmol} / \mathrm{l}$ (CHAMBERLIN et al. 2013) haben. Die Erkrankungsrate an subklinischer Hypocalzämie steigt mit zunehmendem Alter an (REINHARDT et al. 2010, BIJMHOLT et al. 2012, HOSTENS et al. 2012). Außerdem zeigen Kühe mit Hypocalzämie höhere FFS-Konzentrationen, wodurch aufgrund der schlechteren Energiebilanz ein höheres Risiko für Folgeerkrankungen, besteht (REINHARDT et al. 2010, CHAMBERLIN et al. 2013). Kühe mit Hypocalzämie in den ersten zwei Wochen p. p. haben ein erhöhtes Risiko für LMV (GOFF 2008, SEIFI et al. 2011), für geringere Futteraufnahme und Mastitiden (GOFF 2008), sowie für frühzeitigen Abgang vor dem 60. Tag p. p. (SEIFI et al. 2011, ROBERTS et al. 2012).

Im Jahresvergleich sind die Mittelwerte von 2010 und 2011 signifikant niedriger als in den Jahren 2006 bis 2009. Diese Unterschiede der beiden Jahre zu den anderen sind im Laktationsstadienvergleich nur zum Teil nachweisbar und signifikant. 2009 und 2010 verzeichnen a. p. und in der zweiten bis achten Woche p. p. ebenfalls die niedrigsten Mittelwerte, während nach der achten Woche p. p. im Jahr 2010 der höchste Mittelwert mit 2,48 mmol/l beobachtet wurde, welcher auch als einziger über dem Kontrollbereich von 2,12 - 2,46 mmol/l liegt. Die meisten Unterschiede sind aber in der ersten Woche p. p. zu sehen. Da weisen die Jahre 2009 und 2010 die niedrigsten Mittelwerte auf. 2009 liegt als einziger Wert unter dem Kontrollbereich und ist signifikant verschieden zu 2007. 2010 befindet sich an der unteren Grenze dieses Bereiches. Jedoch sind keine weiteren gesicherten Unterschiede nachweisbar.

$\mathbf{P}_{\mathbf{i}}$ verhält sich ähnlich wie Ca. So ist in der ersten Woche p. p. mit 1,88 mmol/l der niedrigste Median zu verzeichnen. Von diesem Abfall der $\mathrm{P}_{\mathrm{i}}$-Konzentrationen p. p. berichten ebenfalls ROSSOW et al. (1975), KIRCHNER et al. (1977), HAGMÜLLER (2002), KIDA (2002b), EVERTZ (2006), HÄDRICH (2007), HECKEL (2009), SÖLLNER-DONATH (2013) und ILLEK (2014). Dies wird mit der verminderten Futteraufnahme sowie der vermehrten Abgabe von $\mathrm{P}_{\mathrm{i}}$ in die Milch kurz nach der Kalbung erklärt (SÖLLNER-DONATH 2013). Dabei sinken die $\mathrm{P}_{\mathrm{i}}$-Konzentrationen zur Kalbung bei einer höheren Körperkondition zum Trockenstellen sowie zur Kalbung stärker ab (DAETZ 2009). Vor der Kalbung $(24,9 \%)$ und in der ersten Woche p. p. $(22,4 \%)$ überwiegen die oberen Abweichungen, während ab der Mittellaktation die Abweichungen unterhalb des Normbereiches höher sind und Werte zwischen 10,9 \% und 12,7 \% aufweisen. Erhöhte $\mathrm{P}_{\mathrm{i}}$-Konzentrationen deuten auf akute Pansenazidosen 86 
(FÜRLL 2013a) sowie ein gestörtes Ca/P-Verhältnis in der Ration hin. Postpartale Hypophosphatämien konnten auch bei $10-20 \%$ der Kühe in Ungarn nachgewiesen werden (BRYDL et al. 2003b, 2006). Als Folge von Hypophosphatämien können verringerte Futteraufnahme, Milchabfall, Lahmheiten und festliegende Kühe auftreten (KUREK et al. 2010). So konnten bei festliegenden Kühen bis zu $50 \%$ niedrigere $\mathrm{P}_{\mathrm{i}}$-Konzentrationen als bei gesunden Kühen festgestellt werden (HEILIG et al 2014). Zusätzlich besteht ein Zusammenhang zwischen Hypophosphatämien und Entzündungen, wie z. B. Endometritiden und Enteritiden. Dabei kommt es durch TNF $\alpha$ zu einer Hemmung des NaP-II-Co-Transporters im Darm und in den Nieren, welches in Folge zu einer verminderten Resorption von Pi führt (FÜRLL 2014a). Auffallend ist in der vorliegenden Untersuchung die hohe Anzahl an oberen Abweichungen bei den Färsen. Dies spiegelt sich auch im Vergleich der Medianwerte wider, welcher als Einziger deutlich außerhalb des Kontrollbereiches liegt. Während SÖLLNER-DONATH (2013) bei Jungkühen in der ersten Laktation bis sechs Wochen p. p. niedrigere Konzentrationen nachgewiesen hat, zeigen die noch nicht abgekalbten Färsen in der eigenen Untersuchung zu $63 \%$ erhöhte $\mathrm{P}_{\mathrm{i}}$-Konzentrationen. Auch LOTTHAMMER (1981) berichtet von höheren Konzentrationen bei den Jungtieren, bis sie drei Jahre alt sind. FÜRLL (2013a) bestätigt ebenfalls diese starke Altersabhängigkeit von $\mathrm{P}_{\mathrm{i}}$.

Im Jahresvergleich ohne die Aufteilung in die Laktationsstadien sind vor allem die zahlreichen Abweichungen oberhalb des Referenzbereiches in den Jahren 2006 (39,7 \%), 2007 (21,2 \%) und 2008 $(27,2 \%)$ auffällig. In den folgenden drei Jahren sind die oberen Abweichungen deutlich geringer. Somit ist ein absteigender Trend der oberen Abweichungen zu erkennen. Die unteren Abweichungen schwanken dagegen während des gesamten Untersuchungszeitraumes. Dem entgegengesetzt zeigten die Untersuchungen von LOBER (2005) einen Anstieg an Hypophosphatämien in dem Zeitraum 1998 bis 2001 von 21,7\% auf 55,6\%. Bei HEROLD (1989) war im Jahresvergleich von 1980 bis 1987 weder bei den oberen noch bei den unteren Abweichungen ein deutlicher Trend zu erkennen. Im Laktationsstadienvergleich sind nur 2006 und 2011 in der ersten Woche p. p. mit Mittelwerten größer 2,0 mmol/l deutlicher höher als die anderen Jahre. Wie schon beim $\mathrm{Ca}$, sind auch in diesem Fall während der ersten Woche p. p. die meisten Schwankungen der Jahre zu verzeichnen. In jedem Stadium ist der Mittelwert von 2008 zu einem anderen Jahr signifikant verschieden. Ante partum und zwei bis acht Wochen p. p. ist 2008 signifikant höher zu 2010, in der ersten Woche p. p. signifikant niedriger zu 2007 und mehr als acht Wochen signifikant höher zu 2006.

Bei dem Parameter CK befindet sich ein großer Teil (69\%) außerhalb des Referenzbereiches ( $\leq 100$ I/U; 1. Wo p. p: $\leq 200$ U/I). Bereits a.p. sind $60 \%$ der Ergebnisse erhöht, während der Median a.p. nur geringgradig größer als $100 \mathrm{U} / \mathrm{I}$ ist. Diese Erhöhung a. p. wurde ebenfalls von HECKEL (2009) beobachtet. Eine Erhöhung der CK-Aktivität kurz vor und nach der Kalbung wird außerdem von BOSTEDT (1974) beschrieben. SATTLER und FÜRLL (2004) konnten bei Kühen mit LMV feststellen, dass Kühe mit fortschreitender Trächtigkeit eine höhere CK-Aktivität aufwiesen als Kühe in früheren Trächtigkeitsstadien. Das kann mit einem gesteigerten Stoffwechsel im fortgeschrittenen 
Trächtigkeitsstadium (CLARK et al. 1994) erklärt werden. In der ersten Woche p.p. ist im Laktationsverlauf der höchste Median von $120 \mathrm{U} / \mathrm{I}$ zu verzeichnen. Aufgrund des erhöhten Referenzbereiches sind jedoch die Abweichungen (40,9 \%) geringer. Von einem Anstieg der CKAktivität durch die Kalbung berichten ebenfalls EVERTZ (2006), GLINDEMANN (2006), HÄDRICH (2007), HECKEL (2009), FINN (2014) und ILLEK (2014). Bei der Kalbung wird das uterine Gewebe einer starken Reizung ausgesetzt, was zu einem Anstieg der CK führt (SATTLER und FÜRLL 2004). Die Mediane im weiteren Laktationsverlauf sind zwar alle unterhalb der Aktivitäten in der ersten Woche p. p, befinden sich jedoch alle oberhalb der Toleranzgrenze. Die Abweichungen nach der ersten Woche sind stark erhöht und steigen im Verlauf der Laktation bis auf $91 \%$ weiter an. Sowohl bei HÄDRICH (2007) als auch bei HECKEL (2009) zeigten die Kühe am 28. Tag p. p. ebenfalls noch erhöhte CK-Aktivitäten, während bei BOSTEDT (1974) bereits fünf bis sechs Tage p. p. wieder niedrige Aktivitäten erreicht waren. Warum die Kühe mit zunehmender Laktationsdauer so zahlreiche Abweichungen aufwiesen, konnte in dieser Untersuchung nicht geklärt werden. Wie bereits erwähnt, werden erhöhte Aktivitäten vorrangig im peripartalen Zeitraum beschrieben und als Folge von Schwergeburten, Nachgeburtsverhalten, Gebärparese sowie mit LMV (KLEISER und FÜRLL 1998) und Endometritiden (SATTLER und FÜRLL 2004) im Zusammenhang gesehen. Erhöhte CKAktivitäten können auch auf einen Mangel an Antioxidantien hinweisen. Denn bei erhöhtem oxidativen Stress kann es infolge von Lipidperoxidation zu einer erhöhten Membranpermeabilität kommen (WILKEN 2003, TAGHIYAR et al. 2013) was zu einer erhöhten Freisetzung von Muskelbestandteilen, wie z. B CK, führen kann (ARMSTRONG et al. 1991, JACKSON 1996). Auffallend sind außerdem die zu $100 \%$ erhöhten Konzentrationen bei den Färsen sowie der erhöhte Medianwert. Bei HECKEL (2009) zeigten die Färsen a.p. ebenfalls signifikant höhere Konzentrationen als Kühe. Dafür nennt der Autor die erhöhte metabolische Belastung sowie die erstmalige erhöhte Beanspruchung des Gewebes im fortgeschrittenen Stadium der Trächtigkeit als mögliche Ursache. ACKERMANN et al. (2013b) beschreiben a. p. ebenfalls höhere Aktivitäten bei Jungkühen, welche mit zunehmender Laktationszahl signifikant absinken, während Kühe in der ersten Laktation am dritten Tag p. p. signifikant höhere Aktivitäten aufweisen als ältere Tiere.

Im Jahresvergleich sind 2007 mit 63,7 \% die wenigsten Abweichungen zu verzeichnen. Bei der Unterteilung in die Laktationsstadien liegen die Abweichungen a. p. bis auf 2007 alle über $60 \%$, während in der ersten Woche p. p. vor allem 2009 mit einer Anzahl an Abweichungen über $70 \%$ auffällt. Der steigende Trend der Abweichungen im Laktationsverlauf ist auch im Jahresvergleich zu beobachten. So sind die Abweichungen in den Phasen 2-8 Wochen p. p. sowie $>8$ Wochen p. p. jeweils ungefähr auf einem Niveau. Davon ausgenommen betragen die Abweichungen 2010 in der Mittellaktation sowie 2006 in der Spätlaktation jeweils $100 \%$. Die Mediane verhalten sich ähnlich. Dabei sind Konzentrationen in der ersten Woche p. p. in den Jahren 2007 und 2008 die Einzigen, welche innerhalb des Toleranzbereiches liegen. Den mit Abstand höchsten Wert von 273,0 U/I verzeichnet das Jahr 2010 in der Mittellaktation. 
Die Mineralstoffe Na (43), K (43), Cl (39), Fe (94) und Mg (37) sowie die AP (10) spielen in dieser Untersuchung aufgrund der geringen Anzahl an Ergebnissen bzw. sehr geringe Anzahl von Abweichungen bei Fe eine untergeordnete Rolle. Jedoch ist anzuraten, die AP in zukünftigen Einsendungen vermehrt zu untersuchen, da für diesen Parameter ein hoher frühdiagnostischer Wert in Bezug auf Gebärparese nachgewiesen ist und bei Aktivitäten a. p. $<45$ U/l das Risiko um 80 \% erhöht ist (ECKERMANN 2007).

\subsubsection{Spurenelemente, B-Carotin, Coeruloplasmin und TEAC}

Die Cu-Konzentrationen befinden sich zum überwiegenden Teil innerhalb des Referenzbereiches von 8,0 - 32,8 $\mu \mathrm{mol} / 1$. Eine geringgradig erhöhte Anzahl an unterversorgten Kühen waren a. p. mit 12,5\% und in der Spätlaktation mit 14,8 \% zu sehen. ILLEK (2014) untersuchte Kühe in Tschechien und BRYDL et al. (2003a) in Ungarn und stellten ebenfalls sowohl a. p. als auch in der Hochlaktation vermehrt Unterversorgungen bei Kühen fest. Bei dem Vergleich der Mediane war dagegen in der ersten Woche p. p. eine leichte Erhöhung auf 13,1 $\mu \mathrm{mol} / \mathrm{l}$ zu beobachten. Eine signifikante Erhöhung in der ersten Woche p. p. konnte auch SÖLLNER-DONATH (2013) verzeichnen. WANG et al. (2014) beschreiben ebenfalls einen Anstieg von $\mathrm{Cu}$ in der ersten Woche a. p. und das Verbleiben dieser erhöhten Konzentrationen für die ersten vier Wochen p. p. ENJALBERT et al. (2002) untersuchten Mutterkühe auf ihr Cu-Konzentration und stellte von der ersten Probenentnahme, bei der die Kühe zwei bis drei Monate a. p. waren, bis zu dem Zeitpunkt drei Wochen p.p. ebenso einen Anstieg von Cu fest. In der vorliegenden Untersuchung ist die etwas erhöhte Anzahl an Abweichungen bei den Färsen auffällig. So waren $21 \%$ der Färsen mit $\mathrm{Cu}$ unterversorgt, während die Kühe nur zu $10 \%$ unterversorgt waren. Der Unterschied zwischen Kühen und Färsen, wobei Kühe höhere $\mathrm{Cu}$ Konzentrationen aufweisen, konnte auch von PAVLATA et al. (2005) beobachtet werden. Kein Unterschied konnten dagegen DU et al. (1996) nachweisen. Eine Cu-Unterversorgung kann zu Leistungsminderung, herabgesetzter Fruchtbarkeit, Anämie, Abmagerung, Bewegungsstörungen, Herzschwäche, Gebärparese sowie zu Haarveränderungen führen (FÜRLL 2013a). Außerdem erhöht eine $\mathrm{Cu}$-Unterversorgung von Kühen das Risiko für Durchfallerkrankungen bzw. Mortalität bei deren Kälbern (ENJALBERT et al. 2006). Dabei wird ein Zusammenhang zwischen den Durchfallerkrankungen und einem gestörten Immunsystem der Kuh, ein gestörter Immuntransfer zum Kalb oder eine herabgesetzte Immunfunktion des Kalbes vermutet.

Im Jahresvergleich war 2009 mit einem Mittelwert von 15,93 $\mu$ mol/l signifikant höher zu den anderen Jahren. Die meisten Abweichungen waren dagegen 2007 mit 13,8\% und 2011 mit 23,4\% zu sehen. Zwischen diesen zwei Jahren besteht kein signifikanter Unterschied, jedoch unterscheiden sie sich signifikant zu den Jahren 2008 bis 2010. Da die Cu-Versorgung im Allgemeinen bei den Kühen als ausreichend bewertet werden kann, wurde auf einen Jahresvergleich innerhalb der Laktationsstadien verzichtet. 
Bei Se zeigten a. p. $21 \%$ der Kühe eine Unterversorgung $(<0,4 \mu \mathrm{mol} / \mathrm{l})$, welche bis acht Wochen p. p. auf $12 \%$ absank. Ab der Kalbung bis zur Spätlaktation überwiegen mit jeweils mindestens $30 \%$ die Überversorgungen $(>0,88 \mu \mathrm{mol} / \mathrm{l})$. So steigen auch die Mediane von a. p. bis 14 Wochen p. p. stetig an. Alle Mediane liegen jedoch innerhalb des Kontrollbereiches von 0,5-0,8 $\mu \mathrm{mol} / \mathrm{l}$. MEGLIA et al. (2004) beobachteten ebenfalls niedrigere Se-Konzentrationen a. p. und zur Kalbung als während der Frühlaktation. SAEED (2010) beschreibt ebenso einen Abfall des Se im Serum von sechs Wochen a. p. bis zur Kalbung mit einem anschließenden leichten Anstieg der Konzentrationen, wobei der Ausgangswert bis zwölf Wochen p. p. nicht wieder erreicht wurde. Bei den Färsen ist der Anteil an Unter- und Überversorgungen bei $20 \%$ und $26 \%$ und damit ähnlich. Bei PAVLATA et al. (2005) zeigten die Kühe den Färsen gegenüber eine höhere GPX, welche indirekt den Se-Status widerspiegelt. WOLF et al. (1998) beobachteten bei der Untersuchung von Kühen, dass Milchkühe zu über $50 \%$ mit Se überversorgt waren, während Mutterkühe eher eine Unterversorgung zeigten. Bei Kühen in Tschechien zeigten die Kühe sowohl a. p. als auch p. p. bis zur Hochlaktation Unterversorgungen, wobei a. p. stärkere Mangelzustände zu sehen waren (ILLEK 2014). Eine vermehrte Überversorgung der Kühe mit 23,6 \% kann auch in den vorliegenden Untersuchungen bestätigt werden. Eine Überversorgung mit Se kann relativ schnell toxische Auswirkungen zeigen, während eine Unterversorgung zur einer Verschlechterung der Leistung und der Fruchtbarkeit sowie zu Bewegungsstörungen durch Muskeldystrophie und Herzschwäche führen kann (FÜRLL 2013a).

Im Jahresvergleich sind bei diesem Parameter große Unterschiede zwischen den Jahren zu sehen. Dabei ist das Jahr 2009 vor allem durch Unterversorgungen (35\%) geprägt, während in den Jahren $2006(36,2 \%)$ und 2007 (36,7 \%) die Überversorgungen überwiegen. In den Jahren 2008, 2010 und 2011 sind die Unter - und Überversorgungen jeweils auf ähnlichem Niveau, um die $20 \%$. Insgesamt ist ein leicht abfallender Trend im Verlauf der Jahre zu beobachten. Diese Verhältnisse von Unter- und Überversorgungen sind auch im Laktationsverlauf zu sehen. Während in den Jahren 2006 und 2007 in allen Laktationsstadien die Überversorgungen überwiegen, sind es im Jahr 2009 die Unterversorgungen. A. p. zeigen die restlichen Jahre ebenfalls vermehrt Unterversorgungen. Post partum überwiegen im Jahr 2008 ebenfalls die Überversorgungen, während 2010 und 2011 die Verhältnisse entweder auf relativ niedrigem Niveau ausgeglichen sind oder im Laktationsverlauf schwanken.

Auf B-Carotin wurden hauptsächlich Kühe von a. p. bis acht Wochen p. p. und Färsen untersucht. Dabei zeigten a. p. $50 \%$ der Kühe eine Unterversorgung von ß-Carotin. In der ersten Woche p.p. sinkt die Anzahl geringfügig auf 47,1\% und erreicht die meisten Abweichungen mit $77 \%$ in der Phase zwei bis acht Wochen p. p. Die Medianwerte verhalten sich entsprechend ähnlich. So ist a. p. mit $7,35 \mu \mathrm{mol} / 1$ der höchste Medianwert erreicht, welcher knapp unterhalb der Referenzgrenze $(<7,4 \mu \mathrm{mol} / \mathrm{l})$ liegt. In der ersten Woche p. p. sinkt der Medianwert auf 4,34 $\mu \mathrm{mol} / \mathrm{l}$ stark ab, befindet sich jedoch durch den angepassten Referenzbereich (1. Wo p. p: <4,02 $\mu \mathrm{mol} / \mathrm{l})$ in dieser Zeit oberhalb der Grenze. Der Median in der zweiten bis achten Woche p. p. mit 4,82 $\mu \mathrm{mol} / \mathrm{l}$ ist geringgradig höher als in der ersten Woche p. p, jedoch stark abweichend vom Kontrollbereich. STÖCKL et al. (1975) 90 
und ILLEK (2014) konnten ebenfalls einen Abfall der Konzentration in den ersten Tagen p. p. bzw. schon zum Zeitpunkt der Kalbung beobachten. Jedoch befanden sich die Konzentrationen in der Untersuchung von STÖCKL et al. (1975) zwei bis drei Wochen p. p. wieder im Referenzbereich, was in der vorliegenden Untersuchung zu $77 \%$ nicht der Fall gewesen ist. Bei ÖHLSCHLÄGER (2006) unterschritten die B-Carotinkonzentrationen sowohl a.p. als auch p. p. bis zur 36. Woche den Referenzbereich von $200 \mu \mathrm{g} / \mathrm{dl}$. CONRADS (2003) stellte zwischen a. p. und ein bis zwei Wochen p. p. einen signifikanten Abfall der Konzentrationen sowie das Verbleiben auf diesem Niveau bis zum erneuten Besamungszeitpunkt fest. GOFF et al. (2002) beobachteten ebenfalls einen starken Abfall der Konzentrationen in den ersten Tagen nach der Kalbung. JOHNSTON und CHEW (1984) verzeichneten den gleichen Verlauf und beschreiben die niedrigsten Konzentrationen vier bis sechs Tage p. p. Ursachen für den Konzentrationsabfall kurz nach der Kalbung können der erhöhte ß-Carotingehalt im Kolostrum (GOFF et al 2002) sowie ein gestörter Fettstoffwechsel, welcher negativen Einfluss auf den Transport von ß-Carotin haben kann (HARASZTI et al 1984), sein. Weitere Ursachen können die unzureichenden Substitutionen in der Ration sein sowie der steigende Anteil von Maissilage in der Ration, welcher zu vermehrtem Auftreten von mikrobiellen Pansenfunktionsstörungen führt (STAUFENBIEL et al 2004). Allerding konnte ÖHLSCHLÄGER (2006) einen direkten Zusammenhang zwischen Konzentrationen im Serum und den ß-Carotingehalt im Futter nicht nachweisen. Ein B-Carotinmangel führt vor allem zu einer Verschlechterung der Fruchtbarkeit (FÜRLL 2013a). Sowohl in Tschechien (ILLEK 2014) als auch in Ungarn (BRYDL et al. 2003a, b, 2006) wurden ebenfalls, sowohl a. p. als auch p. p, starke ß-Carotinmangelzustände festgestellt, wobei vor allem Trockensteher und Frischabkalber Prävalenzen zwischen $70 \%$ und 80\% aufwiesen.

$87 \%$ der Färsen zeigten eine Unterversorgung an. Außerdem konnte ein weit unterhalb des Referenzbereiches liegender Medianwert beobachtet werden. CONRADS (2003) konnte auch geringere $\beta$-Carotinkonzentrationen bei Färsen im Vergleich zu Kühen a. p. nachweisen, wobei nach der Kalbung keine signifikanten Unterschiede mehr auftraten. Dieser Mangel bei den Färsen ist wahrscheinlich auch auf die fehlende Substitution aus Kostengründen zurückzuführen.

Im Jahresvergleich ist von 2008 mit $54 \%$ unterversorgten Kühen bis 2011 mit $64 \%$ ein steigender Trend zu erkennen, welcher auch von LOBER (2003) beobachtet wurde. STAUFENBIEL et al. (2004) konnten ebenfalls von 1995 bis 2004 einen signifikanten Anstieg von Mangelzuständen nachweisen und begründen dies neben dem bereits genannten steigenden Maissilageanteil ebenfalls mit der teuren Substitution von $\beta$-Carotin.

Die Ergebnisse der TEAC befinden sich zu 54,4 \% innerhalb des Referenzbereiches. Bei der Aufteilung in die Laktationsstadien sind ausschließlich von a. p. bis acht Wochen p. p. nennenswerte Probenanzahlen von mindestens 41 vorhanden. Hierbei fallen die zahlreichen Abweichungen von 70,7 \% mit Konzentrationen größer als $320 \mu$ mol/l in der Phase zwei bis acht Wochen p. p. auf. Auch 
bei den Medianen kommt es in der ersten Woche zu einem geringen Abfall auf 295,01 $\mu \mathrm{mol} / \mathrm{l}$ und dann zu diesem stärkeren Anstieg nach der ersten Woche auf 343,06 $\mu \mathrm{mol} / \mathrm{l}$. Der Median von der zweiten bis achten Woche p. p. ist somit der Höchste sowie der Einzigste außerhalb des Referenzbereiches. DÜBELER (2006) konnte zwischen zwei Wochen p. p. und vier Wochen p. p. ebenfalls einen signifikanten Anstieg nachweisen sowie erhöhte Konzentrationen bei Tieren mit linksseitiger LMV und Euterentzündungen. Die Ursache für den TEAC-Anstieg bei den Erkrankungen vermutet der Autor in der verstärkten Freisetzung von Antioxidantien, welche im Fett gespeichert sind. Im Gegensatz dazu konnten nach FÜRLL (2013a) bei Nachgeburtsverhalten, Euterentzündungen und LMV eher niedrigere Konzentrationen festgestellt werden. Bei Kühen mit Gebärparese konnten HEILIG et al. (2014) ebenfalls niedrigere Konzentrationen feststellen und begründen dies mit einem indirekten Zusammenhang zur Ca-Mobilisierung. STOHRER et al. (2003) beschreiben auch einen Abfall der TEAC kurz nach der Kalbung. Jedoch verbleiben die Konzentrationen im Gegensatz zu dieser Untersuchung bis 80 Tage p. p. auf niedrigem Niveau. WILKEN (2003) beobachtete dagegen die niedrigsten Konzentrationen a. p. und erklärt dies mit der herabgesetzten Futteraufnahmekapazität bei Rindern in der Hochträchtigkeit und der damit verbundenen geringeren Aufnahme von exogenen Antioxidantien. Post partum konnte WILKEN (2003) einen kontinuierlichen, jedoch nicht signifikanten Anstieg bis zum Untersuchungsende von 16 Wochen p. p. beobachten. Bei GOERRES und FÜRLL (2002) zeigte sich neben den ebenfalls signifikant niedrigsten Konzentrationen a. p, ein signifikanter Anstieg der TEAC-Konzentrationen am dritten Tag p. p. sowie zwei Wochen p. p. FINN (2014) konnte zudem leicht erhöhte Konzentrationen bei Tieren mit Schwergeburten sowie Erkrankungen p. p. nachweisen. Dieser Autor beurteilt die Bewertung der TEAC jedoch als schwierig, da noch weitere Untersuchungen nötig sind, welche genauen Einflüsse auf die TEAC einwirken bzw. welche Substanzen bestimmt werden, da die TEAC ein Summenparameter ist.

Im Jahresvergleich können keine signifikanten Unterschiede nachgewiesen werden. Die Abweichungen schwanken zwischen $40 \%$ und $50 \%$ und die Mittelwerte befinden sich alle an der oberen Grenze des Referenzbereiches.

Auf Zn, Mn und Coeruloplasmin sind jeweils weniger als 20 Proben untersucht worden und damit in dieser Arbeit nicht verallgemeinernd interpretierbar.

\subsubsection{Zusammenfassung Jahresvergleich}

Bei den meisten Parametern konnten im Jahresvergleich Unterschiede bei den Mittelwerten oder Medianwerten, zum Teil signifikant bzw. anhand der Anzahl von Abweichungen festgestellt werden. Jedoch waren diese Jahre, welche in der Gesamtauswertung Unterschiede aufwiesen, dann im Laktationsverlauf nur zum Teil auffällig. Ausnahme davon war Bilirubin, bei dem das Jahr 2008 in allen Laktationsstadien mit vielen Abweichungen auffiel und Se, bei dem 2009 in allen Laktationsstadien vermehrt Unterversorgungen auftraten. Die meisten Konzentrationen schwanken zwischen den Jahren. Ein leicht ansteigender Trend der Abweichungen ist bei den FFS von 2006 bis 92 
2010 und bei $ß$-Carotin zu sehen und ein absinkender Trend ist bei den oberen Abweichungen von $P_{i}$ zu erkennen. Unterschiedliche Konzentrationen in verschiedenen Jahren konnten neben HEROLD (1989) auch PAYNE et al. (1973) beobachten.

Da Stoffwechselimbalancen in enger Beziehung zur Fütterung stehen, könnte eine Ursache für diese Jahresschwankungen das Klima und die damit verbundenen Ernteerfolge und Inhaltsstoffe der Futterkomponenten sein. Um diese Vermutung zu bestätigen, hätten jedoch weiterreichende Untersuchungen (Futteranalysen in den Betrieben, örtliches Klima und Ernteerfolge) stattfinden müssen. Da aber die Auswertung der Proben rückwirkend erfolgte, war dies nicht mehr möglich. Außerdem fand auch die Beantwortung der Fragebögen zum Teil mehrere Jahre nach der Probeneinsendung statt und dadurch waren meist nur grobe Angaben möglich.

\subsection{Ergebnisse ausgewählter Betriebe und Kühe}

Die Hälfte der Betriebe hat mehr als einmal Proben eingesendet, wobei davon der größte Teil zweimal eingesendet hat. 24 der mehrfach eingesendeten Betriebe waren geeignet, um Verlaufsuntersuchungen durchzuführen. Dabei konnte bei 79,2 \% der Betriebe eine Verbesserung der Stoffwechsellage festgestellt werden. Dieses Ergebnis wurde mit zwei unterschiedlichen Herangehensweisen ermittelt. Dabei ist bei der ersten Variante die Anzahl an Abweichungen der Einzelwerte der jeweiligen Parameter je Einsendung von Relevanz und bei der zweiten Variante wird der Parameter einer Einsendung mit Hilfe der 20-\%-Regel in Bezug auf die Einzelwerte als gesundheitsgefährdend beurteilt oder nicht. Bei beiden Varianten wird jedoch nur beurteilt, ob die Einzelwerte abweichen oder nicht. Die Höhe der Abweichungen bzw. Auslenkungen werden dabei nicht mit beachtet. Das sind somit „Schwarz-Weiß-Systeme“. Zumal klinisch gesunde Tiere veränderte Laborwerte zeigen können und umgekehrt nicht alle klinisch kranken Tiere Konzentrationen aufweisen, die außerhalb des Referenzbereiches liegen (BAUMGÄRTNER 1979) und somit die Beurteilung von „gesund“ und „krank“ nicht immer eindeutig ist (FÜRLL 2013a). Des Weiteren variieren die Abstände zwischen den Einsendungen zwischen mehreren Monaten und bis zu vier Jahren. Das bedeutet, dass die zu $80 \%$ erfolgten Maßnahmen nicht unbedingt einen Einfluss auf die wiederholte Stoffwechseluntersuchung haben müssen. Jedoch kann diese hohe Zahl an erfolgten Maßnahmen als weiterer positiver Punkt, neben der Verbesserung der Stoffwechsellage, in Bezug auf die Notwendigkeit von Stoffwechseluntersuchungen angesehen werden. Außerdem beträgt die durchschnittliche Nutzungsdauer in Deutschland ca. 2,5 Jahre, das bedeutet, dass die meisten Milchkühe bereits in der ersten oder zweiten Laktation zum Schlachten gehen (FÜRLL 2013b). Um diesem Trend entgegen zu wirken, stellen Stoffwechseluntersuchungen ein wichtiges Hilfsmittel dar, um frühzeitig subklinische Erkrankungen zu erkennen und daraus folgenden Maßnahmen zu ergreifen.

Bei der Verlaufsuntersuchung einzelner Parameter wurde überprüft, ob der prozentuale Anteil an Konzentrationen innerhalb des Referenzbereiches sich bei wiederholten Einsendungen eher erhöht 
oder erniedrigt hat. Bei der Mehrzahl der Parameter $\left(\mathrm{Ca}, \mathrm{P}_{\mathrm{i}}\right.$, Hast, Chol, BHB, Bili, $\left.\mathrm{CK}, \mathrm{Cu}\right)$ mit aussagefähigem Verlauf zeigte sich dabei eine höhere Zahl an Verbesserungen. Bei diesen Parametern sind die Abweichungen bzw. die Summe der unteren und oberen Abweichungen im Jahresverlauf entweder schwankend oder tendenziell sinkend $\left(\mathrm{Ca}\right.$ und $\left.\mathrm{P}_{\mathrm{i}}\right)$. Mehr Verschlechterungen zeigten sich ausschließlich bei den FFS und bei Se. Bei den FFS entsprechen diese Veränderungen auch dem leicht ansteigenden Trend der Abweichungen im Jahresverlauf. Bei Se dagegen zeigten die Mittelwerte eher einen leichten abfallenden Trend. Addiert man jedoch die unteren und oberen Abweichungen, bei denen es zu einer Umverteilung im Jahresverlauf kommt, ist ebenfalls ein leichter Anstieg zu erkennen und deckt sich somit auch mit dem Parameterverlauf in den mehrfach untersuchten Betrieben.

Bei den mehrfach untersuchten Kühen ist zwischen der Anzahl mit mehr verbesserten bzw. mehr verschlechterten Parametern kein großer Unterschied, wobei zwei Kühe mehr eine Verbesserung der Parameter zeigten. Da von der Mehrzahl der Kühe nur zwei Einsendungen vorliegen, ist die hohe Anzahl an nur einmal untersuchten Parametern je Kuh nicht verwunderlich. Bei dem Vergleich, welche Parameter sich bei einzelnen Kühen verändert haben, konnten Veränderungen nur bei $\mathrm{P}_{\mathrm{i}}$, Hast, FFS und CK festgestellt werden. Die anderen zeigten entweder keine Veränderung oder wurden nur einmal untersucht. Bei den veränderten Parametern zeigten jedoch alle mehr Verschlechterungen als Verbesserungen. Diese Kühe sind im Gegensatz zu der Gesamtanzahl von Kühen, von welchen Stoffwechselproben eingesendet wurden, nur ein sehr geringer Anteil. Deshalb lassen sich diese Ergebnisse nicht verallgemeinern, sondern stellen eher einen Zusatz dar und sind von sehr individueller Natur. Da diese Kühe aus den bereits analysierten Betrieben stammen, sind außerdem auch hier die großen Differenzen zwischen den Einsendungsintervallen zu beachten.

\subsection{Schlussfolgerungen}

Anhand der vorliegenden Ergebnisse und Analysen können diese Schlussfolgerungen gezogen werden.

- Die häufigsten Abgangsursachen bei Rindern sind nach wie vor Störungen der Fruchtbarkeit, Eutererkrankungen sowie Klauen- und Gliedmaßenerkrankungen.

- Die Gründe für die Einsendung von Stoffwechselproben waren in diesen Betrieben, neben der Abfrage des aktuellen Stoffwechselstatus, ebenfalls hauptsächlich Fruchtbarkeitsprobleme sowie das vermehrte Auftreten von Festliegern, Ketosen und Euterproblemen im Bestand.

- Es kam zu einer Verringerung der durchschnittlichen Probenanzahl je Einsendung im Untersuchungszeitraum von 9,7 auf 5,1. Des Weiteren konnte eine jahreszeitenabhängige stärkere Einsendungshäufigkeit im ersten Jahresquartal beobachtet werden.

- Die meisten Maßnahmen nach den Stoffwechseluntersuchungen erfolgten im Zusammenhang mit der Fütterung. Außerdem stehen viele der Maßnahmen in Verbindung mit dem Mineralstoffhaushalt. 
- Die Parameter mit den meisten Untersuchungsergebnissen waren die FFS, BHB, Se, Hast, Cu, $\mathrm{Ca}$ und $\mathrm{P}_{\mathrm{i}}$.

- Für die Mehrzahl der Parameter konnten Veränderungen im Laktationsverlauf gezeigt werden.

- So zeigten die FFS vor allem a. p. bis acht Wochen p. p. Hinweise auf eine gesteigerte Lipolyse.

○ Gesteigerte BHB-Konzentrationen konnten ab der Kalbung und während der gesamten Laktation bei einer großen Anzahl von Kühen beobachtet werden.

○ Erhöhte Bilirubin-Konzentrationen waren hauptsächlich in der ersten Woche p. p. zu sehen.

○ Die Cholesterolkonzentrationen waren überwiegend im Referenzbereich und der Medianwert sank in der ersten Woche p. p. geringfügig ab.

- Gezeigt werden konnte ein steigender Harnstoffüberschuss im Laktationsverlauf mit einem Gipfel in der Mittellaktation.

○ Eine hohe Anzahl an zum Teil stark erhöhten CK-Konzentrationen wurden sowohl a. p. als auch p. p. gemessen. Dabei erhöhten sich die Abweichungen ab der zweiten Woche p. p. bis zur Spätlaktation mit zunehmendem Laktationsverlauf.

- Die Ca-Konzentrationen waren überwiegend physiologisch, nur in der ersten Woche p. p. kam es zu einem deutlichem Anstieg an Mangelzuständen.

- Beim $P_{i}$ zeigten die Mediane ebenfalls in der ersten Woche p. p. einen Abfall. Außerdem sind a. p. sowie in der ersten Woche p. p. vermehrt Konzentrationen über dem Referenzbereich beobachtet worden.

○ Die $\mathrm{Cu}-$ Konzentrationen zeigten einen Mediananstieg in der ersten Woche p. p. Geringgradig vermehrte Cu-Mangelzustände waren a. p. und in der Spätlaktation zu sehen. Insgesamt war die $\mathrm{Cu}-$ Versorgung jedoch ausgeglichen.

○ Bei Se wurden a. p. vermehrt Mangelzustände und ab der Kalbung bis zur Spätlaktation sowie bei den Färsen vermehrt Überversorgungen beobachtet.

○ Ein ß-Carotinmangel konnte bei zahlreichen Kühen von a. p. bis acht Wochen p. p. festgestellt werden, wobei die meisten Abweichungen von zwei bis acht Wochen p. p. auftraten.

- Bei der TEAC kommt es sowohl bei den Medianen als auch bei den Abweichungen ab der zweiten Woche p. p. zu einem starken Anstieg.

Ein Zusammenhang zu den Hauptabgangsursachen und zu den Einsendungsgründen kann somit auch vermutet werden. So weisen auf die Fruchtbarkeitsprobleme und die im Durchschnitt zu lange ZKZ die erhöhten FFS-, BHB-, Harnstoff- und Bilirubinkonzentrationen, sowie die Unterversorgung von Se a. p. und ß-Carotin hin. Auf die vermehrten Eutererkrankungen deuten ebenfalls die erhöhten FFS-, BHB-, Bilirubinkonzentrationen, sowie die erhöhte TEAC hin. Da die Klauenerkrankungen meist in Folge anderer Erkrankungen, wie Acidosen, Ketosen, erhöhter Fettmobilisation, und Mangelzuständen 
von Antioxidantien und Spurenelementen auftreten (FÜRLL 2013a), sind die abweichenden Konzentrationen der Parameter des Energie-Fett-Leber-Stoffwechsels auf diese oft genannte Abgangsursache ebenfalls hinweisend. Das verstärkte Auftreten von Ketosen kann durch die erhöhte Fettmobilisation, sowohl a. p. als auch p. p. sowie die zahlreichen Abweichungen von BHB während der gesamten Laktation auch bestätigt werden. Die Hypocalzämien in der ersten Wochen p. p. stimmen außerdem mit den Angaben von vermehrtem Auftreten von Festliegern als Probeneinsendungsgrund überein. Somit können die Probleme der Betriebe anhand der Abweichungen bei den verschiedenen Parametern nachvollzogen werden.

Unterschiede zwischen den einzelnen Einsendungsjahren konnten bei den meisten Parametern, zum Teil signifikant, nachgewiesen werden. Auch in den einzelnen Laktationsstadien waren Jahresunterschiede nachweisbar. Die Harnproben spielten in dieser Untersuchung eine untergeordnete Rolle, da nur eine sehr geringe Anzahl an Ergebnissen vorlag und damit ein Vergleich der Laktationsstadien und der Jahre nicht sinnvoll war.

Bei den Färsen waren vor allem die zahlreichen, offensichtlich altersbedingten Hyperphosphatämien, sowie die zu $100 \%$ erhöhten CK-Aktivitäten auffällig. Außerdem konnten bei ihnen vermehrt Cu- und ß-Carotin-Mangelzustände festgestellt werden, während bei Se sowohl Unter- als auch Überversorgungen von Bedeutung waren.

79,2\% der Betriebe, welche mindestens zweimal eingesendet haben, zeigten im Einsendungsverlauf eine Verbesserung der Stoffwechsellage. Außerdem konnte im Einsendungsverlauf bei $\mathrm{Ca}, \mathrm{P}_{\mathrm{i}}$, Hast, Chol, BHB, Bili, CK und $\mathrm{Cu}$ eine Verbesserung und bei den FFS und bei Se eine Verschlechterung in Bezug auf die Anzahl an physiologischen Einzelwerten festgestellt werden.

Diese Untersuchung hat somit gezeigt, dass Stoffwechselkontrollen in Kleinbetrieben von gleicher Notwendigkeit sind wie in Großbetrieben. Da die hauptsächlichen Abgangsursachen in dieser Auswertung die gleichen wie in anderen Untersuchung waren und somit die gleichen Bestandsprobleme auftreten, ist es in Bezug auf die Notwendigkeit von Stoffwechseluntersuchungen irrelevant, ob es sich um Groß- oder Kleinbetriebe handelt. Somit ist nach wie vor eine regelmäßige Stoffwechselkontrolle anzuraten, zumal in dieser Untersuchung gezeigt werden konnte, dass es bei wiederholten Einsendungen mehrheitlich zu einer Verbesserung der Stoffwechsellage gekommen ist. In kleineren Betrieben haben demzufolge peripartale Einzeltieranalysen einen besonderen Informationswert über den Herdenzustand. Die Untersuchungen machen auch deutlich, dass der enge Zusammenhang zwischen Stoffwechselstörungen einerseits sowie Organkrankheiten und Merzungsursachen viel stärker berücksichtigt und veröffentlicht werden müssen. 


\section{$6 \quad$ Zusammenfassung}

Verfasser: Johanna Bothmann

Titel: $\quad$ Stoffwechselmonitoring in kleinen und mittelgroßen Milchrindbetrieben im Emsland

Klinik: Medizinische Tierklinik der Veterinärmedizinischen Fakultät der Universität Leipzig

Eingereicht im September 2014

Bibliografische Angaben: 100 Seiten, 31 Abbildungen, 36 Tabellen, 154 Literaturangaben, Anhang

Schlüsselwörter: Stoffwechselkontrolle, Kleinbetriebe, Milchkühe, Jahresvergleich

Problemstellung: Die frühzeitige Erkennung von Störungen vor ihrer klinischen Manifestation ist das Grundanliegen der Prophylaxe. Da besonders die Krankheiten des Fettmobilisationsyndroms fütterungs- und damit stoffwechselbedingt sind, besitzt deren frühzeitige Feststellung durch Stoffwechselkontrollen im peripartalen Zeitraum herausragende Bedeutung.

Ziel dieser Analyse war es, Erfahrungen für Indikationen, Durchführung und Ergebnisse mehrjähriger Stoffwechselkontrollen in kleinen und mittelgroßen Betrieben auszuwerten und zu dokumentieren. Dazu wurden die von einer tierärztlichen Gemeinschaftspraxis im Emsland betreuten Betriebe anamnestisch charakterisiert, die Indikationen für Untersuchungen, die Kontrollzeiträume in Laktations- und Jahreszeitverlauf sowie in der jährlichen Abfolge erfasst, die Art und Häufigkeit der untersuchten Parameter sowie ihre klinische Bedeutung insgesamt, betriebsweise sowie z.T. für einzelne Kühe bei Mehrfachkontrollen analysiert. Erfasst wurden auch die von den Landwirten eingeleiteten Maßnahmen sowie die Ergebnisse bezüglich des Gesundheitszustands der Kühe.

Versuchsanordnung: Die Anamnesen von 53 Betrieben wurden per Fragebögen erhoben. Aus 60 Betrieben flossen 840 Proben aus 122 Einsendungen mit 793 Blutserumproben und 47 Harnproben von Oktober 2006 bis März 2011 in diese Untersuchung ein. Die Kühe wurden nach Laktationsstadium in die Gruppen ante partum (a. p.), 1. Woche (Wo) post partum (p. p.), 2 - 8 Wo p. p, 9 - 14 Wo p. p, mehr als 100 Tage p. p. und Färsen eingeteilt. Die Parameterauswahl trafen die behandelnden Hoftierärzte mit den Landwirten. Untersucht wurden im Blutserum in absteigender Zahl: Freie Fettsäuren (FFS), ß-Hydroxybutyrat (BHB), Se, Harnstoff, $\mathrm{Cu}, \mathrm{Ca}$, anorganisches Phosphat $\left(\mathrm{P}_{\mathrm{i}}\right)$, Bilirubin, CK, Cholesterol, GLDH, GGT, ß-Carotin, Fe, AST, Total-Protein, Albumin, Na, K, Cl, Mg, Glucose, Gallensäuren, Zn, AP, Kreatinin, Mn, Coeruloplasmin sowie die Trolox Äquivalente Antioxidative Kapazität (TEAC). Harnparameter sind selten untersucht worden. Die Betriebe sind fast ausschließlich Milcherzeugerbetriebe und hatten zwischen 24 und 270 Kühe überwiegend der Rasse Deutsche Holsteins mit einer mittleren Milchleistung von 8718 kg pro Jahr.

Ergebnisse: Die häufigsten Merzungsgründe waren schlechte Fruchtbarkeit, Klauen- und Gliedmaßen- sowie Eutererkrankungen. Die Gründe für die Stoffwechselkontrollen waren die Abfrage 
des aktuellen Stoffwechselstatus sowie das vermehrte Auftreten von Fruchtbarkeitsproblemen, Festliegern, Ketosen und Euterproblemen. Maßnahmen nach der Stoffwechselauswertung waren überwiegend Futterumstellungen sowie die Substitution von Mineralstoffen.

Die Einsendungsschwerpunkte lagen jeweils im ersten Jahresquartal. Die mittlere Probenanzahl/Einsendung sank im Untersuchungszeitraum von 9,7 auf 5,1 ab. Im Durchschnitt wurden 9,9 Parameter/Einsendung untersucht. Bei annähernd $80 \%$ der Einsendungen gaben $40 \%$ bis $70 \%$ der Parameter einen Hinweis auf eine Gesundheitsgefährdung des Bestandes.

Im Laktationsverlauf hatten die FFS a. p. mit 56,7 \% die häufigsten Abweichungen. Nach der Kalbung bis 8 Wo p. p. sanken sie auf $36 \%$ bis $38 \%$ und im weiteren Verlauf auf $<11 \%$ ab. Die BHB-Abweichungen waren gegensätzlich und lagen in der gesamten Laktation über $68 \%$. Die FFS-, BHB- sowie Bilirubin-Medianwerte stiegen in der 1. Wo p. p auf $438 \mu \mathrm{mol} / \mathrm{l}, 0,86 \mathrm{mmol} / \mathrm{l}$ sowie 4,3 $\mu \mathrm{mol} / \mathrm{l}$ und sanken dann kontinuierlich im Laktationsverlauf wieder ab. Die Cholesterol-Medianwerte sanken in der 1 . Wo p. p. auf 2,16 mmol/l ab und stiegen im Laktationsverlauf bis auf 3,93 mmol/l an. $40 \%$ bis $50 \%$ der Kühe hatten in der Mittel- und Spätlaktation einen Harnstoffüberschuss. Ca und $\mathbf{P}_{\mathbf{i}}$ hatten in der 1. Wo p. p. den typischen Konzentrationsabfall auf 2,27 bzw. 1,88 mmol/l, gefolgt von einem kontinuierlichem Anstieg in der Laktation. Hypocalzämien traten zu 13,2 \% in der 1. Wo p. p. auf, Hyperphosphatämien überwiegen a. p. mit $24,9 \%$ und in der 1 . Wo p. p. mit 22,4 \%. Die CKMediane betrugen in der 1. Wo p. p. 175,6 U/l; a.p. sowie ab 1. Wo p. p. waren sie > 100 U/I. Ähnlich verhielten sich die CK-Abweichungen mit 60,4 \% a. p. und 73,6\% bis 90,9\% ab der 2. Wo p. p. Die CK-Aktivitäten der Färsen sind zu $100 \%>100$ U/I. Cu-Mangelzustände wurden bei 12,5\% a. p. und $14,8 \%$ der Kühe in der Spätlaktation beobachtet. Färsen zeigten mit 21,3\% am häufigsten $\mathrm{Cu}$ Unterversorgungen. A. p. bestand zu 20,6 \% Se-Unterversorgungen, p. p. hingegen zu 30,1 bis 37\% eine Se-Überversorgung. B-Carotin-Mangelzustände betrugen a. p. $50 \%$ und p. p. 47,1-77,8 \%. Die TEAC zeigte bei keinen Kontrollen einen Antioxidantienmangel an.

Bei den meisten Parametern waren z.T. signifikante Unterschiede zwischen den einzelnen Untersuchungsjahren festzustellen. Bei den FFS und B-Carotin bestand ein ansteigender Trend an Abweichungen, ein sinkender Trend bei $\mathrm{P}_{\mathrm{i}}$ - Abweichungen. In den sechs Kontrolljahren konnte bei $80 \%$ der Betriebe eine Verbesserung der Stoffwechselsituation dokumentiert werden. Bei den Parametern Ca, $\mathrm{P}_{\mathrm{i}}$, Harnstoff, Cholesterol, BHB, Bilirubin, $\mathrm{CK}$ und $\mathrm{Cu}$ stieg die Zahl physiologischer Werte im Einsendungsverlauf an; nur bei FFS und Se war eine Abnahme zu verzeichnen.

Schlussfolgerungen: In kleinen und mittelgroßen Betrieben lieferten systematische Stoffwechselanalysen im peripartalen Zeitraum frühzeitig kausale Hinweise für die häufigsten Krankheiten und Merzungsursachen. Als informative Parameter bewährten sich Indikatoren des Energiestoffwechsels FSS, BHB und Bilirubin, weiterhin Harnstoff, das Se sowie das B-Carotin. Die systematischen Analysen trugen im Analysenzeitraum zu Verbesserungen in den Betrieben bei. In kleineren Betrieben haben peripartale Einzeltieranalysen besonderen Informationswert über den Herdenzustand. 


\section{Summary}

Author: Johanna Bothmann

Title: Monitoring of metabolism in small to medium-sized dairy farms in Emsland

Clinic: $\quad$ Large Animal Clinic for Internal Medicine, Faculty of Veterinary Medicine, University of Leipzig

Submitted in September 2014

Bibliographic Data: 100 pages, 31 figures, 36 tables, 154 references, appendix

Key words: Metabolism control, smallholder, dairy cow, annual comparison

Thesis outline: The main aim of prophylaxis is the diagnosis of diseases before their clinical manifestation. Since illnesses relating to body fat mobilisation are related to feeding and therefore metabolism, early diagnosis through metabolism controls during the peripartum period is of critical importance.

Aims: The primary aim of this analysis was to evaluate and document reasons for conducting examinations on cows, as well as the implementation and results of metabolism controls in small- to medium-sized dairy farms. Dairy farms under the care of a veterinary practice in Emsland were characterised in terms of their operational structure. Symptoms resulting in examinations, as well as lactation stage, seasonal and annual cycle were recorded. Additionally, the type and frequency of investigated parameters, as well as their clinical significance were analysed through repeated controls for individual cows and whole dairy farms.

Methods: The operational structures of 53 dairy farms were obtained by means of questionnaires. 60 dairy farms submitted 122 batches with 840 samples, consisting of 793 blood serum samples and 47 urine samples from October 2006 to March 2011. The cows were divided into the following groups according to lactation stage: ante partum (a. p.), 1 week (wk) post partum (p. p.), 2-8 wk p. p., 9-14 wk p.p., over 100 days p. p. and heifers. The selection of parameters was done jointly by the veterinary surgeons and dairy farm owners. The following parameters were measured in blood serum samples, in decreasing sample size: non-esterified fatty acids (NEFA), beta-hydroxybutyrate (BHB), Se, urea, $\mathrm{Cu}$, $\mathrm{Ca}$, inorganic phosphate $\left(\mathrm{P}_{\mathrm{i}}\right)$, bilirubin, $\mathrm{CK}$, cholesterol, GLDH, GGT, ß-carotine, Fe, AST, total protein, albumin, $\mathrm{Na}, \mathrm{K}, \mathrm{Cl}, \mathrm{Mg}$, glucose, bile acid, $\mathrm{Zn}, \mathrm{AP}$, creatinine, $\mathrm{Mn}$, ceruloplasmin, as well as trolox equivalent antioxidative capacity (TEAC). Urine samples were seldom analysed. The farms were almost exclusively milk-producing enterprises, consisting of 24 to 270 cows primarily of the breed Deutsche Holsteins with an average milk yield of $8718 \mathrm{~kg}$ per annum.

Results: The main reasons for culling were low fertility, and occurrence of disease in hooves, limbs and udders. Metabolism controls were implemented in order to address requests to establish metabolism status, as well as address concerns about increasing occurrence of fertility problems, 
parturient paresis, and udder problems. Actions taken after the evaluation involved primarily diet adjustments as well as mineral substitutions.

The majority of samples were submitted annually in the first quarter. The average number of samples per batch decreased during the investigation period from 9.7 to 5.1. On average, 9.9 parameters were investigated per batch. For almost $80 \%$ of the submitted batches, $40-70 \%$ of the parameters indicated that the stock was health compromised.

In the lactation period, the NEFA a.p. had the most deviations from the norm (56.7\%). After calving to 8 wk p. p, these dropped to $36 \%-38 \%$, and after that to $<11 \%$. Conversely, the BHB deviations were about $68 \%$ throughout the lactation period. The NEFA, BHB and bilirubin median values rose in the first wk p. p. to $438 \mu \mathrm{mol} / 1,0,86 \mathrm{mmol} / \mathrm{l}$ and 4,3 $\mu \mathrm{mol} / 1$ respectively, and dropped continuously during the lactation period. The cholesterol median values dropped in the first wk p. p. to $2.16 \mathrm{mmol} / \mathrm{l}$ and rose in the lactation period to $3.93 \mathrm{mmol} / \mathrm{l}$. Of the cows assessed, $40 \%$ to $50 \%$ experienced an excess of urea in the middle to late lactation period. In the first wk p. p. concentrations of $\mathbf{C a}$ and $\mathbf{P i}$ showed a typical drop to 2.27 and $1.88 \mathrm{mmol} / \mathrm{l}$ respectively, followed by a continuous increase during lactation. Hypocalcaemia were observed within the first wk p. p. (13.2\%), while hyperphosphataemia dominated a. p. (24.9\%) and in the first wk p. p (22.4\%). CK median values were 175.6 U/I in the first wk p. p., and >100 U/I a. p. and after the first wk p. p. The percentage CK activities deviating from the norm were similarly $60.4 \%$ a. p. and $73.6 \%$ to $90.9 \%$ after the first wk p. p. The CK activities of the heifers were all $>100$ U/I. Cu deficiencies were observed in $12.5 \%$ a. p. and $14.8 \%$ for cows in late lactation phase. Heifers showed the most $\mathrm{Cu}$ deficiencies with $21.3 \%$. Se deficiency was observed in $20.6 \%$ a. p., while p. p. showed $30.1 \%$ to $37 \%$ Se excess. B-carotine deficiencies were observed a. p. $(50 \%)$ and p. p. $(47.1 \%-77.8 \%)$. TEAC did not indicate an anti-oxidant deficiency in the controls.

For most parameters some significant differences were observed between different sample years. NEFA and B-carotine deviations showed an increasing trend, while $\mathrm{P}_{\mathrm{i}}$ deviations showed a decreasing trend. During the six control years an improvement in the metabolism status could be observed for 80 $\%$ of the dairy farms. For $\mathrm{Ca}, \mathrm{P}_{\mathrm{i}}$, urea, chol, $\mathrm{BHB}$, Bilirubin, $\mathrm{CK}$ and $\mathrm{Cu}$ the proportion of values within the norm increased over the study period; a decrease was only detected for NEFA and Se.

Conclusions: In small- to medium-sized dairy farms, systematic metabolism analyses in the peripartum period yielded early warnings for the most common diseases and issues potentially leading to culling. Indicators of energy metabolism, as well as Se and $\beta$-carotine, were shown to be informative parameters. During the analysis phase of this study, the systematic analyses contributed towards improvements at the dairy farms. For small dairy farms, analysis of individual animals provides valuable information about the condition of the herd. 


\section{$8 \quad$ Literaturverzeichnis}

Ackermann S, Gottschalk J, Einspanier A, Jäckel L, Fürll M. Beziehungen zwischen peripartalem Stoffwechsel, Leistung sowie Morbidität bei Holstein Friesian-Kalbinnen eines Bestandes und deren Nutzungsdauer. Tierärztl Prax. 2013a;41(G):88-94.

Ackermann S, Jäckel L, Hädrich G, Heckel F, Fürll M. Peripartaler Stoffwechsel, Merzungsursachen und Nutzungsdauer bei Holstein-Friesian Kühen. Wien Tierärztl Mschr. 2013b;100:10-18.

Adams RS, Stout WL, Kradel DC, Guss SB Jr, Moser BL, Jung GS. Use and Limitations of Profiles in Assessing Health or Nutritional Status of Dairy Herds. J Dairy Sci. 1978;61:1671-79.

Ahmed M, Gelfert CC, Staufenbiel R. Technik der Leberbiopsie beim Rind und Vergleich zweier Methoden zur Bestimmung des Leberfettgehaltes 28. Leipziger Fortbildungsveranstaltung Labordiagnostik in der Bestandsbetreuung; Leipzig 2003 (zitiert vom 10.09.2014); $<$ http://www.vetmed.uni-leipzig.de/ik/wmedizin/labor/laborfortbildung/leipziger_laborfortbildung_ 03.pdf>

Anacker G. Abschlussbericht Analyse der Abgangsursachen von Jungkühen in Thüringen. 2009 (zitiert vom 10.09.2014): 1-44, <http://www.db-thueringen.de/servlets/DerivateServlet/Derivate20214/Analyse der Abgangsursachen.pdf>

Armstrong RB, Warren GL, Warren JA. Mechanisms of exercise-induced muscle fiber injury. Sport Med. 1991;12:184-207.

Baumgärtner W. Ein Beitrag zur Frühdiagnose von Stoffwechselerkrankungen bei Hochleistungsrindern. Dtsch. tierärztl. Wschr. 1979;86:336-43.

Bender S, Gelfert CC, Staufenbiel R. Einsatz der Harnuntersuchung zur Beurteilung des Säure-BasenHaushalts in der Bestandsbetreuung von Milchkuhherden. Tierärztl Prax. 2003;31:132-42.

Bernhard A. Der diagnostische Wert der Harnstoffbestimmung in der Milch im Hinblick auf die Fruchtbarkeit beim Rind. [Dissertation med. vet]. Leipzig: Univ. Leipzig; 1992.

Bijmholt S, Müller K, Leiding C, Hoedemaker M, Bollwein H, Kaske M. Laktationsinzidenzen von Produktionskrankheiten bei Fleckviehkühen in sechs bayerischen Milchviehbetrieben. Tierärztl Prax. 2012;40:347-58. 
Borchardt S, Staufenbiel R. Evaluation of the use of nonesterified fatty acids and $\beta$-hydroxybutyrate concentrations in pooled serum samples for herd-based detection of subclinical ketosis in dairy cows during the first week after parturition. J Am Vet Med Assoc. 2012;240:1003-11.

Bostedt H. Enzymaktivitäten im Blutserum von Rindern in der Zeit um die Geburt. Berl Münch Tierärztl Wschr. 1974;87:365-71.

Brydl E. Occurrence of subclinical metabolic disorders on dairy farms in Hungary between 19911997. Magy Allato. 1999;121:82-4.

Brydl E, Jurkovich V, Könyves L, Tegzes L, Kalman I. Occurrence of subclinical metabolic disorders in large-scale dairy farms in Hungary in 2001. Proceedings of the $11^{\text {th }}$ International Congress ISAH; 2003 Feb 23-27; Mexico City, Mexiko. 2003a; pp. 1-5.

Brydl E, Jurkovich V, Könyves L, Rafai P, Tegzes L. Occurrence of subclinical metabolic disorders in large-scale dairy farms in Hungary in 2002. Proceedings of the 4th Central European Congress for Buiatrics; 2003 April 23-27; Lovran, Kroatien. 2003b, p. 167. zitiert in Gaal T. Epidemiology of Production diseases in high-producing dairy cows - Hungarian experiences. Proceeding of $13^{\text {th }}$ International conference on production diseases in farm animals; 2007 Jul 29 - Aug 4; Leipzig.

Brydl E, Könyves L, Jurkovich V, Tegzes L, Tirián A. 2006. Subclinical metabolic disorders in peripartal dairy cows in Hungary in 2004. 24 $4^{\text {th }}$ World Buiatrics Congress, 2006; Okt 15-19; Nice, France. 2006; Ref.: 0831-1. zitiert in: Gaal T. Epidemiology of Production diseases in high-producing dairy cows - Hungarian experiences. Proceeding of $13^{\text {th }}$ International conference on production diseases in farm animals; 2007 Jul 29 - Aug 4; Leipzig.

Busch W, Methling W, Amselgruber WM. Tiergesunheits- und Tierkrankheitslehre. 1. Aufl. Stuttgart: Parey Verlag; 2004.

Chamberlin WG, Middleton JR, Spain JN, Johnson GC, Ellersieck MR, Pithua P. Subclinical hypocalcemia, plasma biochemical parameters, lipid metabolism, postpartum disease, and fertility in postparturient dairy cows. J dairy Sci. 2013;96:7001-13.

Clark JF, Kuznetsov AV, Khuchua Z, Veksler V, Ventura-Clapier R, Saks V. Creatine kinase function in mitochondria isolated from gravid and non-gravid guinea-pig uteri. FEBS Lett. 1994;347:147-51. 
Conrads A. Einfluss einer Supplementierung mit $\beta$-Karotin in Form einer Injektionslösung (Carofertin $\left.{ }^{\circledR}\right)$ auf die Eutergesundheit von Milchkühen und die Kälbergesundheit [Dissertation med. vet]. Hannover: Tierärztl. Hochsch. Hannover; 2003.

Daetz C. Untersuchungen zur Konditionsentwicklung bei Milchkühen in der Trockenstehperiode mittels ultrasonographischer Messung der Rückenfettdicke und deren Einfluss auf Leistung, Fruchtbarkeit und Tiergesundheit in der Frühlaktation. [Dissertation med. vet] Berlin: Frei Univ. Berlin; 2009.

Drackley JK. Biology of Dairy Cows During the Transition Period: the Final Frontier? J Dairy Sci. 1999;82:2259-73.

Drackley JK. Fütterung und Managment der Milchkuh im peripartalen Zeitraum. Tagungsbericht 9. Symposium Dr. Pieper Fütterung und Management von Kühen mit hohen Leistungen; 2005 (zitiert vom 10.09.2014): 1-37, <http://www.dr-pieper.com/file/89.pdf>

DU Z, Hemken RW, Harmon RJ. Copper Metabolism of Holstein and Jersey Cows and Heifers Fed Diets High in Cupric Sulfate or Copper Proteinate. J Dairy Sci. 1996;79:1873-80.

Dübeler I. Antioxidativer Status in Euterlymphe und Blut bei gesunden und kranken Kühen. [Dissertation med. vet]. Leipzig: Univ. Leipzig; 2006.

Duffield TF, Lissemore KD, McBride BW, Leslie KE. Impact of hyperketonemia in early lactation dairy cows on health and production. J Dairy Sci. 2009;92:571-80.

Dyk PB, Emery RS, Liesmann JL, Bucholtz HF, VandeHaar MJ. Prepartum nonesterified fatty acids in plasma are higher in cows developing peripartum health problems. J Dairy Sci. 1995;78:264.

Eckermann E. Stoffwechseluntersuchungen in der Trockenstehperiode bei gesunden und post partum festliegenden Kühen. [Dissertation med. vet.]. Leipzig: Univ. Leipzig; 2007.

Eicher R. Metabolic Profile Testing in Dairy Herds: Wrong Answer or Wrong Question? Acta Vet Scand Suppl. 2003;98:203.

Enjalbert F, Lebreton P, Salat O, Meschy F, Schelcher F. Effects of copper supplementation on the copper status of peripartum beef cows and their calves. Vet Rec; 2002;151:50-3. 
Enjalbert F, Lebreton P, Salat O. Effects of copper, zinc and selenium status on performance and health in commercial dairy and beef herds: retrospective study. J Anim Physiol Anim Nutr. 2006;90:459-66.

Euler C. Zusammenhänge zwischen peripartalen Veränderungen Stoffwechselrelevanter Blutserum-, Milch- und Körperkonditionsparameter und Erkrankungen der Gebärmutter. [Dissertation med. vet] München: Ludw.-Max.-Uni München; 2009.

Evertz C. Stoffwechseluntersuchungen bei Hochleistungskühen im peripartalen Zeitraum unter Berücksichtigung klinischer Erkrankungen [Dissertation med. vet.]. Leipzig: Univ. Leipzig; 2006.

Finn F. Untersuchungen zum antioxidativen Status und Stoffwechsel bei Färsen im peripartalen Zeitraum [Dissertation med. vet]. Leipzig: Univ. Leipzig; 2014.

Fürll M. Vorkommen, Ätiologie, Pathogenese, Diagnostik und medikamentelle Beeinflussung von Leberschäden beim Rind.[Habilschr. med. vet.]. Leipzig: Univ. Leipzig; 1989.

Fürll M. Spezielle Untersuchungen beim Wiederkäuern. In: Moritz A, Hrsg. Klinische Labordiagnostik in der Tiermedizin. 7. Aufl. Stuttgart: Schattauer-Verlag; 2013a, p. 726-77.

Fürll M. Standardisierte Labordiagnostik bei Rinder. 38. Leipziger Fortbildungsveranstaltung Labordiagnostik in der Bestandsbetreuung; Leipzig 2013b (zitiert vom 10.09.2014); $<$ http://www.vetmed.uni-leipzig.de/ik/wmedizin/labor/laborfortbildung/leipziger_laborfortbildung_ 13.pdf>

Fürll M. Kalium (K) bei Kühen - ein update. Nutztierpraxis. 2014a,14:87-96.

Fürll M. Möglichkeiten zur praktischen Diagnostik von Pansenfermentationsstörungen bei Kühen. Tierärztl Umschau. 2014b;8:315-24.

Fürll M, Fürll B. Stoffwechselcheck bei Milchkühen. Tagungsbericht des 4. Leipziger Tierärztekongress; 2008 17.-19.Jan; Leipzig: 2008.

Fürll M, Schäfer M. Hyperbilirubinämie bei Wiederkäuern. Mh Vet Med. 1993;48:181-5.

Garro CJ, Mian L, Cobos Rold M. Subclinical ketosis in dairy cows: prevalence and risk factors in grazing production system. J Anim Physiol Anim Nutr. 2013; doi: 10.1111/jpn.12141. 
Gelfert CC, Staufenbiel R. Zur Stoffwechselüberwachung in Milchviehherden. Tierärztl. Umschau. 2007;62:176-82.

Ghergariu S, Rowlands GJ, Pop AL, Danielescu N, Moldovan NA. A Comparative Studie of Metabolic Profiles obtained in Dairy Herds in Romania. Brit Vet J. 1984;140:600-8.

Glindemann A. Beziehung zwischen verschiedenen Parametern des Energiestoffwechsels und der Eutergesundheit beim Milchrind unter Berücksichtigung des Melksystems. [Dissertation med. vet] München: Ludw.-Max.-Uni München 2006.

Goerigk D, Steinhöfel I, Fürll M. Peripartaler „Revised Quantitative Insulin Sensitivity Check Index“ (RQUICKI) bei unterschiedlich aufgezogenen Färsen. Wien Tierärztl Mschr. 2011;98:76-81.

Goerres A, Fürll M.(2002):Endotoxine (ET) und ET-Effektoren (ALA-AK, APP) bei häufigen Rinderkrankheiten. In: FÜRLL, M. (Hrsg.): Stoffwechselstörungen bei Wiederkäuern: Erkennen Behandeln - Vorbeugen. Leipzig: Med. Tierklinik; 2002. p. 137-144.

Goff JP. The monitoring, prevention, and treatment of milk fever and subclinical hypocalcemia in dairy cows. Vet J. 2008;176:50-7.

Goff JP, Kimura K, Horst RL. Effect of Mastectomy on Milk Fever, Energy, and Vitamins A, E, and ß-Carotene Status at Parturition. J Dairy Sci. 2002;85:1427-36.

Grummer RR. Impact of changes in organic nutrient metabolism on feeding the transition dairy cow. J Anim Sci. 1995;73:2820-33.

Gürtler H. Zur Absicherung industriemäßiger Milchproduktionsanlagen gegenüber Stoffwechselkrankheiten durch klinisch-chemische Untersuchungsmethoden. Mh Vet Med. 1976;31:481-4.

Hacker U, Siering W. Möglichkeiten der Frühdiagnose von Stoffwechselstörungen bei Milchkühen während der Trächtigkeit und nach dem Abkalben. Mh Vet Med 1979;34:361-4.

Hädrich G. Untersuchungen zu der Entwicklung der Körperkondition, dem peripartalen Stoffwechsel und der Morbidität von Hochleistungskühen. [Dissertation med. vet.]. Leipzig: Univ. Leipzig; 2007.

Haghighat-Jahromi M, Nahid S. Incidence of Subclinical Ketosis in Dairy Cows in Fars Province of Iran and Reproductive Performance in Early Lactetion Period. Asian J Anim Sci. 2011;5:158-61. 
Hagmüller W. Untersuchungen an Braunviehrindern im oberösterreichischen Innviertel Stoffwechselprofile der ersten 100 Laktationstage. [Dissertation med. vet] Hannover: Tierärztl Hochsch. Hannover; 2002.

Haraszti J, Huszenicza GY, Molnár L, Horkai B. Veränderungen gewisser metabolischer Blutparameter ante partum und ihre Bedeutung zur Vorhersage der postpartalen Fortpflanzungschancen. Dtsch Tierärztl Wschr. 1982;89:357-61

Haraszti J, Huszenicza GY, Molnar L, Blaskovits A. Effect of periparturient lipid mobilization on serum total carotene and vitamin A concentrations in cattle. Acta Vet. Hungarica. 1984;32:193-203

Heckel F. Peripartaler Stoffwechsel- und Gesundheitsstatus sowie Fruchtbarkeit bei unterschiedlichen Milchleistungen von Schwarzbunten Kühen [Dissertation med. vet]. Leipzig: Univ. Leipzig; 2009.

Heilig M, Bäuml D, Fürll M. Potenzielle Bedeutung des Spurenelements Selen für die Entstehung der Gebärparese beim Rind. Tierärztl Prax. 2014;5:1-9.

Herold H. Auswertung der prophylaktischen Stoffwechselüberwachung in industriemäßig produzierenden Milchviehanlagen des Bezirkes Leipzig nach TGL 34313, Kategorie A, von 1979 bis 1987 [Diplomschr. med vet]. Leipzig: Univ. Leipzig; 1989.

Hoedemaker M, Mansfeld R, de Kruif A, Heuwieser W. Ergebnisinterpretation und Strategien Betrachtung einzelner Kontrollbereiche In: De Kruif A, Mansfeld R, Hoedemarker M, Hrsg. Tierärztliche Bestandsbetreuung beim Milchrind. 3. Aufl. Stuttgart: Enke; 2014, p. 46-282.

Hoops M. Peripartaler Stoffwechsel und Morbidität bei Hochleistungskühen während eines Jahres. [Dissertation med. vet]. Leipzig: Univ. Leipzig; 2007.

Hostens M, Ehrlich J, Van Ranst B, G Opsomer. On-farm evaluation of the effect of metabolic diseases on the shape of the lactation curve in dairy cows through the MilkBot lactation model. J dairy Sci. 2012;95:2988-3007.

Illek J. Epidemiology of production diseases in dairy cows on Czech dairy farms. Proceedings of 14th Middle European Buiatrics Congress; 2014 May 25-27; Warschau, Polen. 2014.

Jackson M. Oxygen radical production and muscle damage during running exercise. In: Marconnet P, Saltin B, Komi P, Poortmans J. Human muscular function during dynamic exercise. Basel: Karger; 1996. pp. 121-33. 
Johnston LA, Chew BP. Peripartum Changes of Plasma and Milk Vitamin A and B-Carotene Among Dairy Cows with or Without Mastitis. J Dairy Sci. 1984;67:1832-40

Kappel LC, Ingraham RH, Morgan EB, Zeringue L, Wilson D, Babcock DK. Relationship between fertility and blood glucose and cholesterol concentrations in Holstein cows. Am J Vet Res. 1984;45:2607-12.

Kida K. The Metabolic Profile Test: Its Practicability in Assessing Feeding Management and Periparturient Diseases in High Yielding Commercial Dairy Herds. J Vet Med Sci. 2002a;64:557-63.

Kida K. Use of Every Ten-Day Criteria for Metabolic Profile Test after Calving and Dry Off in Dairy Herds. J Vet Med Sci. 2002b;64:1003-10.

Kirchner K, Schulz O, Großmann H. Untersuchungen über das Verhalten einiger Stoffwechselparameter im geburtsnahem Zeitraum bei industriemäßigen gehaltenen Milchrindern. Mh Vet Med. 1977;32:566-8.

Kleiser L, Fürll M. Screening zur Früherkennung einer Disposition für die Dislocatio abomasi bei Kühen. In: Fürll M, Hrsg. Stoffwechselbelastung, -diagnostik und -stabilisierung beim Rind. Leipziger Samstagsakademie, Medizinische Tierklinik der Veterinärmedizinischen Fakultät Leipzig, Akademie für Tierärztliche Fortbildung, Leipzig 1998; 95-104.

Komiyama Y, Adachi T, Ito Y, Hirano K, Sugiura M, Sawaki S. Microassay of Serum Bile Acids by an Enzymatic Cycling Method. Chem Pharm Bull. 1982;30:3796-99.

Könyves L, Szenci O, Jurkovich V, Tegzes L, Tirián A, Solymosi N, Gyulay G, Brydl E. Risk assessment of postpartum uterine disease and consequences of puerperal metritis for subsequent metabolic status, reproduction and milk yield in dairy cows. Acta Vet Hung. 2009;57:155-69.

Kraft W. Referenzbereich, Normalbereich, Normbereich, Normalwert . In: Kraft W, Dürr UM. Klinische Labordiagnostik in der Tiermedizin. 6. Auflage. Stuttgart: Schattauer Verlag; 2005. p. 1-6.

Kraft W, Dürr UM. Leber. In: Kraft W, Dürr UM. Klinische Labordiagnostik in der Tiermedizin. 6. Auflage. Stuttgart: Schattauer Verlag; 2005. p.122-33.

Krinn C. Bedeutung und Entwicklung der Integrierten Tierärztlichen Bestandsbetreuung (ITB) in der Rinderpraxis Statistische Auswertung einer schriftlichen Befragung der Tierärzteschaft der Bundesrepublik Deutschland. [Dissertation med. vet] München: Ludw.-Max.-Univ. München; 2004. 
Kronschnabl C. Ermittlung von laktationsspezifischen Prognosebereichen zur Beurteilung der Konzentration von Blutparametern beprobter Milchkühe [Dissertation med. vet].München: Ludw.Max.-Univ. München; 2010.

Kurek L, Lutnicki K, Banach A. Various types of hypophosphataemia in dairy cows and the clinical implications depending on the intensivity of the deficiency. Bull Vet Inst Pulawy. 2010;54:35-41.

Landeskontrollverband (LKV) WESER-EMS e. V. Jahresbericht 2008. 2008: 1-84.

Landeskontrollverband (LKV) WESER-EMS e. V. Jahresbericht 2010. 2010: 1-84.

Launer P, Storm R. Untersuchungen zur Diagnostik des Natriummangels bei Milchkühen. Mh Vet Med. 1979;34:364-72.

LeBlanc SJ. Monitoring metabolic health of dairy cattle in the transition period. J Repod Dev. 2010; 56 (Suppl): 29-35.

LeBlanc SJ, Herdt TH, Seymour WM, Duffield TF, Leslie KE. Peripartum Serum Vitamin E, Retinol, and Beta-Carotene in Dairy Cattle and Their Associations with Disease. J Dairy Sci. 2004;87:609-19.

LeBlanc SJ, Leslie KE, Duffield TF. Metabolic Predictors of Displaced Abomasum in Dairy Cattle. J. Dairy Sci. 2005;88:159-70.

Lee AJ, Twardock AR, Bubar RH, Hall JE, Davis CL. Blood Metabolic Profiles: Their Use and Relation to Nutritional Status of Dairy Cows. J Dairy Sci. 1978;61:1652-70.

Lober U. in: Hofmann W, Hrsg. Rinderkrankheiten. Innere und chirurgische Erkrankungen des Rindes. 2. Aufl. Stuttgart: Eugen Ulmer; 2005. p. 365

Lotthammer KH. Gesundheits- und Fruchtbarkeitsstörungen beim Milchrind. Klinisch-chemische Untersuchungen als Hilfsmittel zur Herdendiagnostik (Klärung der Ursachen). Tierärztl Prax. 1981;9:541-51.

Lotthammer KH, v Benten K, El Nahas H. Klinisch-chemische Blutuntersuchungen zur Frühdiagnose und Grundlage der Prophylaxe primär nicht infektiöser Erkrankungen des Rindes im Puerperium. Prakt Tierarzt. 1971;13:563-7. 
Mansfeld R, Gruneberg W, Thiemann E, Grunert E. Statistical analysis of metabolic profiles of blood and saliva samples used as a tool for herd diagnostic procedures. Züchtungskunde. 1996;5:325-45.

Martin R, Kersch Y, Sauter-Louis C, Glindemann A, Mansfeld R. Zusammenhänge zwischen verschiedenen Parametern zur Beurteilung der Energiebilanz und Zellsubpopulationen in der Milch eutergesunder Kühe. Tierärztl Prax. 2012;4:209-16.

McArt JA, Nydam DV, Oetzel GR. Epidemiology of subclinical ketosis in early lactation dairy cattle. J Dairy Sci. 2012;95:5056-66.

Meglia GE, Holtenius K, Petersson L, Öhagen P, Persson Waller K: Prediction of vitamin A, vitamin E, selenium and zinc status of periparturient dairy cows using blood sampling during the mid dry period. Acta Vet Scand. 2004;45:119-28.

Miller NJ, Sampson J, Candeias LP, Bramley PM, Rice-Evans CA. Antioxidant activities of carotenes and xanthophylls. FEBS Letters 1996;384:240-2.

Mücke E. TGL- Technische Regeln im Osten Deutschlands. Vom Aliierten Kontrollrat bis zur Normenunion 1945 - 1990. 1. Aufl. Berlin: Beuth Verlag; 2010.

Naumann A. Nutzungsdauer und Lebenseffektivität der Milchkühe in Sachsen-Anhalt. Vortrag zum 32. Tag des Milchviehhalters in Sachsen Anhalt; 2011 (zitiert vom 10.09.2014), <http://www.lkvst.de/index.php?name=content $\&$ csid $=38>$

Oetzel GR. Monitoring and testing dairy herds for metabolic disease. Vet Clin Nord Am Essen Anim Prakt. 2004;20:651-74.

Oetzel GR. Herd-Level Ketosis - Diagnosis and Risk Factors. Proceeding of American Association of bovine practitioners $40^{\text {th }}$ Annual Conference; 2007 September 19; Vancouver, Kanada. pp. 1-25.

Öhlschläger S. Mineralstoff-, Spurenelement- und Vitamingehalte im Blutserum bei erstlaktierenden Kühen (Deutsche Holstein) in Abhängigkeit von deren Versorgungsniveau [Dissertation med. vet]. Hannover: Tierärtzl. Hochsch. Hannover; 2006.

Ospina PA, Nydam DV, Stokol D, Overton TR. Association between the proportion of sampled transition cows with increased nonesterified fatty acids and B-hydroxybutyrate and disease incidence, pregnancy rate, and milk production at the herd level. J Dairy Sci. 2010;93:3595-601. 
Pavlata L, Podhorsky A, Pechova A, Chomat P. Differences in the occurrence of selenium, copper and zinc deficiencies in dairy cows, calves heifers and bulls. Vet Med Czech. 2005;50:390-400.

Payne MJ, Dew SM, Manston R, Faulks M. The use of a metabolic profile test in dairy herds. Vet Rec. 1970;87:150-8.

Payne JM, Rowlands GJ, Manston R, Dew SM. A Statistical Appraisal of the Results of Metabolic Profile Tests on 75 Dairy Herds. Brit Vet J. 1973;129:370-81.

Payne JM, Rowlands GJ, Manston R, Dew SM, Parker WH. A Statistical Appraisal of the Results of the Metabolic Profile Tests on 191 Herds in the B.V.A/A.D.A.S Joint Exercise in Animal Health and Produktivity. Brit Vet J. 1974;130:34-44.

Quiroz-Rocha GF, LeBlanc S, Duffield T, Wood D, Leslie KE, Jacobs RM. Evaluation of prepartum serum cholesterol and fatty acids concentrations as predictors of postpartum retention of the placenta in dairy cows. J Am Vet Med Assoc. 2009;234:790-3.

Rabelo E, Rezende RL, Bertics SJ, Grummer RR. Effects of Pre- and Postfresh Transition Diets Varying in Dietary Energy Density on Metabolic Status of Periparturient Dairy Cows. J Dairy Sci. 2005;88:4375-83.

Reinhardt TA, Lippolis JD, McCluskey BJ, Goff JP, Horst RL. Prevalence of subclinical hypocalcemia in dairy herds. Vet J. 2011;188:122-4.

Reist M, Erdin DK, von Euw D, Tschümperlin KM, Leuenberger H. Hammon HM, Künzi N, Blum JW. Use of treshold serum and milk ketone concentrations to identify risk for ketosis and endometritis in high-yielding dairy cows. Am J Vet Res. 2003;64:188-94.

Roberts T, Chapinal N, LeBlanc SJ, Kelton DF, Dubuc J, Duffield TF. Metabolic parameters in transition cows as indicators for early-lactation culling risk. J Dairy Sci. 2012;95:3057-63.

Römer A. Nutungsdauer Deutscher Milchkühe-wie wichtig ist sie? In: LKV- Landeskontrollverband WESER-EMS e. V. Jahresbericht 2010. 2010: 1-84

Rossow N, Schäfer M, Le Minh Chi, Bethe W. Stoffwechselüberwachung in Anlagen der industriemäßigen Milchproduktion. Mh Vet Med. 1973;29:89-94. 
Rossow N, Beier D, Bethe W, Dudzus M, Gerisch V, Chi LM, Kirchner K, Kreuzberg HJ, Launer P, Mehnert E, Sachse K, Schäfer M, Willer H, Wujanz G. Ergebnisse von Stoffwechseluntersuchungen in Anlagen der industriemäßigen Milchproduktion. Mh Vet Med. 1975;31:486-91.

Rowlands GJ, Pocock RM. A use of the computer as an aid in diagnosis of metabolic problems of dairy herds. J Dairy Res. 1971;38:353-62.

Rowlands GJ, Manston R, Pocock RM, Dew SM. Relationships between stage of lactation and pregnancy and blood composition in a herd of dairy cows and the influences of seasonal changes in management on these relationships. J Dairy Res. 1975;42:349-62.

Rukkwamsuk T, Geelen MJH, Kruip TAM, Wensing T. Interrelation of Fatty Acid Composition in Adipose Tissue, Serum, and Liver of Dairy Cows During the Development of Fatty Liver Postpartum. J Dairy Sci. 2000;83:52-9.

Saeed S. Effect of Selenium Supplementation from Various Dietary Sources on the Antioxidant and Selenium Status of Dairy Cows and Trace Element Status in Dairy Herds. [Dissertation rer. agr]. Berlin: Humboldt Univ. Berlin; 2010.

Saffaf J. Klinische Bedeutung der Leberverfettung bei Kühen in der Medizinischen Tierklinik Leipzig. [Dissertation med. vet.]. Leipzig: Univ. Leipzig; 2014 eingereicht.

Sakha M, Ameri M, Sharifi H, Taheri I. Bovine Subclinical Ketosis in Dairy Herds in Iran. Vet Res Commun. 2007;31:673-9.

Sakowski T, Kuczýnska B, Puppel K, Metera E, Sloniewski K, Barszczewski J. Relationships between physiological indicators in blood, and their yield, as well as chemical composition of milk obtained from organic dairy cows. J Sci Food Agric. 2012;92:2905-12.

Sattler T, Fürll M. Creatine kinase and aspartate aminotransferase in cows as indicators for endometritis. J Vet Med A Physiol Pathol Clin Med. 2004;51:132-7.

Schmaußer M. Beziehungen zwischen verschiedenen Parametern des Energiestoffwechsels und Störungen der Fertilität beim Milchrind unter Berücksichtigung der individuellen Futteraufnahme. [Dissertation med. vet] München: Ludw.-Max.-Univ. München; 2006.

Scholz H. Stoffwechselkontrolle in der Milchkuhherde anhand von Blut- und Milchparametern. Prakt Tierarzt. 1990; Coll Vet XXI: 32-35. 
Schulz K, Frahm J, Meyer U, Kersten S, Reiche D, Rehage J, Dänicke S. Effects of prepartal body condition score and peripartal energy supply of dairy cows on postpartal lipolysis, energy balance and ketogenesis: an animal model to investigate subclinical ketosis. J Dairy Res. 2014,81:257-66.

Schwartau K. Peripartale hämatologische und klinisch-chemische Blutuntersuchungen zur Frühdiagnostik der Dislocatio abomasi, Gebärparese, Retentio secundinarum und Mastitis bei Milchkühen. [Dissertation med. vet.]. Leipzig: Univ. Leipzig; 2012.

Schwendenwein I. Referenzintervalle - Referenzlimits. In: Moritz A, Hrsg. Klinische Labordiagnostik in der Tiermedizin. 7. Aufl. Stuttgart: Schattauer-Verlag; 2013. p. 3-13.

Seidel H, Ehrentraut W. Zur Problematik der Stoffwechselüberwachung von Milchkühen in industriemäßig produzierenden Anlagen aus der Sicht eines Bezirksinstitutes Veterinärwesen. Mh Vet Med. 1976;31:491-3.

Seifi HA, Mirshokraie P, Farzaneh N. Metabolic profile test in Iran: Variations of metabolites around parturition at dairy cattle. Acta Vet Scand Suppl. 2003;98:300.

Seifi HA, LeBlanc SJ, Leslie KE, Duffield TF. Metabolic predictors of post-partum disease and culling risk in dairy cattle. Vet J. 2011;188:216-20.

Sevinc M, Aslan V. The changes of metabolic profile and its association with fat cow syndrome in high yielding cows during dry period and after. Acta Vet Scand Suppl. 2003;98:204.

Söllner-Donath S. Stoffwechseluntersuchungen bei Milchkühen in der ersten und in der Folgelaktation in einer Hochleistungsherde [Dissertation med vet]. Leipzig: Univ. Leipzig; 2013.

Sommer H. Zur Überwachung der Gesundheit des Rindes mit Hilfe klinisch-chemischer Untersuchungsmethoden. Arch exper Vet Med. 1970;24:735-70.

Sommer H. Die Kontrolle der Gesundheit und Nährstoffversorgung bei Milchkühen. Vet Med Nachr. 1985;1:13-35.

Statistisches Bundesamt. Land- und Forstwirtschaft, Fischerei. Viehbestand Vorbericht. Fachserie 3 Reihe 4.1. 2014 (zitiert vom 01.08.2014):1-34; <https://www.destatis.de/DE/Publikationen/ Thematisch/LandForstwirtschaft/ViehbestandTierischeErzeugung/Viehbestand.html> 
Staufenbiel R. Pansenalkalose, Pansenazidose, Pansenfermentationsstörungen - grundlegende Tiergesundheitsprobleme in der Milchkuhhaltung. Tagungsbericht 11. Symposium Dr. Pieper Fütterung und Management von Kühen mit hohen Leistungen; 2011 (zitiert vom 10.09.2014): 33-100, $<$ http://www.dr-pieper.com/file/187.pdf>

Staufenbiel R, Gelfert CC, Panicke L. Prophylaktische veterinärmedizinische Bestandsbetreuung als Maßnahme im Management von Milchkühen. Züchtungskunde. 2004;6:475-93

Steinke K. Langfristiger Einsatz von gentechnisch verändertem Mais (MON810) in der Milchviehfütterung im Hinblick auf Leistungs- und Stoffwechselparameter, Fruchtbarkeit und Tiergesundheit. [Dissertation agrar] München: Techn. Univ. München; 2009.

Stock C. Vergleich von Stoffwechselrelevanten Parametern bei Kühen mit und ohne Puerperalerkrankungen zur Erkennung eines erhöhten Erkrankungsrisiko [Dissertation med. vet] München: Ludw.-Max.-Univ. München 2009.

Stöckl W, Schuh M, Schmid S. Über das Verhalten von Glucose, Thyroxin, Vitamin A, B-Carotin, Methionin und Vitamin B12 im Blut erstgebärender Rinder während der Puerperalphase. J Anim Physiol Anim Nutr. 1975;35:281-8

Stohrer M, Lutz S, Stangassinger M. Antioxidant Status of Calves and Foals Declines After Birth. Acta Vet Scand.Suppl 2003;44:38.

Sunderman FW, Nomoto S. Measurement of human serum ceruloplasmin by its p-phenylenediamine oxidase activity. Clin Chem. 1970;16:903-10.

Taghiyar M, Darvishi L, Askari G, Feizi A, Hariri M, Mashhadi NS, Ghiasvand R. The Effect of Vitamin C and E Supplementation on Muscle Damage and Oxidative Stress in Female Athletes: A Clinical Trial. In J Prev Med. 2013; 4(Suppl 1): 16-23.

TGL 34313. Ministerium für Land-, Forst- und Nahrungsgüterwirtschaft, HA Veterinärwesen. Stoffwechselüberwachung in der Rinderproduktion. 1988 (zitiert vom 10.09.2014): 1-10, $<$ http://www.vetmed.uni-leipzig.de/ik/wmedizin/labor/laborfortbildung/leipziger_laborfortbildung 13.pdf>

Van Saun, RJ. Metabolic profiling and health risk in transition cows. In: Proceedings 37th Annual American Association of Bovine Practitioners Convention; 2004 September 23-25; Ft Worth, Texas. pp. 212-3. 
Van Saun RJ. Indicators of Dairy Cow Transition Risks: Metabolic profiling revisited. Proc 26th World Buiatrics Congress 2010. Santiago, Chile. 14.-18.11.2010. p 65-77.

Vereinigte Informationssysteme Tierhaltung w. V. (VIT). Trends Fakten Zahlen 2013. 2013 (zitiert vom 10.09.2014): 1-96. <http://www.vit.de/fileadmin/user_upload/wirsindvit/jahresberichte/vitJB2013-gesamt.pdf>

Voyvoda H, Erdogan H. Use of a hand-held meter for detecting subclinical ketosis in dairy cows. Res Vet Sci. 2010;89:344-51.

Wang J, Zhu X, Wang Z, Li X, Zhao B, Liu G. Changes in Serum Copper and Zinc Levels in Peripartum Healthy and Subclinically Hypocalcemic Dairy Cows. Biol Trace Elem Res. 2014;159:135-9.

Wangler A, Harms J. Analyse der Abgangsursachen in ausgewählten Milchviehbetrieben Mecklenburg-Vorpommerns unter Einbeziehung einzeltierbezogener Behandlungen und Leistungen. 2009 (zitiert vom 10.09.2014) :1- 50, <http://www.landwirtschaft-mv.de/cms2/LFA_prod/LFA/ content/de/Fachinformationen/Tierproduktion/Milcherzeugung/?\&artikel=1800>

Watanabe R, Takagi M, Yamato O, Otoi T, Tshering C, Okamoto K. Metabolic Profile of Japanese Black Breeding Cattle Herds: Usefulness in Selection for Nutrient Supplementation to Enhance Reproductive Performance and Regional Differences. J Vet Med Sci. 2013;74:481-7.

Whitaker DA, Kelly JM, Smith S. Disposal and disease rates in 340 British dairy herds. Vet Rec. 2000;146:363-7

Wiener B, Richter T, Teichert H. Abschätzung des Bedarfs landwirtschaftlicher Fachkräfte unter Berücksichtigung der demographischen Entwicklung (Schwerpunkt neue Bundesländer).2004 (zitiert vom 10.09.2014):1-50; ISSN 1617-299X <http://www.zsh-online.de/fileadmin/PDF-Dokumente/ Forschungsberichte/04_2FB.pdf>

Wilken H. Endotoxin-Status und Antioxidative Kapazität sowie ausgewählte Stoffwechselparameter bei gesunden Milch- und Mutterkühen. [Dissertation med. vet]. Leipzig: Univ. Leipzig; 2003.

Willer H, Rossow N, Dudzus M. Stichprobenplanung in der Stoffwechselüberwachung von Milchviehherden. Mh Vet Med. 1976;1:497-502. 
Wolf C, Bladt A, Altmann B. Selenversorgung von Kühen - Mangel oder Überschuß? 1. Mitteilung: Diagnostik der Selenversorgung bei Kühen. Prakt Tierarzt. 1998;79:651-6.

Wujanz G, Lachmann G. Zur Problematik der Diagnose und Frühdiagnose von Stoffwechselerkrankungen der Milchkuh im System der veterinärmedizinischen Produktionskontrolle. Wiss Zeitschr KM-Uni. 1972;21:331-336.

Zahn N. Stoffwechseluntersuchung bei klinisch gesunden Kühen unter besonderer Berücksichtigung der Superoxid-Dismutase [Dissertation med. vet]. Leipzig: Univ. Leipzig; 2006. 


\section{$9 \quad$ Anhang}

Tabelle 9.1: Probenanzahl (n), Minimum, Maximum, Quartile (1. und 3.), Median, Mittelwert ( $\bar{x}$ ), Standartabweichung (SD) und p-Wert (anhand KST zur Untersuchung auf Normalverteilung) der untersuchten Parameter von Proben einer tierärztlichen Gemeinschaftspraxis im EL.

\begin{tabular}{|c|c|c|c|c|c|c|c|c|c|}
\hline & $\mathrm{n}$ & Min & Q1 & Median & Q3 & Max & $x$ & $\mathrm{SD}$ & $\mathrm{p}$ (Kol-Sm) \\
\hline Ca $(\mathrm{mmol} / \mathrm{l})$ & 664 & 1,42 & 2,27 & 2,36 & 2,46 & 2,83 & 2,35 & 0,16 & 0,024 \\
\hline $\mathbf{P}(\mathrm{mmol} / \mathrm{l})$ & 638 & 0,55 & 1,78 & 1,98 & 2,22 & 3,52 & 2,01 & 0,39 & 0,031 \\
\hline $\mathbf{F e}(\mu \mathrm{mol} / \mathrm{l})$ & 94 & 7,7 & 20,0 & 23,8 & 27,4 & 39,7 & 23,8 & 6,0 & 0,959 \\
\hline $\mathbf{M g}(\mathrm{mmol} / \mathrm{l})$ & 37 & 0,67 & 0,87 & 0,99 & 1,04 & 1,18 & 0,95 & 0,13 & 0,438 \\
\hline $\mathbf{N a}(\mathrm{mmol} / \mathrm{l})$ & 43 & 137 & 139 & 141 & 143 & 149 & 141 & 3 & 0,232 \\
\hline $\mathbf{K}(\mathrm{mmol} / \mathrm{l})$ & 43 & 3,8 & 4,3 & 4,6 & 4,8 & 5,9 & 4,7 & 0,5 & 0,373 \\
\hline Cl $(\mathrm{mmol} / \mathrm{l})$ & 39 & 94,8 & 97,4 & 99,3 & 101,9 & 105,2 & 99,7 & 2,7 & 0,833 \\
\hline $\begin{array}{l}\text { Harnstoff } \\
(\mathrm{mmol} / \mathrm{l})\end{array}$ & 764 & 0,85 & 3,33 & 4,18 & 5,16 & 9,94 & 4,24 & 1,45 & 0,749 \\
\hline Chol (mmol/l) & 297 & 0,93 & 2,15 & 2,89 & 3,94 & 7,06 & 3,15 & 1,22 & 0,010 \\
\hline BHB (mmol/l) & 773 & 0,17 & 0,51 & 0,66 & 0,89 & 57,00 & 0,86 & 2,09 & 0 \\
\hline FFS $(\mu \mathrm{mol} / \mathrm{l})$ & 774 & 10 & 113 & 176 & 368 & 2043 & 288 & 277 & $<0,001$ \\
\hline AST (U/l) & 94 & 43,1 & 63,9 & 76,1 & 98,2 & 188,6 & 84,4 & 28,5 & 0,043 \\
\hline GGT (U/l) & 154 & 2,0 & 17,2 & 23,0 & 28,3 & 86,0 & 24,5 & 11,7 & 0,010 \\
\hline GLDH (U/l) & 182 & 3,1 & 7,2 & 10,0 & 15,5 & 247,5 & 19,7 & 33,3 & $<0,001$ \\
\hline GS $(\mu \mathrm{mol} / \mathrm{l})$ & 17 & 9,4 & 18,6 & 25,0 & 41,6 & 112,0 & 32,9 & 24,4 & 0,576 \\
\hline Bili $(\mu \mathrm{mol} / \mathrm{l})$ & 504 & 0,2 & 2,0 & 2,9 & 4,1 & 32,9 & 3,5 & 2,9 & $<0,001$ \\
\hline CK (U/l) & 498 & 31,7 & 101,2 & 130,0 & 183,7 & 12491,0 & 282,3 & 843,6 & $<0,001$ \\
\hline $\mathbf{A P}(\mathrm{U} / 19$ & 10 & 19 & 42 & 65,5 & 83 & 102 & 62 & 26 & 0,997 \\
\hline $\begin{array}{l}\text { Glucose } \\
(\mathrm{mmol} / \mathrm{l})\end{array}$ & 22 & 0,47 & 1,53 & 3,14 & 3,44 & 4,19 & 2,56 & 1,17 & 0,188 \\
\hline $\mathbf{T P}(\mathrm{g} / \mathrm{l})$ & 48 & 54,3 & 66,5 & 74,4 & 78,9 & 88,0 & 73,1 & 8,5 & 0,605 \\
\hline Albumin (g/l) & 48 & 25,2 & 30,5 & 33,9 & 36,2 & 38,3 & 33,3 & 3,6 & 0,806 \\
\hline $\begin{array}{l}\text { Kreatinin } \\
(\mu \mathrm{mol} / \mathrm{l})\end{array}$ & 10 & 32 & 62 & 72 & 86 & 105 & 73 & 20 & 0,913 \\
\hline $\mathbf{C u}(\mu \mathrm{mol} / \mathrm{l})$ & 740 & 2,2 & 9,7 & 12,0 & 14,8 & 32,7 & 12,7 & 4,6 & $<0,001$ \\
\hline Se $(\mu \mathrm{mol} / \mathrm{l})$ & 771 & 0,08 & 0,49 & 0,67 & 0,87 & 1,97 & 0,69 & 0,28 & 0,324 \\
\hline $\mathbf{Z n}(\mu \mathrm{mol} / \mathrm{l})$ & 16 & 8,58 & 10,79 & 11,48 & 14,00 & 17,30 & 12,16 & 2,23 & 0,684 \\
\hline $\mathbf{M n}(\mu \mathrm{mol} / \mathrm{l})$ & 10 & 0,4 & 1,4 & 2,6 & 3,5 & 3,7 & 2,4 & 1,2 & 0,951 \\
\hline Cpl (g/l) & 7 & 0,05 & 0,10 & 0,14 & 0,15 & 0,16 & 0,13 & 0,04 & 0,395 \\
\hline $\begin{array}{l}\text { B-Carotin } \\
(\mu \mathrm{mol} / \mathrm{l})\end{array}$ & 147 & 0,60 & 4,30 & 5,60 & 8,04 & 15,55 & 6,65 & 3,54 & 0,007 \\
\hline TEAC $(\mu \mathrm{mol} / \mathrm{l})$ & 266 & 218,17 & 283,23 & 315,55 & 342,27 & 508,53 & 314,9 & 45,28 & 0,443 \\
\hline
\end{tabular}


Tabelle 9.2: Probenanzahl je Laktationsstadium ausgewählter Parameter von eingesendeten Proben einer tierärztlichen Gemeinschaftspraxis im EL

\begin{tabular}{|c|c|c|c|c|c|}
\hline & FFS & BHB & CK & Se & TEAC \\
\hline a. p. & 321 & 321 & 187 & 315 & 150 \\
\hline 0-1Wo p. p. & 109 & 109 & 66 & 103 & 36 \\
\hline bis 8 Wo p. p. & 158 & 158 & 106 & 159 & 41 \\
\hline bis 14 Wo p. p. & 46 & 45 & 43 & 46 & 3 \\
\hline >100d p. p. & 56 & 56 & 44 & 57 & 10 \\
\hline Färsen & 50 & 50 & 36 & 50 & 2 \\
\hline ohne Angabe & 34 & 34 & 16 & 41 & 24 \\
\hline
\end{tabular}

Tabelle 9.3: Probenanzahl und Verteilung anhand des KST der Laktationsstadien ausgewählter Parameter im Jahresvergleich von eingesendeten Proben einer tierärztlichen Gemeinschaftspraxis im EL. (LS: $1=$ a. p.; $2=0-1$ Woche p.p; $3=$ bis 8 Wochen p.p; $4=>8$ Wochen p.p; Verteilung: no $=$ normal verteilt; $\mathrm{nn}=$ nicht normal verteilt)

\begin{tabular}{|c|c|c|c|c|c|c|c|}
\hline & LS & 2006 & 2007 & 2008 & 2009 & 2010 & 2011 \\
\hline \multirow{3}{*}{$\stackrel{\infty}{\Sigma}$} & 1 & $26(\mathrm{nn})$ & $76(\mathrm{nn})$ & 43 (no) & $91(\mathrm{nn})$ & 48 (no) & $37(\mathrm{nn})$ \\
\hline & 2 & 6 (no) & 40 (no) & 14 (no) & 8 (no) & 17 (no) & 24 (no) \\
\hline & 3 & 7 (no) & 48 (no) & 41 (no) & 28 (no) & 18 (no) & 16 (no) \\
\hline \multirow{4}{*}{$\hat{\theta}$} & 1 & 27 (no) & 76 (no) & 43 (no) & 91 (no) & 48 (no) & 37 (no) \\
\hline & 2 & 6 (no) & 40 (no) & 14 (no) & 8 (no) & 17 (no) & 24 (no) \\
\hline & 3 & 7 (no) & $48(\mathrm{nn})$ & $41(\mathrm{nn})$ & $28(\mathrm{nn})$ & 18 (no) & 16 (no) \\
\hline & 4 & 10 (no) & 37 (no) & 38 (no) & 6 (no) & 3 (no) & 7 (no) \\
\hline \multirow{3}{*}{ 竞 } & 1 & 21 (no) & $68(\mathrm{nn})$ & 38 (no) & 67 (no) & & \\
\hline & 2 & $5(\mathrm{no})$ & 38 (no) & 14 (no) & 8 (no) & & \\
\hline & 3 & 5 (no) & 43 (no) & 38 (no) & 18 (no) & & \\
\hline \multirow{4}{*}{ 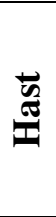 } & 1 & 26 (no) & 74 (no) & 43 (no) & 91 (no) & 48 (no) & 37 (no) \\
\hline & 2 & 6 (no) & 39 (no) & 14 (no) & 8 (no) & 17 (no) & 24 (no) \\
\hline & 3 & 7 (no) & 46 (no) & 41 (no) & 28 (no) & 18 (no) & 16 (no) \\
\hline & 4 & 10 (no) & 32 (no) & 39 (no) & 6 (no) & 3 (no) & 7 (no) \\
\hline \multirow{4}{*}{ 光 } & 1 & 16 (no) & $76(\mathrm{nn})$ & $39(\mathrm{nn})$ & $44(\mathrm{nn})$ & $12(\mathrm{nn})$ & \\
\hline & 2 & 5 (no) & $40(\mathrm{nn})$ & 13 (no) & 4 (no) & 4 (no) & \\
\hline & 3 & 5 (no) & $48(\mathrm{nn})$ & $38(\mathrm{nn})$ & 13 (no) & 2 (no) & \\
\hline & 4 & 6 (no) & $39(\mathrm{nn})$ & $37(\mathrm{nn})$ & 5 (no) & & \\
\hline \multirow{4}{*}{ تَ } & 1 & 26 (no) & 76 (no) & 43 (no) & 86 (no) & 35 (no) & 9 (no) \\
\hline & 2 & 6 (no) & 40 (no) & 14 (no) & 8 (no) & 7 (no) & 1 \\
\hline & 3 & 7 (no) & 48 (no) & 41 (no) & 22 (no) & 10 (no) & 9 (no) \\
\hline & 4 & 10 (no) & 37 (no) & 39 (no) & 6 (no) & 3 (no) & 4 (no) \\
\hline \multirow{4}{*}{$\ddot{E}$} & 1 & 26 (no) & 76 (no) & 43 (no) & 64 (no) & 35 (no) & 9 (no) \\
\hline & 2 & 6 (no) & 40 (no) & 14 (no) & 8 (no) & 7 (no) & 1 \\
\hline & 3 & 7 (no) & 48 (no) & 41 (no) & 19 (no) & 10 (no) & 9 (no) \\
\hline & 4 & 10 (no) & 37 (no) & 39 (no) & 6 (no) & 3 (no) & 4 (no) \\
\hline
\end{tabular}


Tabelle 9.4 Vergleich einzelner Parameter mit positiven ( $\mathrm{P}+$ ) bzw. negativen $(\mathrm{P}-)$ Veränderungen im Einsendungsverlauf ausgewählter Betriebe einer tierärztlichen Gemeinschaftspraxis im EL (P 1x = Betrieb hat Parameter nur eine Einsendung untersuchen lassen)

\begin{tabular}{|c|c|c|c|c|c|c|c|c|}
\hline $\begin{array}{c}\text { Parameter } \\
(\mathrm{P})\end{array}$ & $\begin{array}{c}\mathrm{n} \text { Betr. } \\
\mathrm{P}+\end{array}$ & $\begin{array}{c}\text { \% von } \\
\text { gesamt } \\
(\mathrm{P}+)\end{array}$ & $\begin{array}{c}\mathrm{n} \text { Betr. } \\
\mathrm{P}-\end{array}$ & $\begin{array}{c}\% \text { von } \\
\text { gesamt } \\
(\mathrm{P}-)\end{array}$ & $\begin{array}{c}\mathrm{n} \text { Betr. } \\
\mathrm{P} 1 \mathrm{x}\end{array}$ & $\begin{array}{c}\text { \% von } \\
\text { gesamt } \\
(\mathrm{P} 1 \mathrm{x})\end{array}$ & Gesamt & $\begin{array}{c}\% \\
\text { Gesamt } \\
\text { von 24 } \\
\text { Betr. }\end{array}$ \\
\hline $\mathrm{Fe}$ & 0 & 0 & 1 & 14,3 & 6 & 85,7 & 7 & 29,2 \\
\hline $\mathrm{Mg}$ & 0 & 0 & 0 & 0 & 4 & 100,0 & 4 & 16,7 \\
\hline $\mathrm{Na}$ & 0 & 0 & 0 & 0 & 7 & 100,0 & 7 & 29,2 \\
\hline $\mathrm{K}$ & 0 & 0 & 0 & 0 & 7 & 100,0 & 7 & 29,2 \\
\hline $\mathrm{Cl}$ & 0 & 0 & 0 & 0 & 6 & 100,0 & 6 & 25,0 \\
\hline AST & 0 & 0 & 1 & 14,3 & 6 & 85,7 & 7 & 29,2 \\
\hline GGT & 3 & 23,1 & 0 & 0 & 10 & 76,9 & 13 & 54,2 \\
\hline GLDH & 3 & 20 & 1 & 6,7 & 11 & 73,3 & 15 & 62,5 \\
\hline Glucose & 0 & 0 & 0 & 0 & 3 & 100,0 & 3 & 12,5 \\
\hline TP & 0 & 0 & 1 & 33,3 & 2 & 66,7 & 3 & 12,5 \\
\hline Albumin & 1 & 33,3 & 0 & 0 & 2 & 66,7 & 3 & 12,5 \\
\hline Zn & 0 & 0 & 0 & 0 & 1 & 100,0 & 1 & 4,2 \\
\hline Coeru & 0 & 0 & 0 & 0 & 1 & 100,0 & 1 & 4,2 \\
\hline Krea & 0 & 0 & 0 & 0 & 1 & 100,0 & 1 & 4,2 \\
\hline GS & 0 & 0 & 0 & 0 & 1 & 100,0 & 1 & 4,2 \\
\hline B-Car & 2 & 12,5 & 0 & 0,0 & 14 & 87,5 & 16 & 66,7 \\
\hline
\end{tabular}


Tabelle 9.5: Korrelation nach Pearson zwischen ausgewählten Blutparameter

\begin{tabular}{|c|c|c|c|c|c|c|c|c|c|c|c|}
\hline & & $\begin{array}{c}\text { Chol } \\
\mathrm{mmol} / \mathrm{l}\end{array}$ & $\begin{array}{c}\mathrm{BHB} \\
\mathrm{mmol} / \mathrm{l}\end{array}$ & $\begin{array}{c}\text { FFS } \\
\mu \mathrm{mol} / \mathrm{l}\end{array}$ & $\begin{array}{l}\text { AST } \\
\text { IU/1 } \\
\end{array}$ & $\begin{array}{c}\text { Bili } \\
\mu \mathrm{mol} / \mathrm{l}\end{array}$ & $\begin{array}{l}\text { CK } \\
\text { IU/1 }\end{array}$ & $\begin{array}{c}\mathrm{Cu} \\
\mu \mathrm{mol} / 1\end{array}$ & $\begin{array}{c}\mathrm{Se} \\
\mu \mathrm{mol} / 1\end{array}$ & $\begin{array}{c}\mathrm{Cpl} \\
\mathrm{mg} / \mathrm{l}\end{array}$ & $\begin{array}{c}\beta-\mathrm{Car} \\
\mu \mathrm{mol} / 1\end{array}$ \\
\hline \multirow{3}{*}{ 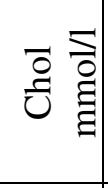 } & 1 & 1 & 0,058 & $-0,402$ & 0,015 & $-0,199$ & 0,093 & 0,062 & 0,079 & 0 & 0,490 \\
\hline & 2 & 297 & 286 & 287 & 94 & 124 & 77 & 248 & 275 & 0 & 73 \\
\hline & 3 & 0 & 0,166 & 0,000 & 0,445 & 0,013 & 0,211 & 0,164 & 0,097 & 0 & 0,000 \\
\hline \multirow{3}{*}{ 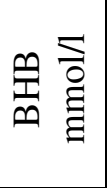 } & 1 & 0,058 & 1 & 0,068 & 0,151 & 0,186 & $-0,037$ & 0,010 & $-0,017$ & 0 & $-0,274$ \\
\hline & 2 & 286 & 773 & 773 & 94 & 503 & 497 & 732 & 761 & 0 & 144 \\
\hline & 3 & 0,166 & 0 & 0,030 & 0,074 & $<0,001$ & 0,206 & 0,396 & 0,321 & 0 & $<0,001$ \\
\hline \multirow{3}{*}{ 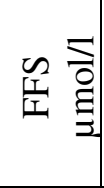 } & 1 & $-0,402$ & 0,068 & 1 & 0,208 & 0,628 & $-0,005$ & 0,093 & $-0,023$ & 0 & $-0,334$ \\
\hline & 2 & 287 & 773 & 774 & 94 & 504 & 498 & 733 & 762 & 0 & 144 \\
\hline & 3 & $<0,001$ & 0,0302 & 0 & 0,022 & $<0,001$ & 0,453 & 0,006 & 0,259 & 0 & $<0,001$ \\
\hline \multirow{3}{*}{ 宗实 } & 1 & 0,015 & 0,151 & 0,208 & 1 & 0 & 0,221 & 0,198 & 0,138 & 0 & 0 \\
\hline & 2 & 94 & 94 & 94 & 94 & 0 & 27 & 94 & 94 & 0 & 0 \\
\hline & 3 & 0,445 & 0,074 & 0,022 & 0 & 0 & 0,134 & 0,028 & 0,092 & 0 & 0 \\
\hline \multirow{3}{*}{ 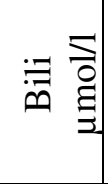 } & 1 & $-0,199$ & 0,186 & 0,628 & 0 & 1 & 0,011 & 0,023 & 0,003 & 0 & $-0,348$ \\
\hline & 2 & 124 & 503 & 504 & 0 & 504 & 427 & 482 & 504 & 0 & 65 \\
\hline & 3 & 0,013 & $<0,001$ & $<0,001$ & 0 & 0 & 0,409 & 0,306 & 0,477 & 0 & 0,002 \\
\hline \multirow{3}{*}{ U气 } & 1 & 0,093 & $-0,037$ & $-0,005$ & 0,221 & 0,011 & 1 & $-0,004$ & 0,041 & 0 & $-0,025$ \\
\hline & 2 & 77 & 497 & 498 & 27 & 427 & 498 & 497 & 498 & 0 & 24 \\
\hline & 3 & 0,211 & 0,206 & 0,453 & 0,134 & 0,409 & 0 & 0,465 & 0,178 & 0 & 0,454 \\
\hline \multirow{3}{*}{ 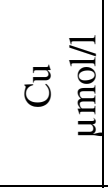 } & 1 & 0,062 & 0,010 & 0,093 & 0,198 & 0,023 & $-0,004$ & 1 & 0,034 & 0,763 & 0,295 \\
\hline & 2 & 248 & 732 & 733 & 94 & 482 & 497 & 740 & 740 & 7 & 146 \\
\hline & 3 & 0,164 & 0,396 & 0,006 & 0,028 & 0,306 & 0,465 & 0 & 0,181 & 0,023 & $<0,001$ \\
\hline \multirow{3}{*}{$\begin{array}{l}\bar{\Xi} \\
\stackrel{0}{\Xi} \\
\Xi \\
\ddot{\infty}\end{array}$} & 1 & 0,079 & $-0,017$ & $-0,023$ & 0,138 & 0,003 & 0,041 & 0,034 & 1 & 0,618 & $-0,236$ \\
\hline & 2 & 275 & 761 & 762 & 94 & 504 & 498 & 740 & 771 & 7 & 147 \\
\hline & 3 & 0,097 & 0,321 & 0,259 & 0,092 & 0,477 & 0,178 & 0,181 & 0 & 0,069 & 0,002 \\
\hline \multirow{3}{*}{$\begin{array}{l}\overline{000} \\
\Xi \\
\vec{u}\end{array}$} & 1 & 0 & 0 & 0 & 0 & 0 & 0 & 0,763 & 0,618 & 1 & $-0,221$ \\
\hline & 2 & 0 & 0 & 0 & 0 & 0 & 0 & 7 & 7 & 7 & 3 \\
\hline & 3 & 0 & 0 & 0 & 0 & 0 & 0 & 0,023 & 0,069 & 0 & 0,4290 \\
\hline \multirow{3}{*}{ 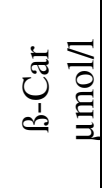 } & 1 & 0,490 & $-0,274$ & $-0,334$ & 0 & $-0,348$ & $-0,025$ & 0,295 & $-0,236$ & $-0,221$ & 1 \\
\hline & 2 & 73 & 144 & 144 & 0 & 65 & 24 & 146 & 147 & 3 & 147 \\
\hline & 3 & $<0,001$ & $<0,001$ & $<0,001$ & 0 & 0,002 & 0,454 & $<0,001$ & 0,002 & 0,429 & 0 \\
\hline \multirow{3}{*}{ 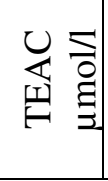 } & 1 & 0,291 & 0,095 & $-0,150$ & 0,245 & $-0,034$ & 0,042 & 0,149 & 0,234 & $-0,043$ & 0,357 \\
\hline & 2 & 187 & 262 & 262 & 85 & 73 & 56 & 253 & 260 & 4 & 80 \\
\hline & 3 & $<0,001$ & 0,062 & 0,007 & 0,012 & 0,388 & 0,378 & 0,009 & $<0,001$ & 0,479 & 0,001 \\
\hline
\end{tabular}

$1=$ Korrelationskoeffizient nach Pearson $\quad 2$ = Gültige Fälle $\quad 3=$ einseitige Signifikanz 


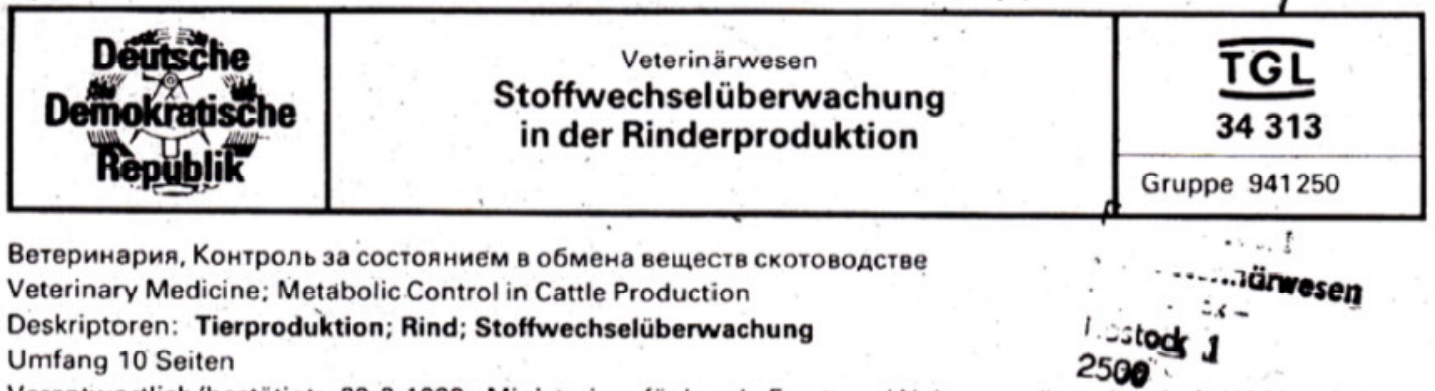

Verantwortlich/bestätigt: 29.3.1988, Ministerium für Land-. Forst- und Nahrungsgüterwirtschaft, HA Veterinärwesen, Berlin

ธ

\section{TERMINI UND DEFINITIONEN}

\section{: Stoffwechselüberwachung}

- Abgestimmtes System von Maßnahmen, Kategorie A ond B, zur Früherkennung, Diagnostik und Bekämp. fung von Stoffwechselstorungen

\section{¿̇ं Stoffwechselstörung}

Veranderung im Ablauf bestimmter Stoffwechselvor. voänge, die durch eine nicht dem Bedarf entsprechende o Versorgung der Tiere mit Nähr- und Wirkstoffen, durch cim Futter enthaltene Schadstoffe und/oder andere beजั lastende Umweltbedingungen verursacht wird und zur g̈Erkrankung oder Leistungsbeeinträchtigung führen Zू.kann.

5๊ 2. SYMBOLE UND ABKÜRZUNGEN

\section{Symbol/Abkürzung Benennung}

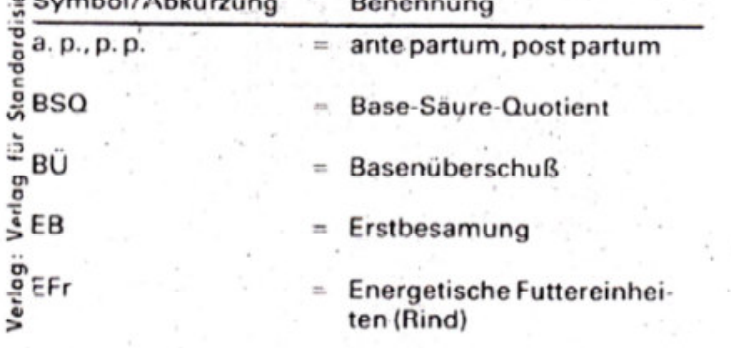

\begin{tabular}{|c|c|c|}
\hline FFTS & $=$ & Fettfreie Trockensubstanz \\
\hline H & $=$ & Harn \\
\hline $\mathrm{K}_{\mathrm{w}} \mathrm{K}_{\mathrm{w}}$ & $=$ & $\begin{array}{l}\text { untere, obere Kontroll- } \\
\text { grenze für Mittelwerte }\end{array}$ \\
\hline$L$ & $=$ & Leber \\
\hline M & $=$ & Milch \\
\hline NSBA & $=$ & $\begin{array}{l}\text { Netto-Säure-Base- } \\
\text { Ausscheidung }\end{array}$ \\
\hline & & : $\quad \cdots$ \\
\hline
\end{tabular}

\begin{tabular}{|c|c|c|c|c|}
\hline Symbol & Abkürz & zung & & Benennung \\
\hline $\bar{P}$ & - & & $=$ & $\begin{array}{l}\text { Blutplasma oder Blut- } \\
\text { serum }\end{array}$ \\
\hline $\mathrm{pCO}_{2}$ & & & - & Kohlendioxid-Partialdruck \\
\hline PEO, & & & $=$ & Protein-Energie-Quotient \\
\hline Ps & & & $=$ & Pansensaft \\
\hline $\mathrm{RFa}$ & & & $=$ & Rohfaser \\
\hline RP, vRP & - & & $=$ & $\begin{array}{l}\text { Rohprotein, verdauliches } \\
\text { Rohprotein }\end{array}$ \\
\hline RZ & & & $=$ & 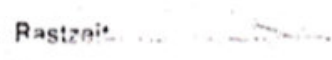 \\
\hline Sk ${ }^{\prime}$ & & & $=$ & $\begin{array}{l}\text { Knochenbioptat bzw. } \\
\text { Knochen }\end{array}$ \\
\hline TS & & & $=$ & Trockensubstanz \\
\hline$T_{u} \cdot T_{a}$ & & & $=$ & $\begin{array}{l}\text { untere, obere Toleranz- } \\
\text { grenze für Einzelwerte }\end{array}$ \\
\hline v & & & $=$ & Vollblut \\
\hline $\mathrm{ZTZ}$ & & & $=$ & Zwischentragezeit \\
\hline
\end{tabular}

\section{ALLGEMEINE FORDERUNGEN}

3.1. Stoffwechselüberwachungen nach Kategorie $A$ sind in Stammkuhherden, Milchviehanlagen mit hoher Tierkonzentration, Beständen mit hohen Leistungen und in weiteren vom Bezirkstierarzt in Abstimmung mit dem Bezirksinstitut für Veterinarwesen (BIV) festzulegenden Milchviehanlagen

- in Perioden besonderer metabolischer Belastungen mindestens zweimal jährlich und

- in Perioden der besonderen Gefährdung der Tiergesundheit durch spezielle Futterstoffe oder -rationen, deren Einsatz unvermeidlich ist. nach Tabellen 1 bis 6 durchzuführen. 
3.2. Stoffwechselüberwachungen nach Kategorie $B$ und Verfolgsuntersuchungen nach. Tabellen 1 bis 9 sind durchzuführen:

In Milchviehanlagen bei Leistungsbeeinträchtigungen und/oder Erkrankungen wie

- unbefriedigende oder zurückgehende. Milchleistung, Rohmilchqualitätsmängel

- Auftreten nicht primär infektiös bedingter Erkrankungen, z. B. Bewegungsstörungen

- Masseverluste

- Fertilitätsprobleme

- ungenügende Lebendmasse und Vitalität der neugeborenen Kälber, unbefriedigende Ergebnisse bei der Kälberaufzucht

In Kälber- und Jungrinderaufzuchtanlagen sowie Mastrinderbeständen bei Leistungsbeeinträchtigungen und/oder Erkrankungēn wie

- ungenügende Massezunahme

- Auftreten nicht primär infektiös bedingter Erkrankungen, z. B. Bewegungsstörungen

- Fertilitätsprobleme

3.3. Ist im Rahmen der Stoffwechselüberwachung nach Kategorie A eine Gefahrdung des Bestandes zu erkennen, ist dieser weiter nach Kategorie B zu unter. suchen.

3.4. Stoffwechselüberwachungen nach Kategorie $A$ und $\mathrm{B}$ umfassen:

- Bestandsanalyse

- klinisch-chemische Untersuchungen
- Befunderhebung

- Festlegung prophylaktischer, metaphylaktischer und therapeutischer Maßnahmen sowie deren Kontrolle hinsichtlich Einhaltung und Effektivität

3.5. Stoffwechselüberwachungen nach Kategorie $A$ und $\mathrm{B}$ sind durch den zuständigen Tierarzt und das BIV terminlich abzustimmen und zu organisieren.

Der Tierarzt hat dem BIV die Bestandsanalyse nach Ta. belle 1 und sonstige für eine Befunderhebung erfor. derliche Daten und Fakten aus dem letzten Untersuchungszeitraum mit den Proben für die klinisch-chemischen Untersuchungen zu übergeben.

Durch das zuständige BIV sind die Untersuchungsergebnisse und deren Bewertung sowie Empfehlungen für die Therapie- und Prophylaxemaßnahmen unverzüglich dem Tierarzt schriftlich mitzuteilen.

3.6. Einzuleitende Maßnahmen im Tierbestand und Kontrolltermine sind vom zuständigen Tierarzt mit der Betriebsleitung festzulegen.

3.7. Die BIV sind verpflichtet, sämtliche Befunde aus den Stoffwechselüberwachungen zu sammeln, jährlich getrennt nach Kategorie A und B statistisch aufzu arbeiten und im Bezirk auszuwerten.

Bis zum 1. Februar des Folgejahres ist das aufgearbeitete Material unter Verwendung eines Formblattes. Beispiel siehe unter Hinweise, dem Institut für ange. wandte Tierhygiene Eberswalde für die Abfassung der Morbiditätsstatistik zu übergeben.

\section{DURCHFÜHRUNG VON STOFFWECHSELÜBERWACHUNGEN}

\subsection{Bestandsanalyse}

Die Bestandsanalyse ist nach folgenden Kriterien durchzuführen:

Tabelle 1

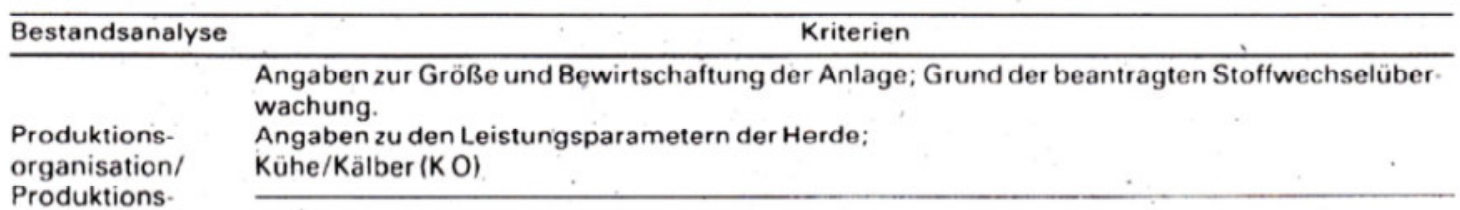

organisation/

ergebnisse

Reproduktionsrate, RZ, ZTZ, Trächtigkeit nach EB, Umrindererrate, Milchleistung. Milchleistung/ Jahr, Milchqualität: Fett-\%, Eiweiß-\%, SHZ, Anteil Qualitätsklasse Q,

Angaben zur Kälberqualität, Erkrankungen, Abgangsursachen

Kälber ( $\mathrm{K} 1$ bis K 3), weibliche Jungrinder (JR 1 bis JR 4)

Massezunahme, Erkrankungen, Abgangsursachen. Erstbesamungsalter, Trächtigkeit nach EB

Mastrinder

Masttagszunahme, Erkrankungen, Abgangsursachen

Fütterung/ Art, Qualität, Herkunft aller eingesetzten Futtermițtel, Futterrationen einschließlich Kennzahlen Rations- $\quad$ der Ration: TS, EFr, RP, vPP, PEQ, RFa, Mengenangaben z. B. aller Mineralstoff-und Wirkstoffzu kenndaten sätze, Ergebnisse von Futtermittelanalysen

Einschätzung der Fütterung:

Haufigkeit des Futterwechsels, Futteraufnahme, Restfutter, Anzahl der Fütterungen/Tag.

Reihenfolge der Rationskomponenten,

Fütterungstechnologie,

Tier-Freßplatz-Verhältnis

Veterinär- Art und Ausmaß des Krankheits- und Abgangsgeschehens, Ergebnisse der klinischen Untersu-

medizinische chungen. Hinweise auf Stoffwechselstörungen; Angabe der prophylaktisch und metaphylaktisch

Kennwerte eingesetzten Arzneimittel und Behandlungsmaßnahmen

Biochemische, toxikologische, virologische, bakteriologische, parasitologische, mykologische

Befunde, Ergebnisse der postmortalen Diagnostik, Schlachttierbefunde aus dem letzten Unter-

suchungszeitraum 
4.2. Klinisch-chemische Untersuchungen

4.2.1. Auswahl des Tiermaterials, Stichprobengröße und Untersuchungszeitpunkte

Tabelle 2

\begin{tabular}{ll}
\hline $\begin{array}{l}\text { Kate- Tiermaterial/ } \\
\text { gorie Untersuchungs- } \\
\text { zeitraum }\end{array}$ & $\begin{array}{c}\text { Stich- } \\
\text { proben- } \\
\text { größe } \\
\text { n }\end{array}$ \\
\hline A $\quad \begin{array}{l}\text { Kühe mithoher aktueller Leistung } \\
\text { 2. bis 8. Woche p. p. }\end{array}$ & 10 \\
\hline B $\quad \begin{array}{l}\text { Suspekte Kühe } \\
\text { 2. bis 8. Woche p. p. }\end{array}$ & 10 \\
& $\begin{array}{l}\text { Frischkalber einschließlich der } \\
\text { suspekten Kälber 1. bis 5: Lebenstag } \\
\text { (LT) }\end{array}$ \\
$\begin{array}{l}\text { Trockensteher } \\
\text { 4. bis 2. Woche a. p. }\end{array}$ & 10 \\
Suspekte Kühe \\
ab 20. Woche p. p.
\end{tabular}

\begin{tabular}{|c|c|c|}
\hline $\begin{array}{l}\text { Kate- } \\
\text { gorie }\end{array}$ & $\begin{array}{l}\text { Tiermaterial/ } \\
\text { Untersuchungs- } \\
\text { zeitraum }\end{array}$ & $\begin{array}{c}\text { Stich- } \\
\text { proben- } \\
\text { größe } \\
\quad n\end{array}$ \\
\hline \multirow[t]{4}{*}{$B$} & $\begin{array}{l}\text { Suspekte Kälber } \\
\text { 2. bis 3. Lcbensmonat }\end{array}$ & 10 \\
\hline & $\begin{array}{l}\text { Suspekte weibliche Jungrinder } \\
\text { 12. bis } 24 \text {. Lebensmonat }\end{array}$ & 10 \\
\hline & $\begin{array}{l}\text { Suspekte Mastrinder } \\
\text { 12. bis 24. Lebensmonat }\end{array}$ & 10 \\
\hline & $\begin{array}{l}\text { Suspekte Tiere zu nicht definierten } \\
\text { Zeitpunkten zur Sicherung der Dia- } \\
\text { gnose }\end{array}$ & 10 \\
\hline
\end{tabular}

Es sind nicht vorbehandelte Tiere auszuwählen. In Abhängigkeit von der Bestandscharakteristik können auch andere und/oder weitere Laktationsabschnitte in die Untersuchungen nach Kategorie A einbezogen werden.

4.2.2. Entnahme, Aufbereitung, Aufbewahrung und Transport der Proben

Tabelle 3

\begin{tabular}{|c|c|c|c|c|c|c|}
\hline & Blut & Harn & Leber & Skelett & Milch & Pansensaft \\
\hline $\begin{array}{l}\text { Proben- } \\
\text { entnahme }\end{array}$ & $\begin{array}{l}\text { Vena-jugularis- } \\
\text { Punktion } \\
2 \text { bis } 4 \mathrm{~h} \text { nach } \\
\text { Fütterung }\end{array}$ & $\begin{array}{l}\text { Katheter/ } \\
\text { Spontanharn } \\
1 \mathrm{~h} \text { vor bis } 2 \mathrm{~h} \\
\text { nach Fütterung }\end{array}$ & $\begin{array}{l}\text { Biopsie im } \\
11 . \text { Interko- } \\
\text { stalraum oder } \\
\text { Entnahme bei } \\
\text { definierten } \\
\text { Schlachtticren }\end{array}$ & $\begin{array}{l}\text { Tubercoxae- } \\
\text { Biopsie oder } \\
\text { Entnahme bei } \\
\text { Schlacht- } \\
\text { tieren }\end{array}$ & $\begin{array}{l}\text { gut durch- } \\
\text { mischtes } \\
\text { 4-Viertel- } \\
\text { Gemelk }\end{array}$ & $\begin{array}{l}\text { Entnahme } \\
2 \text { bis } 4 \text { h nach } \\
\text { der Fütterung }\end{array}$ \\
\hline Behältnis & $\begin{array}{l}\text { Zentrifugenglas } \\
15 \mathrm{ml} \text { oder Plaste- } \\
\text { hülsen } 5 \mathrm{ml} \\
\text { mit/ohne Heparin } \\
\text { für Plasma/Serum }\end{array}$ & $\begin{array}{l}\text { Zentrifugen- } \\
\text { glas } 15 \mathrm{ml}\end{array}$ & $\begin{array}{l}\text { Plastehülse } 5 \mathrm{ml} \\
\text { Plastebeutel }\end{array}$ & loder & $\begin{array}{l}\text { Zentrifuge } \\
\text { 50-ml-Flas }\end{array}$ & er $15 \mathrm{ml}$ oder \\
\hline $\begin{array}{l}\text { erforderliche } \\
\text { Menge }\end{array}$ & $10 \mathrm{ml}$ & $15 \mathrm{ml}$ & $\begin{array}{l}1,5 \mathrm{~g} \text { bei Schlach } \\
0,3 \mathrm{~g} \text { bei Bioptat }\end{array}$ & $\begin{array}{l}\text { htproben, } \\
\text { ten }\end{array}$ & $20 \mathrm{ml}$ & $20 \mathrm{ml}^{\circ}$ \\
\hline $\begin{array}{l}\text { Probenauf- } \\
\text { bereitung }\end{array}$ & $\begin{array}{l}\text { Schnellstmög- } \\
\text { liches Zentrifu- } \\
\text { gieren zur } \\
\text { Plasma/Serum- } \\
\text { Gewinnung vor- } \\
\text { zugsweise in } \\
\text { der Anlage" }\end{array}$ & - & $\begin{array}{l}\text { für histologische } \\
\text { gen: Aufnahme } \\
\text { in } 3,5 \% \text { ige Form } \\
\text { lösung }\end{array}$ & $\begin{array}{l}\text { Untersuchun- } \\
\text { des Bioptates } \\
\text { naldehyd- }\end{array}$ & - & $\begin{array}{l}\text { unverzüglich } \\
\text { nach Entnahme } \\
\text { auf } 2 \text { bis } 5^{\circ} \mathrm{C} \\
\text { kühlen }\end{array}$ \\
\hline $\begin{array}{l}\text { Aufbewah- } \\
\text { rung und } \\
\text { Transport }\end{array}$ & \multicolumn{6}{|c|}{$\begin{array}{l}\text { bei } 2 \text { bis } 5 \text { "C in der Anlage; Transport zur Untersuchungsstelle in Thermosgefäßen oder Kühlta- } \\
\text { schen, Kühlmittel: Eiswasser. Das Probenmaterial muß der Untersuchungsstelle am Entnahmetag } \\
\text { zur weiteren Bearbeitung zur Verfügung stehen. }\end{array}$} \\
\hline
\end{tabular}

Die speziellen Bedingungen für die Einsendung zusätzlicher biologischer Materialien oder von Futtermitteln sind mit der Untersuchungsstelle abzustimmen.

1 Unter Berücksichtigung der Aufbewahrungs- und Transportbedingungen muß das Zentrifugieren grundsätzlich bis $6 h$, bei Proben zur Glukosebestimmung bis $2 \mathrm{~h}$, nach der Probenentnahme erfolgt sein. Bei Zeitüberschreitung ist nur noch die Bestimimung eines eingeschränkten Parameterspektrums möglich. 
4.2.3. Untersuchungsspektrum Erläuterungen zu Tabelle 4

\begin{tabular}{cl}
\hline $\begin{array}{l}\text { Untersuchungs- Erläuterung } \\
\text { zeitraum }\end{array}$ & Kälber 1. bis 5. Lebenstag \\
\hline 1 & Kälber 2. bis 3. Lebensmonat \\
2 & weibliche Jungrinder und Färsen \\
3 & 12. bis 24. Lebensmonat \\
& Mastrinder 12. bis 24. Lebensmonat \\
4 & Trockensteher 4. bis 2. Woche a. p. \\
5 & Frischkalber 1. bis 5. Tag p. p. \\
6 & Kühe 2. bis 8. Woche p. p. \\
7 & Kühe ab 20. Woche p. p. \\
8 & \\
\hline
\end{tabular}

In Klammern gesetzte Kenngrößen sind nach Möglichkeit zu bestimmen; bei in Klammern gesetzten Untersuchungsmaterialien ist die Bestimmung der betreffenden Kenngrößen nur bei begründetem Verdacht notwendig. Tabelle 4

\begin{tabular}{|c|c|c|c|c|c|c|c|c|c|c|c|}
\hline $\begin{array}{l}\text { Untersuchungszeitraum/ } \\
\text { Kategorie }\end{array}$ & & $\begin{array}{l}1 \\
\mathrm{~B}\end{array}$ & $\begin{array}{l}2 \\
\mathrm{~B} \\
\end{array}$ & $\begin{array}{l}3 \\
\mathbf{B} \\
\end{array}$ & $\begin{array}{l}4 \\
\mathrm{~B} \\
\end{array}$ & $\begin{array}{l}5 \\
\mathrm{~B} \\
\end{array}$ & $\begin{array}{l}6 \\
\mathrm{~B} \\
\end{array}$ & A & 7 & B & $\begin{array}{l}8 \\
\mathrm{~B} \\
\end{array}$ \\
\hline Magnesium & & & $\mathrm{P}, \mathrm{H}$ & $\mathbf{P}, \mathrm{H}$ & $P, H$ & $(\mathrm{P}, \mathrm{H})$ & $\mathrm{P}, \mathrm{H}$ & $P, H$ & & $\mathrm{P}, \mathrm{H}$ & $P, H$ \\
\hline Kalzium & & & $\mathbf{P}$ & $\mathbf{P}$ & $P$ & $\mathbf{P}$ & $\mathbf{P}$ & & & $\mathbf{P}$ & $\mathbf{P}$ \\
\hline Phosphor anorg. & & & $\mathrm{P}, \mathrm{H}$ & $\mathrm{P}, \mathrm{H}$ & $\mathrm{P}, \mathrm{H}$ & $\mathrm{P}, \mathrm{H}$ & $\mathrm{P}, \mathrm{H}$ & $\mathrm{P}, \mathrm{H}$ & & $\mathrm{P}, \mathrm{H}$ & P.H \\
\hline Alkalische Phosphatase & & & $\mathbf{P}$ & $\mathbf{P}$ & $P$ & $\mathbf{P}$ & & & & $\mathbf{P}$ & $\mathbf{P}$ \\
\hline Natrium & & & & (H) & & H & & H & & H & $\mathrm{H}$ \\
\hline $\left.\begin{array}{l}\text { Asche/Volumen; } \\
\text { Asche/FFTS }\end{array}\right\}$ & . & & & & Sk & (Sk) & & & & (Sk) & (Sk) \\
\hline $\left.\begin{array}{l}\beta \text {-Hydroxybutyrat } \\
\text { Azeton/Ketokörper) } \\
\text { Glukose }\end{array}\right\}$ & $\cdot$ & $\mathbf{P}$ & & & & & & $\begin{array}{l}P \\
M\end{array}$ & & $\begin{array}{l}P \\
M \\
P\end{array}$ & \\
\hline NSBA/pH-Wert & & & $\mathrm{H}$ & $H$ & $\mathrm{H}$ & H & & H & & H & H \\
\hline (BSO) & & & (H) & (H) & (H) & (H) & & (H) & & (H) & (H) \\
\hline $\mathrm{BÜ}, \mathrm{pCO}_{2}, \mathrm{pH}-$ Wert & & v & & & & & & & & & \\
\hline Harnstoff & 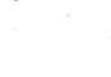 & & $\mathbf{P}$ & $\mathbf{P}$ & $\mathbf{P}$ & $\mathbf{P}$ & & $P, M$ & & $\begin{array}{l}\mathrm{P}, \mathrm{M} \\
\mathrm{P}, \mathrm{M}\end{array}$ & P.M \\
\hline Eiweiß & & $\mathbf{P}$ & & & $\mathbf{P}$ & & & $P, M$ & & (L) & M \\
\hline Albumin & & & & & $\mathbf{P}$ & & & & & $\mathbf{P}$ & \\
\hline$\gamma$-Globulin & & $\mathbf{P}$ & & & & & & & & & \\
\hline $\begin{array}{l}y \text {-Globulin } \\
\text { (Kolostrum) }\end{array}$ & & M. & & & & & & & & & \\
\hline Bilirubin & & & & & $\mathbf{P}$ & $\mathbf{P}$ & , & $\mathbf{P}$ & & $\mathbf{P}$ & $\mathbf{P}$ \\
\hline Aspartataminotransferase & & & & & $\mathbf{P}$ & $P$ & & & & $\mathbf{P}$ & $\mathbf{P}$ \\
\hline$\gamma$-Glutamyltranspeptidase & & & & & $\mathbf{P}$ & $\mathbf{P}$ & & & & $\mathbf{P}$ & $\mathbf{P}$ \\
\hline $\begin{array}{l}\text { Hämoglobin } \\
\text { Hämatokrit }\end{array}$ & & v & v & & & & & $v$ & & v & \\
\hline Eisen & & & $\mathbf{P}$ & & & & & & & & \\
\hline Eisenbindungskapazität & & & $\mathbf{P}$ & & & & & & & & \\
\hline Soxhlet-Henkel-Zahl & & & & & & & & & & M & M \\
\hline $\left.\begin{array}{l}\text { Gesamtazidität } \\
\text { Milchsäure } \\
\text { Ammoniak } \\
\text { pH-Wert } \\
\text { Harnstoff }\end{array}\right\}$ & & & & & & & & & & Ps & Ps \\
\hline
\end{tabular}




\begin{tabular}{|c|c|c|c|c|c|c|c|c|c|c|}
\hline $\begin{array}{l}\text { Untersuchungszeitraum/ } \\
\text { Kategoric }\end{array}$ & $\begin{array}{l}1 \\
\text { B }\end{array}$ & $\begin{array}{l}2 \\
\mathrm{~B}\end{array}$ & $\begin{array}{l}3 \\
\mathrm{~B}\end{array}$ & $\begin{array}{l}4 \\
\mathrm{~B}\end{array}$ & $\begin{array}{l}5 \\
\mathrm{~B}\end{array}$ & $\begin{array}{l}6 \\
\text { B }\end{array}$ & A & 7 & B & $\begin{array}{l}8 \\
\text { B }\end{array}$ \\
\hline Spurenelemente $^{21}$ & 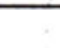 & $\bar{x}$ & $x$ & $\mathrm{x}$ & $x$ & $\mathrm{x}$ & $\mathrm{x}$ & & $\mathrm{x}$ & $x$ \\
\hline Vitamin A & & & & $P(L)$ & & $P(L)$ & & & $P(L)$ & \\
\hline Karotin & & & & $P$ & & $P$ & & & $P$ & \\
\hline (Fett) & & & & & & $\cdot$ & & & (L) & \\
\hline $\left.\begin{array}{l}\text { Triglyzeride } \\
\text { Cholesterol } \\
\text { Gesamtlipide }\end{array}\right\}$ & & & & & & & & . & (P) & \\
\hline (Histologische Untersuchung) & & & & & & ' & & & L & \\
\hline
\end{tabular}

Die Bestimmung der einzelnen Kenngrößen hat nach den verbindlichen klinisch-chemischen Untersuchungsmethoden für veterinärmedizinische Einrichtungen der DDR zu erfolgen.

Die Untersuchungen nach Kategorie A dürfen mit Screening-Methoden durchgeführt werden.

Die Anzahl der zu untersuchenden Kenngrößén nach Kategorie B, siehe Tabelie 4, darf unter Berücksichtigung der aktuellen Fragestellung von der Untersuchungsstelle reduziert oder auch erweitert werden. Dabei sind die in Tabelle 5 aufgeführten Kenngrößen für problembezogene Stoffwechselüberwachungen zu berücksichtigen.

2 In Spurenelementmangelgebieten ist die Versorgung der Tiere mit Kupfer, Zink, Mangan und lod durch entsprechende Untersuchungen im Blutplasma bzw. in der Leber bzw. im Harn zu überprüfen.

Tabelle 5

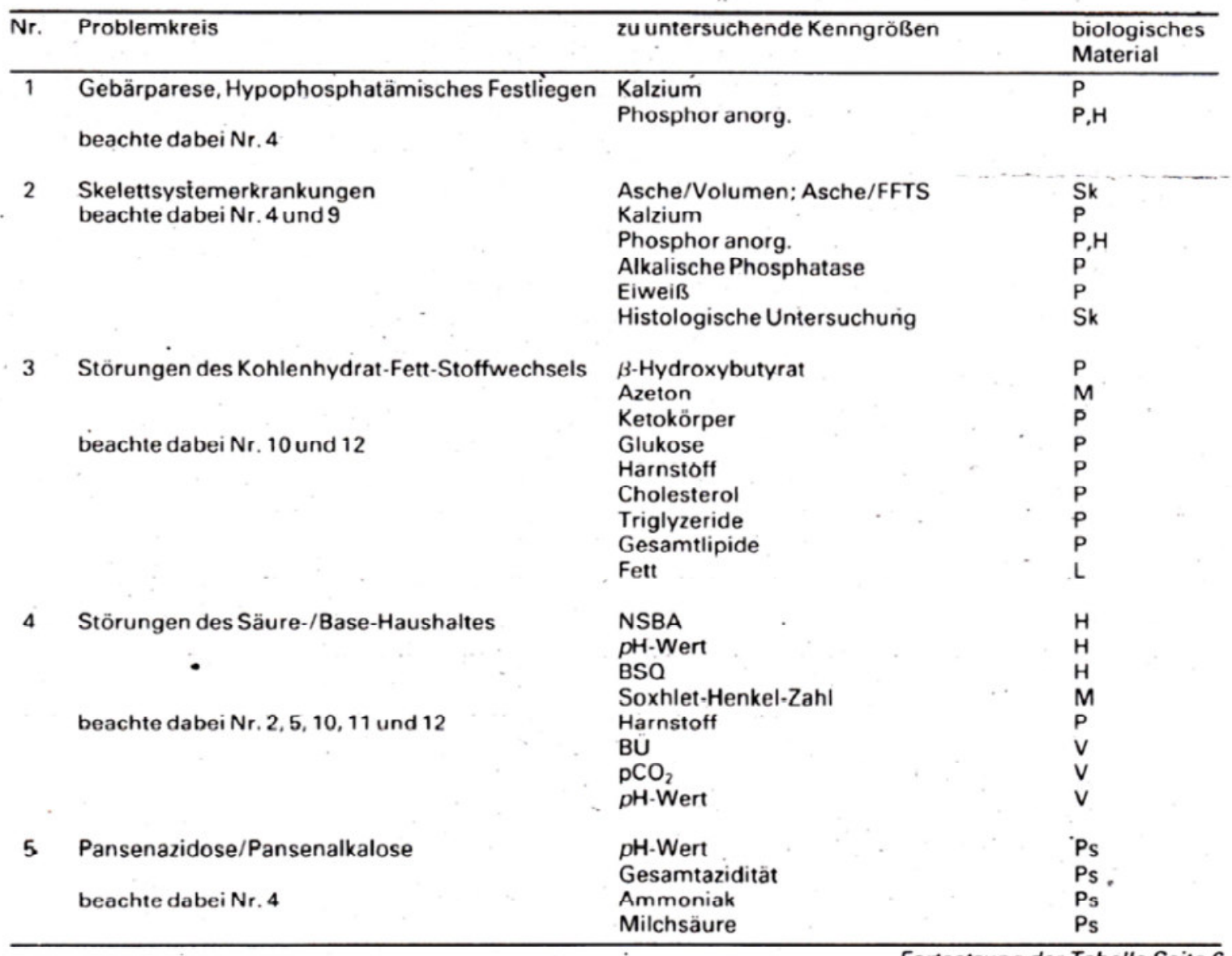


Fortsetzung der Tabelle

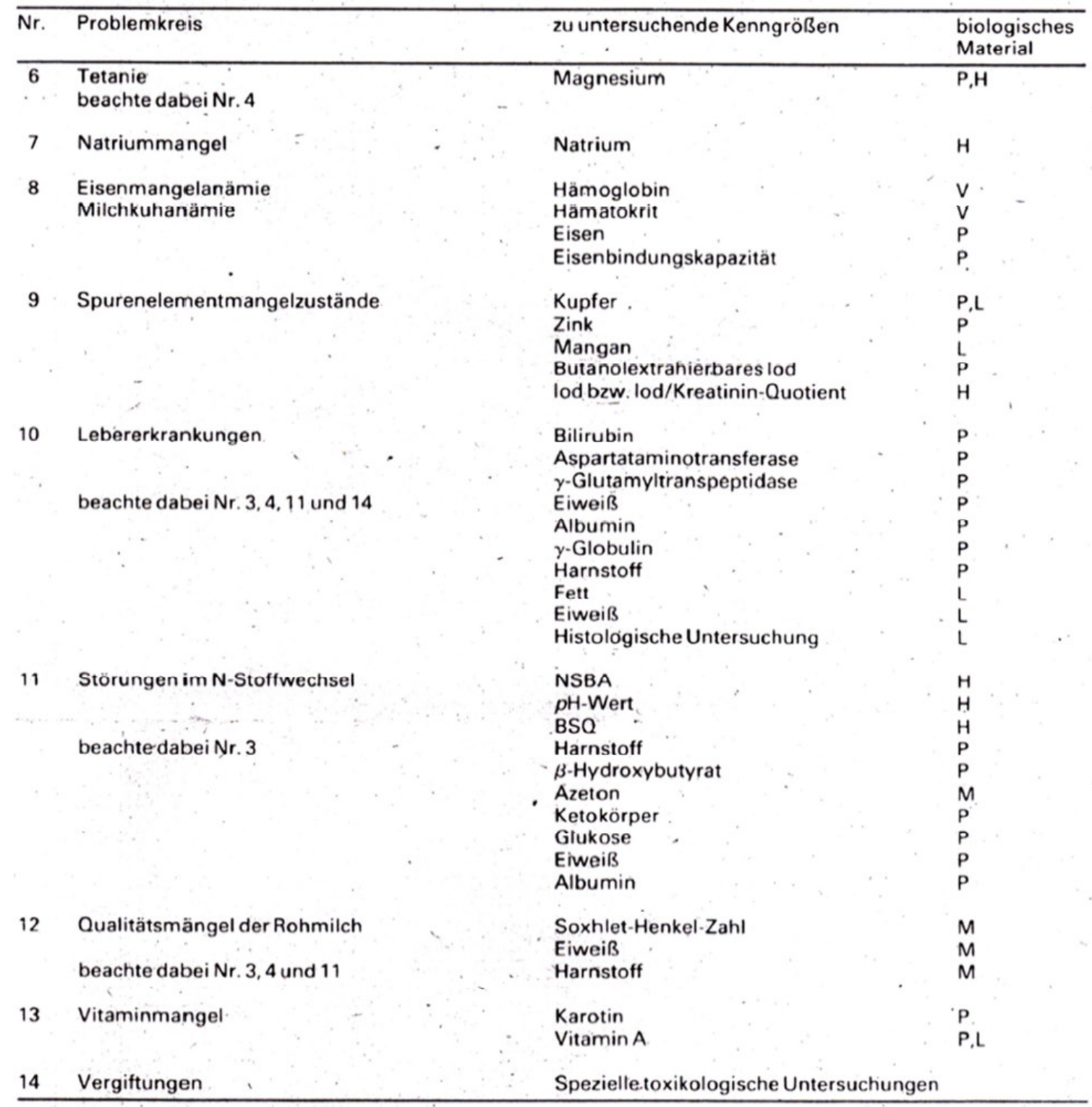

4.2.4. Richtwerte für klinisch-chemische Kenngrößen

4.2.4.1. Kühe: Frischkalber, Kühe 2, bis 8 . Woche p. p., Kühe ab 20. Woche p. p. Trockensteher 4. bis 2. Woche a.p Tabelle 6

\begin{tabular}{|c|c|c|c|c|c|c|c|c|}
\hline Kenngröße & $\begin{array}{l}\text { biol. } \\
\text { Mat. }\end{array}$ & $\begin{array}{l}\text { Maßein- } \\
\text { heit }\end{array}$ & & $K_{u}$ & $\mathrm{~K}_{\mathrm{o}}$ & $T_{u}$ & $T_{0}$ & \\
\hline Magnesium & $P$ & $\mathrm{mmol} / \mathrm{l}$ & . & 1,00 & 1,23 & 0,90 & 1,32 & \\
\hline & H & $\mathrm{mmol} / \mathrm{l}$ & & . & & 0,90 & & \\
\hline Kalzium & $\mathrm{P}$ & $\mathrm{mmol} / \mathrm{l}$ & & $2.12^{3)}$ & $2.46^{3 \prime}$ & $2,00^{31}$ & $2.54^{3)}$ & \\
\hline & & & & 2,45 & 2,72 & 2,35 & 2,82 & \\
\hline
\end{tabular}

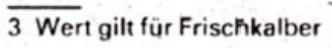


Fortsetzung der Tabelle

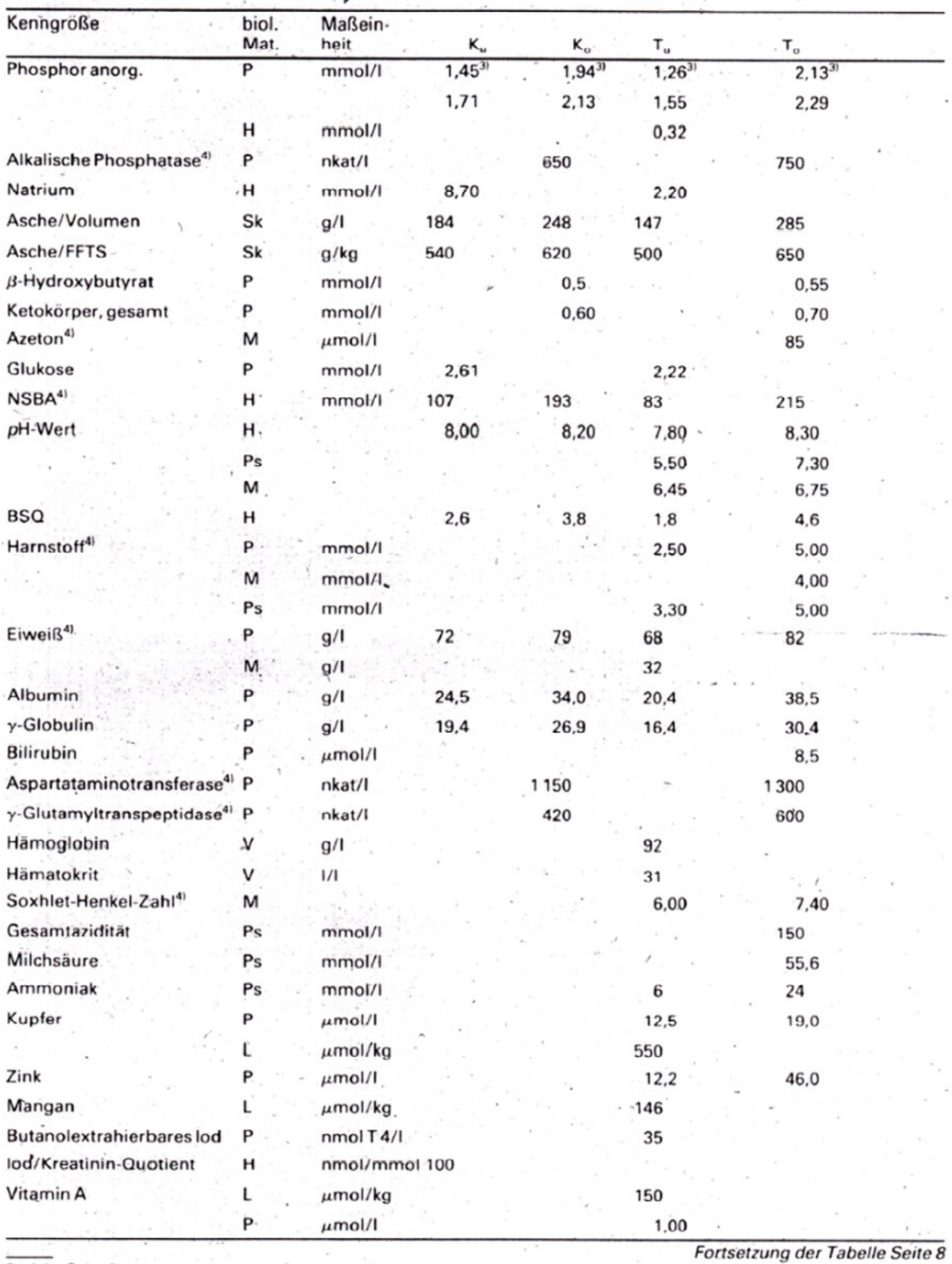

3 siehe Seite 6

4 Kenngröße nicht aussagekräftig bei Frischkalber̃n 
Fortsetzung der Tabelle

\begin{tabular}{|c|c|c|c|c|c|c|c|}
\hline Kenngröße & $\begin{array}{l}\text { biol. } \\
\text { Mat. }\end{array}$ & $\begin{array}{l}\text { Maßein- } \\
\text { heit }\end{array}$ & $\mathrm{K}_{\mathrm{u}}$ & $\mathrm{K}_{\mathrm{o}}$ & $T_{u}$ & $T_{0}$ & \\
\hline Karotin $^{31}$ & $P$ & $\mu \mathrm{mol} / \mathrm{I}$ & & & 4,0 & & \\
\hline Fett & L & $\mathrm{g} / \mathrm{kg}$ & & & & 70 & \\
\hline Triglyzeride & $P$ & $\mathrm{mmol} / \mathrm{l}$ & & & 0.2 & 0,5 & \\
\hline Cholesterol & $\mathbf{P}$ & $\mathrm{mmol} / \mathrm{l}$ & & & 2,5 & 4,5 & \\
\hline Gesamtlipide & L & $g / 1$ & & 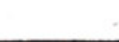 & 1,5 & 4,5 & \\
\hline \multicolumn{8}{|c|}{$\begin{array}{l}\text { 4.2.4.2. Kälber } \\
\text { Tabelle } 7 \text { Kälber 1. bis 5. Lebenstag }\end{array}$} \\
\hline Kenngröße & $\begin{array}{l}\text { biol. } \\
\text { Mat. }\end{array}$ & $\begin{array}{l}\text { Maßein- } \\
\text { heit }\end{array}$ & $\mathrm{K}_{\mathrm{u}}$ & $\mathrm{K}_{\mathrm{o}}$ & $\mathrm{T}_{\mathrm{u}}$ & $T_{\dot{0}}$ & \\
\hline pH-Wert & $\mathrm{v}$ & & & & 7,38 & 7.42 & \\
\hline BÜ & v & $\mu \mathrm{mol} / \mathrm{I}$ & & & -2.5 & +3.0 & \\
\hline $\mathrm{pCO}_{2}$ & v & $\mathrm{kPa}$ & $\cdot$ & & 5,2 & $6, \underline{0}$ & \\
\hline$\gamma$-Globulin & $P$ & $g / 1$ & & & 10.0 & & \\
\hline Dichte des Kolostrums & M & $\mathrm{g} / \mathrm{ml}$ & & & 1,045 & & \\
\hline Hämoglobin & v & $\mathrm{g} / \mathrm{ml}$ & & & 105 & & \\
\hline Hämatokrit & v & $1 / 1$ & & & 0.31 & & \\
\hline \multirow[t]{2}{*}{ Magnesium } & $P$ & $\mathrm{mmol} / \mathrm{I}$ & & & 0,9 & & \\
\hline & $\mathrm{H}$ & mṃol/l & & & 0,9 & & \\
\hline \multirow[b]{3}{*}{ Fisen } & $P$ & $\mathrm{mmol} / \mathrm{l}$ & 2,5 & 2,9 & 2,4 & 3.0 & \\
\hline & $\mathrm{H}$ & $\mathrm{mmol} / \mathrm{l}$ & & & 0,32 & & \\
\hline & $\mathbf{P}$ & $\mu \mathrm{mol} / \mathrm{l}$ & 25 & & 20 & & \\
\hline Eisenbindungskapazität & $P$ & $\mu \mathrm{mol} / \mathrm{l}$ & 90 & & 80 & & \\
\hline $\begin{array}{l}\text { Quotient Eisen/Eisenbin- } \\
\text { dunqskappazität }\end{array}$ & $P$ & & 0,2 & & 0,15 & & \\
\hline Hämoglobin & V & $9 / 1$ & & & 110 & . & \\
\hline Hämatokrit & $v$ & $1 / 1$ & & & 0,31 & & \\
\hline Phosphor anorg. & $P$ & $\mathrm{mmol} / \mathrm{I}$ & 2,4 & 2.9 & 2,2 & 3.0 & \\
\hline Alkalische Phosphatase & $\mathrm{P}$ & nkat/I & 1000 & 1800 & 800 & 2000 & \\
\hline NSBA & $\mathrm{H}$ & $\mathrm{mmol} / \mathrm{l}$ & -30 & +50 & -60 & +60 & \\
\hline$p H \cdot$ Wert & $\mathrm{H}$ & & 6.6 & 7.5 & 6.0 & 8.0 & $\cdot$ \\
\hline Harnstoff & $\mathrm{P}$ & $\mathrm{mmol} / \mathrm{I}$ & 2.7 & 3,2 & 2,4 & 3,4 & \\
\hline Spurenelemente & $P, L$ & & & nach Tat & Ile 6 & & \\
\hline
\end{tabular}

4.2.4.3. Weibliche Jungrinder, Färsen und Mastrinder, 12. bis 24. Lebensmonat Tabelle 9

\begin{tabular}{|c|c|c|c|c|c|c|c|c|}
\hline Kenngroße & & $\begin{array}{l}\text { biol. } \\
\text { Mat. }\end{array}$ & $\begin{array}{l}\text { Maßein- } \\
\text { heit }\end{array}$ & $K_{w}$ & $\mathrm{~K}_{\mathrm{u}}$ & $T_{u}$ & $T_{0}$ & \\
\hline \multirow[t]{2}{*}{ Magnesium } & & $P$ & $\mathrm{mmol} / \mathrm{l}$ & 1.00 & 1,23 & 0,9 & 1,32 & \\
\hline & & $\mathrm{H}$ & $\mathrm{mmol} / \mathrm{l}$ & & & 0,9 & & \\
\hline Kalzium . & & $P$ & $\mathrm{mmol} / \mathrm{l}$ & 2,50 & 2,80 & 2,40 & 3,00 & \\
\hline \multirow[t]{2}{*}{ Phosphos anorg. } & - & $P$ & $\mathrm{mmol} / \mathrm{l}$ & $2,10^{51}$ & $2.70^{51}$ & $1,90^{5 !}$ & $3.00^{51}$ & \\
\hline & & & & $2.20^{6 !}$ & $2,90^{6 !}$ & $2,10^{6)}$ & $3,00^{61}$ & \\
\hline
\end{tabular}

5 Wert gilt fur 12. Lebensmonat
6 Wert gilt fur 24. Lebensmonat

3 siehe Seite 6 
Fortsetzung der Tabelle

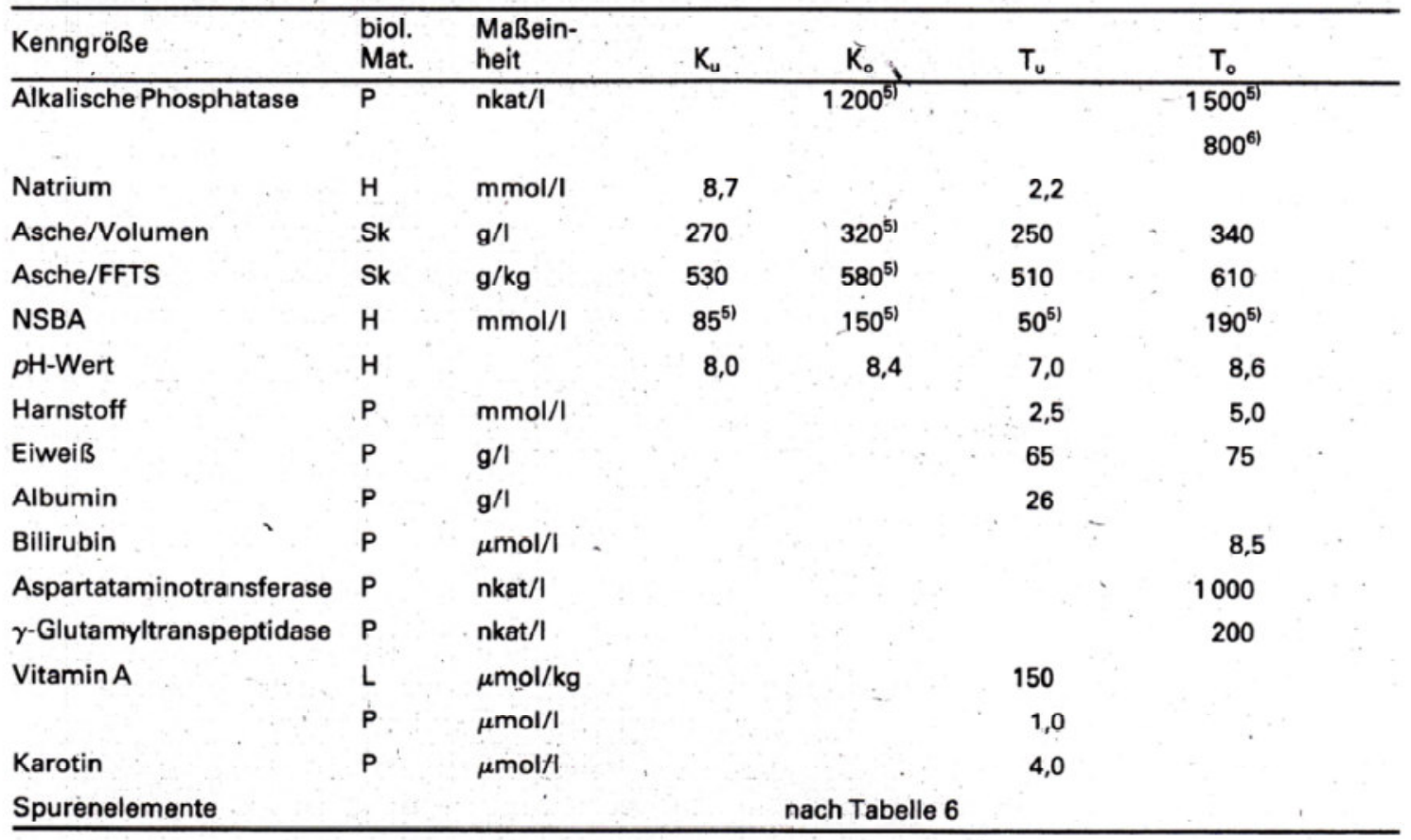

4.2.5. Bewertung klinisch-chemischer Ergebnisse

Aus den Einzelergebnissen der Stichprobe ist für jede Kenngröße der Mittelwert zu errechnen. Die Tiergruppen der Stichprobe und/oder des Bestandes ist bezüglich einer.Kenngröße als suspekt zu betrachten, wenn

- der Mittelwert kleiner als die untẹre $\left(\mathrm{K}_{\mathrm{u}}\right)$ oder größer als die obere $\left(\mathrm{K}_{\mathrm{o}}\right)$ Kontrollgrenze

und/oder

- mehr als $20 \%$ der Einzelwerte unterhalb der unteren Toleranzgrenze $\left(T_{u}\right)$ oder oberhalb der oberen Toleranzgrenze $\left(T_{0}\right)$ liegen.

Die Untersuchungsergebnisse sind komplex zu bewerten. Dabei sind insbesondere die Beziehungen zwischen den einzelnen Kenngrößen zu berücksichtigen. Lassen die Ergebnisse keine eindeutige Bewertung zu, dann ist das Untersuchungsspektrum entsprechend den Möglichkeiten zu erweitern.

Hinweise

Ersatz für TGL 34313 Ausg. 9.82

Änderungen: Titel geändert; Erweiterung des Inhaltes auf Rinderproduktion insgesamt; Präzisierung der Forderungen; redaktionelle Überarbeitung; Tabelle siehe Seite 15

Ausarbeiter: Institut für angewandte Tierhygiene Baumannweg 8, Eberswalde, 1300 
Seite 10 TGL 34313

STOFFWECHSELÜBERWACHUNG RINDERPRODUKTION - MORBIDITÄTSSTATISTIK 19 ..... Bezirk: Kategorie! A/B

Anzahl untersuchter Betriebe:

Anzahl Bestandsuntersuchungen:

Bestandsuntersuchungen ohne Beanstandungen:

Anzahl Bestandsuntersuchungen im einzelnen Untersuchungszeitraum:

Kälber 1. bis 5. LT

Kälber 2. bis 3. LM

(2):

Jungrinder (JR 1 bis JR 4)

(3):

Mastrinder

(4):

Trockensteher

(5):

Kühe 2. bis 8.W.p.p.

Kühe ab 20. W. p. p.

(7):

Frischkalber (6):

Sonstige Tiergruppen (9):

Anteil einzelner Stoffwechselstörungen in den Untersuchungszeiträumen (1) bis (9) in \% bezogen auf die Zahl der Bestandsuntersuchungen in den einzelnen Untersuchungszeiträumen

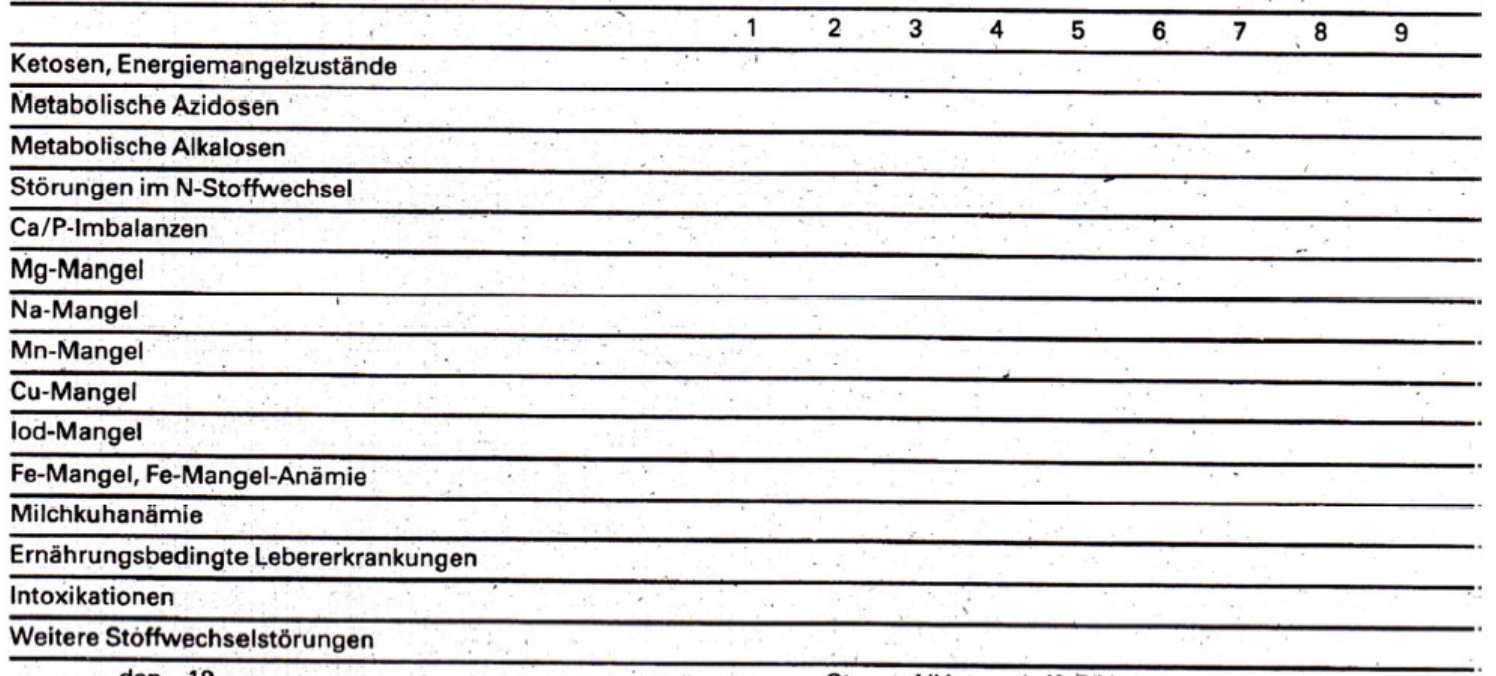




\section{Danksagung}

Als erstes möchte ich mich ganz herzlich bei Herrn apl. Prof. Dr. Manfred Fürll für das Überlassen des Themas und die Betreuung bei der Erstellung dieser wissenschaftlichen Arbeit bedanken.

Bei den Tierärzten Dr. Theo Kossen, Dr. Wolfgang Hasseler, Dr. Frank Magnus, Frau Heike Knüttel und den Mitarbeitern der Veterinärgemeinschaft Papenburg möchte ich mich für die Einsendung der Proben und die freundliche Unterstützung bei der Befragung der Landwirte bedanken.

Vielen Dank auch an alle Landwirte, die mir bereitwillig alle Fragen beantwortet haben. Ein spezieller Dank geht dabei an Karin und Fokko Kramer, auf deren Hof ich eine wunderschöne Zeit in familiärer Atmosphäre erleben durfte.

Außerdem bedanke ich mich ganz herzlich bei den Mitarbeitern des Labors der Medizinischen Klinik Leipzig für die zusätzliche Analyse der Rückstellproben.

Ein Herzliches Dankeschön geht auch an Juliane Wende, Anke Bauer und Amelie Bandel, die sich Zeit genommen haben, diese Arbeit Korrektur zu lesen.

Bei Andrea Müller bedanke ich mich ganz herzlich für die Hilfe bei der Englische Zusammenfassung. Auch meinem Mann und unseren wundervollen Söhnen möchte ich danken, dass sie diese Zeit mit mir durchlebt haben.

Der größte Dank gilt meinen Eltern, die mich bei allem unterstützt und bestärkt haben und immer voller Freude auf unsere Söhne aufgepasst haben. Danke, dass Ihr immer für uns da seid 